\title{
Ensino e aprendizagem de Geometria Analítica no Ensino Médio: uma experiência com coordenadas $e$ cálculo de distâncias no plano e no espaço
}

Cynthia Militão Domingos

\author{
DISSERTAÇÃO APRESENTADA \\ $\mathrm{AO}$ \\ INSTITUTO DE MATEMÁTICA E ESTATÍSTICA \\ DA \\ UNIVERSIDADE DE SÃO PAULO \\ PARA \\ OBTENÇÃO DO TÍTULO \\ DE \\ MESTRE EM CIÊNCIAS
}

Programa: Mestrado Profissional de Ensino de Matemática

Orientadora: Profa. Dra. Ana Paula Jahn

São Paulo, 9 de Fevereiro, 2018 


\section{Ensino e aprendizagem de Geometria Analítica no Ensino Médio: uma experiência com coordenadas $e$ cálculo de distâncias no plano e no espaço}

Esta versão da dissertação contém as correções e alterações sugeridas pela comissão julgadora durante a defesa da versão original do trabalho, realizada em 09/02/2018. Uma versão original está disponível no Instituto de Matemática e Estatística da Universidade de São Paulo.

Comissão Julgadora:

- Profa. Drª. Ana Paula Jahn (orientadora) - IMEUSP

- Prof ${ }^{a}$. Dr ${ }^{\mathrm{a}}$. Martha Salermo Monteiro - IME-USP

- Prof ${ }^{a}$. Dr ${ }^{a}$. Nielce Meneguelo Lobo Costa UNIAM 


\section{Agradecimentos}

Meus primeiros agradecimentos são dedicados à minha família que me deu todo o suporte necessário desde sempre para que eu pudesse conseguir realizar meus objetivos e chegar até aqui. Em especial à minha mãe Odete, meu irmão Willian, minha tia Onice e minha avó Iria (in memoriam), que sempre acreditaram no meu potencial.

Aos meus amigos que me apoiaram ao longo deste período e compreenderam meu afastamento e, em especial, à Tauany, Rafael e Matheus que sempre estiveram presentes nos momentos de angústias e desabafos.

Aos meus professores da Educação Básica, em especial às professoras Lucy e Bárbara por despertarem meu amor à Matemática tornando-se minhas principais inspirações para o trabalho em sala de aula.

Aos professores do IME - USP que fizeram parte do meu processo de formação na Graduação, em especial aos professores Antônio Carlos Brolezzi, Heloisa Daruiz Borsari, Rodrigo Bissacot Proença e Zara Issa Adud, pelas aulas inspiradoras, conselhos e dicas que levo até hoje para minha prática docente.

Aos professores do IME - USP do curso de Mestrado Profissional, por proporcionarem um amadurecimento de meus conhecimentos sobre Ensino de Matemática e, em especial, à Profa. Ana Paula Jahn pelas orientações nesta dissertação.

Ao Colégio Alfa Omega e à E.E. Sapopemba, funcionários e professores que conheci ao longo do tempo que me dedico ao ensino. Em especial à Elisa e ao Fernando que me deram oportunidade e confiam no meu trabalho, contribuindo em minha evolução como professora, e aos colegas Lucas e Milton pelas trocas de experiências e angústias.

Aos meus alunos que são minha principal motivação para sempre dar o melhor de mim e não desistir, em especial, Arthur, Danieli, Felipe, Giovana, Igor, Kimberly, Leonardo, Luiz, Marina e Victor, hoje meus amigos, que muito me inspiraram contribuindo para meu crescimento como professora. 


\section{Resumo}

\section{DOMINGOS, C. M. Ensino e aprendizagem de Geometria Analítica no Ensino}

Médio: uma experiência com coordenadas e cálculo de distâncias no plano e no espaço. 2018. 219 f. Dissertação (Mestrado) - Instituto de Matemática e Estatística, Universidade de São Paulo, São Paulo, 2018.

Este trabalho aborda questões relativas ao ensino e à aprendizagem da Geometria Analítica no Ensino Médio. Teve como objetivo principal apresentar uma proposta de atividades para o ensino dos tópicos relativos a coordenadas cartesianas e cálculo de distâncias no plano e no espaço, buscando a compreensão dos alunos e não na memorização de fórmulas. Para o estudo, adotou-se como fundamentação a teoria dos registros de representação semiótica, de Raymond Duval e foi utilizado o software Geogebra para auxiliar o trabalho com os registros gráfico, algébrico e numérico, em particular nas atividades de conversão. Alguns trabalhos de pesquisa, bem como práticas docentes, indicam que muitos alunos apresentam dificuldades na interpretação de fórmulas, de equações e inequações, não atribuindo significados para tais expressões algébricas. Uma análise feita em livros didáticos mostrou que, de um modo geral, o ensino de Geometria Analítica é apresentado por meio de uma abordagem essencialmente algébrica, com destaque para o uso de fórmulas e, nos exercícios, a representação algébrica é a mais utilizada nas soluções. Nota-se também, uma ausência da abordagem de objetos e conceitos no espaço, porém essa abordagem pode ser vista como essencial para a formação integral do estudante na Educação Básica. Considerou-se que o uso da Janela $3 D$ do Geogebra, articulada à Janela 2D, pode apoiar um trabalho sobre coordenadas e distâncias no espaço, permitindo ampliar o estudo da Geometria Analítica no Ensino Médio de forma a colaborar com o desenvolvimento da habilidade de visualização espacial pelos alunos. Visando uma pesquisa de caráter qualitativo, utilizou-se o Design Experiment, que é uma metodologia com foco na análise dos processos de aprendizagem de domínios matemáticos específicos. Foram elaboradas atividades com o uso do Geogebra e materiais concretos para introduzir coordenadas e distâncias no espaço. Um conjunto de tarefas foi aplicado a um grupo de seis alunos da $3^{\text {a }}$ Série do Ensino Médio de uma escola pública paulistana. A análise dos dados mostrou a plena viabilidade de um trabalho no espaço nesse nível de escolaridade, bem como a pertinência do uso dos recursos escolhidos, com os quais os alunos puderam observar, experimentar e, sobretudo, articular diferentes representações dos objetos e relações geométricas, apropriandose dos conceitos em questão.

Palavras-chave: Geometria Analítica, Coordenadas, Distâncias, Geogebra, Materiais concretos, Registros de representação semiótica. 


\section{Abstract}

\section{DOMINGOS, C. M. Teaching and learning of Analytical Geometry in High}

\section{School: an experience with coordinates and calculation of distances in the}

plane and in space. 2018. 219 f. Dissertação (Mestrado) - Instituto de Matemática e

Estatística, Universidade de São Paulo, São Paulo, 2018.

This study addresses issues related to teaching and learning Analytical Geometry in High School. Its main objective was to present a activities for the teaching of the Cartesian coordinated topics and the calculation of distances both realized in the plane and the space, seeking understanding and not in the memorization of formulas. In order to do so, we adopted as theoretical foundation the registers of semiotic representation, a theory elaborated by Raymond Duval and the software Geogebra was used to assist the work with the graphic, algebraic and numerical registers, in particular in the conversion activities. Some research papers, as well as teaching practices, indicate that many students present difficulties in the interpretation of formulas, equations and inequalities, not assigning meanings to such algebraic expressions. An analysis in didactic books showed that, in general, the teaching of Analytical Geometry is presented through a more algebraic approach, with emphasis on the use of formulas and, in exercises, algebraic representation is the most used as a solution. We also note an absence of the approach of objects and concepts in space, but this approach can be seen as essential for the integral formation of the student in Basic Education. It was considered that the use of the $3 D$ Geogebra Window, linked to the 2D Window of Geogebra, can support a work on coordinates and calculation of distances in space, allowing to enlarge the study of Analytical Geometry in High School in order to collaborate with the development of ability for spatial visualization by students. Aiming at a qualitative research, Design Experiment was used, which is a methodology focused on the analysis of the learning processes of specific mathematical domains. Activities were developed using Geogebra and concrete materials to introduce coordinates and distances in space. A set of tasks was applied to a group of six high school students from a public school in São Paulo. The data analysis showed the full viability of a work in space in this level of schooling, as well as the pertinence of the use of the chosen resources. With them, students were able to observe, experiment and, above all, articulate different representations of objects and geometric relations, appropriating the concepts in question.

Keywords: Analytical Geometry, Coordinates, Distances, Geogebra, Concrete materials, Registers of semiotic representation. 


\section{Sumário}

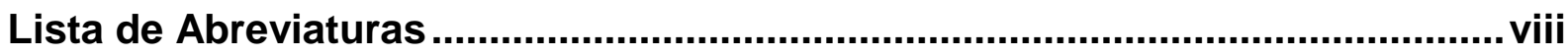

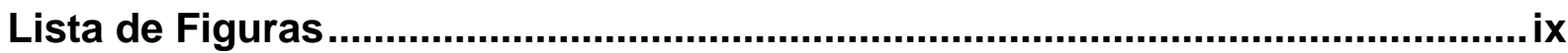

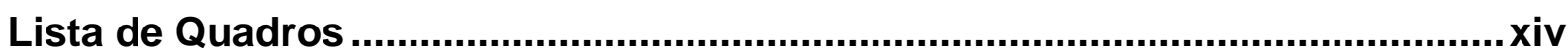

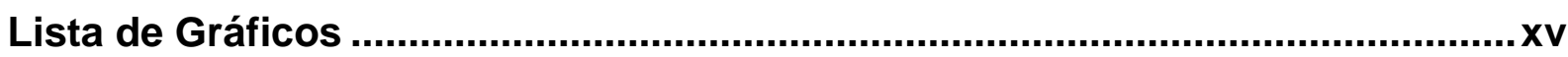

Lista de Tabelas .................................................................................................

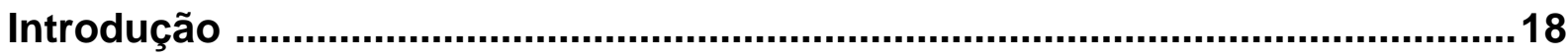

Capítulo 1 - Fundamentação Teórica .....................................................................31

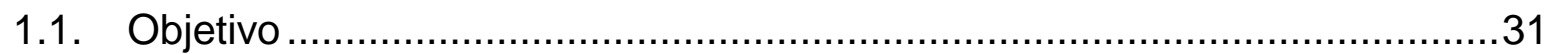

1.2. Os registros de representação semiótica .................................................32

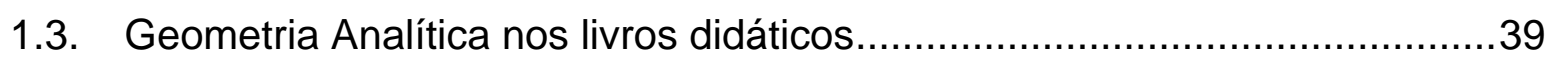

1.3.1. Registros de representação semiótica nos livros didáticos ....................44

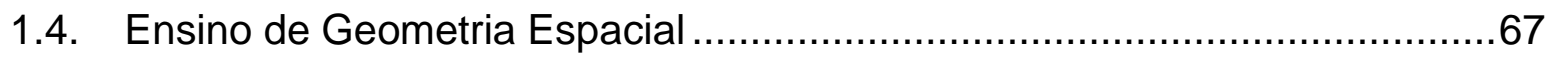

1.5. Alguns trabalhos sobre o ensino de Geometria Analítica............................72

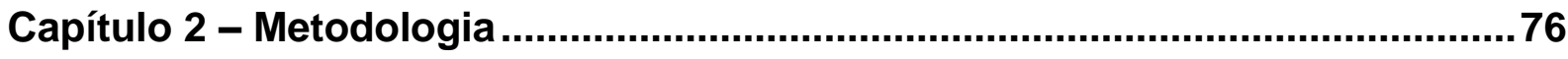

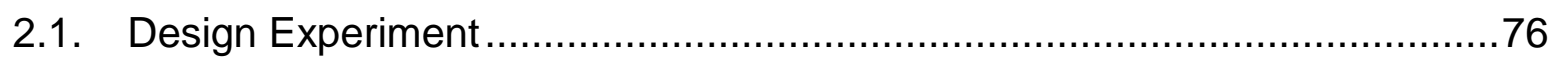

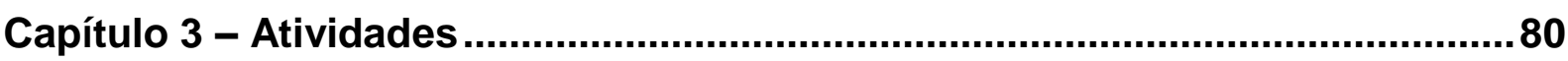

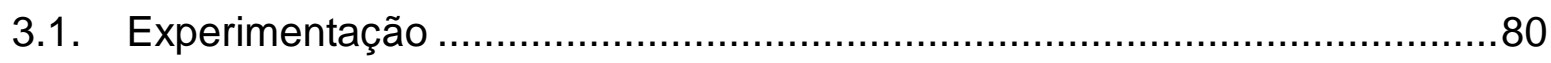

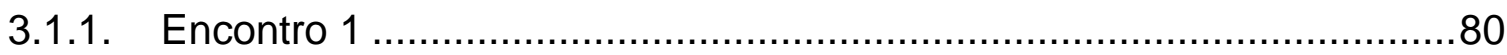

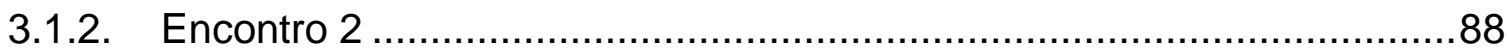

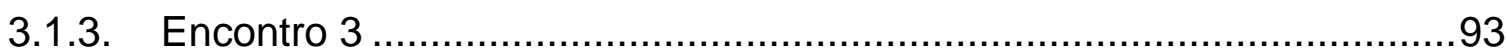

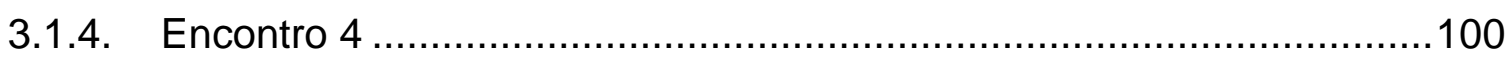

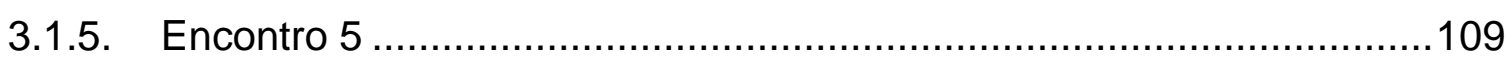

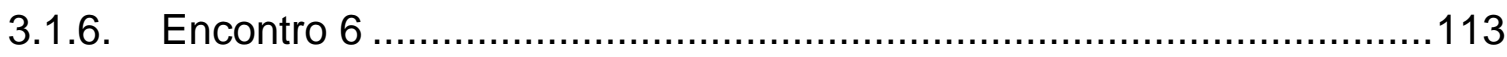

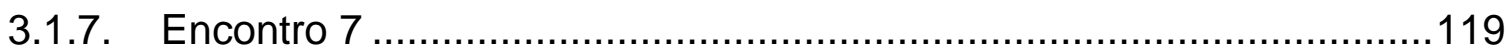

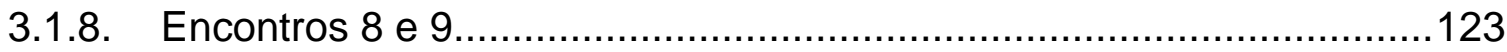

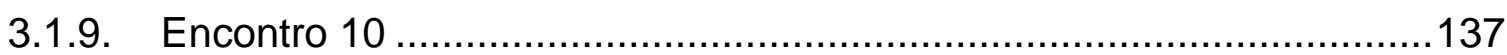

3.2. Propostas de atividades para continuidade de exploração de coordenadas

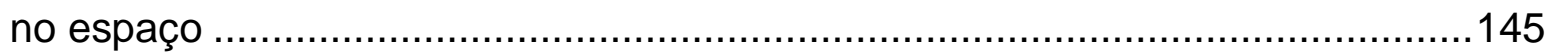

3.2.1. Atividade 1: Coordenadas no Espaço..............................................146 
3.2.2. Atividade 2: Projeções de pontos nos planos coordenados e nos eixos coordenados.

3.2.3. Atividade 3: Distância de um ponto aos eixos e planos coordenados .156

3.2.4. Atividade 4: Distância entre dois pontos no plano e no espaço............160

3.2.5. Atividade 5: Distância entre ponto e reta no plano - Composição de áreas 163

Capítulo 4 - Conclusão 168

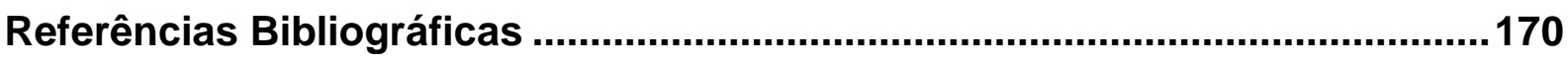

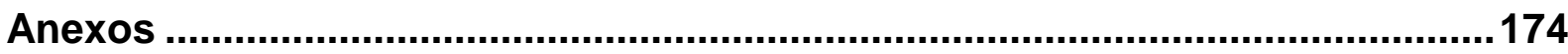

Anexo I - Análise do questionário para estudantes ingressantes do IME e IF USP 2016 174

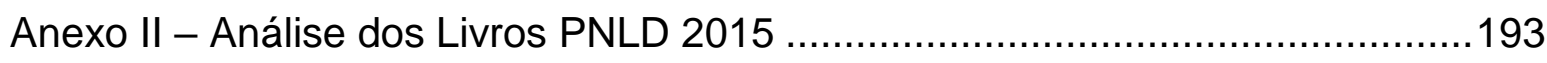

Anexo III - Atividades aplicadas na experimentação ........................................201

Anexo IV - Construção do Jogo da Velha 3D .............................................215 


\section{Lista de Abreviaturas}

ENEM - Exame Nacional do Ensino Médio

HVE - Habilidade de Visualização Espacial

PCNEM - Parâmetros Curriculares Nacionais Ensino Médio

PNLD - Programa Nacional do Livro Didático

RA - Registro Algébrico

RG - Registro Gráfico

RLN - Registro Língua Natural

RN - Registro Numérico 


\section{Lista de Figuras}

Figura 1: Questão 142 Caderno Rosa ENEM 2013 ...........................................23

Figura 2: Questão 163 Caderno Rosa ENEM 2014 ............................................24

Figura 3: Questão 139 Caderno Rosa ENEM 2016 ............................................25

Figura 4: Questão 154 Caderno Rosa ENEM 2016 ...............................................26

Figura 5: Projeto realizado no software Scketchup .............................................27

Figura 6: Eixos coordenados do espaço utilizados no Scketchup...........................28

Figura 7: Ideia de coordenadas por meio das dimensões do retângulo ....................28

Figura 8: Resposta apresentada por aluno no questionário .....................................29

Figura 9: Esquema das Atividades Cognitivas envolvendo Representações .............37

Figura 10: Representações gráfica e algébrica de uma parábola ............................38

Figura 11: Apresentação de distâncias entre dois pontos na reta real no Volume 1.40

Figura 12: Apresentação de distâncias entre dois pontos no plano no Volume 1 .....41

Figura 13: Sistemas de coordenadas no plano em SOUZA .....................................41

Figura 14: Sistemas de coordenadas no plano em PAIVA ......................................42

Figura 15: Distância entre dois pontos pertencentes a retas paralelas aos eixos Ox e

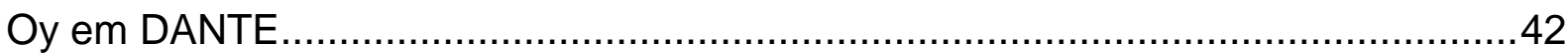

Figura 16: Abordagem sobre distância entre dois pontos no plano em PAIVA .........43

Figura 17: Observação sobre distância entre dois pontos em LEONARDO ..............43

Figura 18: Abordagem sobre distância entre ponto e reta no plano em PAIVA .........44

Figura 19: Enunciados de exercícios sobre coordenadas no plano em LEONARDO

Figura 20: Enunciados de exercícios sobre distância entre dois pontos em

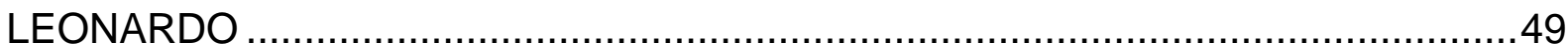

Figura 21: Enunciados de exercícios sobre distância de ponto à reta em DANTE ...49 Figura 22: Enunciados de exercícios sobre coordenadas no plano de PAIVA no

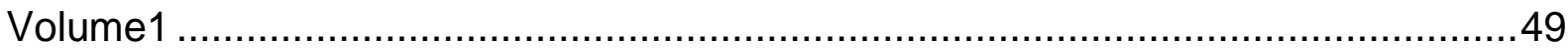

Figura 23: Exercício de conversão do RN para o RLN em LEONARDO ....................51

Figura 24: Exercício de conversão do RN para o RLN (resolução) em LEONARDO 51

Figura 25:Exercício de conversão do RG para o RN em LEONARDO .....................52

Figura 26: Exercício de conversão do RG para o RN (resolução) em LEONARDO..52

Figura 27: Resolução alternativa para o ex 8 de LEONARDO .................................53

Figura 28: Exercício de conversão do RLN para o RG em LEONARDO ...................53

Figura 29: Exercício de conversão do RLN para o RG (resolução) em LEONARDO54 Figura 30: Exercício de conversão do RLN para o RG (resolução continuação) em

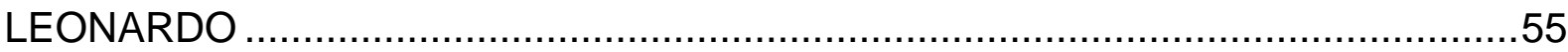

Figura 31: Exercício de conversão do RLN para o RA em DANTE ..........................56

Figura 32: Exercício de conversão do RLN para o RA (resolução) em DANTE .........57

Figura 33: Exercício de conversão do RLN para o RA (resolução continuação) em

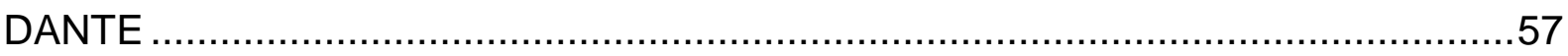


Figura 34: Exercício de conversão do RA para o RG em DANTE...........................57

Figura 35: Exercício de conversão do RA para o RG (resolução) em DANTE...........58

Figura 36: Exercício de conversão do RLN para o RG em PAIVA ...........................59

Figura 37: Exercício de conversão do RLN para o RG (continuação) em PAIVA .....60

Figura 38:Exercício de conversão do RLN para o RG (resolução) em PAIVA ..........60

Figura 39: Exercício de conversão do RLN para o RG (resolução continuação) em

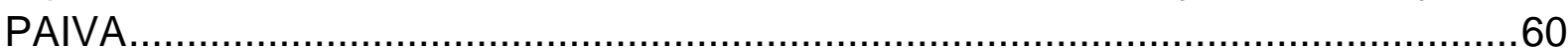

Figura 40: Exercício de conversão do RN para o RA em PAIVA ............................61

Figura 41: Exercício de conversão do RN para o RA (resolução) em PAIVA ...........61

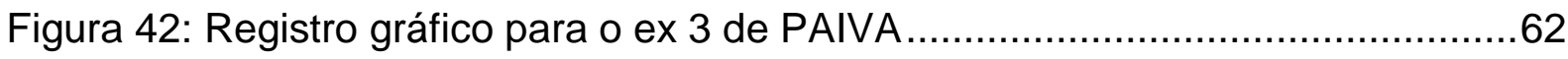

Figura 43: Exercício de conversão do RN para o RG em SOUZA ..........................64

Figura 44: : Exercício de conversão do RN para o RG (resolução) em SOUZA .......65

Figura 45: : Exercício de conversão do RG para o RA em SOUZA ........................66

Figura 46: : Exercício de conversão do RG para o RA (resolução) em SOUZA .......66

Figura 47:Tetraedro $A B C D$ representado em um suporte plano .............................69

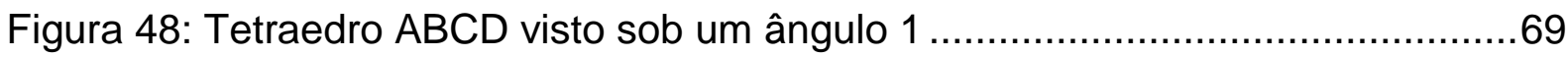

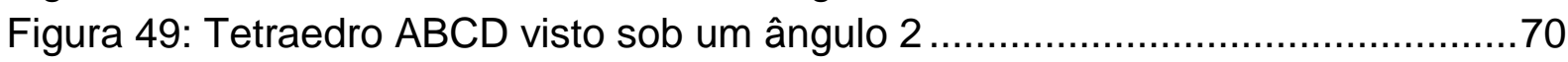

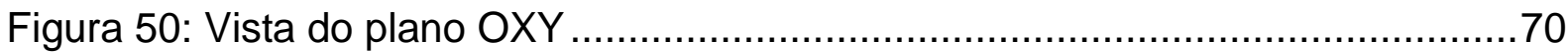

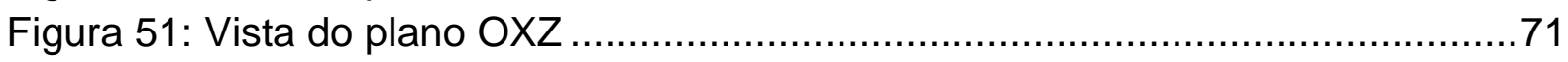

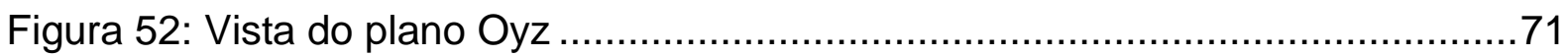

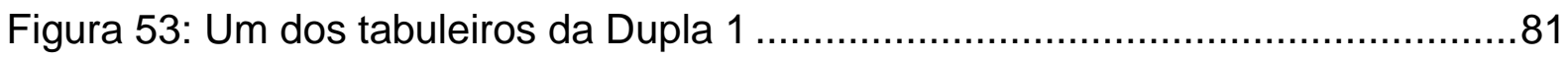

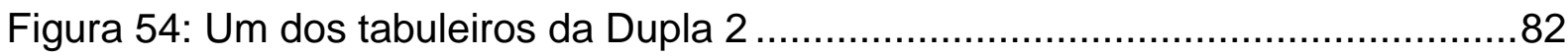

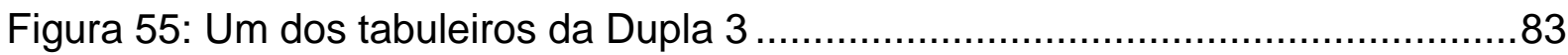

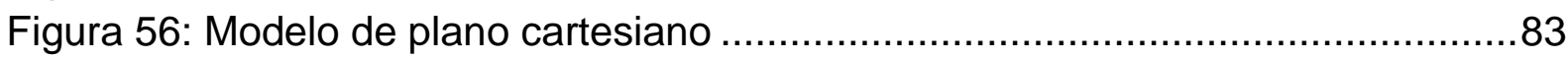

Figura 57: Modelo do plano cartesiano na cartolina após a dinâmica ........................84

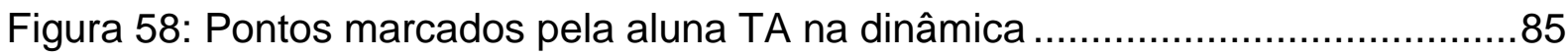

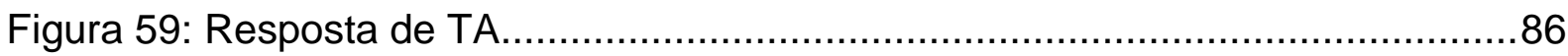

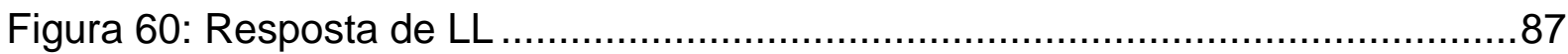

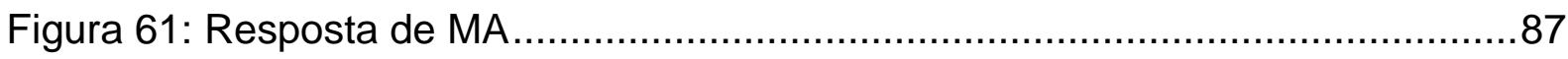

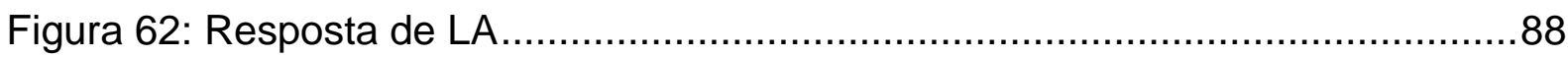

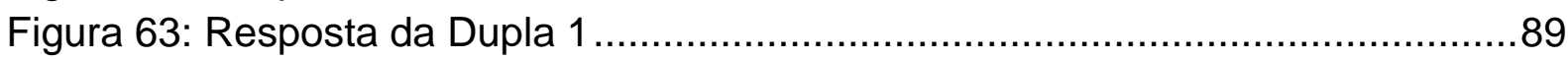

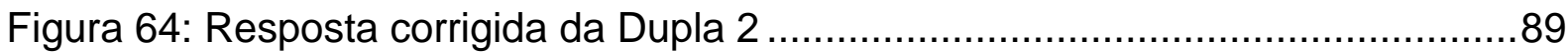

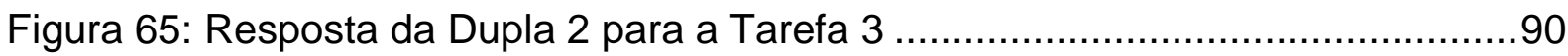

Figura 66: Resposta da Dupla 1 para a Tarefa 4 ..............................................91

Figura 67: llustração do Sistema de Coordenadas no Espaço utilizando o Geogebra

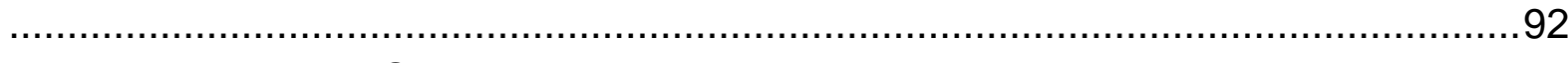

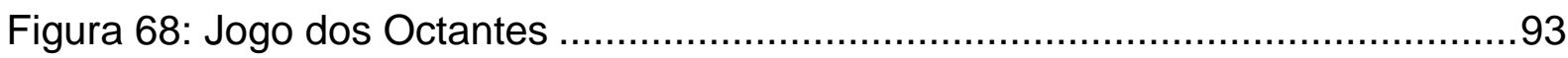

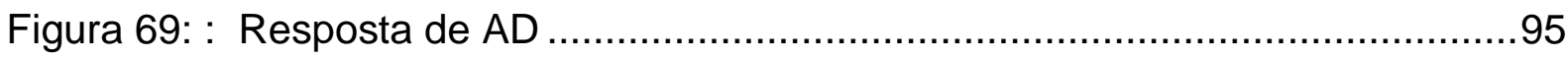

Figura 70: Resposta de AD após correção do erro ..............................................95

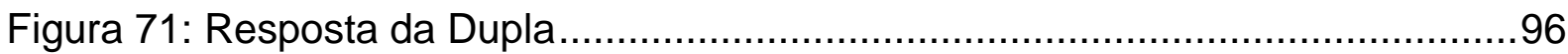

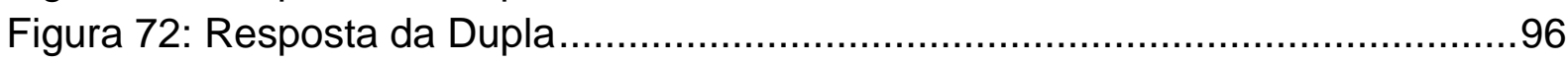

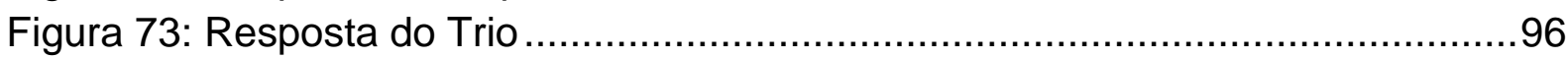




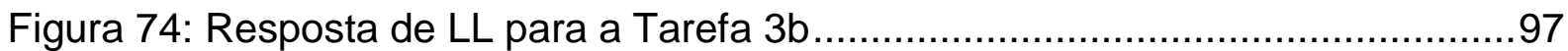

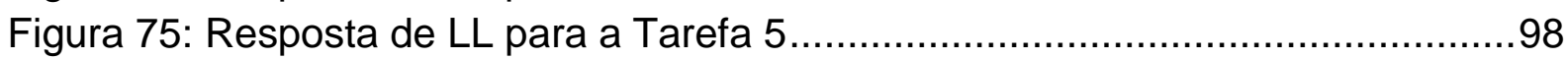

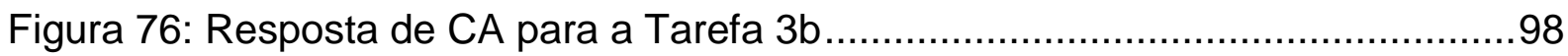

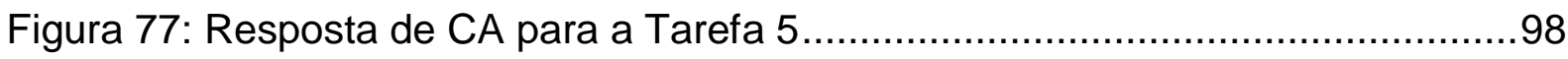

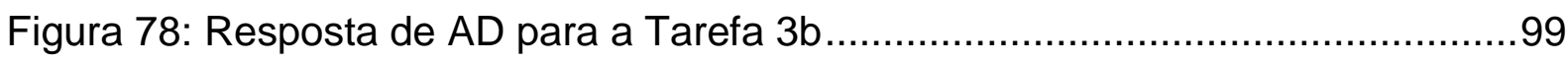

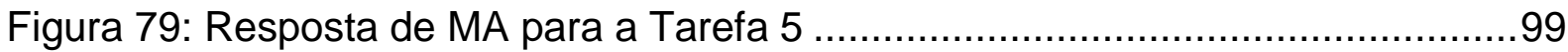

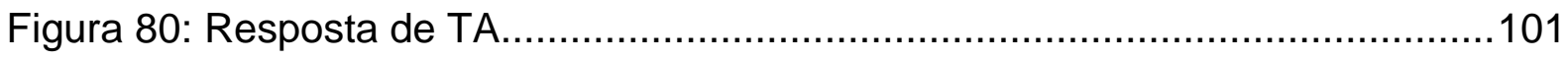

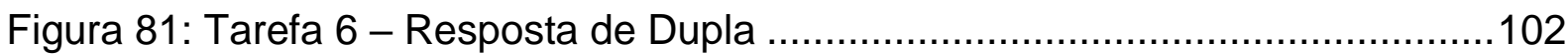

Figura 82: Tarefa 7 - Resposta de Dupla …………....................................102

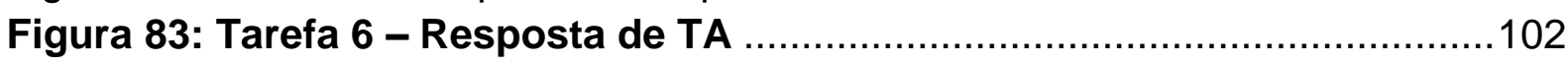

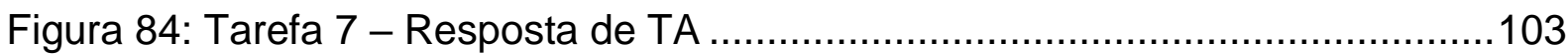

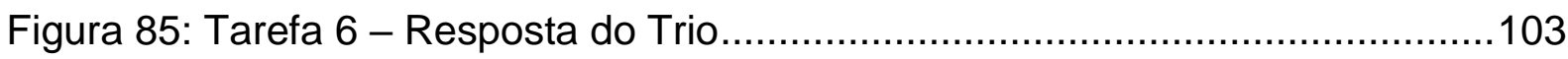

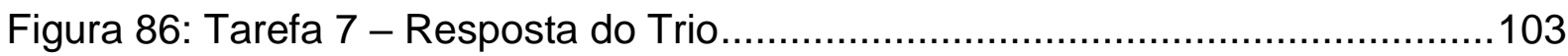

Figura 87: Tarefa 8 - Resposta da Dupla .....................................................104

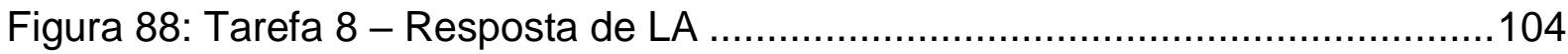

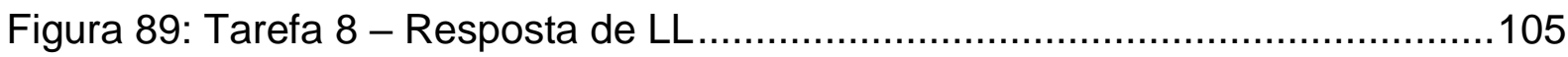

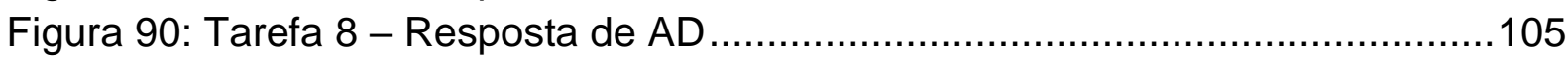

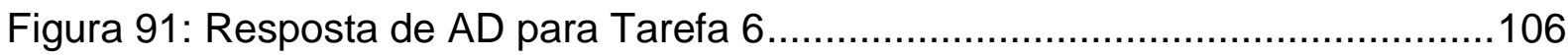

Figura 92: Verificação da resposta de AD e LL .................................................106

Figura 93: Casos particulares de simetria nos eixos Ox e Oy ......................107

Figura 94: Tarefa 8 - Resposta corrigida de AD e LL ........................................107

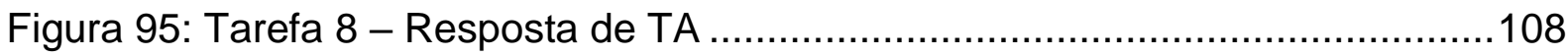

Figura 96: Tarefa 10a - Resposta da Dupla 1 …….........................................109

Figura 97: Tarefa 10b - Resposta da Dupla 1 ...............................................110

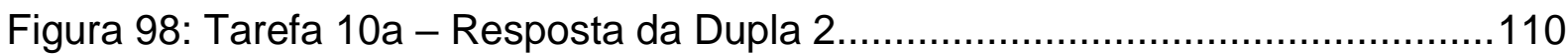

Figura 99: Tarefa 10b - Resposta da Dupla 2 .................................................110

Figura 100: Tarefa 10a - Resposta da Dupla 3..............................................110

Figura 101: Tarefa 10b - Resposta da Dupla 3 ..............................................110

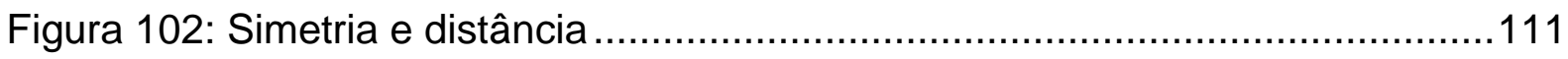

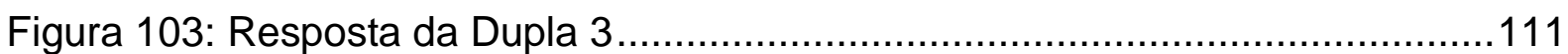

Figura 104: Tarefa 11 - Resposta da Dupla 1.................................................112

Figura 105:Tarefa 11 - Resposta da Dupla 2 ...............................................112

Figura 106: Tarefa 11 - Resposta da Dupla 3.................................................113

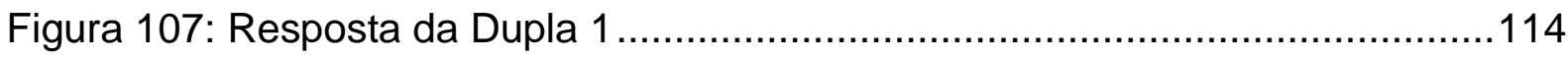

Figura 108: Resposta da Dupla 1 para o item d ................................................114

Figura 109: Resposta corrigida da Dupla1 ....................................................115

Figura 110: Resposta corrigida da Dupla 1 para o item d ..................................115

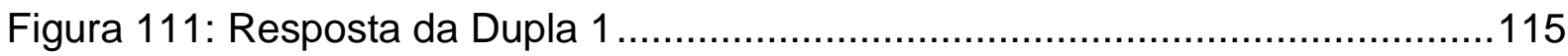

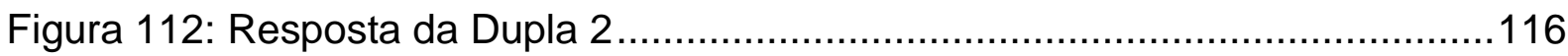

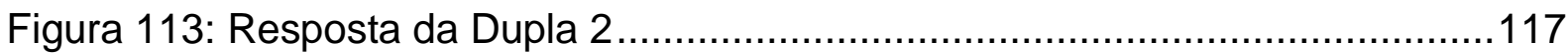

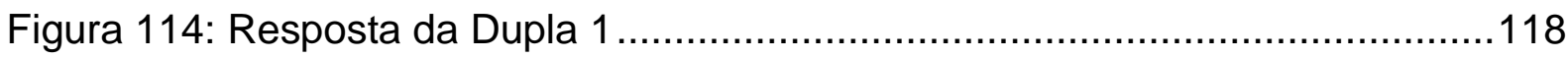

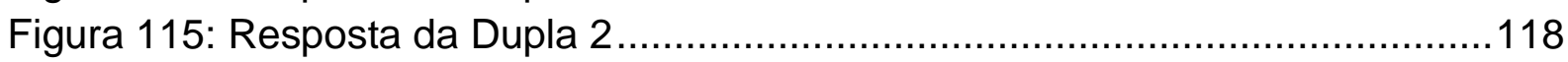


Figura 116: Sistema de coordenadas do espaço no Geogebra ............................120

Figura 117: Modelo construído pelo Trio 1 ...................................................121

Figura 118: Modelo construído pelo Trio 2 ………….....................................122

Figura 119: Sistema de eixos no modelo da Dupla 2 e Sistemas de eixo

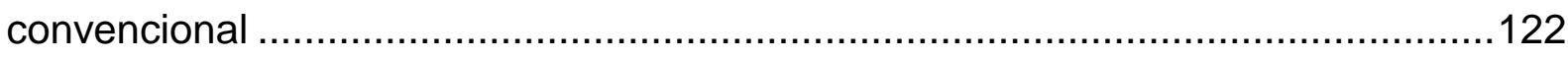

Figura 120: Primeira tentativa apresentada pela Dupla $1 \ldots \ldots \ldots \ldots \ldots \ldots \ldots \ldots \ldots \ldots \ldots \ldots . . . . .124$

Figura 121: Segunda tentativa apresentada pela Dupla 1 ..................................125

Figura 122: Representação apresentada pela Dupla 2 .......................................126

Figura 123: Representação apresentada pela Dupla 3 ......................................126

Figura 124: Representação do sistema de coordenadas do espaço na Janela 2D do

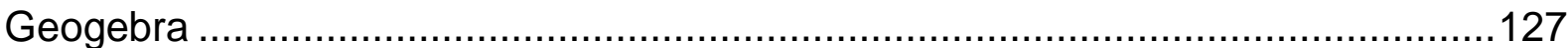

Figura 125: Passo a passo para o ponto $(2,4,3)$............................................128

Figura 126: Resposta apresentada pela Dupla1 para a Tarefa 3 .........................128

Figura 127: Resposta Apresentada pela Dupla 3 para a Tarefa 3 .......................129

Figura 128: Resposta apresentada pela Dupla 2 para Tarefa 3 ...........................129

Figura 129: Resposta apresentada pela Dupla 1 para a tarefa 4 .........................129

Figura 130:Resposta apresentada pela Dupla 2 para a Tarefa 4 ..........................130

Figura 131: Resposta apresentada pela Dupla 3 para a Tarefa 4 .........................130

Figura 132: Resposta apresentada pela Dupla 1 para as Tarefa 5 e Tarefa 6........131

Figura 133: Resposta apresentada pela Dupla 2 para as Tarefa 5 e Tarefa 6 ........131

Figura 134: Resposta apresentada pela Dupla 3 para as Tarefa 5 e Tarefa 6 ........131

Figura 135: Resposta apresentada pela Dupla 1 para a Tarefa $7 \ldots \ldots \ldots \ldots \ldots \ldots \ldots \ldots . . . .132$

Figura 136: Resposta apresentada pela Dupla 3 para Tarefa $7 \ldots \ldots \ldots \ldots \ldots \ldots \ldots \ldots \ldots . . .132$

Figura 137: Imagem base para a primeira resposta apresentada pela Dupla 3 para a

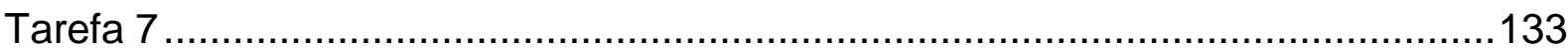

Figura 138: Imagem base para completar a resposta apresentada pela Dupla 3 para

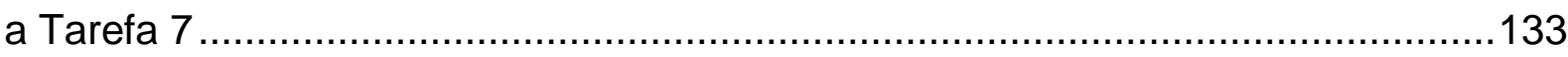

Figura 139: Resposta apresentada pela Dupla 2 para a Tarefa $7 \ldots \ldots \ldots \ldots \ldots \ldots \ldots \ldots \ldots . . .134$

Figura 140: Resposta apresentada pela Dupla 1 para a Tarefa 8a.......................134

Figura 141: Resposta apresentada pela Dupla 1 para a Tarefa 8b .......................134

Figura 142: Resposta apresentada pela Dupla 2 para a Tarefa 8a .......................135

Figura 143: Resposta apresentada pela Dupla 2 para a Tarefa 8b ......................135

Figura 144: Resposta apresentada pela Dupla 3 para a Tarefa 8a ........................136

Figura 145: Resposta apresentada pela Dupla 3 para a Tarefa 8a após a intervenção 136

Figura 146: Resposta apresentada pela Dupla 3 para a Tarefa 8b......................136

Figura 147: Exemplar do Jogo da Velha 3D ................................................137

Figura 148: Alunos jogando o Jogo da Velha 3D ...........................................138

Figura 149: Orientação dos eixos escolhida pela Dupla 1 para a Tarefa 1 .............139

Figura 150: Resposta apresentada pela Dupla 1 para a Tarefa 1 ........................139

Figura 151: Resposta apresentada pela Dupla 2 para a Tarefa 1 ..........................140

Figura 152: Resposta apresentada pela Dupla 3 para a Tarefa 1 ..........................140 


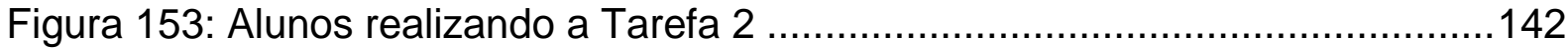

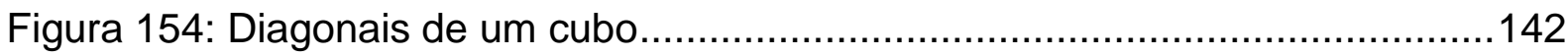

Figura 155: Resposta apresentada pela Dupla 1 para a Tarefa 2........................143

Figura 156: Resposta apresentada pela Dupla 2 para a Tarefa 2 .........................143

Figura 157: Reposta apresentada pela Dupla 3 para a Tarefa 2 ...........................144

Figura 158: Interação entre o espaço $O X Y Z$ e o plano $O X Z$ no Geogebra ..............147

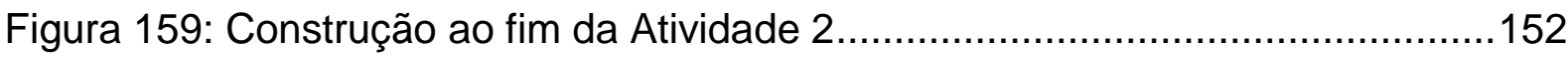

Figura 160: Construção de plano paralelo ao plano $O X Y$ passando pelo ponto $A \mathrm{e}$

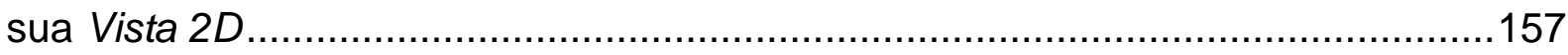

Figura 161: Imagem para a determinação da distância entre dois pontos no espaço

Figura 162: Construção do trapézio para a composição das áreas .......................164

Figura 163: Resposta esperada Questão 2 item a ...........................................180

Figura 164: Resposta obtida para Questão 2 Item a ..........................................181

Figura 165: Resposta obtida para Questão 2 Item a ..........................................181

Figura 166: Resposta obtida para Questão 2 Item a .........................................181

Figura 167: Resposta esperada Questão 2 item b .............................................182

Figura 168: Resposta obtida para Questão 2 Item b.........................................183

Figura 169: Resposta esperada Questão 2 item c ..............................................183

Figura 170: Resposta obtida para Questão 2 Item c ..........................................184

Figura 171: Resposta obtida para Questão 2 Item c ..........................................184

Figura 172: Resposta obtida para Questão 2 Item c .........................................184

Figura 173: Resposta esperada Questão 2 item d ............................................188

Figura 174: Resposta obtida para Questão 2 Item d..........................................188

Figura 175: Resposta esperada Questão3 na reta..............................................189

Figura 176: Resposta esperada Questão 3 no plano …………….....................189

Figura 177: Resposta esperada Questão 3 no espaço .......................................190

Figura 178: Resposta obtida para Questão 3 ……...........................................191

Figura 179: Resposta obtida para Questão 3...............................................191

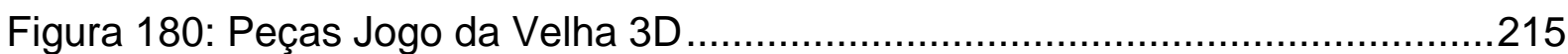

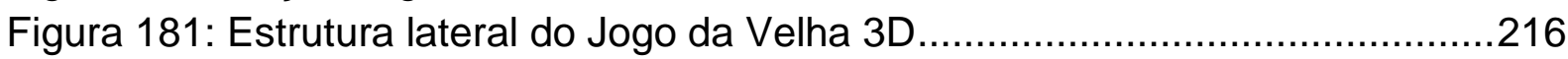

Figura 182: Esboço da estrutura lateral do Jogo da Velha 3D .............................216

Figura 183: Passo 1 do tabuleiro do Jogo da Velha 3D .......................................217

Figura 184: Passo 2 do tabuleiro do Jogo da Velha 3D ......................................217

Figura 185: Esboço do Passo 2 do tabuleiro do Jogo da Velha 3D .......................217

Figura 186: Passo 3.1 do tabuleiro do Jogo da Velha 3D ......................................217

Figura 187: Passo 3.2 do tabuleiro do Jogo da Velha 3D ...................................217

Figura 188: Passo 4 do tabuleiro do Jogo da Velha 3D .....................................217

Figura 189: Passo 5 do tabuleiro do Jogo da Velha 3D ......................................218

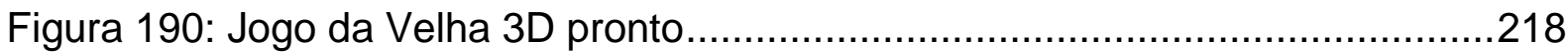

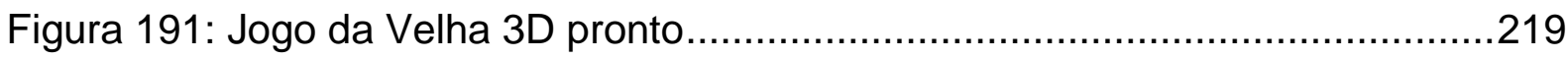

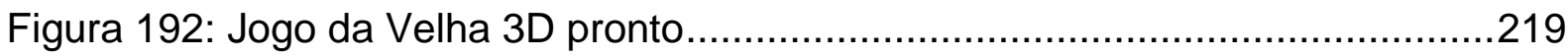




\section{Lista de Quadros}

Quadro 1: Tipos de registros para uma circunferência .......................................33

Quadro 2: Exemplo de tratamento em um registro de representação semiótica.......34

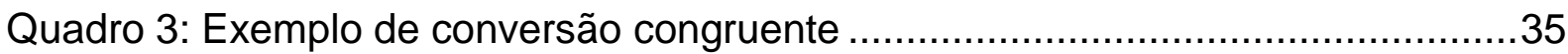

Quadro 4: Exemplo de conversão não congruente .......................................... 35

Quadro 5: Exemplo de congruência heterogênea ...........................................36 


\section{Lista de Gráficos}

Gráfico 1: Quantidade de exercícios propostas no Volume 1 de cada coleção.........40

Gráfico 2: Quantidade de exercícios propostos no Volume 3 de cada coleção.........45

Gráfico 3: Apresentação dos objetos geométricos nos exercícios propostos por

coleção no Volume 1 .......................................................................46

Gráfico 4: Apresentação dos objetos geométricos nos exercícios propostos por

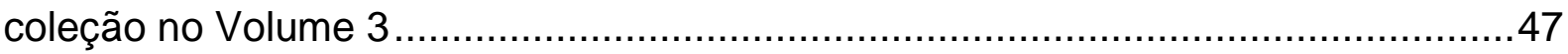

Gráfico 5: Conversão entre registros nos exercícios propostos por Coleção ............50

Gráfico 6: Tipos de conversão em LEONARDO ...............................................56

Gráfico 7:Tipos de conversão em DANTE..................................................

Gráfico 8: Tipos de conversão em PAIVA ......................................................63

Gráfico 9: Tipos de conversão em SOUZA ....................................................67

Gráfico 10: Respostas apresentadas pelos estudantes para a Questão 2 item a ...181

Gráfico 11: Respostas apresentadas pelos estudantes para a Questão 2 item b ...182

Gráfico 12: Respostas apresentadas pelos estudantes para a Questão 2 item c ...183

Gráfico 13: Respostas apresentadas pelos estudantes para a Questão 2 item d ...188

Gráfico 14: Respostas apresentadas pelos estudantes para Questão 3................191 


\section{Lista de Tabelas}

Tabela 1: Competências e Habilidades do ENEM associadas à Geometria .22

Tabela 2: Registros mais valorizados nos exercícios sobre coordenadas no plano por coleção nos Volumes 1 e 3

Tabela 3: Registros mais valorizados nos exercícios sobre cálculo de distâncias no plano por coleção. 48

Tabela 4: Sinais das coordenas no plano 51

Tabela 5: Jogo dos Octantes. 93

Tabela 6: Exemplo de conversão congruente entre registro numérico e registro língua natural para pontos simétricos em relação ao eixo OX. 100 Tabela 7: Análise da congruência na conversão entre os registros numérico e algébrico para pontos simétricos 108

Tabela 8: Interpretação gráfica das soluções das Dupla 2 e Dupla 3 para a Tarefa 2 144

Tabela 9: Respostas apresentadas pelos estudantes na Questão 1 Item a 175

Tabela 10: Respostas apresentadas pelos estudantes na Questão $1 \mathrm{ltem} b$ 176

Tabela 11: Respostas apresentadas pelos estudantes na Questão 1 Item c. 177

Tabela 12: Respostas apresentadas pelos estudantes na Questão 1 Item d 178 Tabela 13: Respostas apresentadas pelos estudantes na Questão 1 Item e 179 


\section{Introdução}

O tema matemático abordado neste trabalho refere-se ao campo da Geometria Analítica, mais especificamente, coordenadas cartesianas no plano e no espaço e cálculo de distâncias no plano e no espaço.

O interesse pelo tema surgiu após duas experiências de ensino sobre distância entre dois pontos no plano cartesiano. Na primeira, apresentamos o tema aos alunos por meio do uso da uma fórmula $d(A, B)=\sqrt{\left(x_{A}-x_{B}\right)^{2}+\left(y_{A}-y_{B}\right)^{2}}$ e na segunda, utilizamos representações gráficas e o auxílio de conhecimentos prévios dos alunos em Geometria Plana ${ }^{1}$, ou seja, não apresentamos inicialmente a fórmula, como geralmente é feito no material didático utilizado pelas escolas.

Observamos que o primeiro grupo de alunos aplicou indiscriminadamente a fórmula, de forma mecânica, mesmo para situações simples de segmentos paralelos aos eixos coordenados. Já o segundo grupo analisou primeiro e realizou cálculos baseados na interpretação de cada caso. Na continuidade dos estudos, por exemplo, na introdução de equação de circunferência, embora outros elementos interfiram nessa situação e sejam de difícil compreensão (noções de variável e lugar geométrico), os alunos de ambos os grupos não reconheceram facilmente o uso do conceito de distância entre dois pontos para determinação da referida equação.

Essas experiências nos levaram à reflexão sobre nossas escolhas didáticopedagógicas para o ensino da Geometria Analítica, de forma a levar os alunos à construção - com significado - de seus principais conceitos. Um pressuposto que assumiremos de início é a introdução de conceitos e propriedades sem ênfase no uso de fórmulas prontas, já que não somente obtivemos um maior sucesso utilizando-as minimamente, como encontramos respaldo em pesquisas sobre o tema, como veremos mais adiante.

Segundo o PCNEM (BRASIL, 2000), a Geometria Analítica tem como função principal fazer um tratamento algébrico de objetos geométricos, e por outro lado, levar os alunos à interpretação geométrica de equações e inequações e resolução

\footnotetext{
${ }^{1}$ No caso, precisávamos que os alunos conhecessem as características de um triângulo retângulo e o Teorema de Pitágoras.
} 
de problemas algébricos com a ajuda da Geometria. Além disso, seu ensino deve garantir uma compreensão maior de tais objetos e não priorizar a memorização de fórmulas ou de tipos específicos de equações. Com essa compreensão, o aluno é levado a perceber novas ferramentas matemáticas que podem ser utilizadas em um problema, dependendo das características apresentadas pelo mesmo.

Entre os conteúdos e habilidades que devem ser desenvolvidos a partir do ensino da Geometria Analítica, segundo o referido documento, estão:

- Interpretar e fazer uso de modelos para resolução de problemas geométricos;

- Associar situações e problemas geométricos a suas correspondentes formas algébricas e representações gráficas e viceversa;

- Construir uma visão sistemática das diferentes linguagens e campos de estudo da Matemática, estabelecendo conexões entre eles. (BRASIL, 2000, p. 125)

Para caracterizar o ensino atual e observar como os livros didáticos abordam o tema, realizamos uma breve análise de quatro ${ }^{2}$ das seis coleções aprovadas no Guia do PNLD 2015 - Ensino Médio (BRASIL, 2014).

A "mecanização" do ensino de Geometria Analítica não vai ao encontro do que é prescrito nos documentos oficiais, nem das recomendações de pesquisas na área de Educação Matemática. É a situação na qual, muitas vezes, os alunos até sabem trabalhar com fórmulas e aplicá-las, mas não compreendem os conceitos por trás delas e as características dos objetos geométricos em jogo.

Também acreditamos que o fato dos alunos não terem compreensão dos conceitos relativos a coordenadas no plano e como se relacionam, dificultam as aplicações relacionadas ao cálculo de distâncias.

O primeiro contato que os alunos possuem com coordenadas cartesianas no plano ocorre nos anos finais do Ensino Fundamental e revisam quando iniciam 0 estudo de funções, porém muitas vezes essa apresentação é feita apenas em seu registro numérico, para auxiliar a representação gráfica, contrariando o que dizem os PCNEM.

\footnotetext{
${ }^{2}$ Para a análise dos livros didáticos, consideramos apenas as quatro coleções a que tivemos acesso na Escola.

${ }^{3}$ Programa Nacional do Livro Didático
} 
O estudo das funções permite ao aluno adquirir a linguagem algébrica como a linguagem das ciências, necessária para expressar a relação entre grandezas e modelar situações-problemas, construindo modelos descritivos de fenômenos e permitindo várias conexões dentro e fora da própria matemática. (BRASIL, 2000, $\mathrm{p}$ 121)

Por esse motivo, sentimos a necessidade de, antes do trabalho com distâncias, fazer um estudo de como é abordado o tema sobre coordenadas cartesianas e suas representações semióticas.

Achamos interessante incluir nesta pesquisa um estudo sobre coordenadas cartesianas e distâncias no espaço, ainda que o estudo de objetos no espaço, na Educação Básica, seja feito apenas em um contexto geométrico ou métrico, sem uma visão analítica.

Como afirmam Braviano e Lunardelli,

Apesar da Habilidade de Visualização Espacial ser muito importante em diversas áreas, os alunos da educação básica não apresentam bons resultados quando são submetidos a testes específicos. Possivelmente tais alunos terão dificuldades nos campos da matemática relacionados à geometria espacial e, mesmo aqueles cursando graduação em cursos como arquitetura, engenharias e artes, necessitando preencher a lacuna deixada na sua trajetória escolar. (BRAVIANO, LUNARDELLI, 2013, p.10)

Em sua pesquisa, esses autores concluem que o trabalho com Habilidade de Visualização Espacial (HVE) não está ligado à idade em que o aluno se encontra, pois o experimento realizado por eles com alunos dos anos finais do Ensino Fundamental e do Ensino Médio ( $1^{\underline{a}}$ e $2^{\underline{a}}$ Séries) promoveu melhoras significativas em todas as turmas.

Esta pesquisa confirma a importância de se explorarem mais recursos lúdicos como estratégias didáticas, aumentando o estímulo e o potencial de contribuição do processo ensino-aprendizagem na formação dos alunos. Os resultados específicos apontam para a validade de uma capacitação dos estudantes para melhorar a HVE, o que pode contribuir para minimizar problemas futuros na vida acadêmica e profissional. As aulas de matemática mostram-se um espaço adequado para a realização dessas atividades. (BRAVIANO, LUNARDELLI, 2013, p.10) 
A Escola Básica deve atuar na vida do aluno de modo que o mesmo, ao terminar o ciclo obrigatório de estudos, seja capaz de ter uma atuação autônoma em sua vida social, bem como dar continuidade a seus estudos. Segundo os PCNEM,

Em nossa sociedade, o conhecimento matemático é necessário em uma grande diversidade de situações, como apoio a outras áreas do conhecimento, como instrumento para lidar com situações da vida cotidiana ou, ainda, como forma de desenvolver habilidade de pensamento. (BRASIL, 2000, p. 111)

O estudo da Geometria é um meio que possibilita ao aluno desenvolver algumas habilidades que o tornarão um cidadão capaz de resolver problemas do dia-a-dia.

\begin{abstract}
A Geometria, ostensivamente presente nas formas naturais e construídas, é essencial à descrição, à representação, à medida e ao dimensionamento de uma infinidade de objetos e espaços na vida diária e nos sistemas produtivos e de serviços. No Ensino Médio, trata das formas planas e tridimensionais e suas representações em desenhos, planificações, modelos e objetos do mundo concreto. Para o desenvolvimento desse tema são propostas quatro unidades temáticas: geometrias plana, espacial, métrica e analítica. (BRASIL, 2000, p. 123)
\end{abstract}

Nesta pesquisa, iremos nos focar no estudo da Geometria no espaço tridimensional e na importância da visualização espacial para o indivíduo. Essa habilidade é relatada por Joly et al. (2011, p. 182), como "a aptidão de manipular, rodar, torcer e inverter as imagens dos objetos" e por eles considerada a mais importante das aptidões espaciais.

Concordamos com os autores citados e observamos que o Exame Nacional do Ensino Médio (ENEM) vem trazendo questões que exploram e avaliam como o estudante resolve problemas relacionados à visualização espacial, segundo a matriz de competências e habilidades do referido Exame. Na Tabela 1, reproduzimos as competências relativas à área de Geometria. 
Tabela 1: Competências e Habilidades do ENEM associadas à Geometria

\begin{tabular}{|c|l|}
\hline \multicolumn{2}{|c|}{$\begin{array}{c}\text { Competência de Área 2 - Usar o conhecimento geométrico para realizar a leitura } \\
\text { e a representação da realidade e agir sobre ela. }\end{array}$} \\
\hline H6 & $\begin{array}{l}\text { Interpretar a localização e a movimentação de pessoas/objetos no espaço } \\
\text { tridimensional e sua representação no espaço bidimensional. }\end{array}$ \\
\hline H7 & Identificar características de figuras planas ou espaciais. \\
\hline H8 & $\begin{array}{l}\text { Resolver situação-problema que envolva conhecimentos geométricos de } \\
\text { espaço e forma. }\end{array}$ \\
\hline H9 & $\begin{array}{l}\text { Utilizar conhecimentos geométricos de espaço e forma na seleção de } \\
\text { argumentos propostos como solução de problemas do cotidiano. }\end{array}$ \\
\hline
\end{tabular}

Fonte: http://portal.mec.gov.br, acesso em 19/12/2017

A seguir, a título de ilustração, selecionamos algumas questões que envolvem visualização espacial e relacionam-se mais especificamente com a habilidade $\mathrm{H} 6$ mencionada na Tabela 1.

\section{Exemplo 1: ENEM 2013}

Gangorra é um brinquedo que consiste de uma tábua longa e estreita equilibrada e fixada no seu ponto central (pivô). Nesse brinquedo, duas pessoas sentam-se nas extremidades e, alternadamente, impulsionam-se para cima, fazendo descer a extremidade oposta, realizando, assim, o movimento da gangorra. Considere a gangorra representada na figura, em que os pontos $A$ e $B$ são equidistantes do pivô.

A projeção ortogonal da trajetória dos pontos $A$ e $B$, sobre o plano do chão da gangorra, quando esta se encontra em movimento, é: 


\section{Figura 1: Questão 142 Caderno Rosa ENEM 2013}

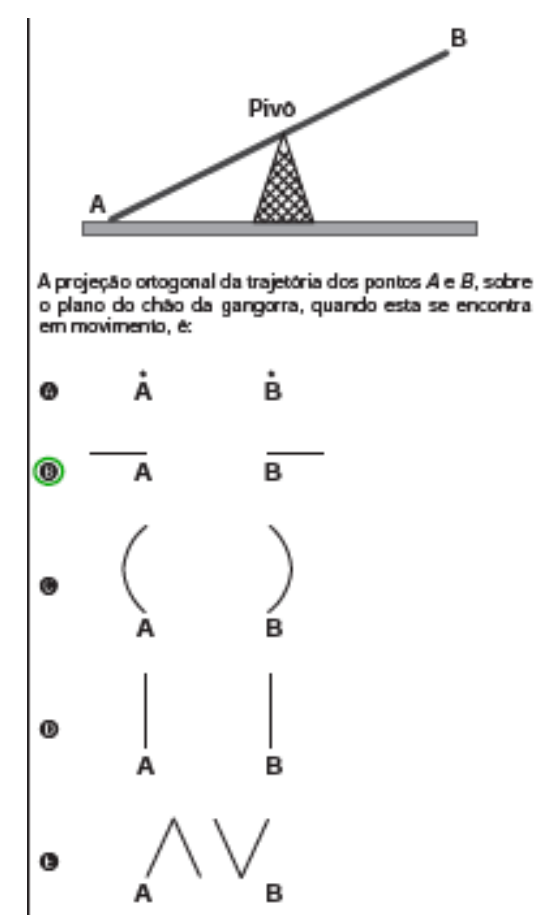

Fonte: www.inep.gov.br/prova-e-gabarito, acesso em 19/12/2017

\section{Exemplo 2: ENEM 2014}

$O$ acesso entre os dois andares de uma casa é feito através de uma escada circular (escada caracol), representada na figura. Os cinco pontos $A, B, C, D, E$ sobre o corrimão estão igualmente espaçados, e os pontos $P$, $A$ e $E$ estão em uma mesma reta. Nessa escada, uma pessoa caminha deslizando a mão sobre o corrimão do ponto $A$ até o ponto $D$.

A figura que melhor representa a projeção ortogonal, sobre o piso da casa (plano), do caminho percorrido pela mão dessa pessoa é: 


\section{Figura 2: Questão 163 Caderno Rosa ENEM 2014}

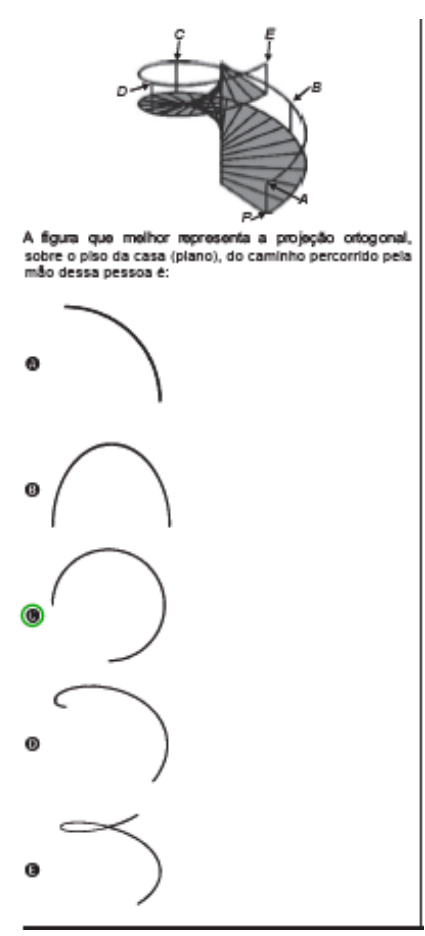

Fonte: www.inep.gov.br/prova-e-gabarito, acesso em 19/12/2017

\section{Exemplo 3: ENEM 2016}

A figura representa o globo terrestre e nela estão marcados os pontos $A, B$ e C. Os pontos $A$ e $B$ estão localizados sobre um mesmo paralelo, e os pontos $B$ e $C$, sobre um mesmo meridiano. É traçado um caminho do ponto $A$ até $C$, pela superfície do globo, passando por $B$, de forma que o trecho de $A$ até $B$ se dê sobre o paralelo que passa por $A$ e $B$ e, o trecho de $B$ até $C$ se dê sobre o meridiano que passa por $B$ e $C$. Considere que o plano a é paralelo à linha do equador na figura.

A projeção ortogonal, no plano $\alpha$, do caminho traçado no globo pode ser representada por: 
Figura 3: Questão 139 Caderno Rosa ENEM 2016

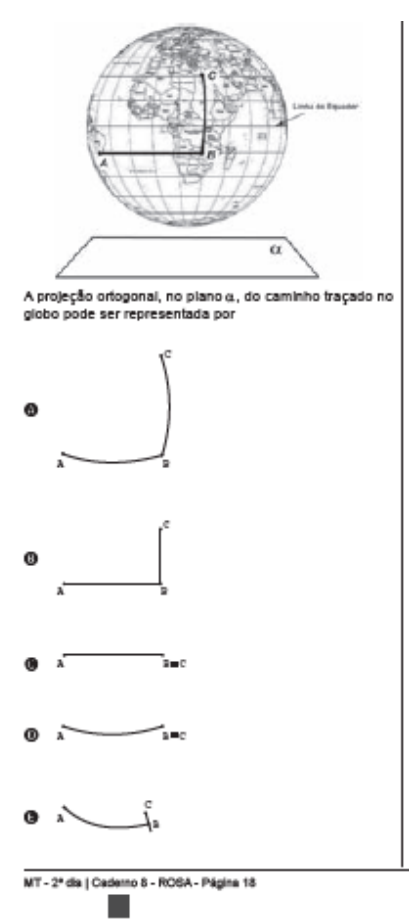

Fonte: www.inep.gov.br/prova-e-gabarito, acesso em 19/12/2017

\section{Exemplo 4: ENEM 2016}

Os alunos de uma escola utilizaram cadeiras iguais às da figura para uma aula ao ar livre. A professora, ao final da aula, solicitou que os alunos fechassem as cadeiras para guardá-las. Depois de guardadas, os alunos fizeram um esboço da vista lateral da cadeira fechada.

Qual é o esboço obtido pelos alunos? 
Figura 4: Questão 154 Caderno Rosa ENEM 2016

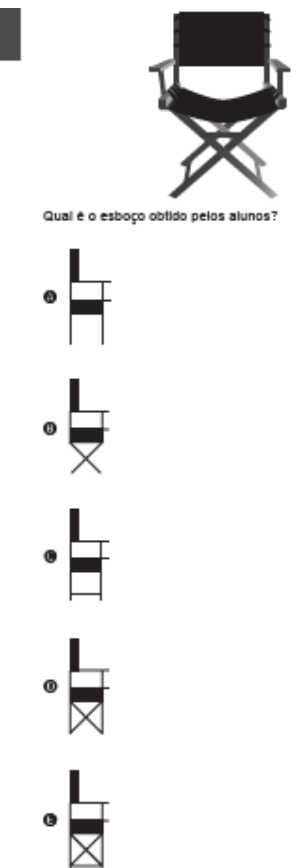

Fonte: www.inep.gov.br/prova-e-gabarito, acesso em 19/12/2017

Nos exemplos apresentados anteriormente, observamos que o conceito de projeção é o tema central de cada questão, sendo as representações de cada situação feitas no plano. $\mathrm{O}$ aluno deve visualizar os objetos e realizar os movimentos e transformações mentalmente, pois, em geral, é a "ferramenta" possível nas condições em que o aluno se encontra ao realizar a prova.

Possuir a habilidade de visualização espacial é importante, pois é utilizada em várias áreas do conhecimento e ainda em situações do dia-a-dia das pessoas. Segundo Verona e Lopes

Atualmente, inúmeras profissões utilizam os conceitos geométricos, entre elas pode-se citar: a engenharia, a arquitetura, a astronomia, as pesquisas nas ciências exatas, as atividades de uma costureira, de um mestre de obras, de um coreógrafo, de um artista plástico, de um atleta ou técnico. Sendo assim, a importância da Geometria é inquestionável, tanto sob o ponto de vista prático quanto do aspecto instrumental na organização do pensamento (VERONA, LOPES, s/d, p. 2) 
Dentre os exemplos apresentados pelas autoras, vamos citar a Arquitetura, onde um profissional da área, ao realizar um projeto, utiliza-se de software que realiza representações em perspectiva, visando reproduzir a situação real, e com os quais pode-se ter uma noção de como ficariam seus projetos depois de prontos.

Vemos nas figuras que seguem, um exemplo de um projeto realizado com um software de modelagem 3D.

Figura 5: Projeto realizado no software Scketchup

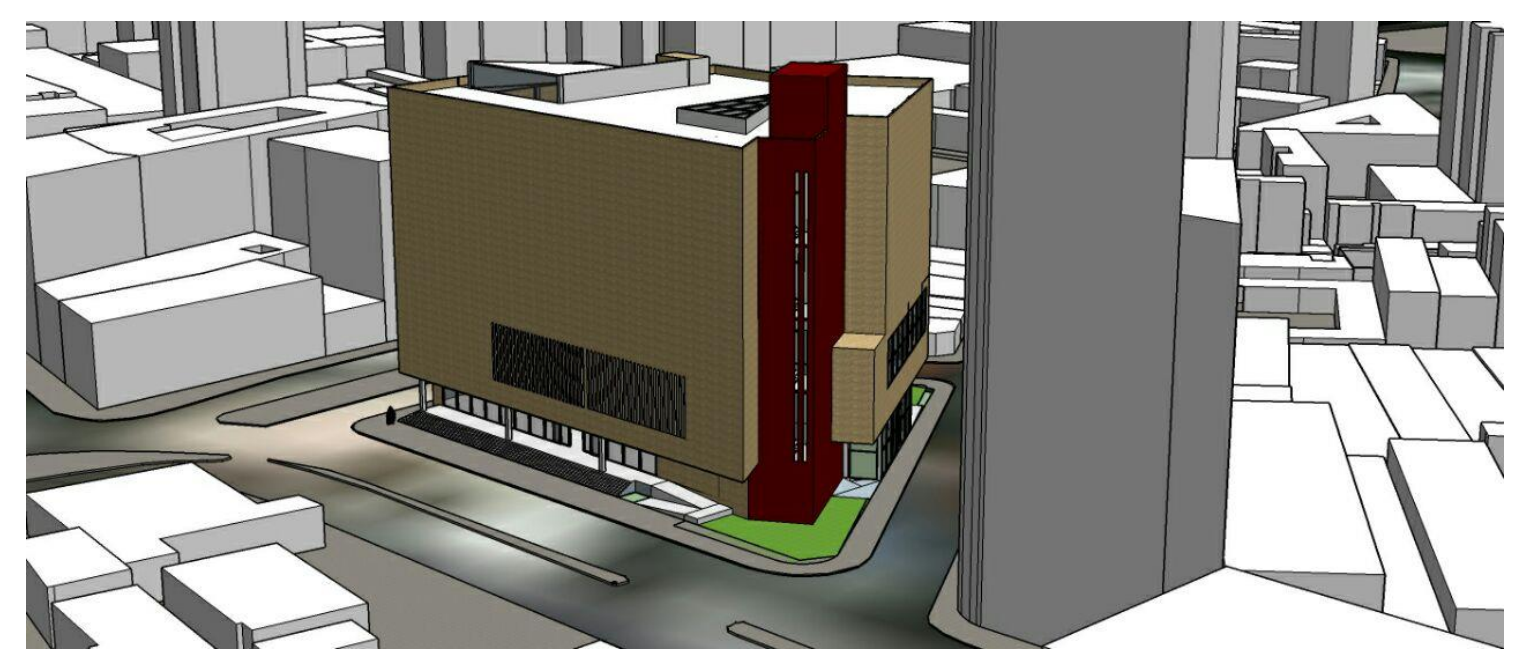

Fonte: A autora

Observando as figuras a seguir, notamos uso dos eixos coordenados, assim como as coordenadas no plano aparecem, de maneira implícita, ou seja, por meio das dimensões de retângulos formados, no exemplo, (Figura 7) temos 6,78 m ao Sul 48,81 ao Leste. 
Figura 6: Eixos coordenados do espaço utilizados no Scketchup

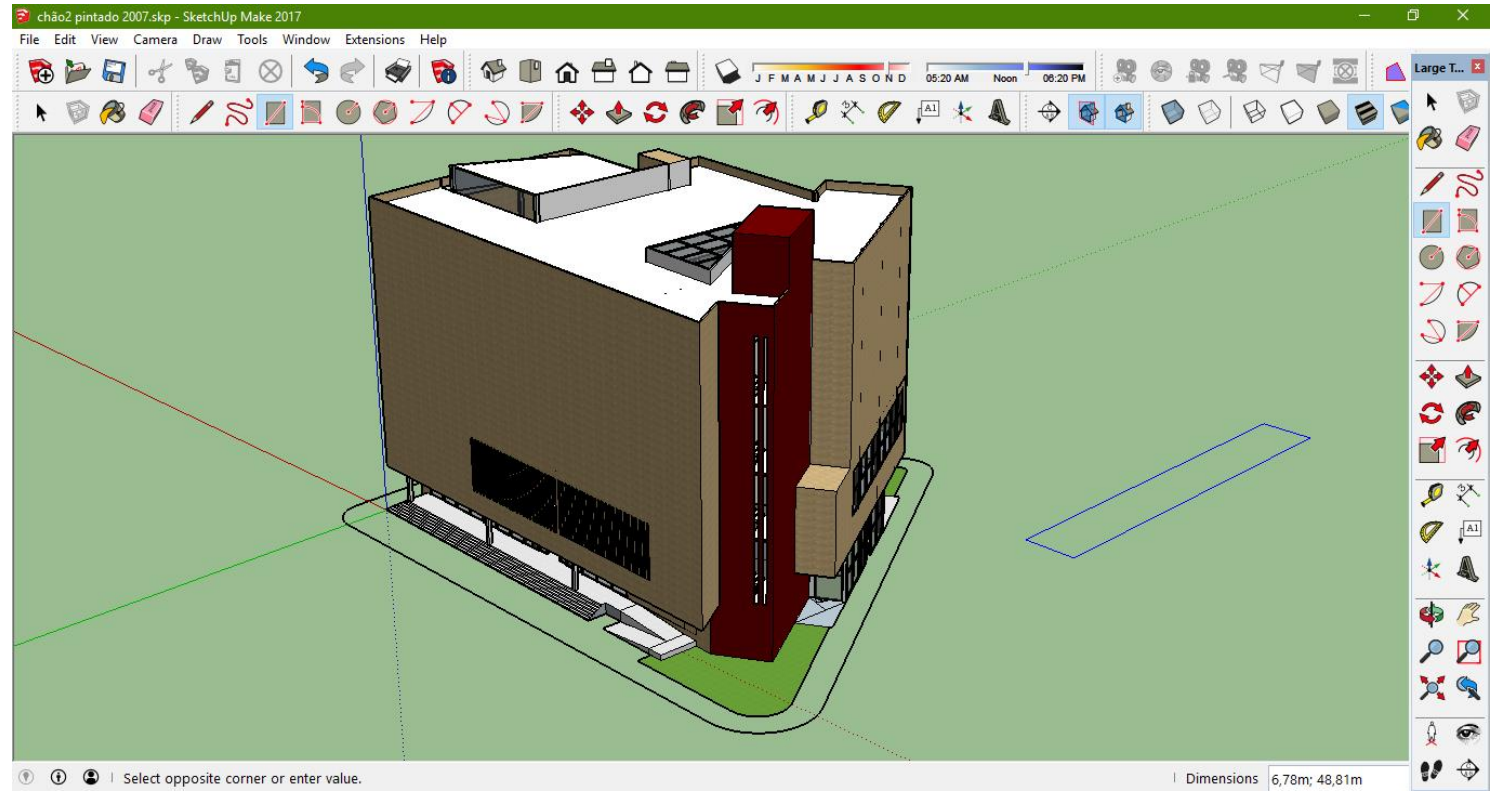

Fonte: A autora

Figura 7: Ideia de coordenadas por meio das dimensões do retângulo

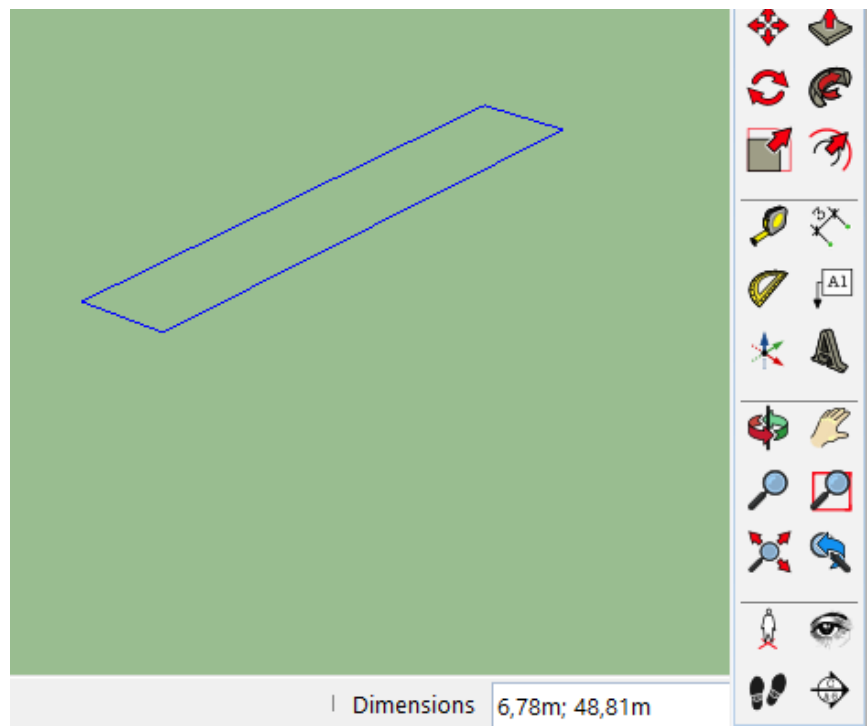

Fonte: A autora

Para corroborar com alguns pressupostos iniciais do nosso trabalho, um questionário ${ }^{4}$ foi aplicado informalmente em duas turmas de alunos ingressantes nos cursos de Licenciatura em Matemática e Licenciatura em Física da Universidade

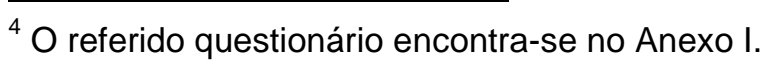


de São Paulo ${ }^{5}$, na disciplina de Geometria Analítica - ministrada no $1^{\circ}$ semestre de 2016 em ambos os cursos. O objetivo do questionário (aplicado no $1^{\circ}$ dia de aula) era o de verificar os conhecimentos prévios dos estudantes acerca do cálculo de distâncias e possíveis interpretações para equações e inequações dadas. Os resultados mostraram que os alunos, ao serem confrontados com equações ou desigualdades do tipo $x=1, x<0, x=y, x^{2}=9$ e $y^{2}+x^{2}-4=0$, não as interpretaram como representações de objetos geométricos, no caso, como conjuntos de pontos da reta real, do plano ou do espaço.

Alguns poucos alunos associaram algumas expressões ao gráfico de equação, como por exemplo, a representação da figura a seguir (Figura 8), que indica a interpretação equivocada da inequação $x^{2}>1$.

Figura 8: Resposta apresentada por aluno no questionário

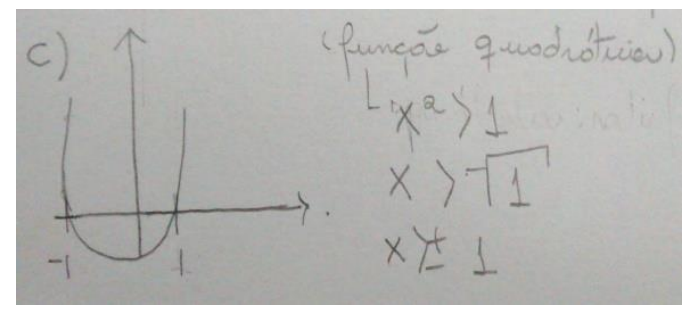

Fonte: Questionário

Ao serem questionados sobre o significado de algumas equações, a maioria fez uma simples "tradução" em língua natural das referidas expressões, não explicitando algum significado particular para elas. Para a expressão $x=1$, por exemplo, 61\% dos estudantes de Matemática e 55\% dos estudantes de Física responderam que "o valor de $x$ é igual 1" não mencionando o que essa equação, ou mais particularmente a letra $x$, pode representar. No caso de $x^{2}=9$, quase $\frac{1}{4}$ dos estudantes de Matemática e 10\% dos estudantes de Física identificaram a expressão como uma "equação do $2^{\circ}$ grau". E mais da metade (25 em 44 na Matemática e 19 em 31 na Física) dos estudantes apresentaram a resolução da equação, indicando os valores -3 e 3 para a incógnita $x$.

\footnotetext{
${ }^{5} 75$ alunos no total, no $1^{\circ}$ semestre de 2016.
} 
Em relação ao cálculo de distância euclidiana entre dois pontos ${ }^{6}$, muitos confundiram a distância entre dois pontos na reta real com a distância no plano e, no caso do espaço, a maioria respondeu nunca ter estudado, o que era previsível.

Nessa questão sobre distâncias, apenas $6 \%$ dos estudantes de Física apresentaram uma resposta correta aos três itens. Esse resultado já era esperado, dado que a abordagem no Ensino Médio é, geralmente, feita apenas no plano e praticamente não se aborda nem coordenadas na reta real, nem no espaço.

$\mathrm{Na}$ análise dos resultados apresentados, encontramos a necessidade de uma abordagem no espaço, pois acreditamos que a dificuldade que os alunos encontraram nas questões sobre espaço se dá pela defasagem que apresentam em Geometria Espacial.

Segundo Resende e Ferreira (2013), o ensino de Geometria Espacial proporciona ao aluno uma capacidade de abstração e auxilia na resolução de problemas práticos.

Fazer uso de formas geométricas espaciais para representar partes do mundo real e do conhecimento geométrico para leitura, compreensão e ação sobre a realidade são habilidades destacadas no PCNEM (BRASIL, 2000) no que se refere ao ensino de Geometria Espacial no Ensino Médio.

A busca por entender o espaço em que vivemos, identificar a existência de objetos e figuras e as relações entre essas formas no espaço real faz da geometria um objeto de conhecimento particularmente relevante e motivador. (RESENDE, FERREIRA, 2003, p. 2)

Considerando a importância da Geometria, em especial da Geometria Analítica, para a formação integral do aluno e as dificuldades observadas no ensino, a seguir apresentamos os objetivos dessa pesquisa e alguns trabalhos que nos serviram de fundamentação teórica.

\footnotetext{
${ }^{6}$ Questão aplicada apenas para 31 estudantes de Física.
} 


\section{Capítulo 1 - Fundamentação Teórica}

\subsection{Objetivo}

Nesta pesquisa, temos como objetivo apresentar situações didáticas voltadas ao ensino da Geometria Analítica, em particular para o estudo de coordenadas cartesianas e cálculo de distâncias no plano e no espaço.

Conhecendo informações sobre dois objetos, por exemplo, as coordenadas de dois pontos ou equação de uma reta e as coordenadas de um ponto, podemos calcular a distância entre esses objetos utilizando diversos conceitos de Geometria e partindo de casos particulares. Porém, se esses objetos são quaisquer, por exemplo, dois pontos quaisquer, é mais interessante conhecer uma "regra" que seja válida para todos os casos.

Para expressar essa regra ou relação, necessitamos do auxílio de letras visando apresentar os objetos de forma genérica. Queremos mostrar a importância de se utilizar letras como uma forma "generalizadora" de representar objetos. Segundo Lins e Gimenez (1997), a necessidade de generalizar surge quando os alunos passam a notar o que é comum a um conjunto de casos particulares. Utilizamos essas ideias para abordar os conceitos de coordenadas cartesianas e os alunos a darem significado ao cálculo de distância via coordenadas cartesianas.

As atividades a serem propostas têm como meta fazer os alunos a conjecturarem regras ou estratégias para cálculos de distâncias e, então, validarem ou não suas conjecturas.

Para criar um contexto favorável à elaboração dessas conjecturas, os alunos serão incentivados a utilizar diversos registros de representação semiótica, pois segundo Duval,

em matemática, as representações semióticas não são somente indispensáveis para fins de comunicação, elas são necessárias ao desenvolvimento da atividade matemática. (DUVAL, 2009, p. 15)

Para o desenvolvimento das tarefas, faremos uso da Geometria Dinâmica, 
uma vez que esse tipo de ambiente auxilia na verificação experimental de conjecturas, permitindo produzir ou analisar um número maior de casos particulares, além de possibilitar o uso de mais de um registro de representação. Escolhemos o software Geogebra para a realização dessas atividades, em especial por disponibilizar representações gráficas de objetos tridimensionais em uma Janela $3 D$.

Faremos uso também de materiais manipuláveis uma vez que podem "facilitar a observação, análise, desenvolver raciocínio lógico e crítico, sendo excelente para auxiliar o aluno na construção dos seus conhecimentos”. (TURRIONI, PEREZ, 2006, p. 61).

Na sequência, apresentamos os principais elementos da Teoria dos Registros de Representação Semióticas de Raymond Duval, na qual estão embasados os estudos preliminares realizados para o desenvolvimento das atividades.

\subsection{Os registros de representação semiótica}

Quando estudamos Matemática, estamos interessados em compreender as características e propriedades de seus objetos e as relações entre eles. Entretanto, uma das dificuldades encontradas está no fato desses objetos não terem existência concreta, ou seja, eles existem apenas no mundo das ideias (são de natureza abstrata), não sendo acessíveis por um de nossos sentidos.

Segundo Duval,

A particularidade da aprendizagem das matemáticas considera que essas atividades cognitivas requerem a utilização de sistemas de expressão e de representação além da linguagem natural ou das imagens. (DUVAL, 2009, p.13)

Por esse motivo, para se ter acesso a esses objetos de forma "concreta" é necessário representá-los e, para isso, utilizamos representações semióticas. Essas representações provém de sistemas particulares de signos como, por exemplo, a língua natural ou a escrita algébrica, os quais tem suas características próprias de significada e funcionamento. Esses sistemas correspondem aos registros de 
representação semióticas referidos pelo autor que destaca, em Matemática, os principais:

- Registro da língua natural - utilização de línguas maternas;

- Registro geométrico ou figural - utilização de figuras geométricas planas ou espaciais; construção com instrumentos;

- Registro dos sistemas de escrita e de cálculo - numéricos, algébricos, simbólicos;

- Registro gráfico - utilização de sistemas de coordenadas.

Segundo D’Amore (2005), semiosis refere-se ao processo de produção de representação por meio de signos e noesis, uma aquisição conceitual de um objeto. Seguindo essas definições, esse autor concorda com Duval (2009) quando este afirma que "não existe noesis sem semiosis", ou seja, para dar significado a um objeto é necessário representá-lo de uma forma "concreta" e, fazer essa representação é uma necessidade do homem.

Como o objetivo é a compreensão de um conceito matemático a ser estudado, faz-se necessário representá-lo de diferentes maneiras, usando assim várias representações, usando várias representações em um mesmo registro ou em registros distintos.

Por exemplo, um dos objetos de estudo na Geometria Analítica é a circunferência que pode ser representada nos seguintes registros.

Quadro 1: Tipos de registros para uma circunferência

\begin{tabular}{|c|c|c|}
\hline REGISTRO GRÁFICO & REGISTRO ALGÉBRICO & $\begin{array}{c}\text { REGISTRO LÍNGUA } \\
\text { NATURAL }\end{array}$ \\
\hline & & \\
\hline
\end{tabular}


Para cada tipo de registro semiótico haverá mais de uma representação semiótica, e com isso, ao se mudar de uma representação $A$ para uma representação $B$, 0 registro se mantêm, porém ao mudar o registro, necessariamente a representação deve mudar também.

O conjunto de atividades cognitivas da semiótica, denominado "características da semiótica", possui três elementos, a saber:

1) Produção de uma representação em um sistema específico;

2) Tratamento: transformações das representações no sistema que obedecem a suas regras;

3) Conversão da representação em um dado sistema para uma representação em outro sistema.

Quando se trabalha dentro de um mesmo registro, a modificação ocorrida quando se manipula uma representação inicial e encontra-se uma segunda representação é denominada tratamento, ou seja, uma transformação de representação interna a um determinado registro. Um exemplo de tratamento pode ser encontrado na relação entre equações reduzida e geral de uma circunferência.

Quadro 2: Exemplo de tratamento em um registro de representação semiótica

\begin{tabular}{|c|c|}
\hline \multicolumn{2}{|c|}{ Circunferência de raio 4 e cento em $(-4,3)$} \\
\hline Equação reduzida para equação geral & Equação geral para equação reduzida \\
\hline$(x+4)^{2}+(y-3)^{2}=16$ & $x^{2}+y^{2}+8 x-6 y+9=0$ \\
$x^{2}+8 x+16+y^{2}-6 y+9=16$ & $x^{2}+8 x+16+y^{2}-6 y+9=16$ \\
$x^{2}+y^{2}+8 x-6 y+9=0$ & $(x+4)^{2}+(y-3)^{2}=16$ \\
\hline
\end{tabular}

Fonte: Autora

Uma transformação entre representações de registros distintos é denominada por Duval (2009) de conversão, ou seja, é uma transformação externa em relação ao registro de representação de partida. A conversão que ocorre entre registros pode ser classificada em congruente ou não-congruente.

$\mathrm{Na}$ conversão congruente nota-se uma correspondência semântica entre as unidades significantes de ambos os registros e ela é feita de forma espontânea e quase imediata pelo sujeito. Além disso, na conversão no sentido inverso, encontrase a representação inicial do registro de partida. A conversão é praticamente 
reduzida a uma codificação de cada elemento da situação, usando as regras e símbolos do registro de chegada.

A seguir, temos duas representações de um ponto cuja conversão, nos dois sentidos é congruente.

Quadro 3: Exemplo de conversão congruente

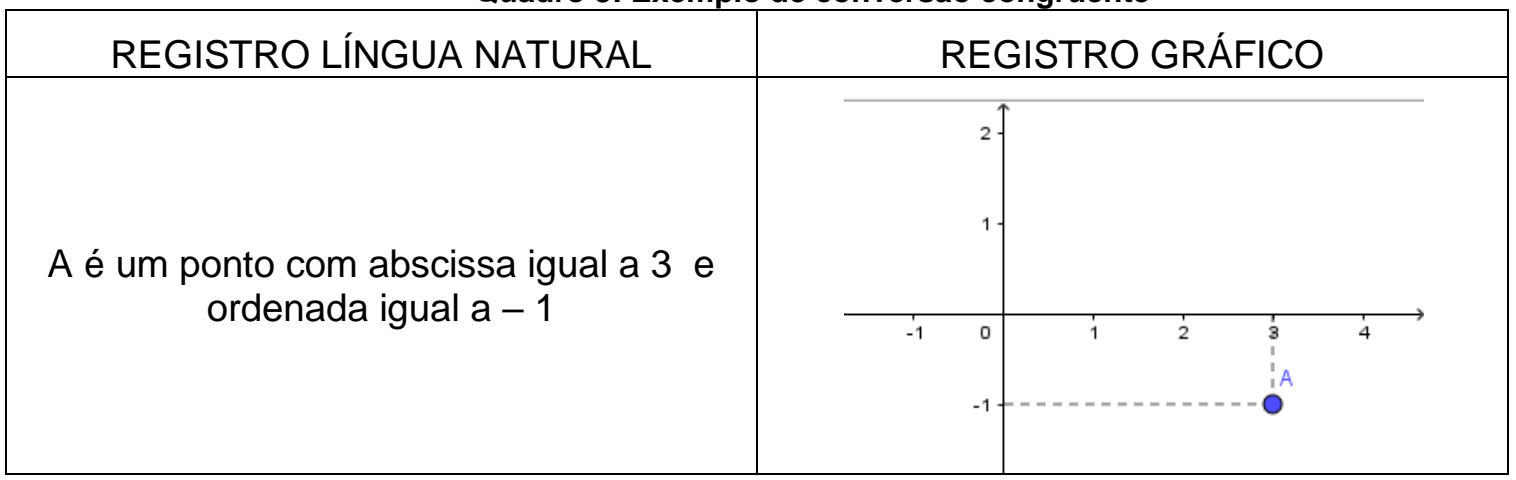

Fonte: Autora

Já no caso da não congruência, a conversão deixa de ser feita de maneira imediata, ou seja, são necessários conhecimentos prévios sobre as características apresentadas no registro de partida para fazer a conversão. Isso se dá pela falta de correspondência semântica entre as unidades significantes nos dois registros. Em geral, há necessidade de interpretação de informações contidas na representação inicial, para identificação de características correspondentes no outro registro.

Considere as representações no registro língua natural e no registro algébrico de uma circunferência. No caso, para chegar à equação geral no registro simbólicoalgébrico é necessário conhecimentos sobre como determinar a equação reduzida de uma circunferência, aplicando a propriedade de equidistância de pontos da circunferência ao centro dado. As informações das coordenadas do centro e medida do raio não têm significantes "diretos" na representação da equação geral.

Quadro 4: Exemplo de conversão não congruente

\begin{tabular}{|c|c|}
\hline REGISTRO LÍNGUA NATURAL & REGISTRO ALGÉBRICO \\
\hline $\begin{array}{c}\mathcal{C} \text { é uma circunferência de raio } 10 \mathrm{e} \\
\text { centrada no ponto }(6,-8)\end{array}$ & $\mathcal{C}: x^{2}+y^{2}-12 x+16 y=0$ \\
\hline
\end{tabular}

Fonte: Autora

Em alguns casos temos o que é chamado de "fenômeno da heterogeneidade da congruência", onde a conversão é congruente em um sentido, mas não no outro. 
Isso acontece, no exemplo abaixo, envolvendo a representação de uma reta em seus registros algébrico e numérico.

Quadro 5: Exemplo de congruência heterogênea

\begin{tabular}{|c|c|c|}
\hline REGISTRO ALGÉBRICO & \multicolumn{2}{|c|}{ REGISTRO NUMÉRICO } \\
\hline$y=4 x+1$ & $\boldsymbol{x}$ & $\boldsymbol{y}$ \\
\hline & -3 & -11 \\
\hline & 2 & 9 \\
\hline
\end{tabular}

Fonte: Autora

A conversão do registro algébrico para o registro numérico é simples, pois basta tomar alguns pontos com coordenadas $(x, 4 x+1)$ e isso a torna congruente. Já a conversão do registro numérico para o registro algébrico não se dá forma imediata e, sendo assim, é não-congruente.

Segundo Duval, para construir um conceito matemático é necessário utilizar vários registros de representação semiótica, ou seja, é necessário representá-lo em um registro, tratá-lo neste registro e fazer conversão para outro registro. Para D’Amore (2005), a construção do conhecimento em Matemática se dá pela união dessas três ações sobre os conceitos. 
Figura 9: Esquema das Atividades Cognitivas envolvendo Representações

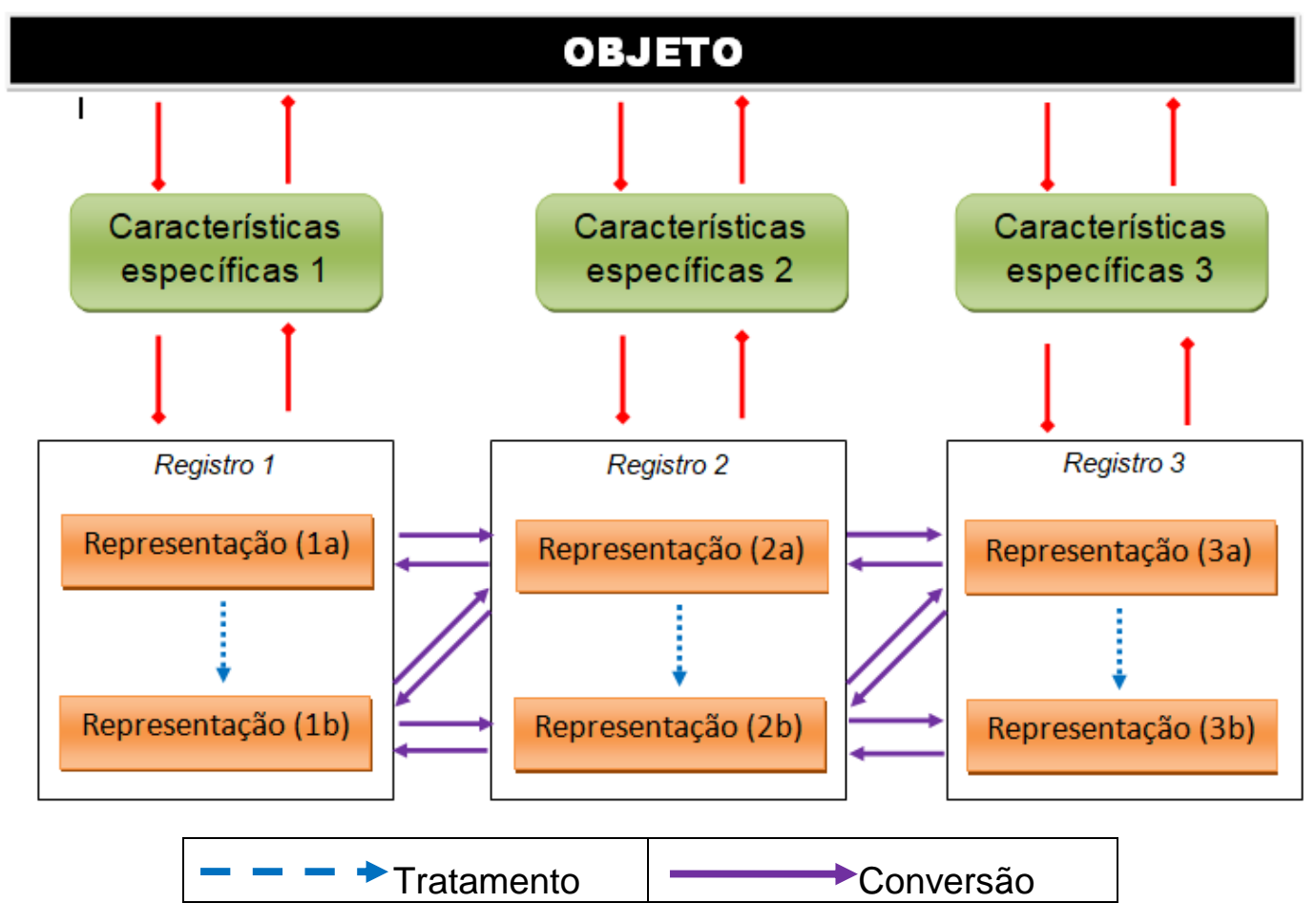

Fonte: Autora

As características específicas do objeto a ser representado dependem do registro escolhido e, com isso, duas representações em registros diferentes terão conteúdos diferentes.

Ainda segundo D'Amore,

Não apenas não existe noesis sem semiosis, mas a semiosis é assumida como sendo uma característica necessária para garantir o primeiro passo na direção da noesis. (D’AMORE, 2005, p. 60)

Isso se dá pelo fato de que o uso de diversos registros de representação semiótica é típico do pensamento humano e que a criação e o desenvolvimento de novos sistemas semióticos são marcos de progresso do conhecimento.

Uma característica específica de um objeto pode estar explícita ou não e isso depende do registro escolhido. Por exemplo, considere uma parábola, e suas representações gráfica e algébrica.

No caso do coeficiente linear, conseguimos identificá-lo em ambas as representações, sem muito esforço, desde que conceitualmente reconhecido. 
A representação gráfica deixa explicita a quantidade de raízes que a parábola possui e com a representação algébrica só é possível fazendo o cálculo do discriminante, ou seja, são necessários alguns conhecimentos prévios e eventuais tratamentos para concluir isso.

É por esta razão que se pode afirmar que cada representação evidencia componentes conceituais distintos do objeto representado.

Figura 10: Representações gráfica e algébrica de uma parábola

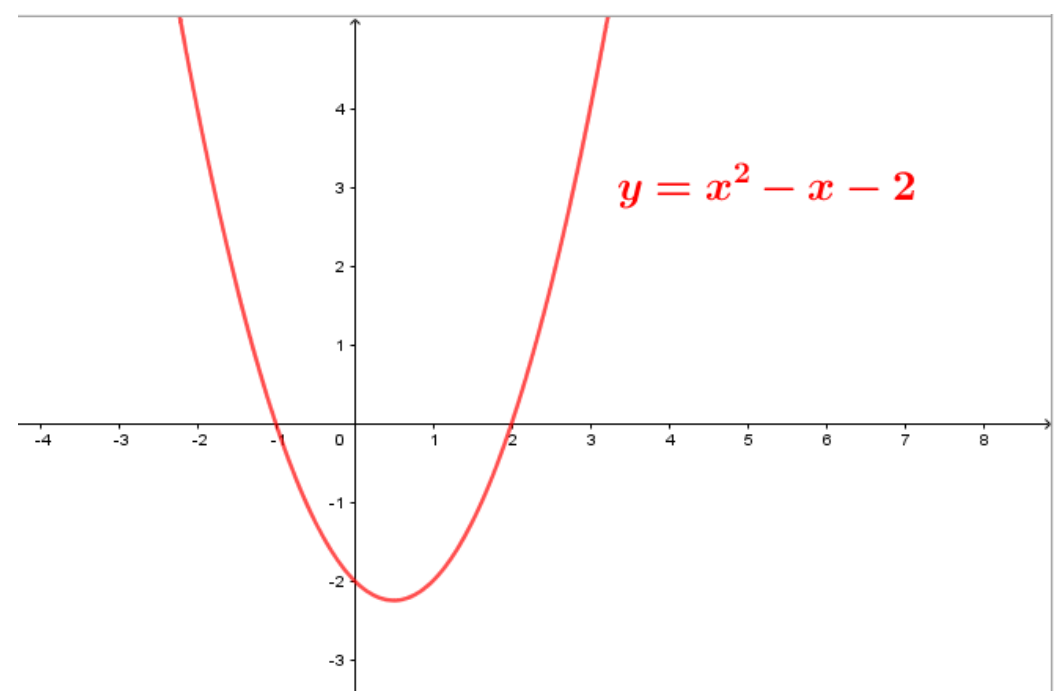

Fonte: Autora

Segundo a teoria de Duval, a conversão tem papel central em relação ao tratamento, ou seja, a atividade de conversão é a mais importante dentre as características semióticas. D'Amore (2005) complementa dizendo que é na conversão que aparecem os casos de não-congruência e que, também, pressupõem uma coordenação de dois registros de representação, que não ocorre espontaneamente no início das aprendizagens e nem é obtida de modo natural. Outro motivo da importância das atividades de conversão vem do fato de permitirem a definição de variáveis cognitivas independentes, tornando possível observações e experimentações relativamente precisas e elaboradas do ponto de vista conceitual. Com isso, as conversões de representações devem ganhar uma atenção especial por parte de professores e pesquisadores. Isso porque, concordamos com os autores quando afirmam que a forma de pensar e visualizar em Matemática está diretamente associado ao uso de representações semióticas, como tentamos evidenciar no exemplo anterior. 
Segundo D'Amore (2005), no ensino de Matemática, costuma-se atribuir maior importância ao tratamento e isso pode ser notado nos próprios livros didáticos. Como veremos mais adiante nos conteúdos referentes à Geometria Analítica, há uma grande quantidade de exemplos e exercícios voltados para o registro algébrico, envolvendo apenas atividades de tratamento nesse registro.

Consideramos, apoiados nos autores citados, que trabalhar com vários registros é a melhor forma de se apropriar de um conceito. Porém, a conversão entre esses registros deve ser feita de maneira adequada, senão as representações não se articulam, podendo levar à ideia de representarem objetos diferentes.

\subsection{Geometria Analítica nos livros didáticos}

Esta pesquisa possui como público alvo professores que lecionam na Educação Básica e, por esse motivo, sentimos a necessidade de uma análise na forma como os livros didáticos abordam os conteúdos de Geometria Analítica. Os conteúdos de interesse do nosso trabalho são pontos, distância entre dois pontos e distância de ponto a reta no plano e no espaço.

Para essa análise foram escolhidas quatro das seis coleções aprovadas pelo PNLD 2015, a saber: 1) Conexões com a Matemática (LEONARDO, 2013); 2) Matemática: Contexto e Aplicações (DANTE, 2014); 3) Matemática - Paiva (PAIVA, 2013) e 4) Novo Olhar: Matemática (SOUZA, 2013). Todas as coleções são apresentadas em três volumes, um para cada série do Ensino Médio.

A Geometria Analítica é abordada, na maioria das coleções, no último volume, referente à $3^{a}$ Série do Ensino Médio, porém o sistema de coordenas cartesianas e as coordenadas no plano são assuntos apresentados no Volume 1 das coleções, devido a sua utilização no estudo de funções.

A coleção de SOUZA (2013) apresenta coordenadas cartesianas no plano de forma sucinta e isso é feito na parte dedicada ao produto cartesiano e relações entre conjuntos, sendo que os exercícios propostos não estão focados nas representações de pontos em um sistema de coordenadas. Já nas coleções de, 
LEONARDO (2013), PAIVA (2013) e DANTE (2014), o sistema de coordenadas no plano é feito de forma mais detalhada e com exercícios que enfatizam as representações de pontos.

Gráfico 1: Quantidade de exercícios propostas no Volume 1 de cada coleção

— Coordenadas no Plano Distância entre dois pontos no Plano

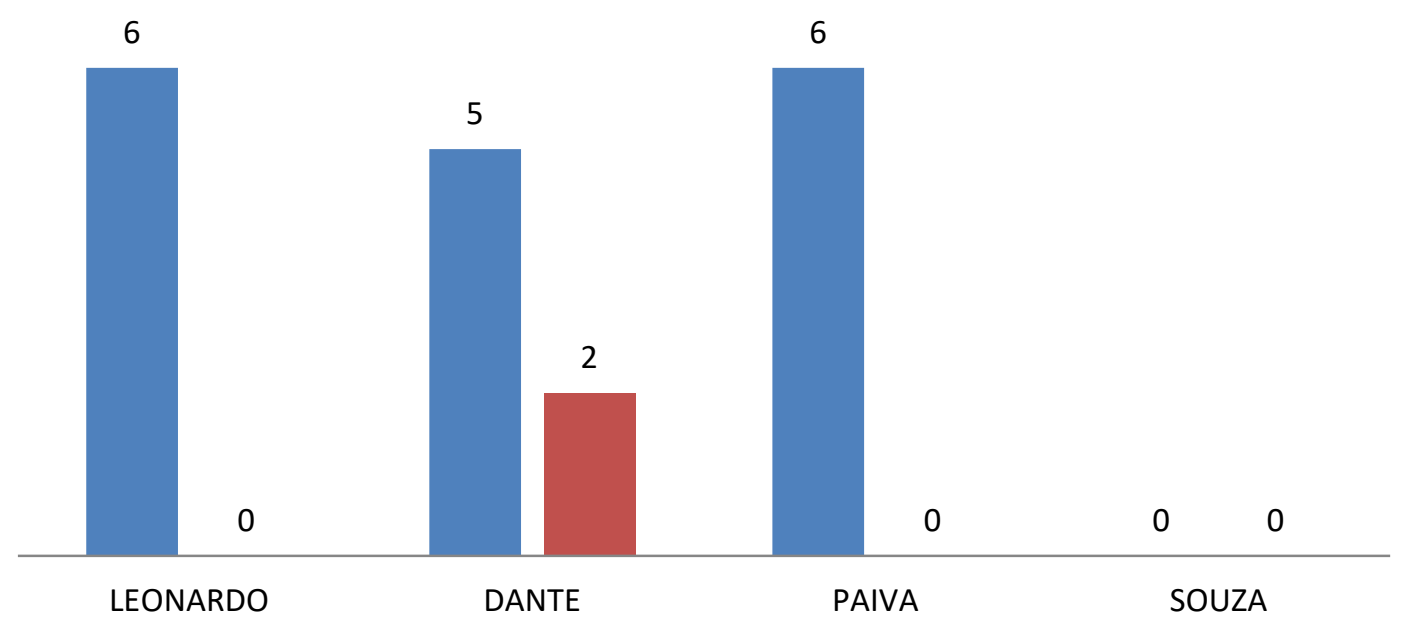

Fonte: A autora

Um diferencial observado na coleção de DANTE (2013) é o fato de apresentar primeiramente, a distância entre dois pontos na reta real (Figura 11), e depois, distância entre dois pontos no plano (Figura 12). O caso de distância entre pontos na reta real é feito no capítulo sobre conjuntos numéricos. As demais coleções analisadas não apresentam estudo sobre cálculo de distância.

Figura 11: Apresentação de distâncias entre dois pontos na reta real no Volume 1

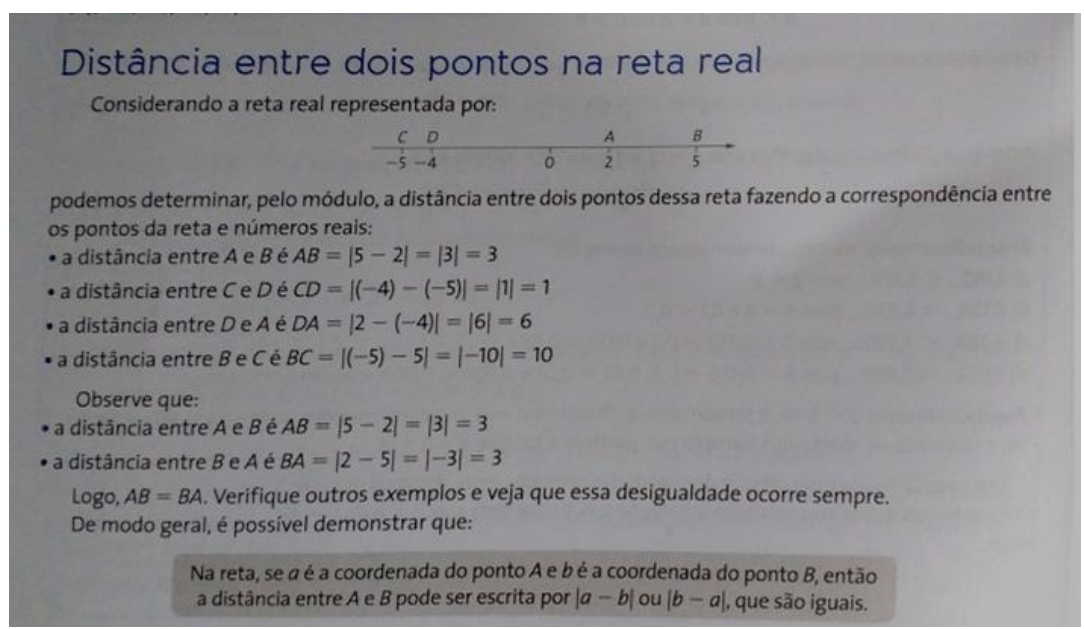

Fonte: Dante (2014, Vol 1, p.24) 
Figura 12: Apresentação de distâncias entre dois pontos no plano no Volume 1

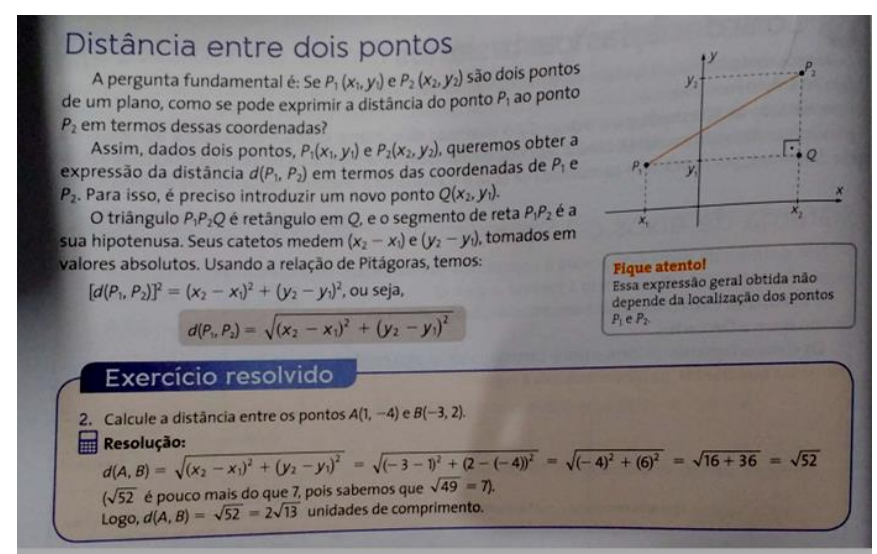

Fonte: Dante (2014, Vol. 1,p.50)

No Volume 3, as coleções começam apresentando, em sua introdução, o sistema de coordenadas cartesianas no plano e pontos como pares ordenados, abordando apenas o plano. Na coleção PAIVA (2013) (Figura 14) essa apresentação é feita de forma bastante sucinta e superficial, talvez porque o autor esteja considerando o conteúdo já trabalho no Volume 1 de sua coleção.

Figura 13: Sistemas de coordenadas no plano em SOUZA

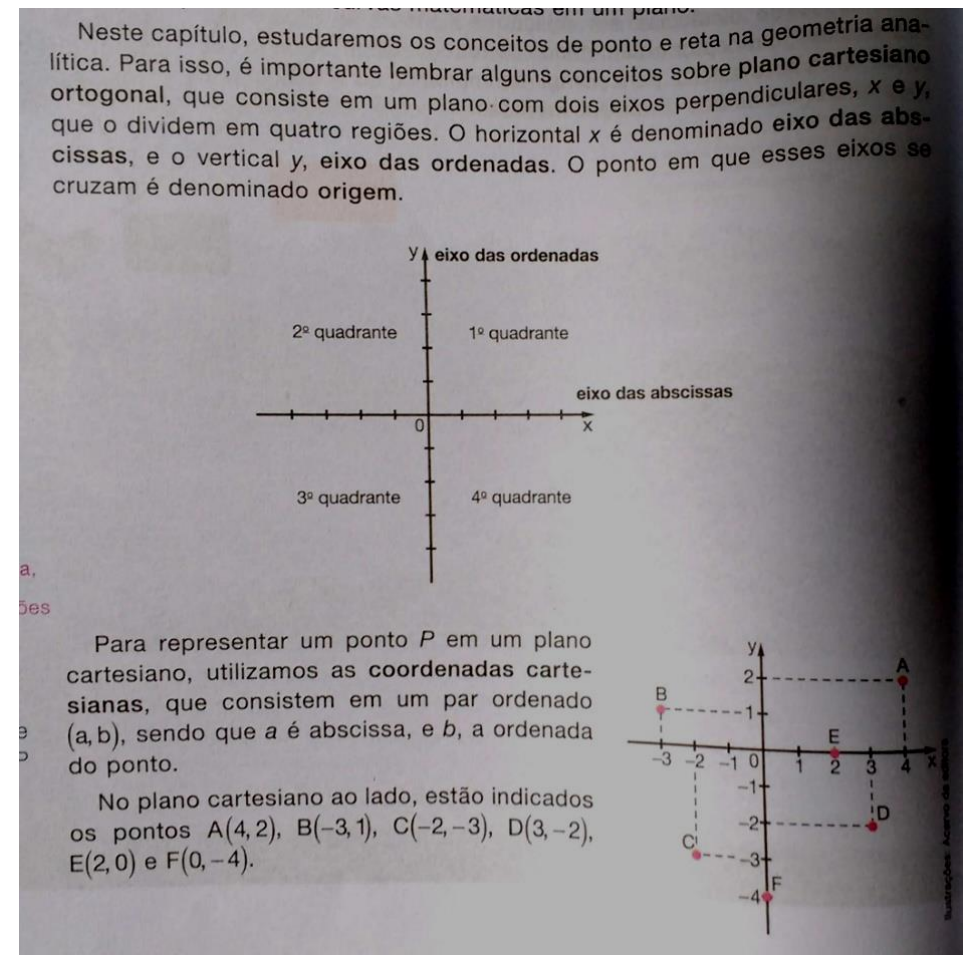

Fonte: Souza (2013, Vol. 3, p.150) 
Figura 14: Sistemas de coordenadas no plano em PAIVA

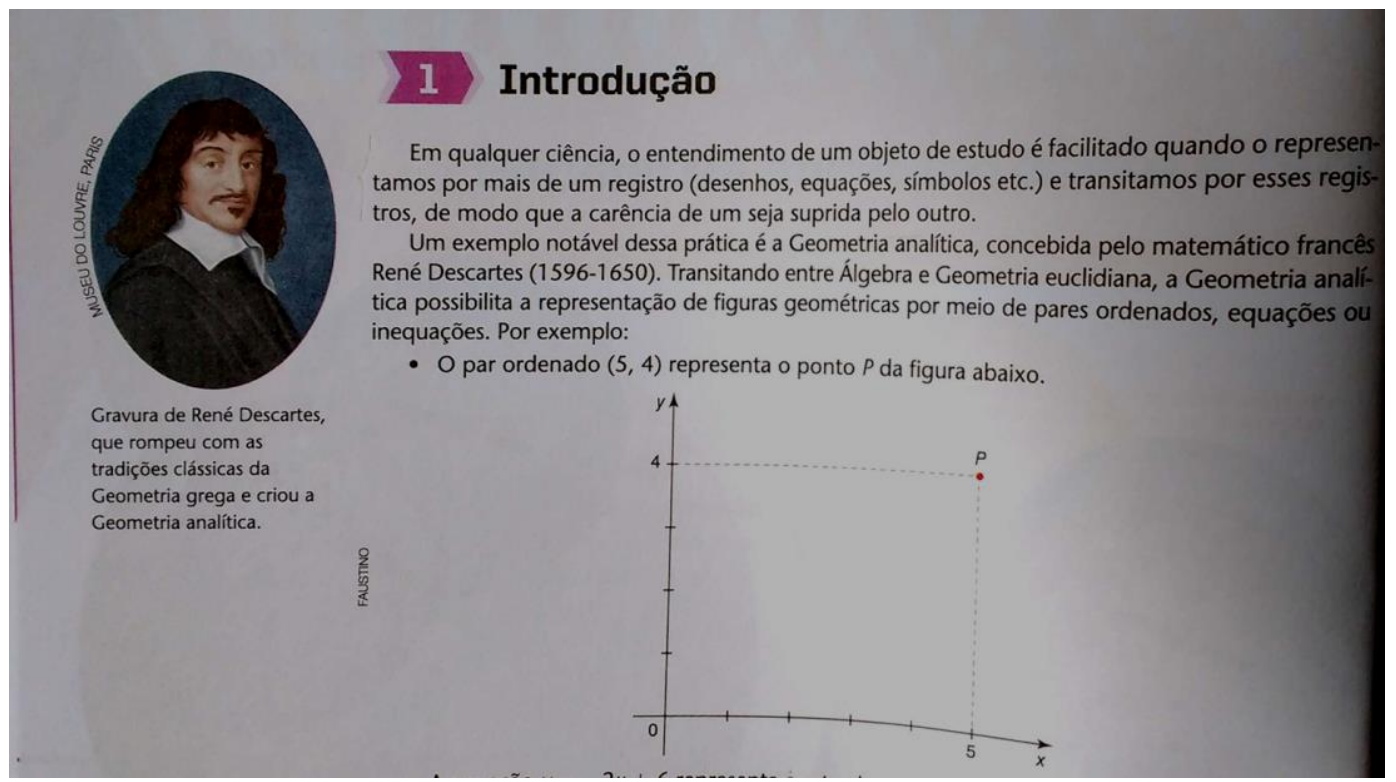

Fonte: Paiva (2013, Vol. 3, p.36)

Após apresentar pontos no contexto da geometria analítica, as coleções começam a tratar de distâncias, abordando o assunto apenas no plano, conforme prescrevem as orientações curriculares. O estudo da distância entre dois pontos na reta real não é tratado explicitamente, somente nos casos de distância entre dois pontos sendo extremidades de segmentos paralelos aos eixos (Figura 15), e sempre no plano, sendo que o espaço nem é citado.

Figura 15: Distância entre dois pontos pertencentes a retas paralelas aos eixos Ox e Oy em DANTE

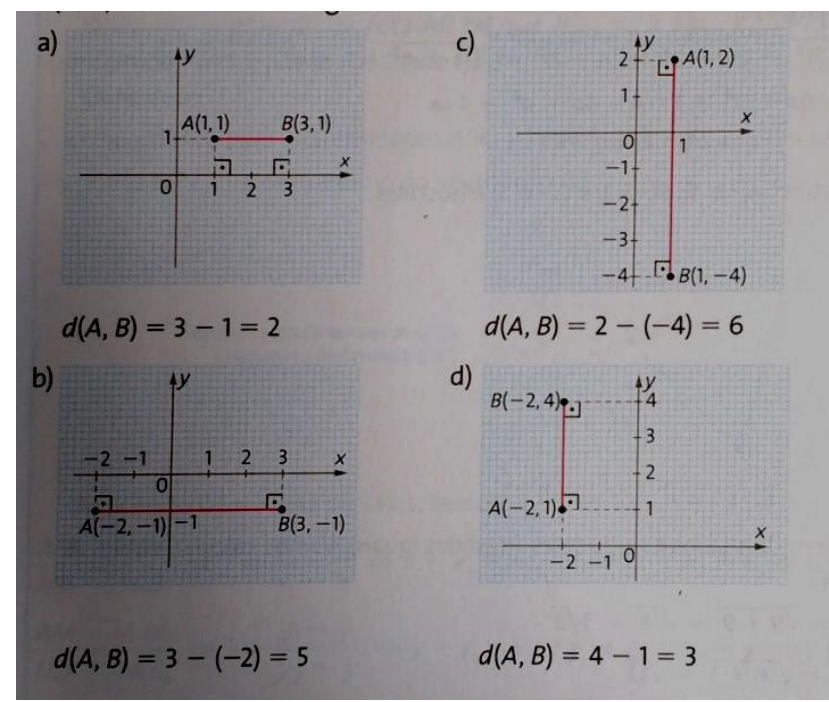

Fonte: Dante (2014, Vol. 3, p.71) 
A distância entre dois pontos é introduzida em todas as coleções por meio de exemplos que utilizam o registro gráfico de pontos e observando a formação de um triângulo retângulo. A medida da hipotenusa desse triângulo coincide numericamente com a distância entre os pontos e com o auxilio do Teorema de Pitágoras é possível determiná-la.

Figura 16: Abordagem sobre distância entre dois pontos no plano em PAIVA

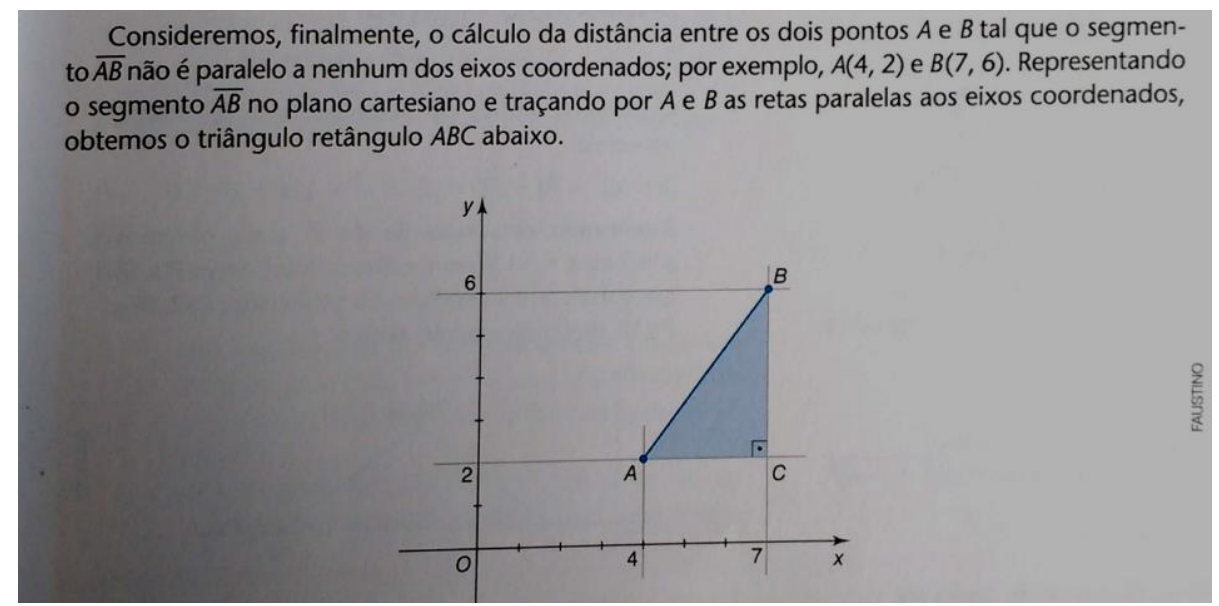

Fonte: Paiva (2013, Vol. 3, p.37)

O caso geral, ou seja, para dois pontos quaisquer, é apresentado em todas as coleções por meio da fórmula $\sqrt{\left(x_{A}-x_{B}\right)^{2}+\left(y_{A}-y_{B}\right)^{2}}$. Apenas PAIVA não apresenta uma demonstração da mesma em seu texto.

As coleções DANTE (2014), PAIVA (2013) e SOUZA (2013) apresentam, entre os exemplos, casos de segmentos paralelos aos eixos $O X$ e $O Y$, já a coleção LEONARDO (2013), apenas faz uma observação sobre tais casos.

Figura 17: Observação sobre distância entre dois pontos em LEONARDO

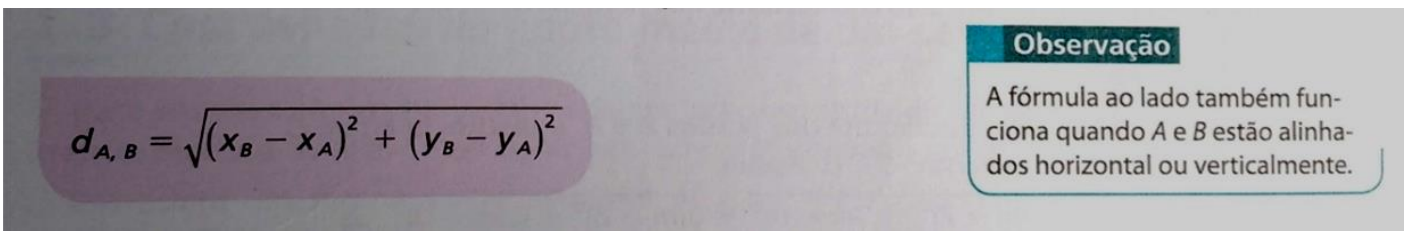

Fonte: Leonardo (2013, Vol. 3, p.85)

Em todas as coleções, a distância entre ponto e reta é introduzida por meio de um exemplo (Figura 18), e a resolução é feita utilizando-se o conceito de retas perpendiculares. 
Figura 18: Abordagem sobre distância entre ponto e reta no plano em PAIVA

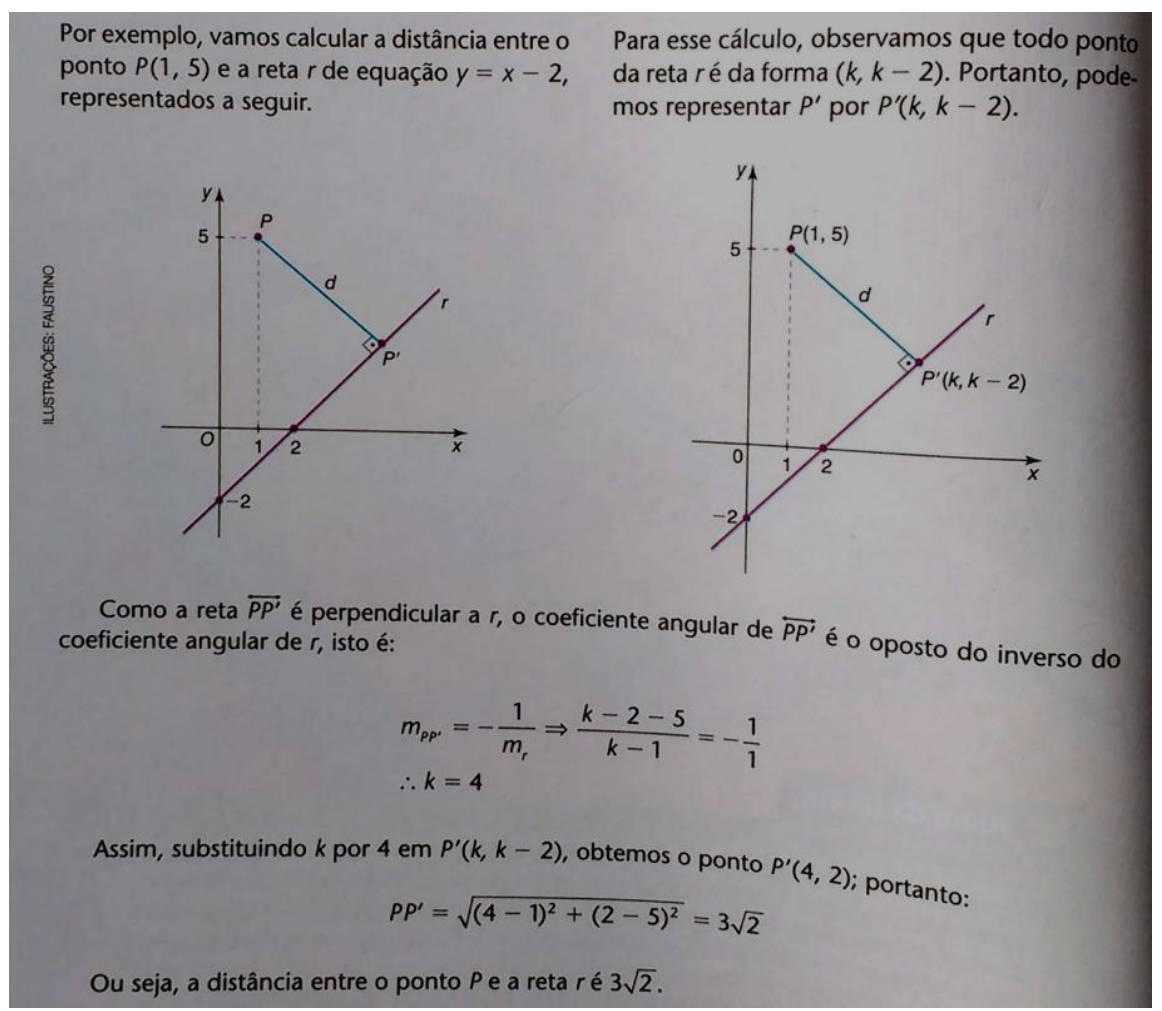

Fonte: Paiva (2013, Vol. 3, p.74)

A apresentação da fórmula $d=\frac{\left|a x_{P}+b y_{P}+c\right|}{\sqrt{a^{2}+b^{2}}}$ é apresentada, nas quatro coleções, sem demonstração. Dessa forma, não é possibilitada a oportunidade ao aluno de compreender a conexão entre a fórmula e os exemplos anteriores.

\subsubsection{Registros de representação semiótica nos livros didáticos}

Neste tópico, faremos uma análise dos exercícios propostos pelas coleções com foco nos registros de representação semiótica. Para isso coletamos a quantidade de exercícios cada coleção propõe para os alunos. 
Gráfico 2: Quantidade de exercícios propostos no Volume 3 de cada coleção.

- Pontos e coordenadas cartesianas — Distância entre dois pontos

Distância entre ponto e reta

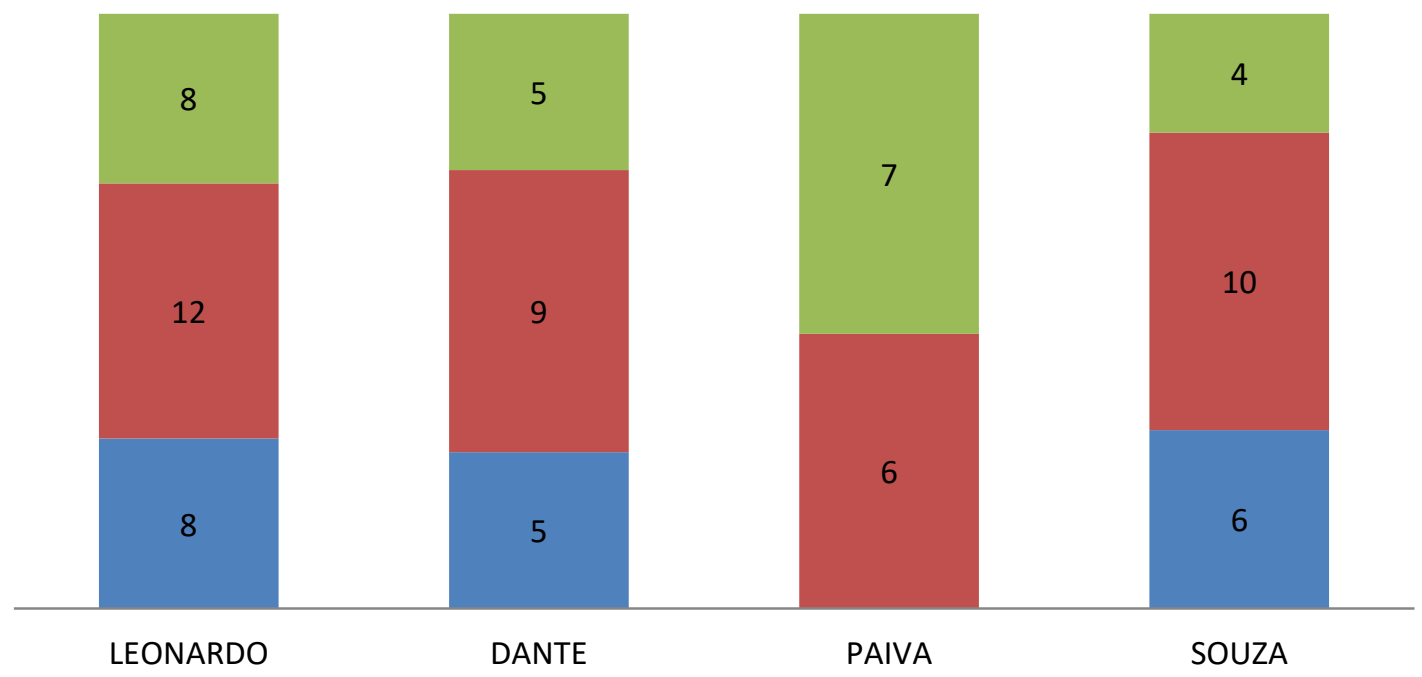

Fonte: A autora

A maioria das coleções analisadas prioriza, em seu Volume 3, exercícios sobre distância entre dois pontos, LEONARDO (43\% dos exercícios), DANTE (47\% dos exercícios), PAIVA (46\% dos exercícios) e SOUZA (50\% dos exercícios).

Dentre os exercícios propostos ${ }^{7}$ pelas coleções observamos quais são os tipos de registros presentes nas apresentações dos objetos geométricos ou que devem ser utilizados nas resoluções desses e, no caso de mais de um registro, como se dá a conversão entre eles.

\footnotetext{
${ }^{7}$ Consideramos os Volumes 1 e 3 de cada coleção.
} 
Gráfico 3: Apresentação dos objetos geométricos nos exercícios propostos por coleção no Volume 1

Registro Agébrico $\quad$ Registro Gráfico $\quad$ Registro Lingua Natural $\quad$ Registro Numérico

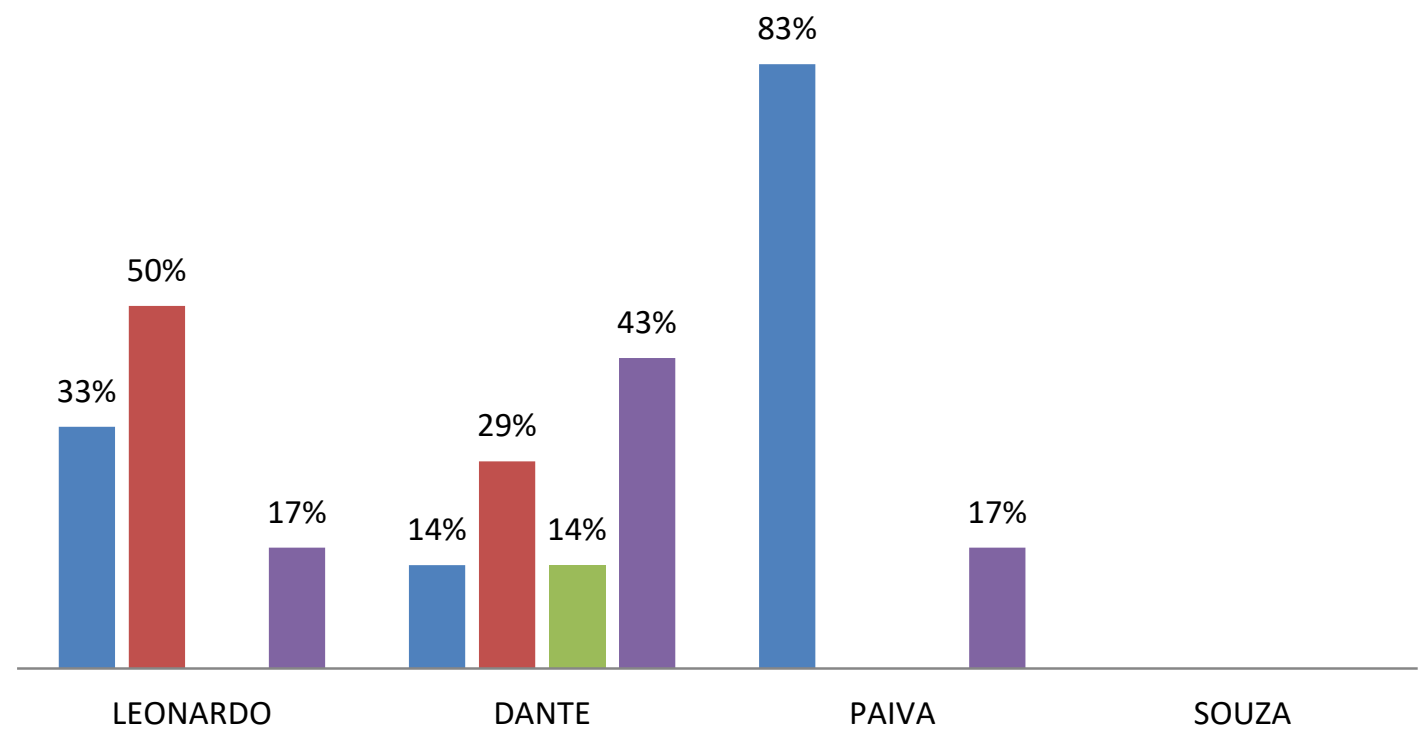

Fonte: A autora

Observamos quatro registros utilizados para representar pontos e retas.

- Registro algébrico (RA): os pontos têm suas coordenadas apresentadas por meio de expressões algébricas, e as retas são apresentadas pelas suas equações.

- Registro gráfico (RG): os pontos e retas são apresentados por meio de sua representação geométrica em um sistema de coordenadas cartesianas.

- Registro língua natural (RLN): os pontos são apresentados por meio de uma característica sobre sua posição no plano ou alguma relação entre suas coordenadas.

- Registro numérico (RN): os pontos são conhecidos e apresentados como pares ordenados de números. 
Gráfico 4: Apresentação dos objetos geométricos nos exercícios propostos por coleção no Volume 3

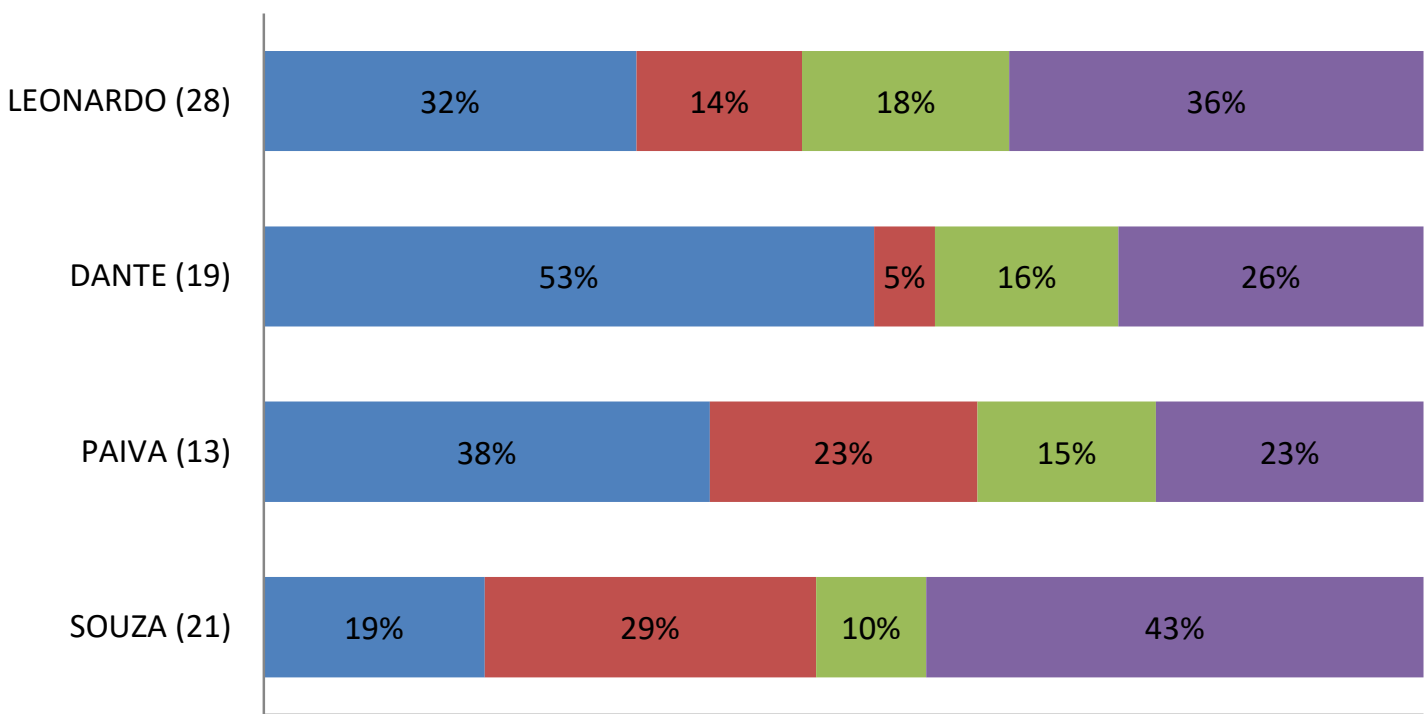

Registro Agébrico $\square$ Registro Gráfico $\square$ Registro Lingua Natural $\quad$ Registro Numérico

Fonte: Autora

Analisando separadamente os exercícios sobre coordenadas no plano e o cálculo de distância, notamos que para cada caso existe uma preferência de registro para apresentar os objetos.

Tabela 2: Registros mais valorizados nos exercícios sobre coordenadas no plano por coleção nos

\begin{tabular}{|c|c|c|c|c|}
\hline Coleção & $\begin{array}{c}\text { Volumes 1 e 3 } \\
\text { Registro } \\
\text { Algébrico }\end{array}$ & $\begin{array}{c}\text { Registro } \\
\text { Gráfico }\end{array}$ & $\begin{array}{c}\text { Registro } \\
\text { Língua } \\
\text { Natural }\end{array}$ & $\begin{array}{c}\text { Registro } \\
\text { Numérico }\end{array}$ \\
\hline $\begin{array}{c}\text { Conexões com a } \\
\text { Matemática }\end{array}$ & 4 & 6 & --- & 4 \\
\hline $\begin{array}{c}\text { Matemática: Contexto e } \\
\text { Aplicações }\end{array}$ & 3 & 3 & 2 & 4 \\
\hline Matemática -Paiva & 5 & --- & --- & 1 \\
\hline Novo Olhar: Matemática & 1 & 2 & 1 & 6 \\
\hline
\end{tabular}

Fonte: Autora

Vemos que a maioria dos exercícios sobre coordenadas no plano apresenta os pontos nos registros numérico ou gráfico, sendo o caso de LEONARDO (10/14), DANTE (7/12) e SOUZA (8/10). Acreditamos que isso se faz pela presença da conversão entre esses registros muitas vezes necessária na resolução de exercícios e problemas envolvendo outros conteúdos de geometria analítica. 
Figura 19: Enunciados de exercícios sobre coordenadas no plano em LEONARDO

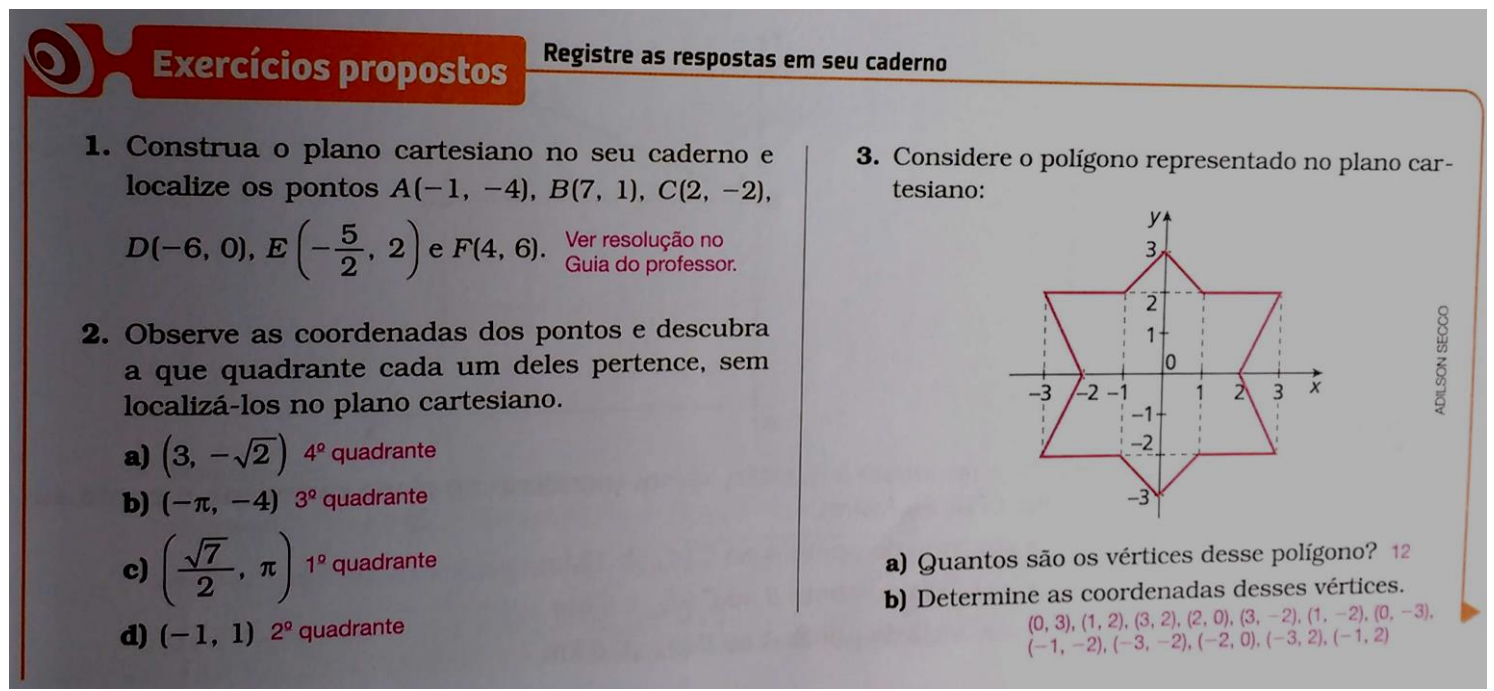

Fonte: Leonardo (2013, Vol. 3, p.83)

Para os exercícios de cálculo de distâncias, esperávamos que pontos e retas fossem apresentados de forma equilibrada entre os registros algébrico, geométrico e numérico, mas o que constatamos é que as coleções valorizam muito mais o registro algébrico para distância entre ponto e reta e o registro numérico para distância entre dois pontos, muitas vezes oferecendo exercícios que fazem apenas tratamentos de representações no interior desse registro.

Tabela 3: Registros mais valorizados nos exercícios sobre cálculo de distâncias no plano por coleção

\begin{tabular}{|c|c|c|c|c|}
\hline Coleção & $\begin{array}{c}\text { Registro } \\
\text { Algébrico }\end{array}$ & $\begin{array}{c}\text { Registro } \\
\text { Gráfico }\end{array}$ & $\begin{array}{c}\text { Registro } \\
\text { Língua } \\
\text { Natural }\end{array}$ & $\begin{array}{c}\text { Registro } \\
\text { Numérico }\end{array}$ \\
\hline $\begin{array}{c}\text { Conexões com a } \\
\text { Matemática }\end{array}$ & 7 & 1 & 5 & 7 \\
\hline $\begin{array}{c}\text { Matemática: Contexto e } \\
\text { Aplicações }\end{array}$ & 8 & --- & 2 & 4 \\
\hline Matemática-Paiva & 5 & 3 & 2 & 3 \\
\hline Novo Olhar: Matemática & 3 & 4 & 1 & 3 \\
\hline
\end{tabular}

Fonte: A autora 
Figura 20: Enunciados de exercícios sobre distância entre dois pontos em LEONARDO

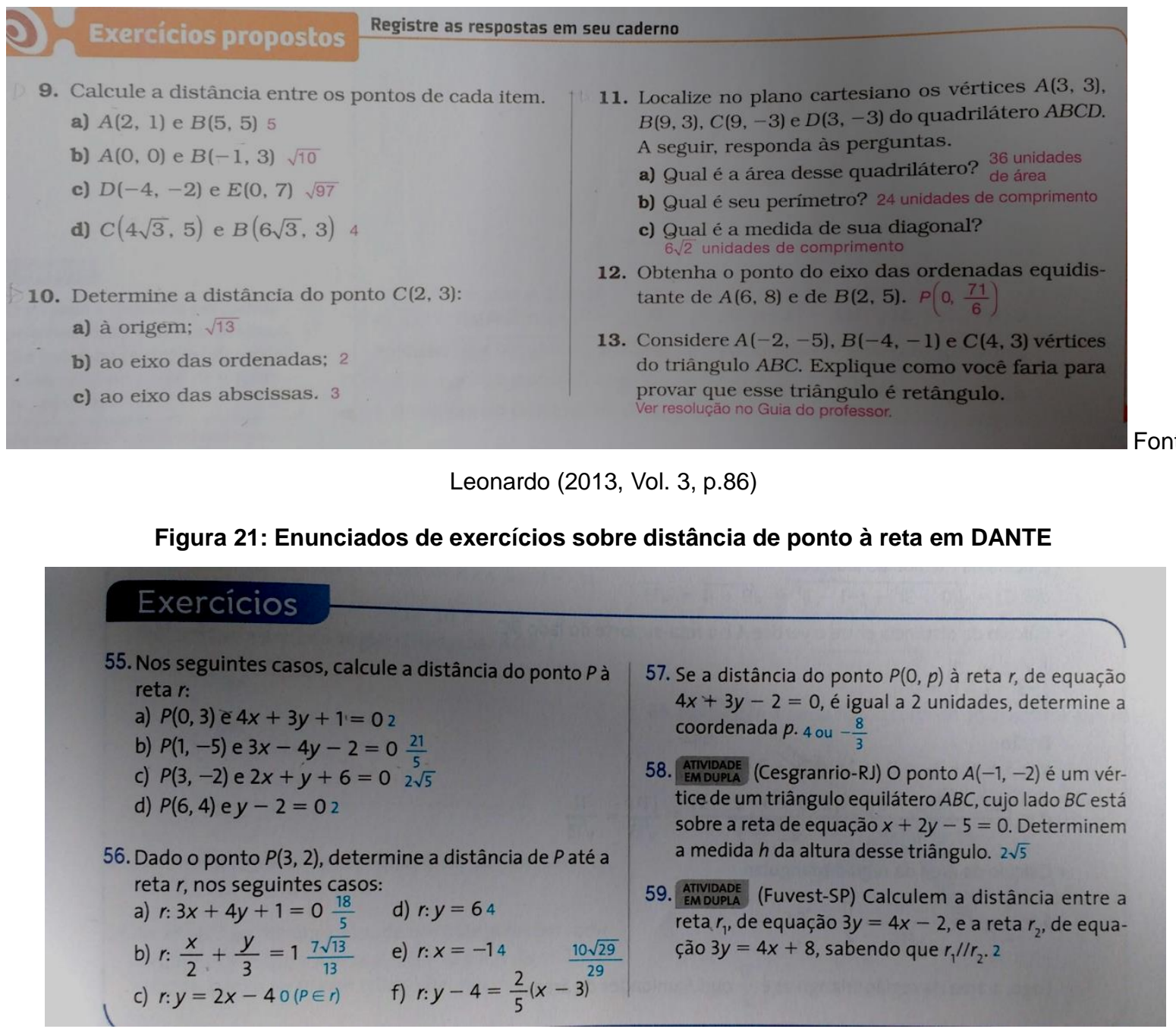

Fonte: Dante (2014, Vol. 3, p.89)

No Volume 3 de sua coleção, PAIVA (2013) comenta sobre a importância da representação de objetos matemáticos em vários registros, mas no caso do estudo de coordenadas no plano, faz pouco uso de diferentes registros.

Figura 22: Enunciados de exercícios sobre coordenadas no plano de PAIVA no Volume1

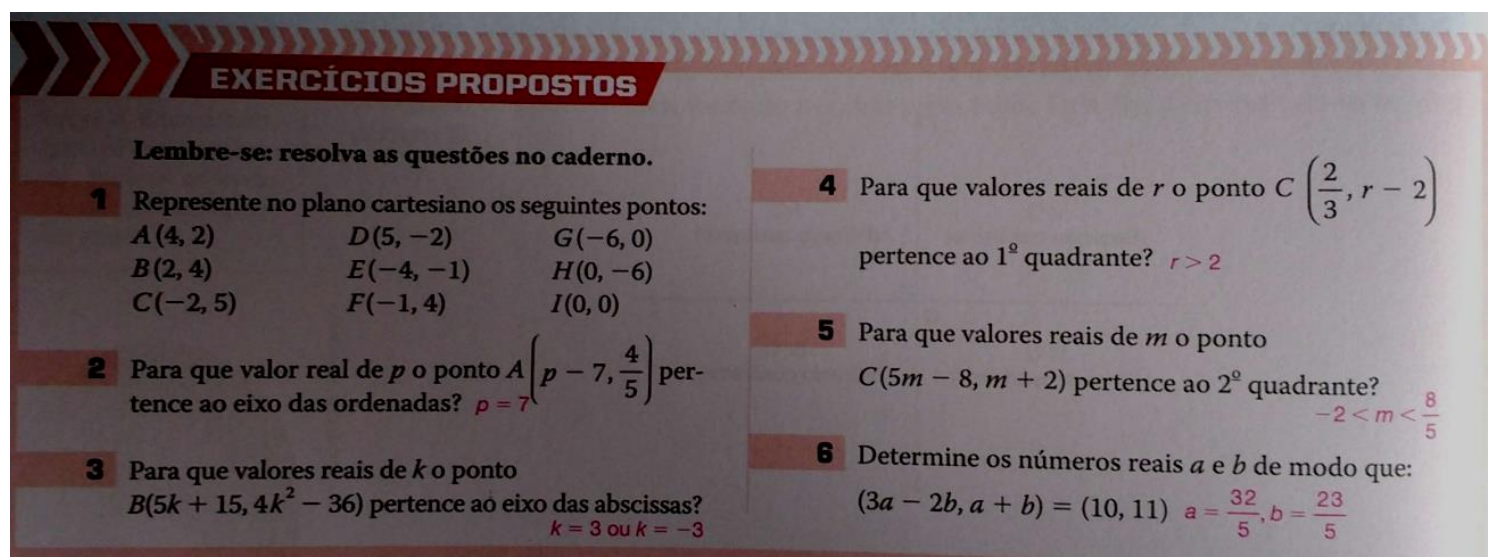


$\mathrm{Na}$ resolução de um exercício pode ser necessário o uso de mais de um registro, por isso analisamos a existência ou não de atividades de conversão entre os registros e para essa verificação utilizamos as resoluções apresentadas nos Manuais do Professor.

Gráfico 5: Conversão entre registros nos exercícios propostos por Coleção

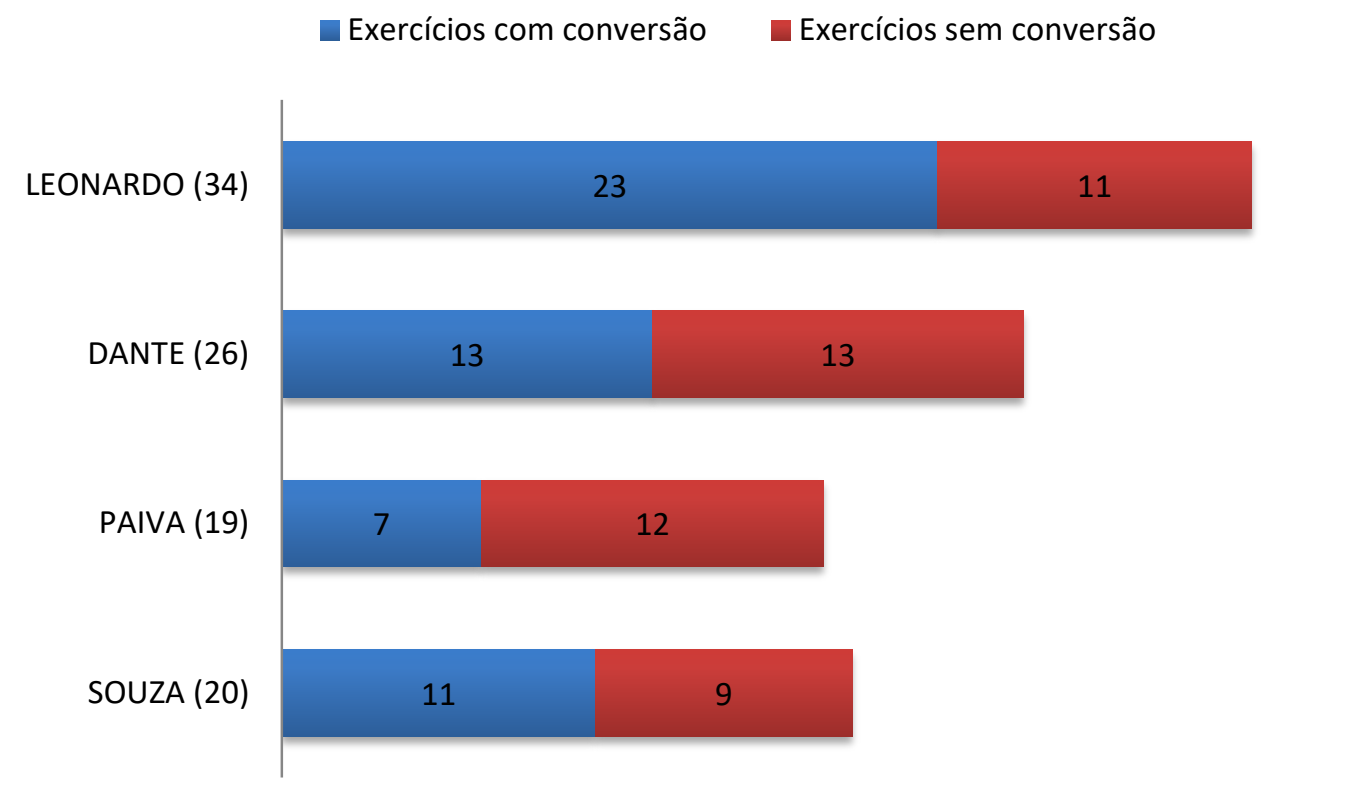

Fonte: Autora

A seguir selecionamos alguns exemplos de exercícios com suas resoluções que apresentam algum tipo de conversão entre registros em cada coleção.

\section{Conexões com a Matemática (LEONARDO)}

\section{Exercício 2 (coordenadas no plano)}

O exercício apresenta conversão do registro numérico para o registro língua natural. 
Figura 23: Exercício de conversão do RN para o RLN em LEONARDO

2. Observe as coordenadas dos pontos e descubra a que quadrante cada um deles pertence, sem localizá-los no plano cartesiano.

a) $(3,-\sqrt{2}) 4^{\circ}$ quadrante

b) $(-\pi,-4) 3^{\circ}$ quadrante

c) $\left(\frac{\sqrt{7}}{2}, \pi\right) 1^{\circ}$ quadrante

d) $(-1,1) 2^{\circ}$ quadrante

Fonte: LEONARDO (2013, Vol 3, p.83)

Figura 24: Exercício de conversão do RN para o RLN (resolução) em LEONARDO

2. a) Temos $x=3>0$ e $y=-\sqrt{2}<0$, então o ponto $(3,-\sqrt{2})$ pertence ao $4^{\circ}$ quadrante.

b) Temos $x=-\pi<0$ e $y=-4<0$, então o ponto $(-\pi,-4)$ pertence ao $3^{\circ}$ quadrante.

c) Temos $x=\frac{\sqrt{7}}{2}>0$ e $y=\pi>0$, então o ponto $\left(\frac{\sqrt{7}}{2}, \pi\right)$ pertence ao $1^{\circ}$ quadrante.

d) Temos $x=-1<0$ e $y=1>0$, então o ponto $(-1,1)$ pertence ao $2^{\circ}$ quadrante.

Comentário: Nos exercícios 1 e 2, é importante observar se os alunos não apresentam dificuldade na quantificação e localização no plano cartesiano de valores expressos com raiz quadrada ou na representação fracionária.

Fonte: LEONARDO (2013, Vol. 3, p.72 Guia do Professor)

A conversão é não congruente, pois para resolução do exercício o aluno deve conhecer a relação entre as coordenadas e seus sinais.

Tabela 4: Sinais das coordenas no plano

\begin{tabular}{|c|c|}
\hline$x>0$ e $y>0$ & $1^{\circ}$ quadrante \\
\hline$x<0$ e $y>0$ & $2^{\circ}$ quadrante \\
\hline$x<0$ e $y<0$ & $3^{\circ}$ quadrante \\
\hline$x>0$ e $y<0$ & $4^{\circ}$ quadrante \\
\hline
\end{tabular}

Fonte: Autora

\section{Exercício 8 (coordenadas no plano)}

O exercício apresenta uma conversão congruente do registro geométrico para o registro algébrico. 


\section{Figura 25:Exercício de conversão do RG para o RN em LEONARDO}

8. O ponto $P$ representado abaixo pertence à bissetriz dos quadrantes impares.

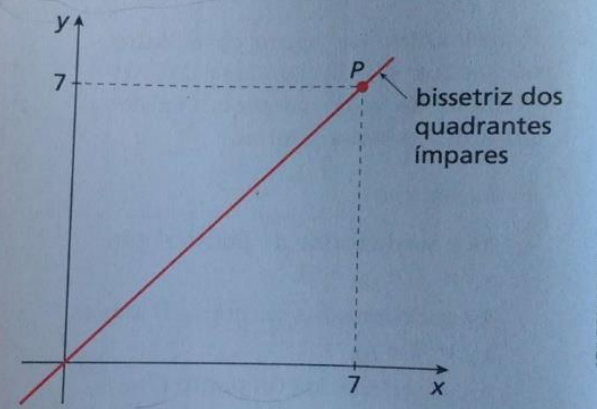

Calcule a distância do ponto $P$ à origem do sistema de eixos coordenados. Você pode usar a estratégia elaborada no exercício anterior. $7 \sqrt{2}$

Fonte: LEONARDO (2013, Vol. 3, p.85)

Figura 26: Exercício de conversão do RG para o RN (resolução) em LEONARDO

8. Como o ponto $P$ pertence à bissetriz dos quadrantes ímpares, as coordenadas desse ponto são $(x, x)$. Aplicando o teorema de Pitágoras, temos:

$d_{P, O}=\sqrt{x^{2}+x^{2}}=x \sqrt{2}$

Como $x=7$, então $d_{P, O}=7 \sqrt{2}$.

Comentário: Seria interessante fazer as atividades 7 e 8 no mesmo dia, pois nessas atividades há uma sequência de raciocínios complementares. Se achar conveniente, peça aos alunos que encontrem a fórmula para um ponto $P$ qualquer (em que $P$ é um ponto da bissetriz dos quadrantes impares).

Fonte: LEONARDO (2013, Vol. 3, p.73 Guia do Professor)

A resolução considerou apenas os casos onde $x>0$, pois para valer para todo número real, devemos ter $\sqrt{x^{2}+x^{2}}=\sqrt{2 x^{2}}=|x| \sqrt{2}$.

Podemos observar que o exercício também pode ser resolvido sem a necessidade de conversão e o uso da fórmula, pois nota-se um triângulo retângulo com vértices $O=(0,0), P=(7,7)$ e $Q=(7,0)$ e ao usar o Teorema de Pitágoras a resolução torna-se apenas um tratamento no registro gráfico. 
Figura 27: Resolução alternativa para o ex 8 de LEONARDO

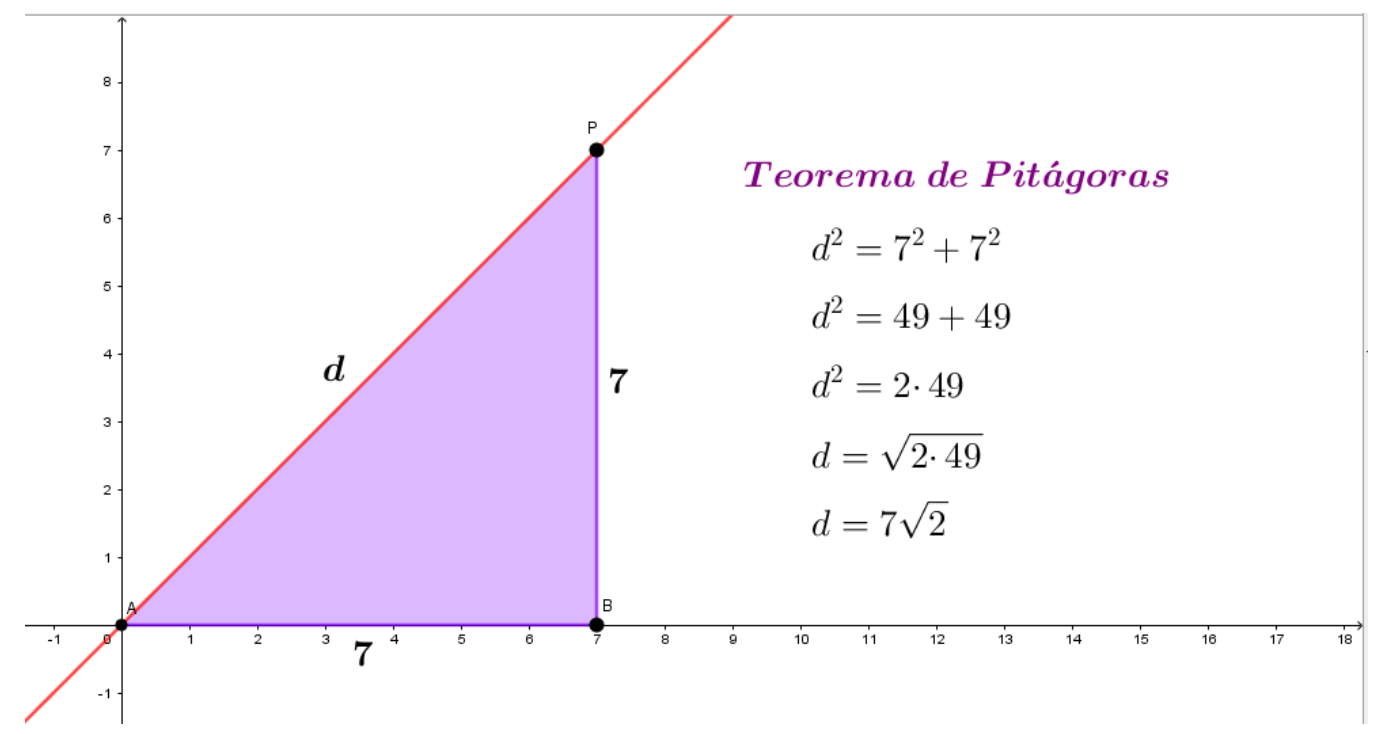

Fonte: A autora

\section{Exercício 19 (distância entre dois pontos)}

Este exercício apresenta mais de um tipo de conversão, partindo do registro língua natural apresentado no enunciado.

\section{Figura 28: Exercício de conversão do RLN para o RG em LEONARDO}

19. Considere no plano cartesiano os pontos $P(2,3)$ e $Q(5,3)$. Após girar o segmento $\overline{P Q}$ em torno de $P$ em um ângulo de $60^{\circ}$ no sentido horário, obtém-se o segmento $\overline{P R}$. Ver resolução no Guia do professor.

a) Ilustre a situação em um plano cartesiano.

b) Qual é a medida do segmento $\overline{P Q}$ ? E do segmento $\overline{P R}$ ? Explique.

c) Classifique o $\triangle P Q R$ quanto aos lados.

d) Quais as coordenadas do ponto $R$ ?

e) Refaça os itens anteriores supondo agora que o movimento do segmento $\overline{P Q}$ ocorra no sentido anti-horário. O que você pode concluir?

Fonte: LEONARDO (2013, Vol.3, p.87) 
Figura 29: Exercício de conversão do RLN para o RG (resolução) em LEONARDO

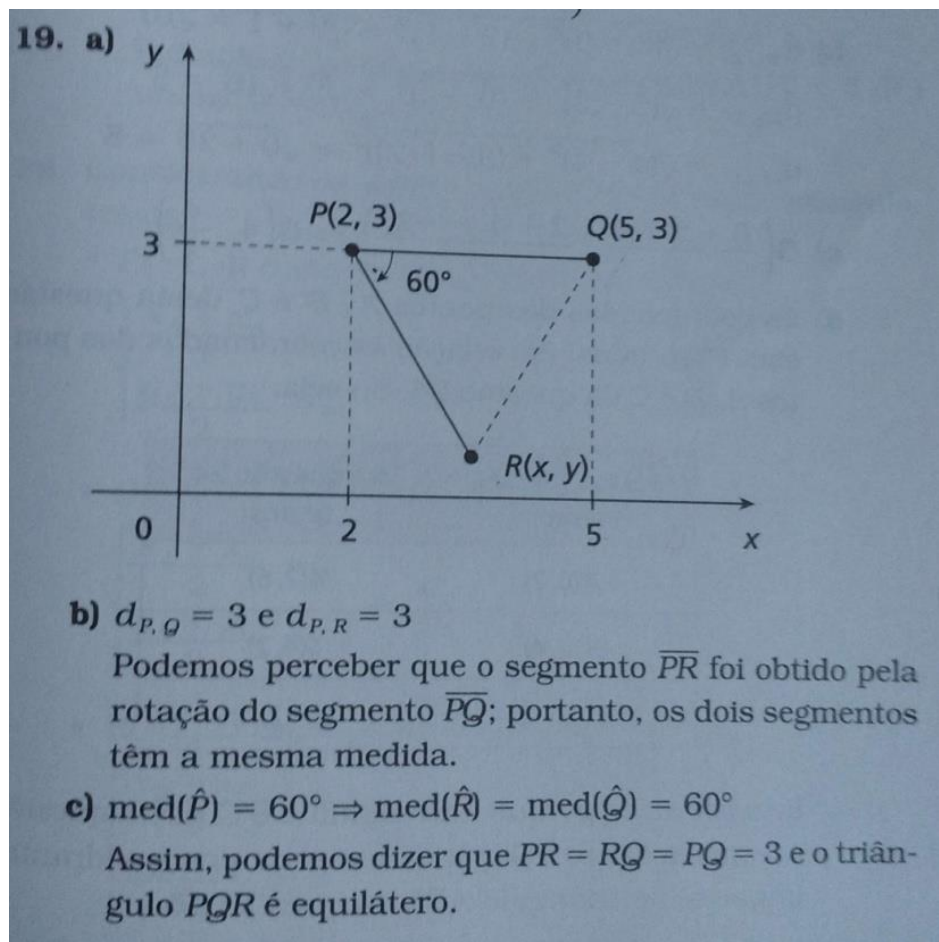

Fonte: LEONARDO (2013, Vol.3, p.75 Guia do Professor) 
Figura 30: Exercício de conversão do RLN para o RG (resolução continuação) em LEONARDO

d) $d_{P, Q}=d_{P, R}$

$3=\sqrt{(2-x)^{2}+(3-y)^{2}}$

$4-4 x+x^{2}+\not-6 y+y^{2}=\varnothing$

$x^{2}+y^{2}-4 x-6 y+4=0(I)$

$d_{P, R}=d_{Q, R}$

$\sqrt{(2-x)^{2}+(3-y)^{2}}=\sqrt{(5-x)^{2}+(3-y)^{2}}$

$(2-x)^{2}+(3-y)^{2}=(5-x)^{2}+(3-y)^{2}$

$4-4 x+\frac{x^{2}}{2}=25-10 x+x^{2}$

$6 x=21$

$x=\frac{7}{2}$

Substituindo $x$ por $\frac{7}{2}$ em (I), temos:

$\frac{49}{4}+y^{2}-14-6 y+4=0$

$y^{2}-6 y+\frac{9}{4}=0$

$y=\frac{6+3 \sqrt{3}}{2}$ ou $y=\frac{6-3 \sqrt{3}}{2}$

Sabemos que $y$ é menor que 3 , pois a rotação de $\overline{P Q}$ foi no sentido horário, temos: $y=\frac{6-3 \sqrt{3}}{2}$

Logo, as coordenadas de $R$ são:

$\left(\frac{7}{2}, \frac{6-3 \sqrt{3}}{2}\right)$

e) Na rotação de $\overline{P Q}$ no sentido anti-horário o segmento obtido, $\overline{P R}$, terá medida 3.

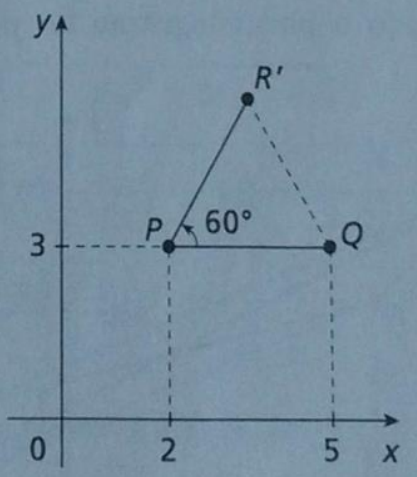

O triângulo $P Q R$ ' é equilátero.

Podemos concluir que as coordenadas do ponto $R^{\prime}$ serão $\left(\frac{7}{2}, \frac{6+3 \sqrt{3}}{2}\right)$, ou seja, o valor de $y$ será o outro valor encontrado no item d para $y$.

Fonte: LEONARDO (2013, Vol. 3, p.75 Guia do Professor)

a) Conversão congruente para o registro gráfico;

b) Conversão congruente para o registro numérico; 
c) Conversão não-convergente do registro gráfico (item a) para o registro língua natural. Aqui o aluno deve ter conhecimentos sobre classificações de triângulos;

d) Conversão congruente para o registro algébrico;

e) Conversão congruente para o registro gráfico.

A coleção apresenta uma variedade de conversões, apenas os casos $R A \rightarrow R N$ e $R L N \rightarrow R N$ não são tratados nos exercícios.

Gráfico 6: Tipos de conversão em LEONARDO

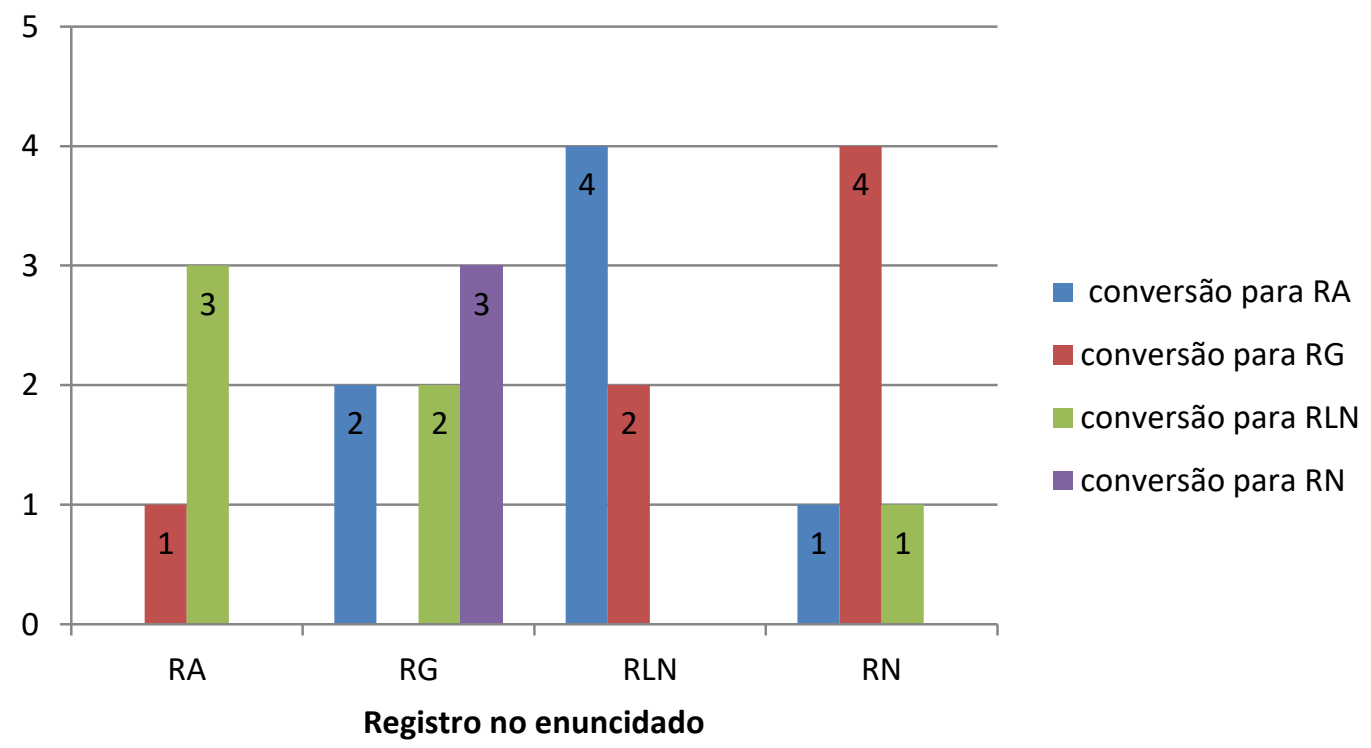

Fonte: A autora

Matemática: Contexto e Aplicações (DANTE)

\section{Exercício 9 (distância entre dois pontos)}

O exercício apresenta uma conversão do registro língua natural para o registro algébrico.

Figura 31: Exercício de conversão do RLN para o RA em DANTE

9. Um ponto $P$ pertence ao eixo das abscissas e é equidistante dos pontos $A(-1,2)$ e $B(1,4)$. Quais são as coordenadas do ponto $P$ ? $P(3,0)$ 
Figura 32: Exercício de conversão do RLN para o RA (resolução) em DANTE

9. Se $P$ pertence ao eixo das abscissas, então suas coordenadas são a e 0 . Como $P(a, 0)$ é equidistante de $A$ e $B$, devemos ter $d(P, A)=d(P, B)$. Assim:

Fonte: DANTE (2014, Vol.3, p.296 Manual do Professor)

Figura 33: Exercício de conversão do RLN para o RA (resolução continuação) em DANTE

$$
\begin{aligned}
& \sqrt{(a+1)^{2}+(0-2)^{2}}=\sqrt{(a-1)^{2}+(0-4)^{2}} \Rightarrow \\
& \Rightarrow a^{2}+2 a+1+4=a^{2}-2 a+1+16 \Rightarrow 4 a=12 \Rightarrow a=3 \\
& \text { Logo, o ponto } P \text { é }(3,0) \text { e as coordenadas do ponto P são } 3 \text { e } 0 .
\end{aligned}
$$

Fonte: DANTE (2014, Vol. 3, p.296 Manual do Professor)

A conversão é congruente, pois os termos "abscissa" e "equidistantes" são correspondentes à primeira coordenada do ponto e a mesma distância, respectivamente. Feita a conversão o tratamento se dá no registro algébrico.

\section{Exercício 58 (distância entre ponto e reta)}

O exercício é um exemplo em que se realizam duas conversões $(R A \rightarrow R G \rightarrow$ $\mathrm{RA})$.

Figura 34: Exercício de conversão do RA para o RG em DANTE

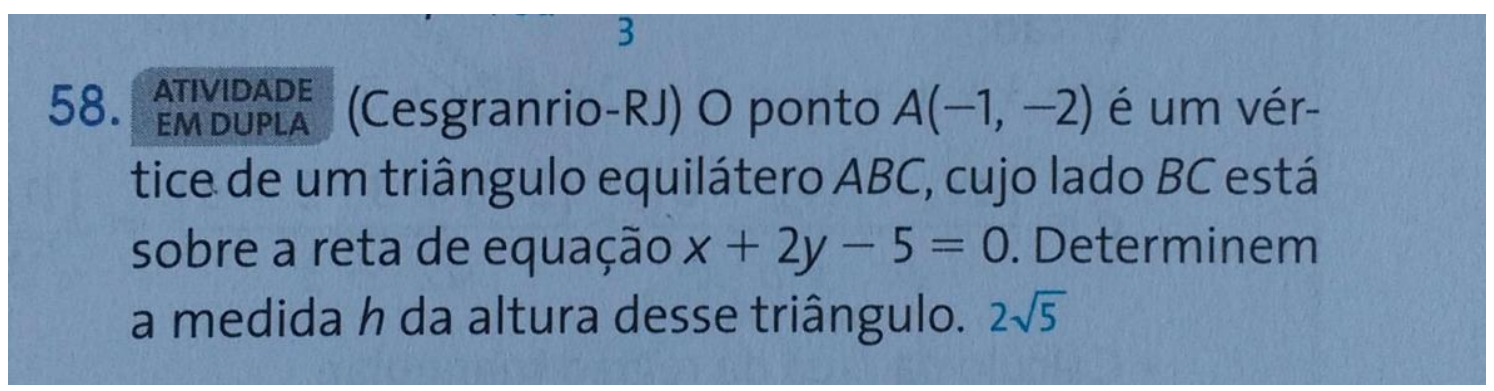

Fonte: DANTE (2014, Vol. 3, p.89) 
Figura 35: Exercício de conversão do RA para o RG (resolução) em DANTE

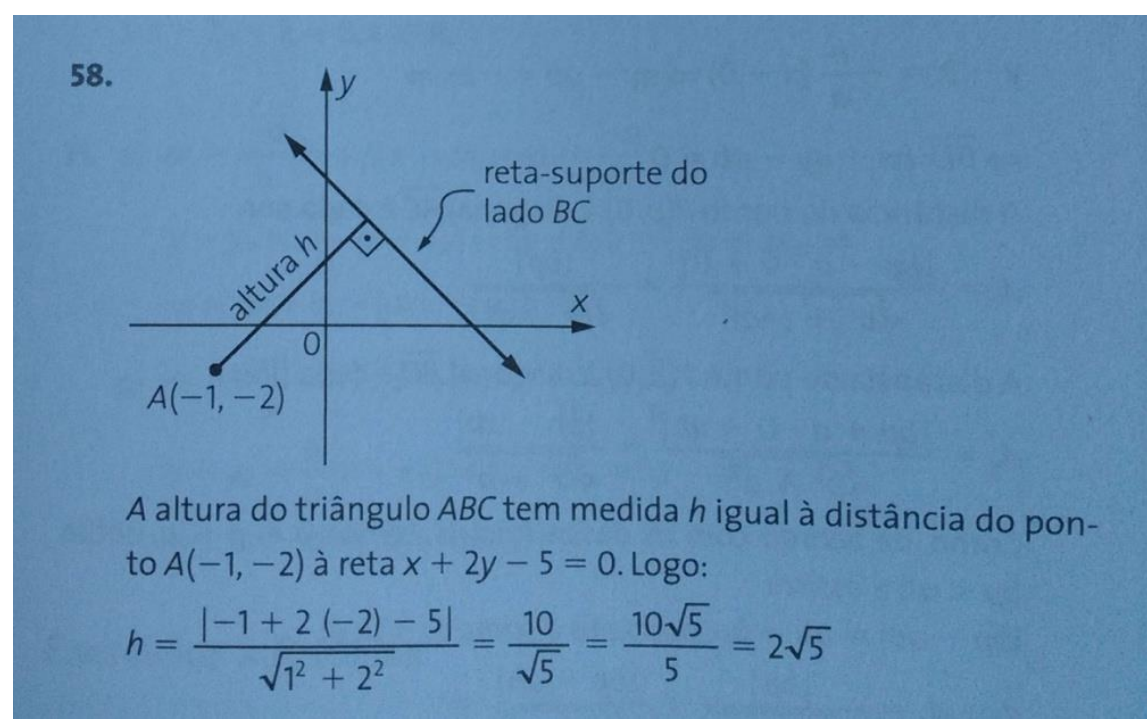

Fonte: DANTE (2014, Vol.3, p.303 Manual do Professor)

O tratamento ocorre no registro de origem, o algébrico, mas a solução utiliza o registro geométrico para auxiliar no entendimento do problema.

A coleção não utiliza muitas conversões e quando as faz é apenas de um tipo. A única variação ocorre quando o registro utilizado no enunciado é RLN a partir da qual são feitas conversões para os outros três registros analisados.

Gráfico 7:Tipos de conversão em DANTE

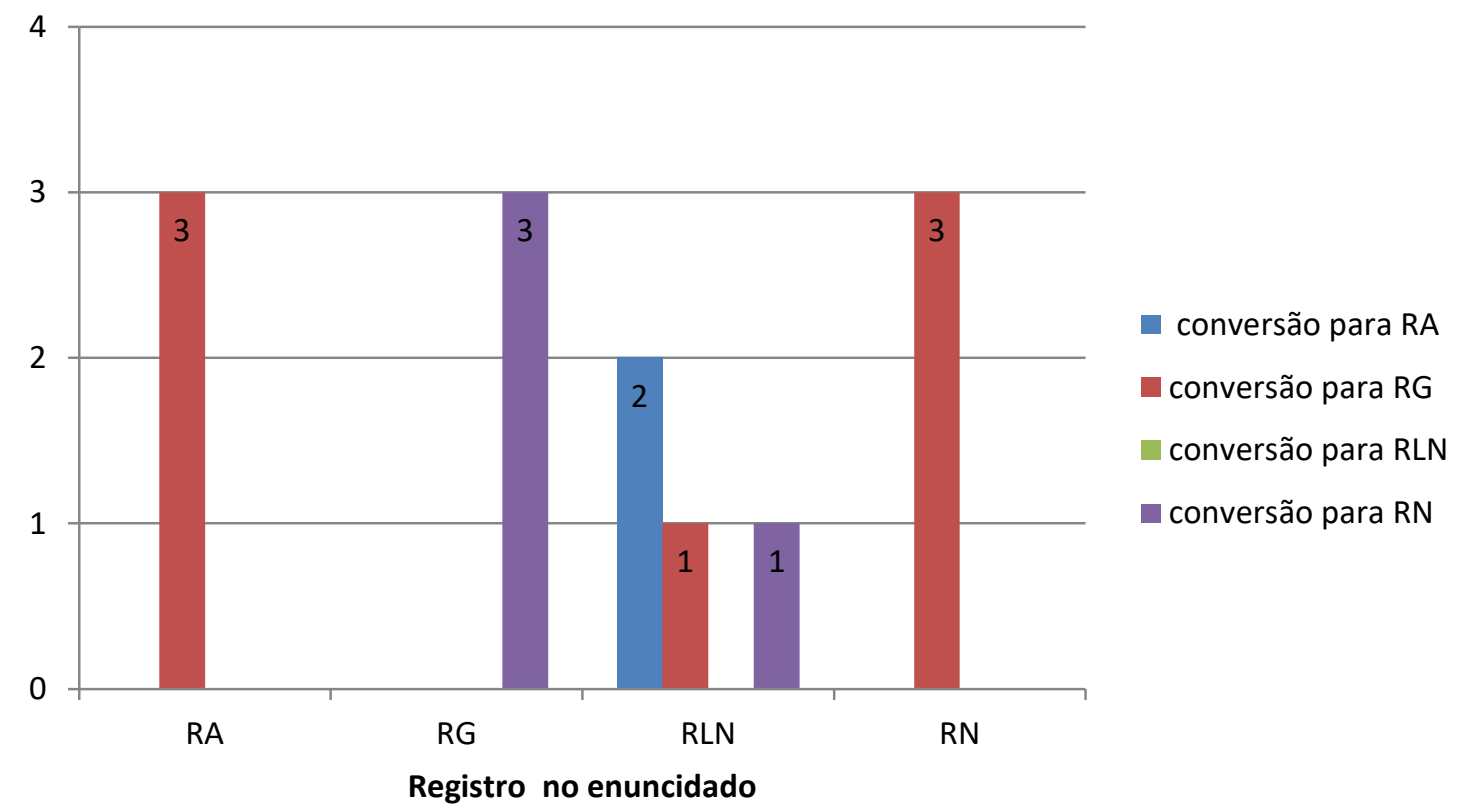

Fonte: A autora 
- Matemática - Paiva (PAIVA)

\section{Exercício 3 (distância entre dois pontos)}

O exercício é dividido em itens e apresenta seu enunciado no registro língua natural.

Figura 36: Exercício de conversão do RLN para o RG em PAIVA

3 Em um exercício militar, um submarino, parado em um ponto $O$ do mar, totalmente submerso, tem a missão de navegar até um ponto $B$.

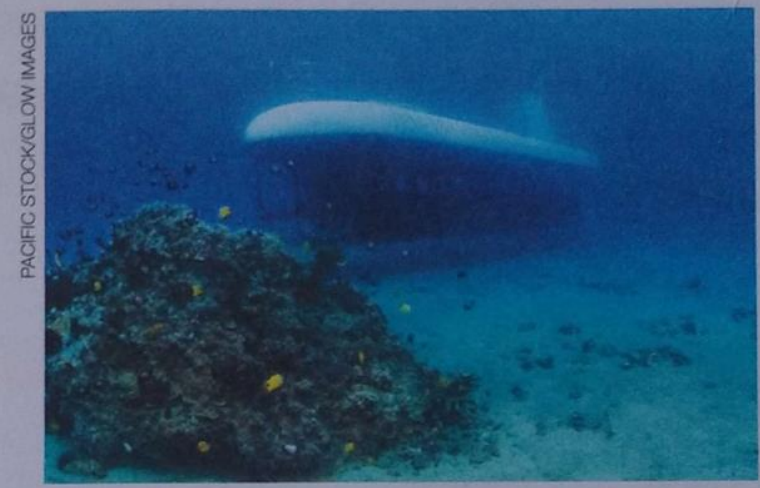

Para não ser localizado, o comandante desligou os equipamentos de emissão e recepção de sinais e se preparou para a navegação manual. Para isso, estabeleceu um sistema cartesiano de origem $O$, adotando o quilômetro como unidade nos eixos, o eixo $O y$ no sentido norte e o eixo $O x$ no sentido leste.<smiles>NC(O)S</smiles>

Em seguida, navegou horizontalmente $2,4 \mathrm{~km}$ em linha reta no sentido norte e, depois, $1 \mathrm{~km}$ em linha reta no sentido oeste, estacionando exatamente no ponto $B$.

a) Determine as coordenadas do ponto $B$ em relação ao sistema cartesiano adotado pelo comandante.

Fonte: PAIVA (2013, Vol3, p.39) 
Figura 37: Exercício de conversão do RLN para o RG (continuação) em PAIVA

b) Que distância percorreu o submarino no trajeto descrito, de $O$ até $B$ ? $3,4 \mathrm{~km}$

c) Que distância teria percorrido o submarino se fosse em linha reta de $O$ até $B$ ? 2,6 km

Fonte: PAIVA (2013, Vol 3, p.39)

Figura 38:Exercício de conversão do RLN para o RG (resolução) em PAIVA

3 a) Representando o ponto $B$ no plano cartesiano, temos:

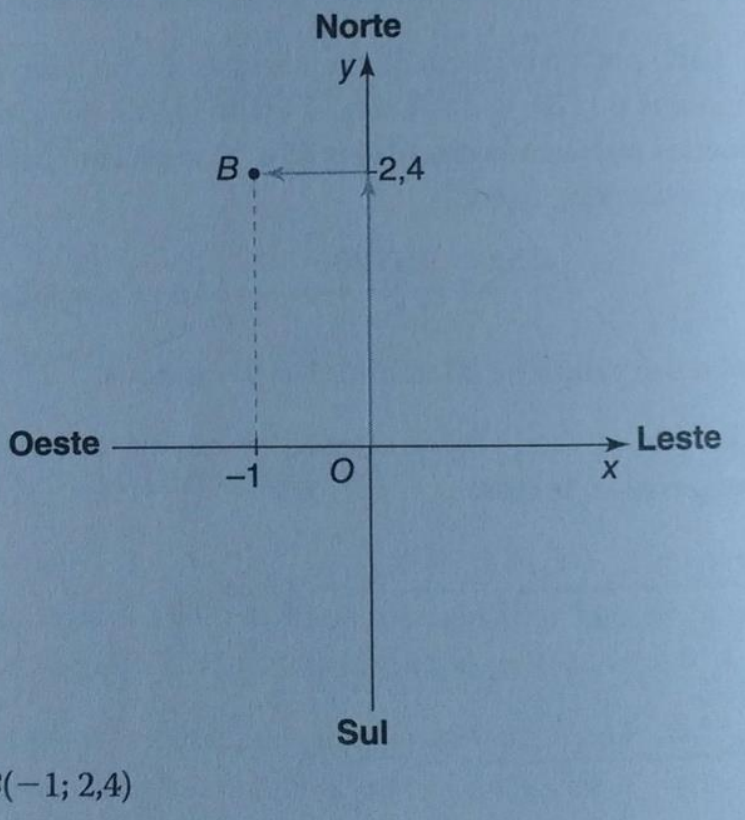

Fonte: PAIVA (2013, Vol. 3, p.60, Suplemento com orientação para o professor)

Figura 39: Exercício de conversão do RLN para o RG (resolução continuação) em PAIVA

b) A distância $d$ percorrida pelo submarino, em quilômetro, é dada por:

$$
d=|2,4|+|-1|=3,4
$$

c) Se o submarino tivesse ido em linha reta de $O$ até $B$, a distância percorrida seria o comprimento do segmento $\overline{O B}$. Calculando essa distância, em quilômetro, temos:

$$
O B=\sqrt{(-1-0)^{2}+(2,4-0)^{2}}=\sqrt{6,76}=2,6
$$

Fonte: PAIVA (2013, Vol. 3, p.61, Suplemento com orientação para o professor) 
Conversão congruente entre o registro numérico, mas passando pelo registro gráfico. O registro gráfico foi utilizado apenas para auxiliar na visualização do problema, mas o problema pode ser resolvido diretamente do registro língua natural para o registro numérico;

a) Tratamento no registro gráfico;

b) Conversão do registro gráfico para o registro algébrico, onde é feito o tratamento.

\section{Exercício 3 (distância entre ponto e reta)}

O exercício apresenta uma conversão do registro numérico para o registro algébrico.

Figura 40: Exercício de conversão do RN para o RA em PAIVA

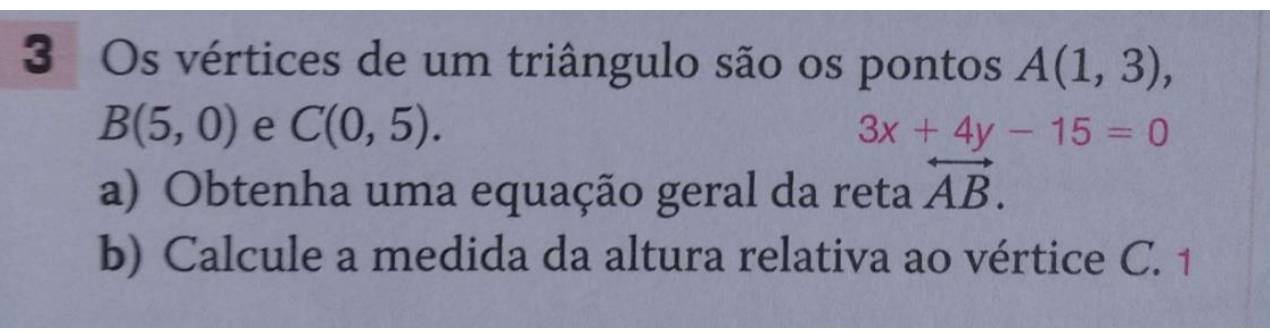

Fonte: PAIVA (2013, Vol. 3, p.75)

Figura 41: Exercício de conversão do RN para o RA (resolução) em PAIVA

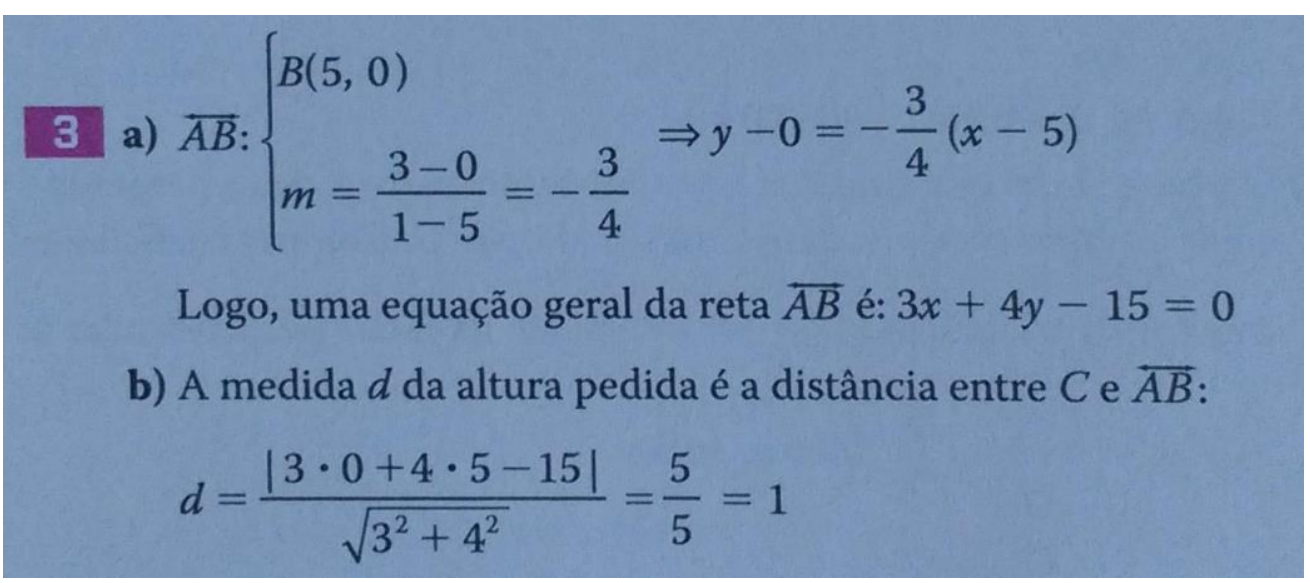

Fonte: PAIVA (2013, Vol. 3, p.71 Suplemento com orientação para o professor)

a) A conversão entre os registros é não-congruente, pois para encontrar a equação da reta $\overleftrightarrow{A B}$ o aluno deve ter conhecimentos prévios sobre o assunto. 
b) Tratamento no registro algébrico.

O exercício poderia apresentar o registro gráfico para auxiliar na resolução.

Figura 42: Registro gráfico para o ex 3 de PAIVA

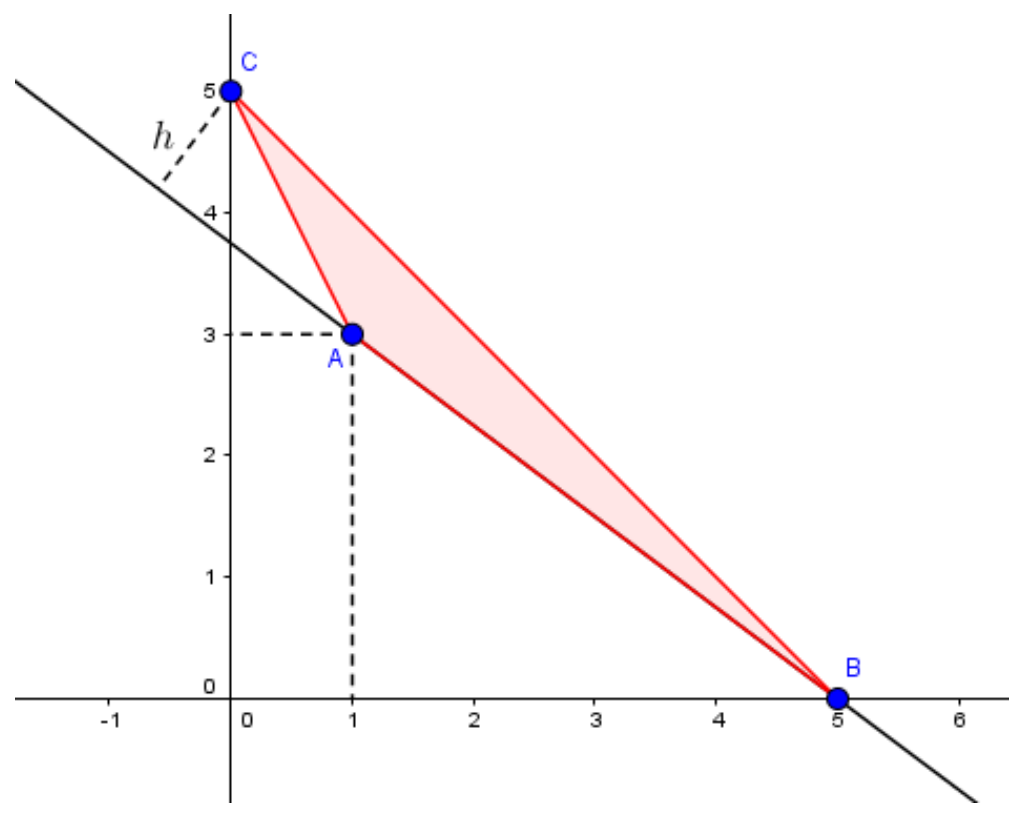

Fonte: A autora

$\mathrm{Na}$ coleção apenas $37 \%$ dos exercícios apresentam conversão entre registros. Todos os exercícios que apresentam seus objetos no RA exigem apenas tratamento, já os outros casos fazem conversão para pelo menos dois registros diferentes. Dentre as conversões tratadas, nenhuma é mais utilizada que a outra. 
Gráfico 8: Tipos de conversão em PAIVA

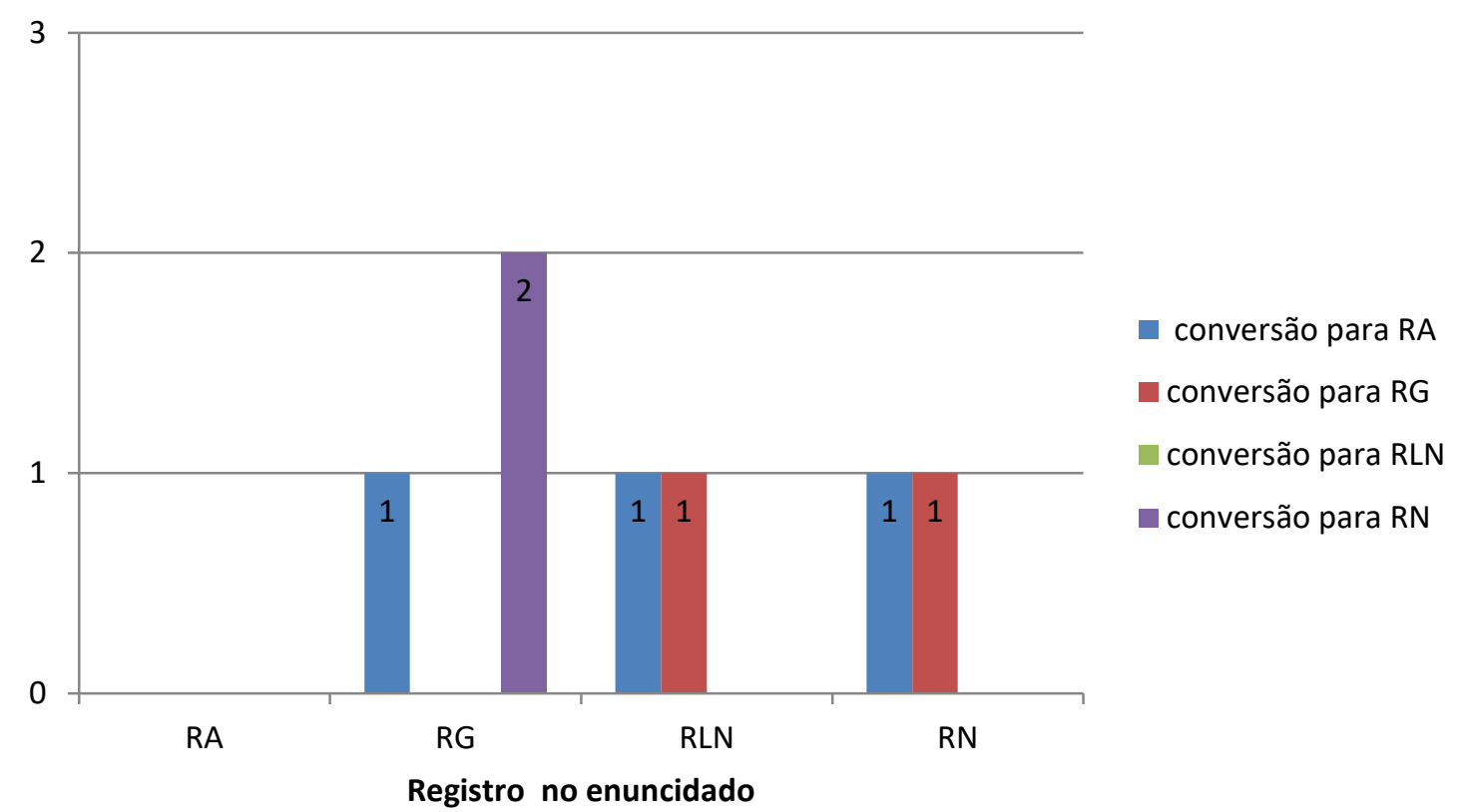

Fonte: A autora

\section{Novo Olhar: Matemática (SOUZA)}

\section{Exercício 3 (coordenadas no plano)}


Figura 43: Exercício de conversão do RN para o RG em SOUZA

3. (OBMEP) A figura mostra quatro polígonos desenhados em uma folha quadriculada. Para cada uma dessas figuras foi assinalado, no plano cartesiano à direita, o ponto cujas coordenadas horizontal e vertical são, respectivamente, seu perímetro e sua área.

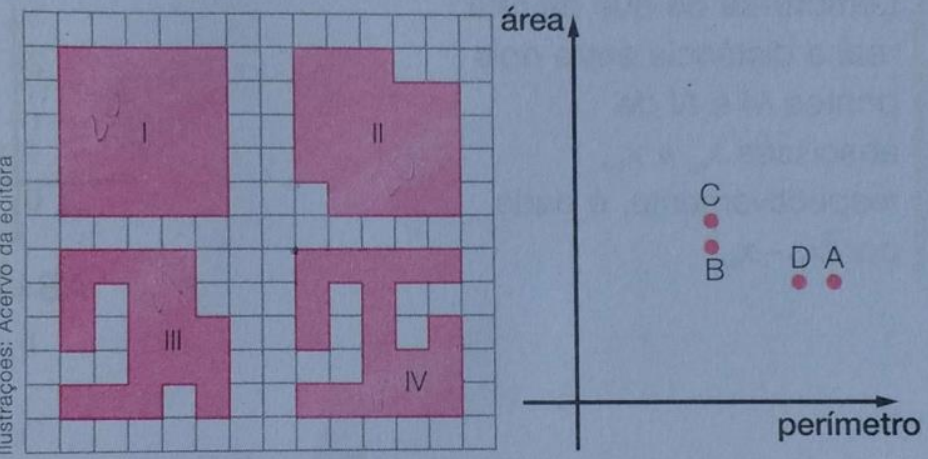

Qual é a correspondência correta entre os polígonos e os pontos? $\mathrm{c}$
a) I-A, II-D, III-B, IV-C
b) I-D, II-A, III-C, IV-B
c) I-C, II-B, III-D, IV-A
d) $I-C, I I-A, I I I-B, I V-D$
e) I-C, II-B, III-A, IV-D

Fonte: SOUZA (2013, Vol.3, p.151) 
Figura 44: : Exercício de conversão do RN para o RG (resolução) em SoUZA

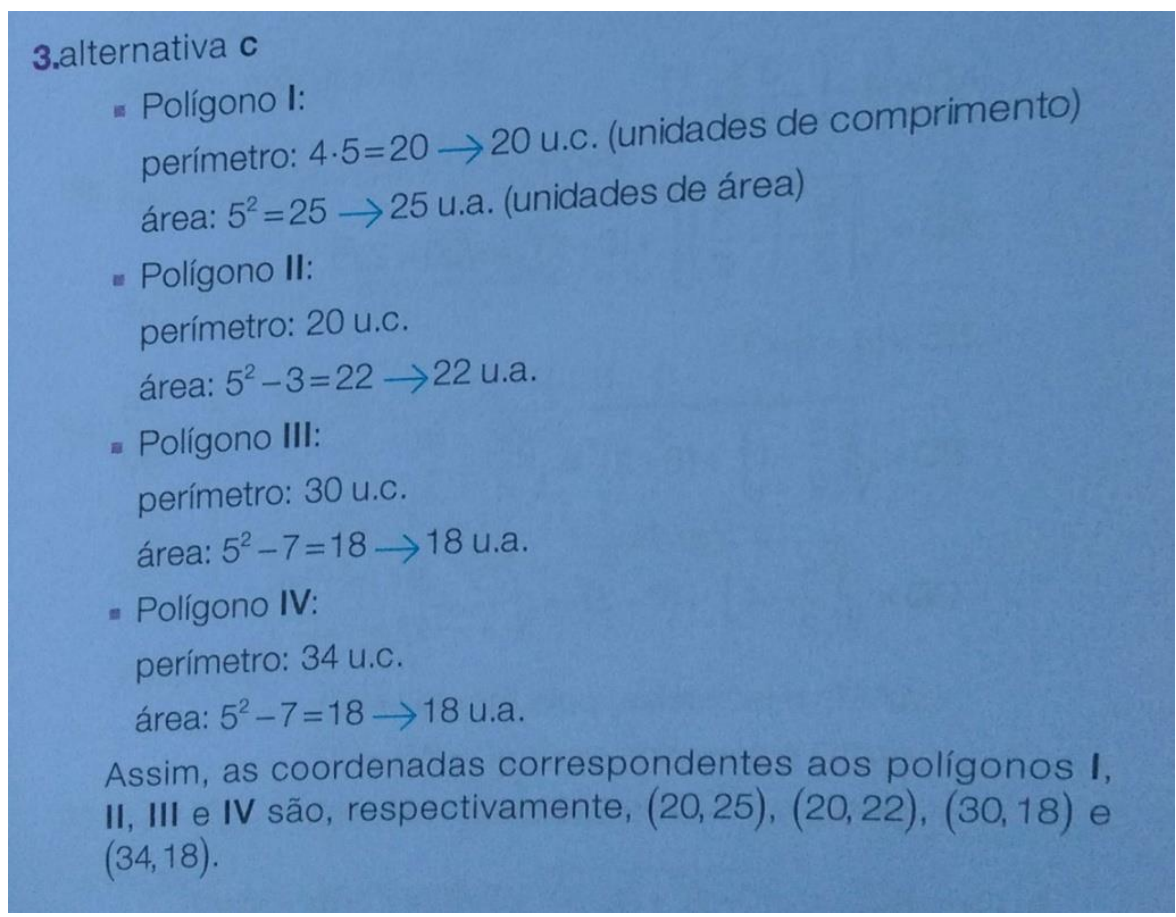

Fonte: SOUZA (2013, Vol. 3, p.115 Orientações para o professor)

O exercício exige do aluno a noção de área e perímetro de figuras planas. Isso faz com que a congruência entre os registros, do numérico para o geométrico, seja não-congruente.

\section{Exercício 97 (distância entre ponto e reta)}

O exercício chama atenção por apresentar os objetos em registros diferentes, o que não ocorre nas outras coleções analisadas. 
Figura 45: : Exercício de conversão do RG para o RA em SOUZA

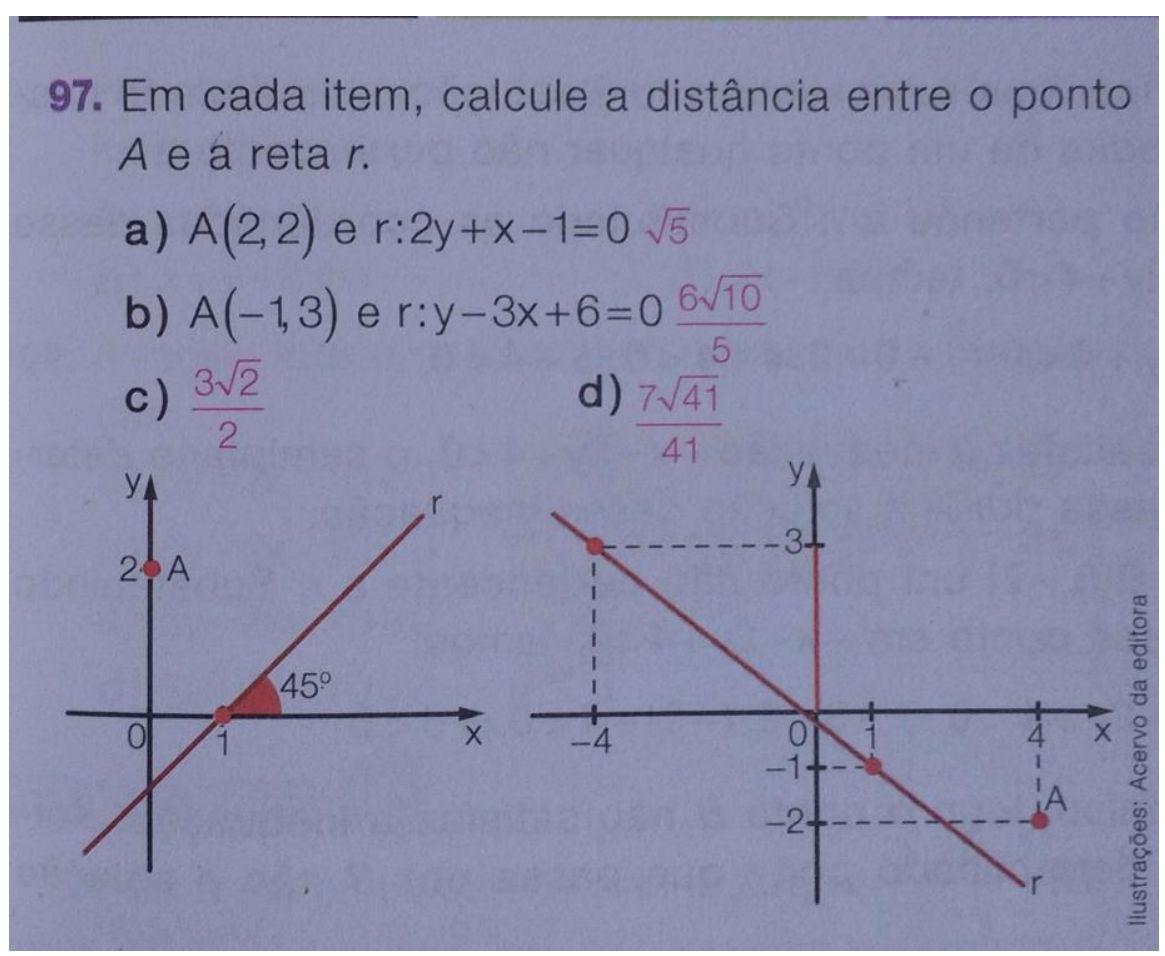

Fonte: SOUZA (2013, Vol. 3, p.183)

Figura 46: : Exercício de conversão do RG para o RA (resolução) em SOUZA

$$
\begin{aligned}
& \text { 97. a) } r: x+2 y-1=0 \\
& d=\frac{|2+2 \cdot 2-1|}{\sqrt{1^{2}+2^{2}}}=\frac{|5|}{\sqrt{5}}=\sqrt{5} \\
& \text { b) } s:-3 x+y+6=0 \\
& d=\frac{|-3 \cdot(-1)+3+6|}{\sqrt{(-3)^{2}+1^{2}}}=\frac{|12|}{\sqrt{10}}=\frac{6 \sqrt{10}}{5} \\
& \text { c) } r: y-0=\operatorname{tg} 45^{\circ} \cdot(x-1) \Rightarrow x-y-1=0 \\
& d=\frac{|0-2-1|}{\sqrt{1^{2}+(-1)^{2}}=\frac{|-3|}{\sqrt{2}}=\frac{3 \sqrt{2}}{2}} \\
& \text { d) } r: \mid \begin{array}{cc}
x \quad y \quad 1 \mid \\
-4 \quad 1 \mid=0 \Rightarrow 4 x+5 y+1=0 \\
1 \quad-1 \quad 1 \mid
\end{array} \\
& d=\frac{\mid \begin{array}{cc}
4 \cdot 4+5 \cdot(-2)+1 \mid \\
\sqrt{4^{2}+5^{2}}
\end{array}=\frac{|7|}{\sqrt{41}}=\frac{7 \sqrt{41}}{41}}{}
\end{aligned}
$$

Fonte: SOUZA (2013, Vol. 3, p.126 Orientações para o professor) 
Os itens (a) e (b) apresentam apenas tratamento no registro algébrico. Os itens (c) e (d) apresentam uma conversão não-congruente do registro geométrico para o registro algébrico. Cada um tem uma solução diferente para a determinação da equação da reta, o que exige do aluno um conhecimento amplo sobre retas.

Assim como PAIVA, em SOUZA, os exercícios apresentados no registro algébrico não necessitam de conversão. Nota-se que a conversão é mais utilizada entre os registros gráfico e numérico e não existe uma variação dos tipos de conversão entre os registros (apenas seis foram verificados).

Gráfico 9: Tipos de conversão em SOUZA

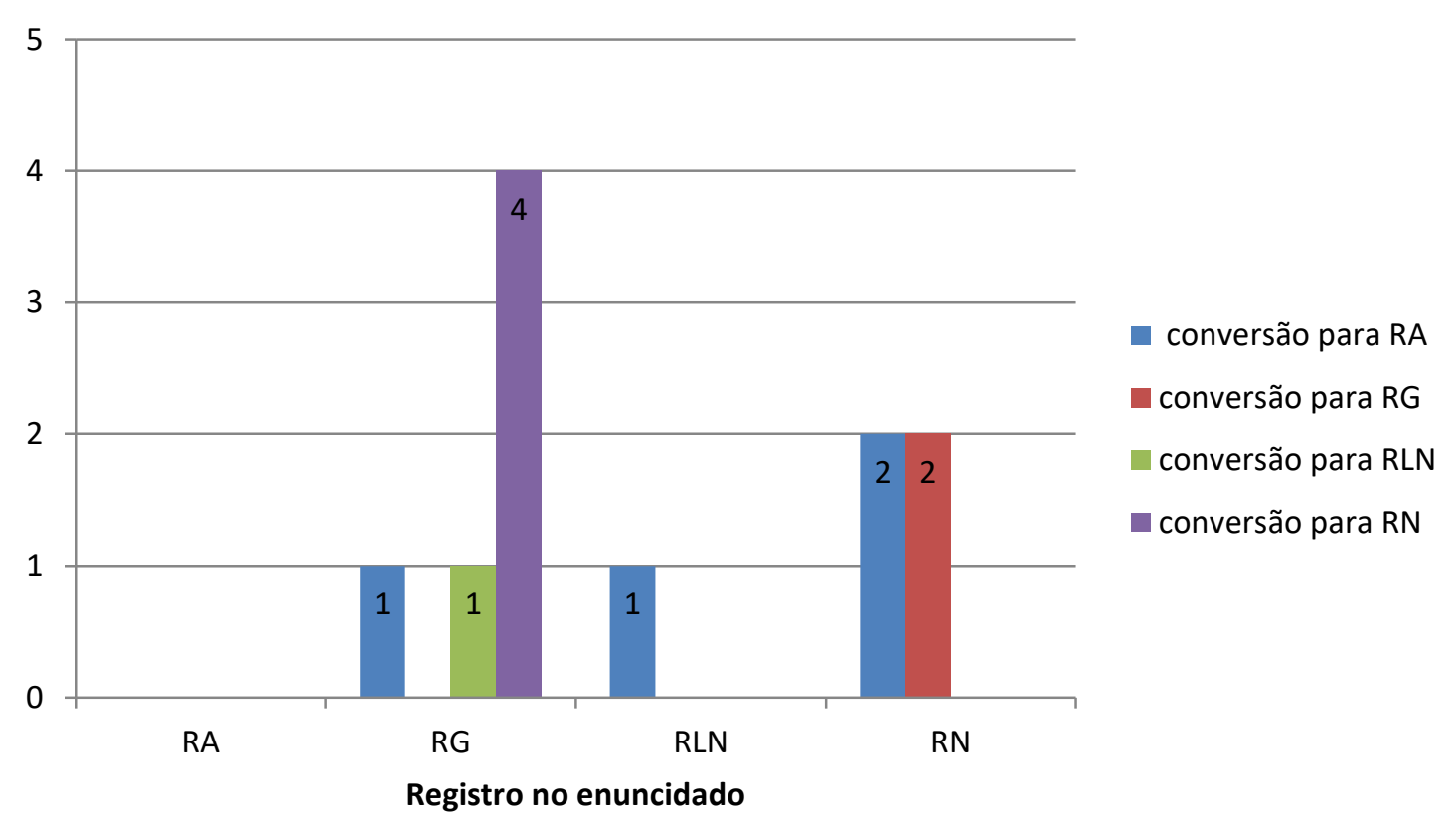

Fonte: A autora

Analisando as resoluções apresentadas nos manuais do professor das coleções, nota-se que a maioria dá mais enfoque para o uso de fórmulas e apresenta exercícios em que a representação algébrica é mais utilizada na solução.

\subsection{Ensino de Geometria Espacial}


A geometria permite 0 desenvolvimento de diversas habilidades $e$ competências e é considerada de grande importância para desenvolvimento cognitivo dos alunos. Segundo os PCNEM (2000)

Usar as formas geométricas para representar ou visualizar partes do mundo real é uma capacidade importante para a compreensão e construção de modelos para resolução de questões da Matemática e de outras disciplinas. (PCNEM 2000, p. 123)

Ainda segundo os PCNEM (2000), a Geometria Espacial, deve ser apresentada aos alunos através dos poliedros e dos corpos redondos de uma maneira a levá-los a fazer relações com estruturas que observam no mundo real, além de associar esses objetos a suas diferentes representações bidimensionais, como projeções, planificações, cortes e desenhos.

Quando nos deparamos com um problema de geometria, muitas vezes, fazer a figura que o representa facilita essa resolução. Porém, segundo DUVAL (2012, p. 118), "ver uma figura em geometria é uma atividade cognitiva mais complexa do que o simples reconhecimento daquilo que uma imagem mostra".

Ele identifica três tipos de interpretações - ditas apreensões - que podemos ter ao ver uma figura (ou uma representação figural): apreensão perceptiva, apreensão operatória, apreensão discursiva e apreensão sequencial.

- Apreensão perceptiva: a figura mostra características que não dependem do enunciado e os elementos nele apresentados nem sempre são tão explícitos, gerando duas atitudes que se contradizem, ou seja, os objetos enunciados não são necessariamente aqueles que aparecem espontaneamente.

- Apreensão operatória: trata das possíveis modificações e reorganizações que se pode fazer na figura para ajudar na resolução do problema. Essas modificações podem ser

a) Mereológicas: relaciona parte e todo, ou seja, divide a figura em partes homogêneas ou heterogêneas, que podem ser recombinadas.

b) Óticas: aumenta, diminui ou deforma a figura.

c) Posicionais: desloca ou rotaciona a figura.

- Apreensão discursiva: ao contrário da apreensão perceptiva, as hipóteses apresentadas no enunciado são de extrema importância para a resolução do exercício, ou seja, as propriedades pertinentes e as únicas aceitáveis dependem do que é colocado no enunciado como hipóteses. 
Durante uma aula que envolve objetos espaciais, possuímos, muitas vezes, apenas a lousa e/ou o livro didático para representá-los. Sendo os suportes desses recursos planos e estáticos, o aluno pode não conseguir visualizar a relação entre os diferentes planos no espaço, em particular a profundidade que o objeto tem. Um exemplo disso pode ser visto na representação de um tetraedro, conforme Figura 47.

Figura 47:Tetraedro $A B C D$ representado em um suporte plano

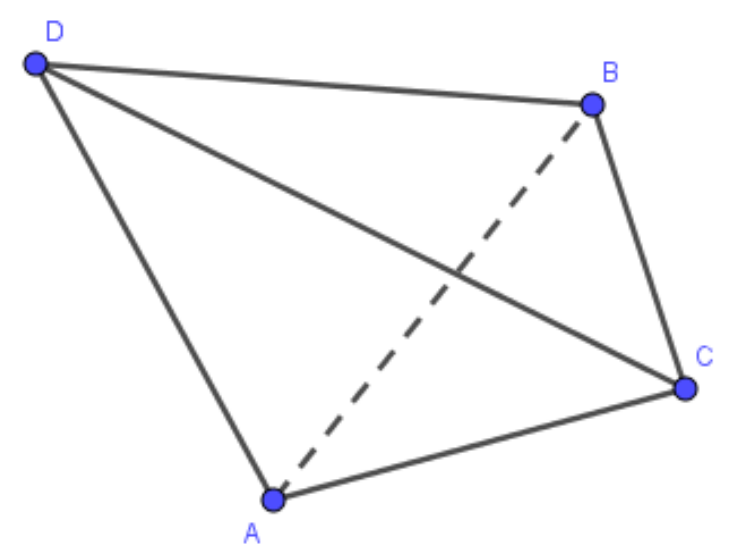

Fonte: A autora

O professor, ao desenhar o objeto na lousa, não garante que o aluno consiga "ver" ou identificar que se trata de um tetraedro de base $A B C$ e vértice $D$, pois pode "enxergar" um quadrilátero $A B C D$ com suas diagonais, e assim não atentando para algumas propriedades do objeto.

Já utilizando a Janela $3 D$ do Geogebra, podemos representar o tetraedro $A B C D$ e com sua característica dinâmica, é possível mover o objeto e observá-lo sob diferentes pontos de vista.

Figura 48: Tetraedro ABCD visto sob um ângulo 1

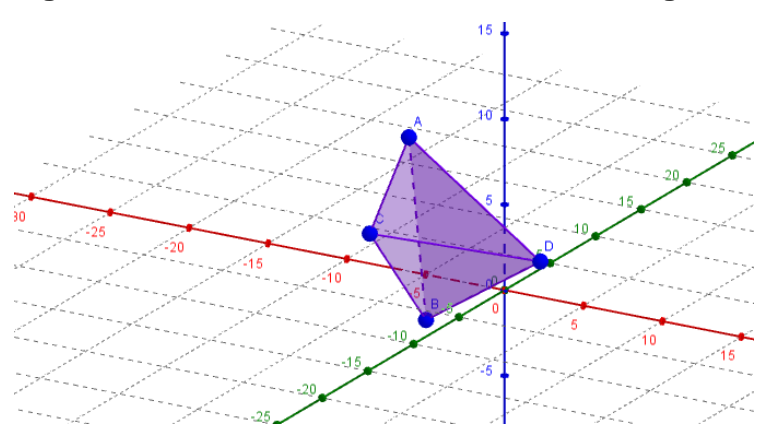


Fonte: Autora

Figura 49: Tetraedro ABCD visto sob um ângulo 2

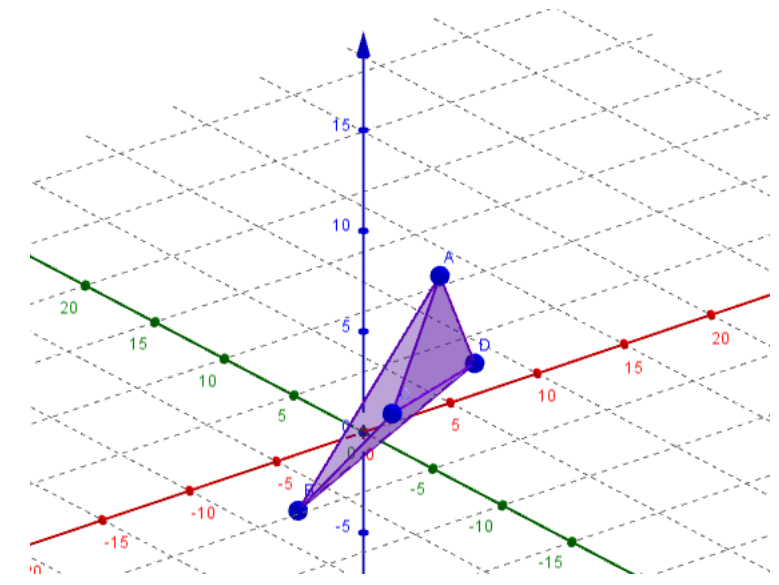

Fonte: Autora

Além disso, é possível visualizar as vistas do objeto nos planos paralelos aos planos $O X Y, O X Z$ e $O Y Z$.

Figura 50: Vista do plano OXY

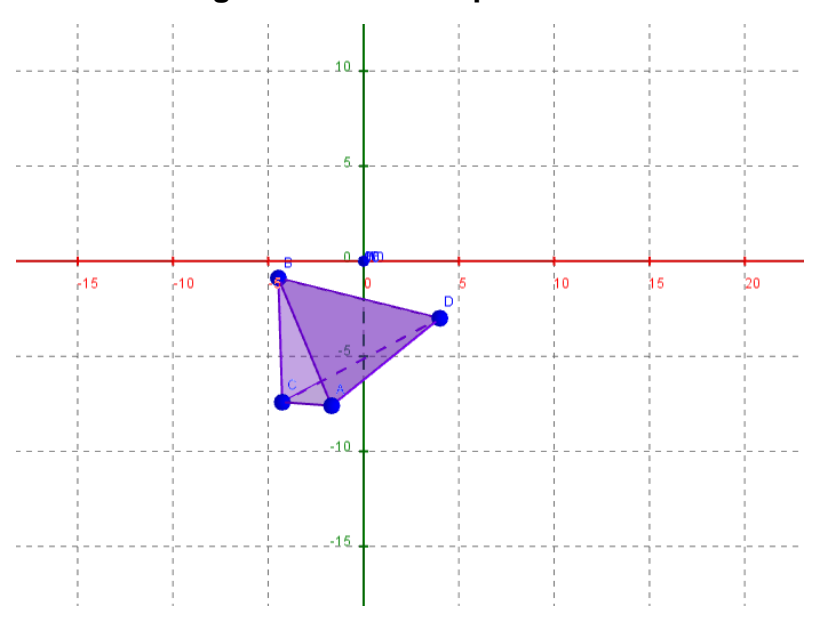

Fonte: Autora 


\section{Figura 51: Vista do plano OXZ}

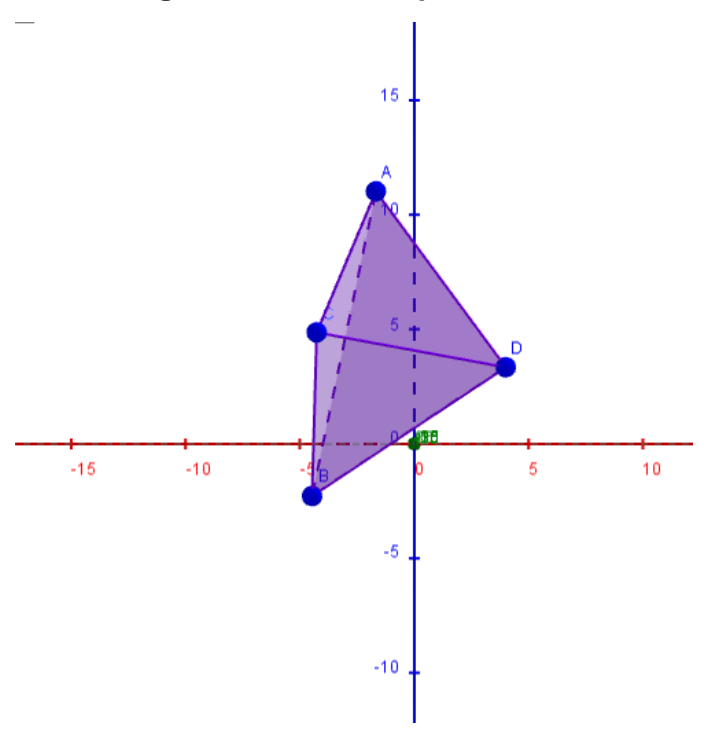

Fonte: Autora

Figura 52: Vista do plano Oyz

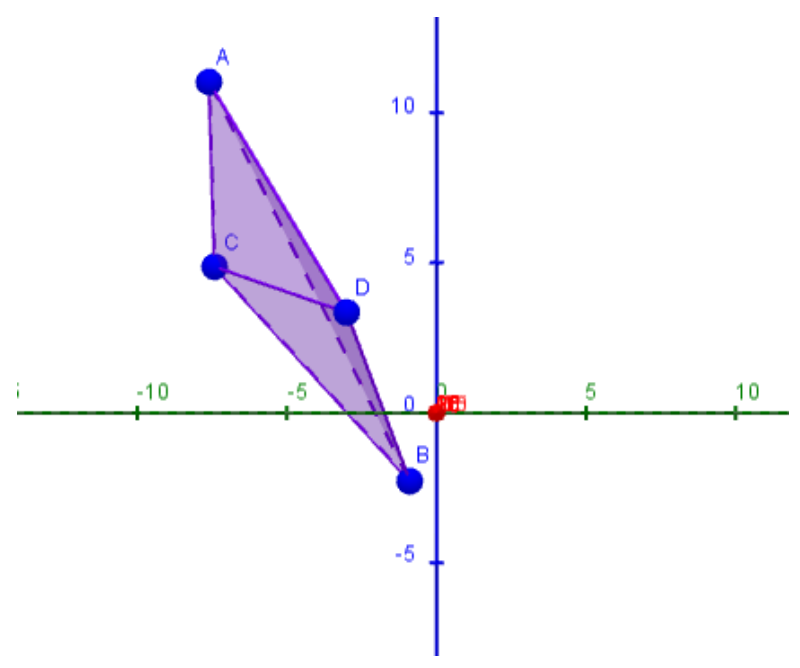

Fonte: Autora

A utilização da Janela $3 D$ do Geogebra tem sua importância no ensino e aprendizagem de Matemática, sendo tema de estudo de vários trabalhos, como por exemplo, o apresentado por Cardoso, Calixto e Souza Júnior (2014), referente a um estudo sobre volume de sólidos com o auxílio do software Geogebra 3D. Segundo os autores,

Recursos computacionais destinados ao ensino de geometria espacial permitem a construção rápida e precisa de figuras geométricas, permitindo ainda a exploração de formas, propriedades 
e invariâncias dos objetos. (CARDOSO, CALIXTO, SOUZA JR., 2014, p.756)

O Geogebra é uma ferramenta de fácil acesso, pois se trata de um software livre. Sua versão 5.0 disponibiliza uma Janela $3 D$ para construções de objetos espaciais, permitindo trabalhar com duas interfaces simultaneamente, a saber, a Janela $2 D$ e a Janela $3 D$.

O trabalho de Cardoso, Calixto e Souza Jr. (2014) propõe uma maneira de apresentar a ideia intuitiva de volume, começando por um bloco retangular reto preenchido por cubos de arestas unitárias e seus múltiplos, seguido da utilização do Princípio de Cavalieri.

Os autores concluem o trabalho observando que a utilização do software "permitiu aos estudantes desenvolverem habilidades para identificar características de figuras planas e espaciais" (CARDOSO, CALIXTO, SOUZA JR., 2014, p. 763). Concluem também que o uso do Geogebra contribuiu para a autonomia na construção do conhecimento de cada estudante, pois possibilitou a manipulação dos objetos geométricos estudados e a investigação matemática utilizada não seria possível em um ambiente lápis\&papel. Essa também será nossa opção, por entender que esse ambiente pode potencializar as atividades envolvendo representações semióticas, uma vez que permite múltiplas representações de um mesmo objeto na tela do computador.

\subsection{Alguns trabalhos sobre o ensino de Geometria Analítica}

Neste tópico apresentaremos um resumo sobre dois trabalhos estudados por Borsoi (2015) e Halberstadt e Fiorezi (2015) com o objetivo de mostrar algumas abordagens sobre o ensino de Geometria Analítica.

O estudo feito por Borsoi (2015) busca entender quais os efeitos causados no aprendizado do conceito de reta com a utilização do software GrafEq, e ênfase no uso das representações gráfica e algébrica que o software proporciona. 
A autora questiona o fato do ensino de Geometria Analítica, em geral, não atingir seus objetivos em relação ao conhecimento matemático e para ela isso ocorre pelo fato de se dar um enfoque maior na representação algébrica dos objetos geométricos. Justificando a escolha do software, menciona que a Geometria Analítica é um conteúdo que deveria levar o aluno a trabalhar com as representações geométrica, gráfica e algébrica ao mesmo tempo. Além disso, o uso de software ajuda na experimentação de hipóteses e na exploração de diferentes representações de um objeto matemático.

A proposta didática apresentada por Borsoi (2015) consiste em reproduzir bandeiras de países escolhidas pela professora, utilizando equações de retas e com o auxilio dos recursos do software GrafEq. Com essa atividade, pretendia levar o aluno a trabalhar com as duas representações simultaneamente, e assim, observar relações ente elas.

As atividades foram realizadas em 12 (doze) encontros de 50 minutos com alunos do $3^{\circ}$ Ano do Ensino Médio de uma escola da rede estadual de Farroupilha/RS. Os encontros foram divididos em duas etapas: na primeira, os alunos trabalharam em grupo para proporcionar a troca de ideias entre eles e na segunda, tiveram suas ações e estratégias trabalhadas individualmente.

Segundo a autora, durante a realização das atividades, o professor exerceu o papel de mediador, fazendo alguns questionamentos e provocações e, devido ao uso do ambiente computacional, era esperado que o direcionamento da sua prática seja diferente da habitual.

Inicialmente, o desenvolvimento das atividades foi considerado válido na medida em que os alunos mostraram-se interessados, por "acharem divertido" e desafiador fazer as atividades propostas. Eles iniciaram as atividades com algumas dificuldades na compreensão dos conceitos relacionados à reta e no decorrer das mesmas, notou-se que os alunos percebiam com mais facilidade quais "movimentos" os gráficos realizavam quando se alteravam os parâmetros na equação da reta. O software GrafEq permitiu trabalhar com os registros gráfico e algébrico da Geometria Analítica e também compreender as relações entre eles, possibilitando a construção 
de significado da relação entre os coeficientes da equação da reta e suas características no registro gráfico (BORSOI, 2015).

O trabalho apresentado por Halberstadt e Fiorezi (2015) também investigou a estrutura semiótica do software GrafEq e teve como objetivo principal trabalhar os conceitos de reta e circunferência por meio de seus registros de representação geométrico, algébrico e gráfico.

O trabalho propõe ao aluno reproduzir imagens de ilusões de ótica no referido software e, para isso, fazer uso de equações de retas e circunferências e de inequações. As imagens de ilusões de ótica apresentadas geralmente são formadas seguindo um padrão de figuras geométricas e, pensando nisso, foi proposto ao aluno buscar uma forma de generalizar o registro algébrico dos objetos utilizados. Outra noção importante abordada no trabalho é o fato de o software apresentar os registros algébrico e gráfico na mesma tela, facilitando o processo de análise da relação ou articulação entre ambos. Também apoiados em Duval (2009), os autores consideram que trabalhar em mais de um registro de representação é importante pelo fato de que algumas características de um objeto podem não ser observadas em um determinado registro, mas podem ser explicitadas em outro.

A escolha do software deu-se pela possibilidade de apresentar conteúdos matemáticos em sala de aula e, no caso das atividades, facilitar o trabalho com equações e inequações em Geometria Analítica. Alguns aspectos importantes citados no estudo são as possibilidades de representar vários objetos em uma mesma tela, de fazer o registro algébrico de maneiras distintas e a possibilidade de representar equações de forma generalizada através de seus parâmetros.

Com essas atividades, os autores buscaram mostrar em que medida o software GrafEq pode contribuir na aprendizagem dos conceitos de Geometria Analítica, dado que proporcionou aos alunos uma interação com os registros algébrico e gráfico de seus objetos. Concluem que a utilização de imagens de ilusões de ótica foi uma escolha acertada, pois contribuiu para a identificação de variáveis pertinentes às representações dos objetos da Geometria Analítica e também contribuiu com o desenvolvimento do pensamento generalizador. 
Embora tenhamos identificado diversos trabalhos integrando ambientes computacionais que enfatizam o uso de diferentes representações semióticas, pudemos entender que são mais escassos estudos envolvendo conceitos da Geometria Analítica no espaço tridimensional, o que nos propormos a investigar em nosso estudo.

Estamos considerando a hipótese de que o desenvolvimento da habilidade de visualização espacial, bem como uma maior familiaridade com a ideia de associar situações e problemas geométricos a suas formas algébricas e representações gráficas (e vice-versa) passa pela ampliação do estudo da Geometria Analítica, com a introdução de sistemas de coordenadas e distâncias no espaço. 


\section{Capítulo 2 - Metodologia}

\subsection{Design Experiment}

Visando uma pesquisa de caráter qualitativo, utilizamos o Design Experiment que é uma metodologia com foco na análise dos processos de aprendizagem de domínios específicos.

Uma característica dessa metodologia é a não necessidade de se limitar a uma sequência didática de atividades, pois o principal interesse do professorpesquisador são os significados construídos pelos estudantes. Ao contrário de que, segundo Karrer (2006), consideram os estudantes como "recipientes a serem tratados", não como o foco da análise, ou seja, os estudantes são apenas seres passivos que executam uma sequência de atividades, o design enfatiza as trajetórias de aprendizagem dos alunos.

O Design Experiment se preocupa em estabelecer o discurso a ser desenvolvido, as regras de participação, as ferramentas e materiais utilizados e os significados das relações entre esses elementos.

Segundo Karrer (2006), as situações criadas pelo professor-pesquisador devem motivar os estudantes a mudar a forma de pensar. Para que isso ocorra, o método permite mudanças nas atividades durante o experimento, de modo que elas possam atingir seus objetivos.

O Design Experiment é uma metodologia que pode ser aplicada a grupos pequenos e que considera estudantes, professores e pesquisadores como colaboradores do processo; o tempo de aplicação não é definido a priori, podendo levar poucas horas, dias ou meses, já que depende do progresso do grupo pesquisado.

Para iniciar o experimento, deve-se definir a intenção teórica da pesquisa e fazer um levantamento bibliográfico das pesquisas já existentes na área. Após essas etapas cumpridas, um trabalho "piloto" é elaborado para estabelecer as conjecturas 
que serão testadas e revisadas, a respeito das interpretações iniciais e entendimentos dos estudantes.

Para que o Design Experiment alcance seus objetivos, a coleta de informações através de registros (áudio-gravação, por exemplo) e questionários se faz necessária, já que o entendimento do fenômeno de investigação se dá durante o experimento. A análise dos erros dos estudantes é importante, pois indicará o que se poderá fazer em atividades futuras.

A metodologia do Design Experiment exige que o professor conduza as atividades de forma interativa com os estudantes. Essa interação é classificada em dois tipos, a primeira uma interação receptiva e intuitiva, onde o professorpesquisador não distingue seu conhecimento do conhecimento do aluno, o que ocorre a qualquer momento do experimento. A segunda é uma interação analítica, onde o professor-pesquisador identifica raciocínios que enriquecerão experimentos futuros. Ao interagir com os estudantes, o professor-pesquisador terá uma direção e possibilidades de caminhos a serem trabalhados, criando assim meios para uma mudança na forma de pensar dos alunos.

A metodologia do Design Experiment pode ser encontrada no trabalho apresentado por Karrer (2006) que teve como objetivo analisar os processos de aprendizagem do conteúdo de transformações lineares no plano. A autora queria observar que tipo de construção os estudantes realizavam quando deparados com o conceito matemático de transformação linear.

O trabalho apresenta como base norteadora a teoria dos registros de representação de Raymond Duval, tendo como objetivos estudar as características apresentadas em conversões de registros no conteúdo das transformações lineares no plano. Também foi avaliado o potencial do software Cabri-Géometre por possibilitar representações dinâmicas e por ser uma ferramenta auxiliar nas atividades de conversão envolvendo registros gráficos, geométricos e algébricos.

O experimento foi aplicado a um grupo de 6 estudantes universitários da área de Computação que possuíam conhecimentos prévios de transformações lineares. Os encontros foram realizados em um laboratório de informática onde cada estudante possuía um computador para realização das atividades. Todos os 
encontros foram gravados e as atividades dos estudantes tiveram suas imagens em tela capturadas constantemente para análises posteriores.

As hipóteses para a pesquisa foram a de apresentar atividades que favorecessem diversas representações de uma transformação linear; a utilização do software Cabri-Géometre ajudaria o estudante a realizar conjecturas e experimentálas com o objetivo de validá-las; as atividades levariam os estudantes a compreender as especificidades de cada tipo de registro e a relação entre eles.

A pesquisa iniciou com a aplicação de um trabalho "piloto" com um estudante do curso de Engenharia da Computação de uma Instituição Particular de Ensino Superior, que já havia cursado a disciplina de Álgebra Linear. Como o estudante não conhecia o Cabri-Géometre, fez-se um estudo preliminar sobre o mesmo. A aplicação "piloto" levou a pesquisadora a reformular suas atividades, e as mudanças estavam relacionadas a aplicação das transformações lineares a objetos diferentes de polígonos e vetores; acrescentar nas atividades explicações orais sobre as descrições apresentadas pelo estudante e estabelecer reflexões e interpretações de aspectos já dominados a fim de evitar a mecanização na resolução das tarefas; uma mudança na ordem de aplicação das atividades para um maior aproveitamento nas atividades mais complexas; alguns enunciados foram reescritos, porém mantendo seus objetivos.

O Design Experiment foi desenvolvido em duas etapas. Na primeira, realizada no ambiente papel\&lápis e de forma individual, onde quatro atividades foram desenvolvidas compostas por tarefas similares as encontradas em livros didáticos de Álgebra Linear ou que exploravam os aspectos geométricos das transformações geométricas. A segunda etapa possuía nove atividades realizadas nos ambientes papel\&lápis e Cabri-Géometre, onde os estudantes trabalharam em duplas com situações sobre as transformações lineares.

Utilizaremos esse estudo como base para o desenvolvimento de nossa parte experimental, buscando organizar e realizar de forma similar todas as etapas do design uma vez que nossos intentos se aproximam daqueles da pesquisa de Karrer (2006). Também realizaremos a coleta de dados com um grupo reduzido de alunos. 


\section{Capítulo 3 - Atividades}

\subsection{Experimentação}

Este capítulo traz observações feitas por nós durante aplicações de atividades de acordo com as necessidades do grupo de alunos que participaram do experimento.

As atividades foram aplicadas para um grupo de voluntários formado por 6 (seis) alunos $^{8}$ da $3^{\text {a }}$ Série do Ensino Médio da Escola Estadual Sapopemba, ao longo de 10 encontros - um encontro por semana de 50 minutos de duração cada.

Os temas abordados nos encontros durante a experimentação foram sobre coordenadas cartesianas no plano e espaço. Para a elaboração das atividades, nos baseamos nos constructos da teoria dos registros de representações semióticas (DUVAL, 2009) e dos trabalhos de Lorenzato (2006) sobre o uso de materiais manipuláveis no ensino de Matemática.

\subsubsection{Encontro 1}

Participaram desse encontro 6 alunos que serão designados na continuidade desse texto por: AD, CA, LL, LA, MA e TA.

A seguir, descrevemos as atividades desenvolvidas nesse encontro, buscando explicitar as produções dos alunos e suas principais dificuldades.

Iniciamos o encontro com uma adaptação do Jogo de Batalha Naval e, como todos já conheciam os objetivos e regras do jogo original, apresentamos as regras que foram adaptadas para a experimentação, a saber:

\footnotetext{
${ }^{8}$ Os alunos participantes e seus pais/responsáveis assinaram o TERMO DE CONSENTIMENTO LIVRE E ESCLARECIDO (TCLE) pelo qual ficaram cientes dos objetivos da nossa pesquisa.
} 
Cada jogador recebeu 7 embarcações (1 porta avião, 1 encouraçado, 2 cruzadores e 3 submarinos) e um tabuleiro compostos pelos 4 quadrantes do plano cartesiano. Localizaram suas embarcações de modo cada quadrante contenha pelo menos uma embarcação.

Foi exposto pela professora que para acertar a embarcação de seu oponente, o jogador deveria acertar um dos vértices dos quadrados que compõem a embarcação. Para isso, cada aluno deveria falar as coordenadas do ponto desejado ao seu oponente. Uma vez esclarecidas as regras, foi dado início as atividades.

A ficha distribuída aos alunos com a descrição da atividade encontra-se no Anexo III.

Os alunos demoraram um pouco para se adaptarem a tais regras e, para que pudessem jogar, optamos por estender um pouco o tempo (10 minutos). Os alunos jogaram em duplas formadas da seguinte maneira: Dupla 1 - CA e MA; Dupla 2 AD e TA; e Dupla 3 - LL e LA.

Realizamos o jogo com o objetivo de verificar o que os alunos recordavam sobre coordenadas de pontos no plano cartesiano e observar suas possíveis dificuldades nesse tipo de tarefa. Nas figuras 53 e 54 podemos observar os tabuleiros de duas duplas com suas embarcações representadas.

Figura 53: Um dos tabuleiros da Dupla 1

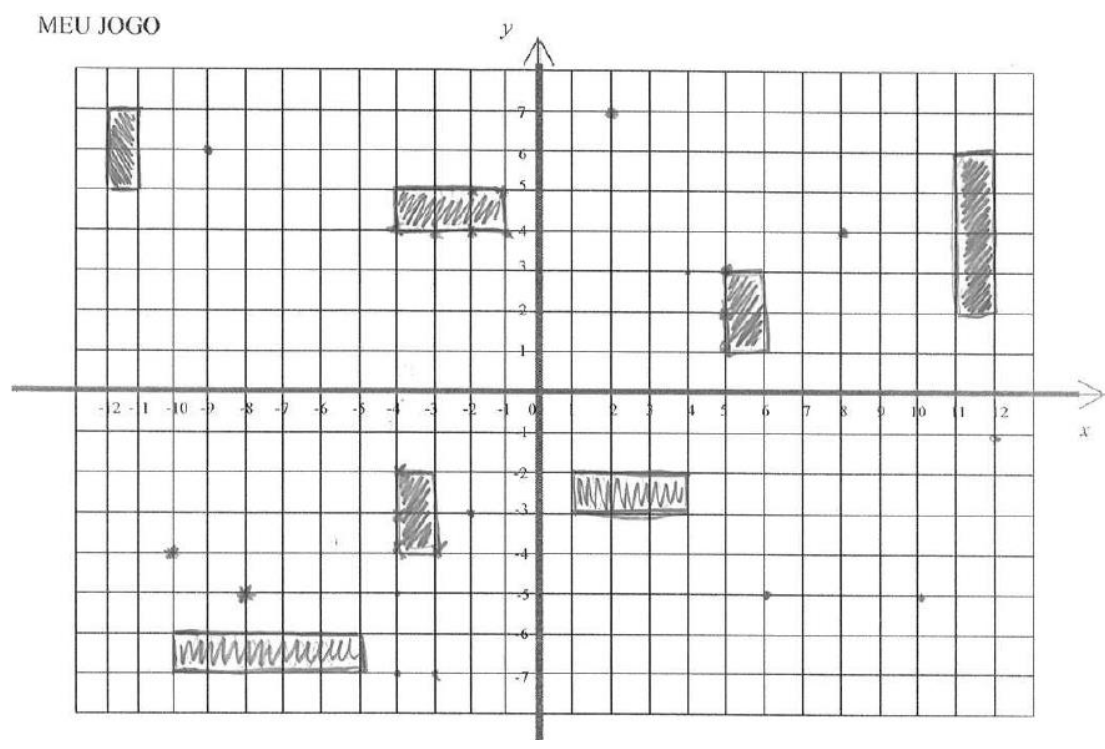

Fonte: Material da experimentação 
Figura 54: Um dos tabuleiros da Dupla 2

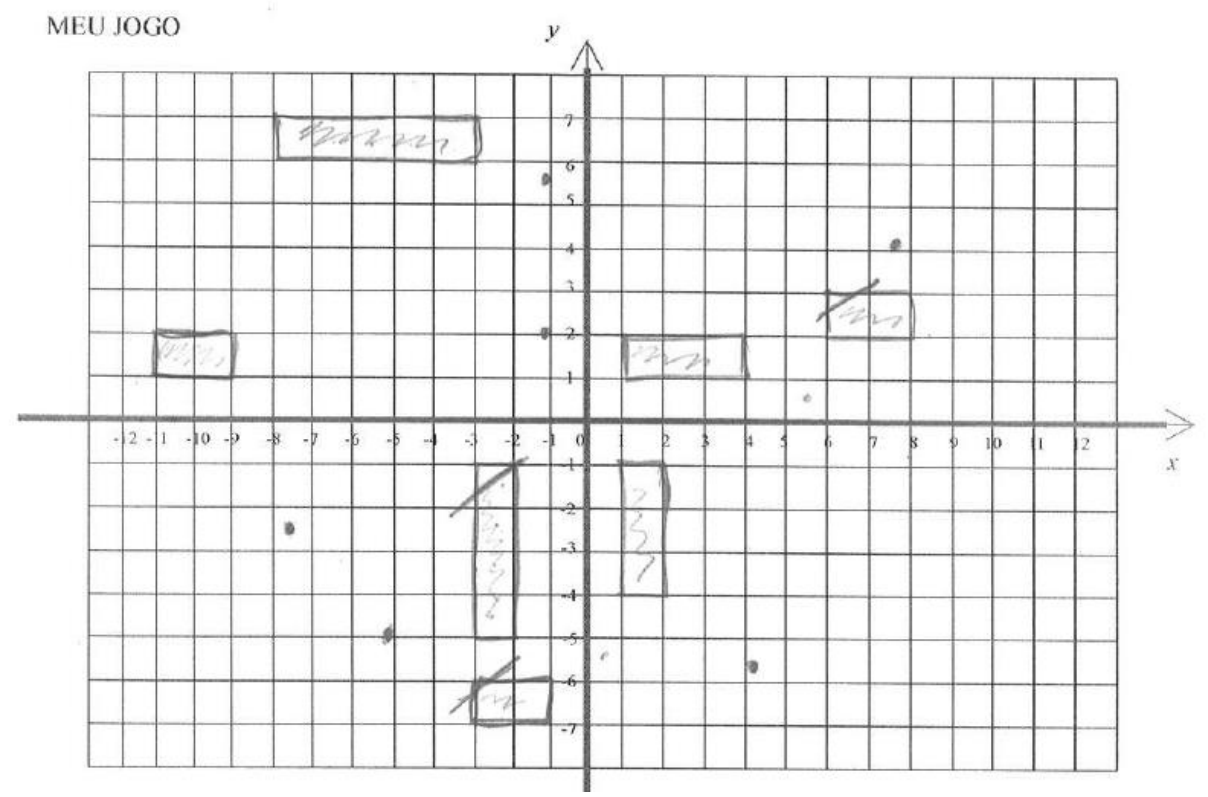

Fonte: Material da experimentação

Durante o jogo, observamos que alguns alunos apresentaram algumas dificuldades, como por exemplo, na marcação de alguns "tiros". Na figura 54 , as marcações não foram feitas nos pontos da malha quadriculada. Isso pode ter ocorrido em função dos alunos não atentarem para o que foi explicitado (não compreenderam plenamente a regra) e/ou influência da experiência anterior com o jogo original, no qual essa particularidade não ocorre.

Em seus quadros de jogadas, os alunos representaram apenas os pontos e não coordenadas, o que já era esperado. 
Figura 55: Um dos tabuleiros da Dupla 3

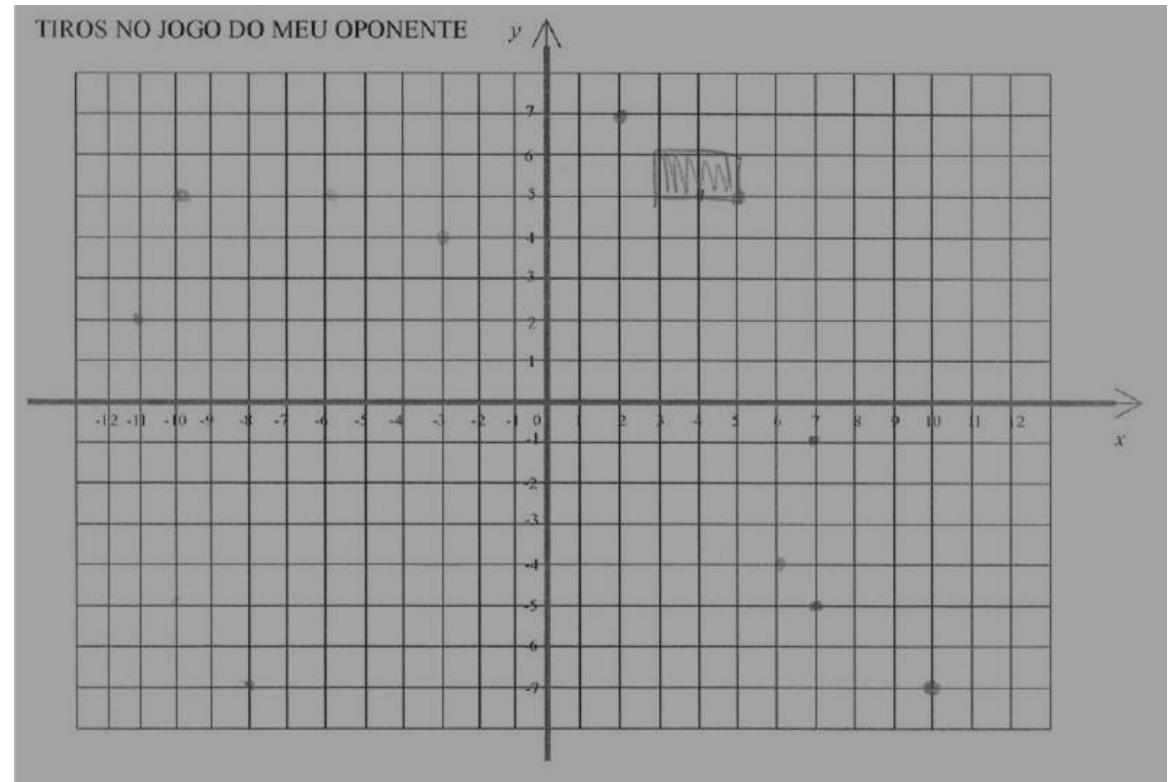

Fonte: Material da experimentação

Logo após a realização do jogo, discutimos sobre o plano cartesiano, de forma dialogada com os alunos, visando destacar conjuntamente seus elementos, tais como os eixos (retas orientadas), origem e unidades de medidas em cada eixo e a nomenclatura correspondente.

Figura 56: Modelo de plano cartesiano

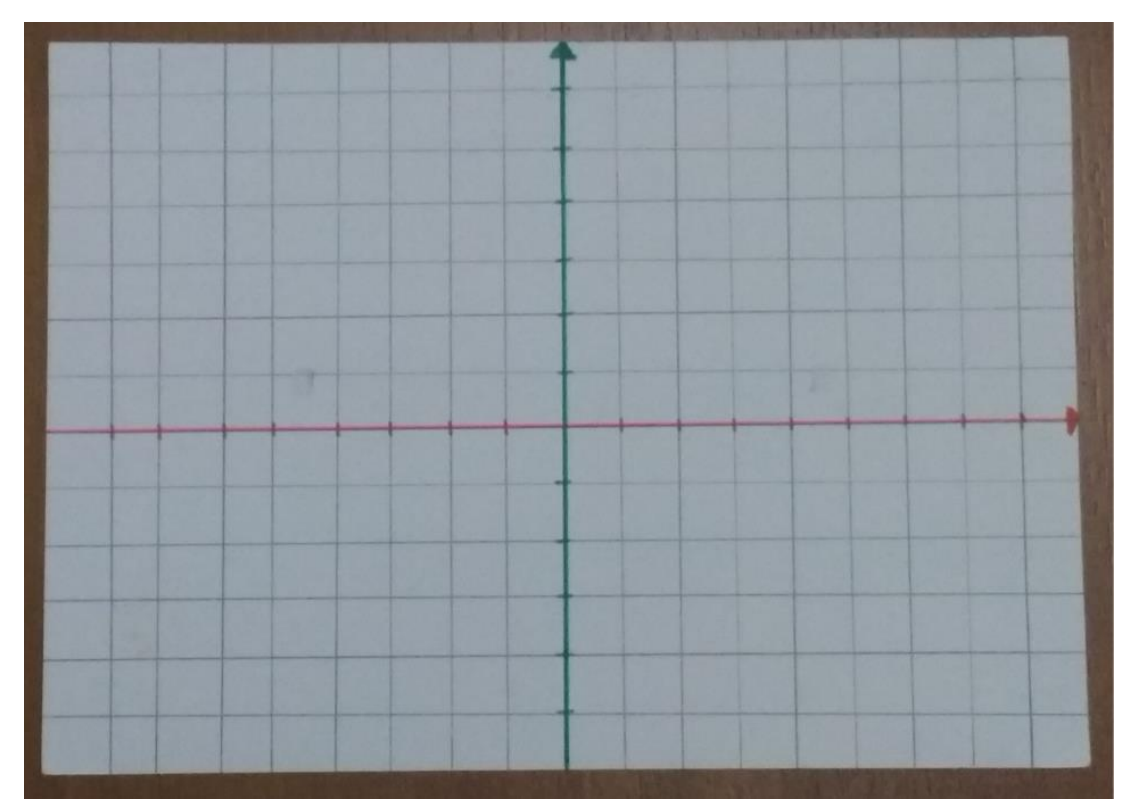

Fonte: Autora 
Realizamos uma dinâmica, com objetivo de avaliar como os alunos realizavam conversões entre registros. Para isso, apresentamos alguns pontos dispostos no plano cartesiano e cada um dos alunos deveria apresentar oralmente as coordenadas do ponto que sorteou. Na segunda parte, cada um sorteou as coordenadas de um ponto e fez a representação gráfica no plano cartesiano.

Figura 57: Modelo do plano cartesiano na cartolina após a dinâmica

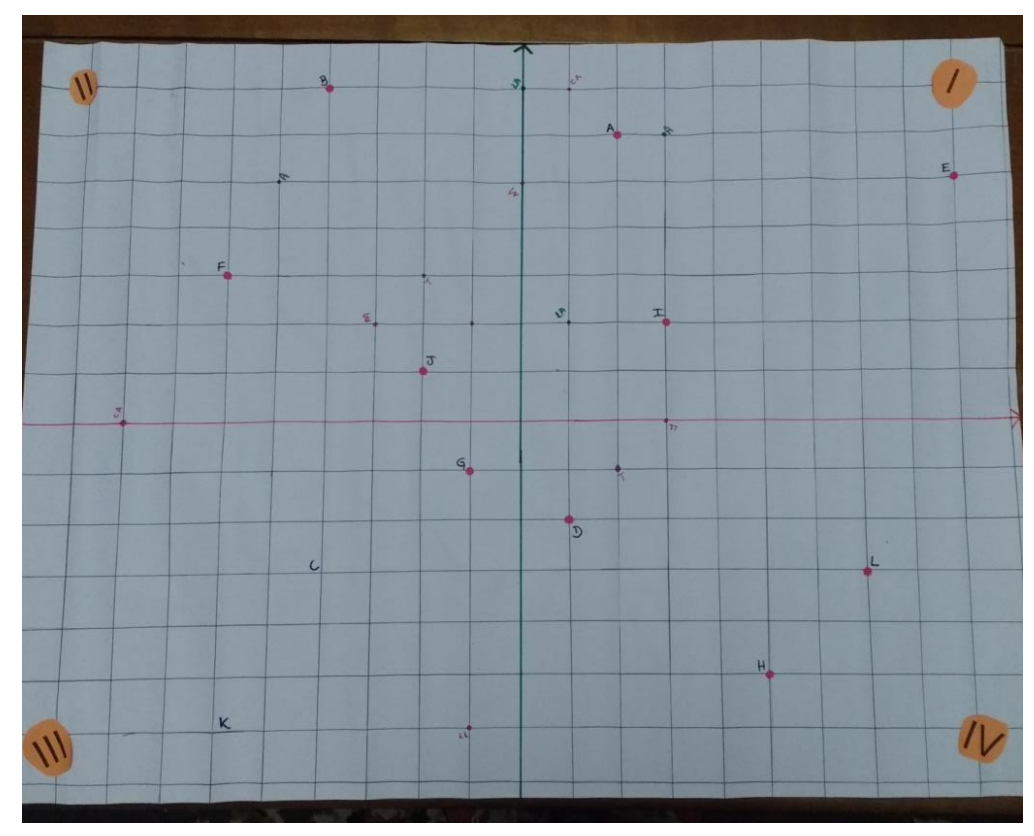

Fonte: A autora

A aluna TA apresentou dificuldades nas duas partes da tarefa. Na primeira, indicou para o ponto $I=(3,2)$ as coordenadas $(3,0)$, sendo corrigida pelos colegas e na segunda parte, ao realizar a marcação de seu primeiro ponto, trocou a ordem das coordenadas $x$ e $y$, ou seja, o ponto que sorteou foi $(2,-1)$, mas marcou o ponto $(-1,2)$. Com isso, podemos supor que a aluna, nesse primeiro caso, não observou corretamente a ordem do par de números reais. Visto o erro da colega, os próprios alunos ajudaram-na a corrigir e marcar o ponto $(2,-1)$ no plano cartesiano corretamente, destacando a importância da ordem das coordenadas na descrição do ponto. 


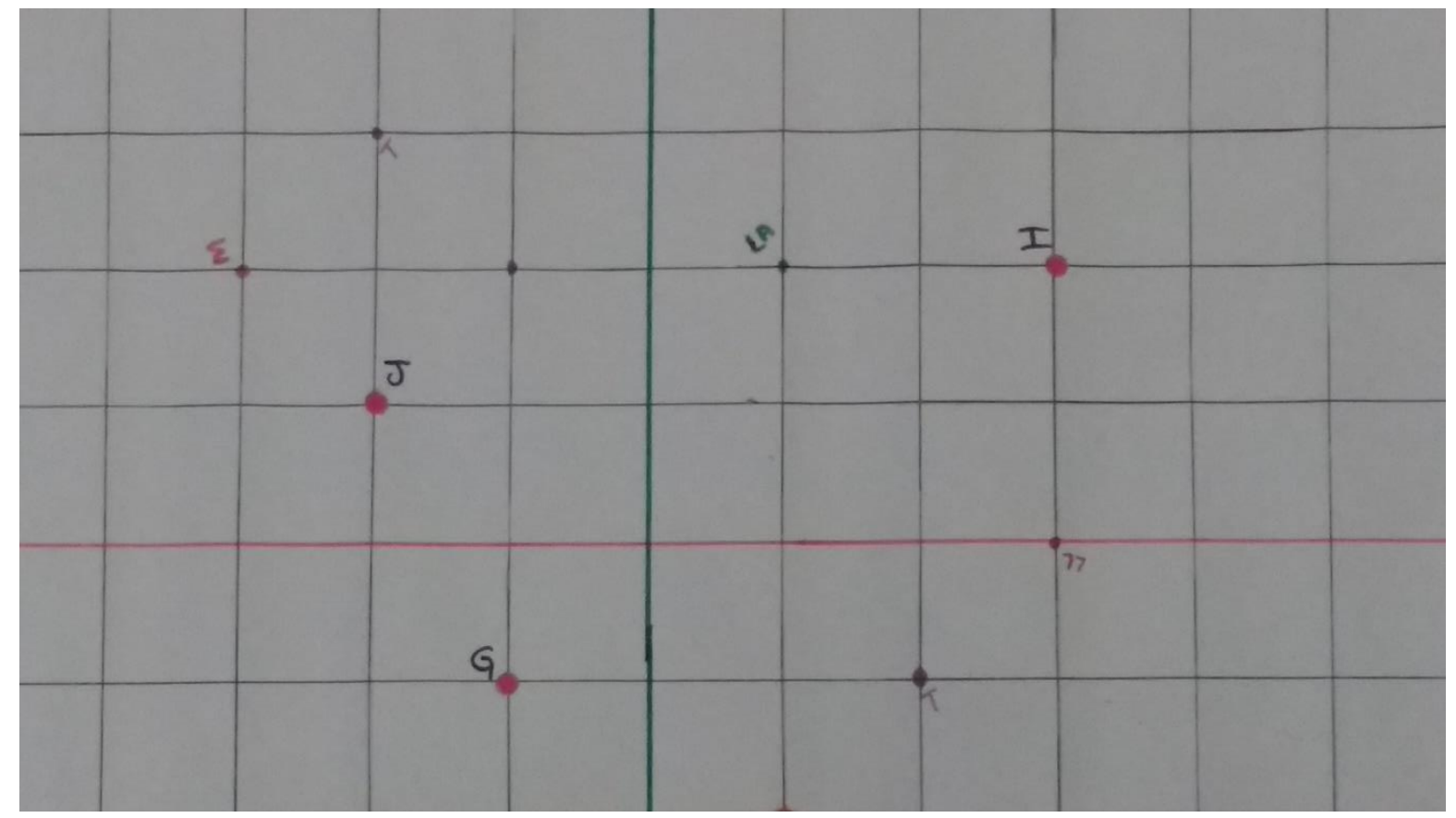

Fonte: Autora

$\mathrm{Na}$ primeira parte da dinâmica realizamos uma conversão entre o registro gráfico e o registro língua natural (as coordenadas foram apresentadas oralmente). Já na segunda parte, a conversão se fez entre os registros numérico e gráfico.

Ambas as conversões são congruentes, pois ao realizar a conversão no sentido inverso, o registro de partida é encontrado novamente sem alterações.

Para finalizar esse primeiro encontro, os alunos responderam individualmente à seguinte questão: 
"Você acabou de ser apresentado a um sistema de coordenadas cartesianas. Agora, descreva todos os seus elementos (origem, eixos, quadrantes) e como se deve proceder para representar pontos nesse sistema elou indicar as coordenadas de pontos já marcados".

As alunas CA, MA, TA e LL apresentaram como respostas apenas a descrição dos elementos do plano cartesiano, sendo que CA e MA o fizeram de uma forma mais clara, e TA e LL mostraram algumas confusões de conceitos ao fazerem suas descrições, como por exemplo, "os quadrantes têm a mesma medida" (cf. Figura 60) ou "são os quadrados em que colocamos o número da posição que queremos no plano" (cf. Figura 59). Nesta última resposta, a aluna TA pode ter confundido o termo quadrante com "quadradinhos" em que marcava os pontos no jogo da atividade anterior.

Figura 59: Resposta de TA

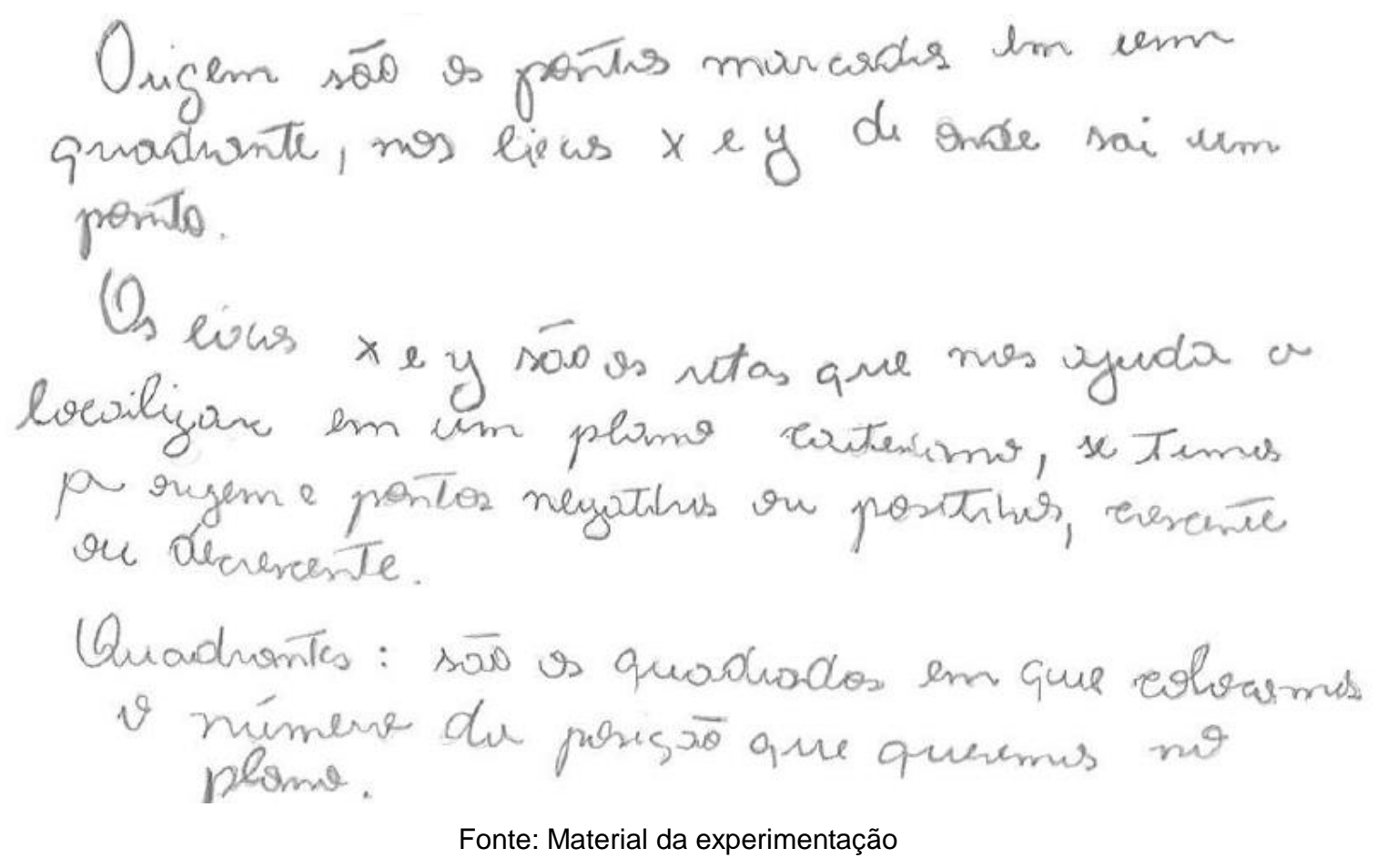


Figura 60: Resposta de LL

(1) plane corteriano tem $\theta$ ixso $x$ e $y$ usinde $\theta x$ na howportal i $\theta$ y ma verdical, Qs quadrantis tim a memas medida e

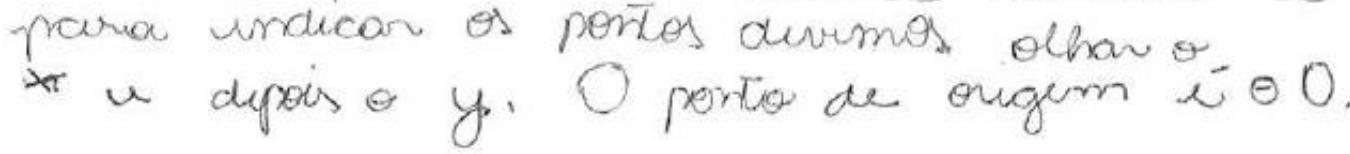

Fonte: Material da experimentação

O aluno $A D$, mesmo sem precisão, apresentou como se deve proceder para representar um ponto graficamente. O aluno LA foi o que deu uma resposta mais completa, sendo que, para descrever os eixos, utilizou a palavra "linha", mas foi o único que apresentou a ideia de "graduar" os eixos, quando falou que as "linhas" têm números.

A ideia de que os eixos são perpendiculares apareceu explicitamente nas respostas de LL, LA e MA, que descrevem os eixos como horizontal (eixo $x$ ) e vertical (eixo y).

\section{Figura 61: Resposta de MA}

D invo que evtós na vertical reperenta y e no horigontal representar $\theta x$.

a erigem é $\theta$ ponto $(0,0)$ que neprenenta 0

no ervo $y$ e 0 no $\sin \theta x$.

E há ly quadranter, sende.

$1^{\circ}$ ( $x$ e y powtivor)

$2^{\circ}$ ( $x$ nequitive e Y pritive)

$3^{\circ}$ ( $x$ e 4 negativor)

$4^{\circ}$ ( $x$ poitive e y negative).

Fonte: material da experimentação 


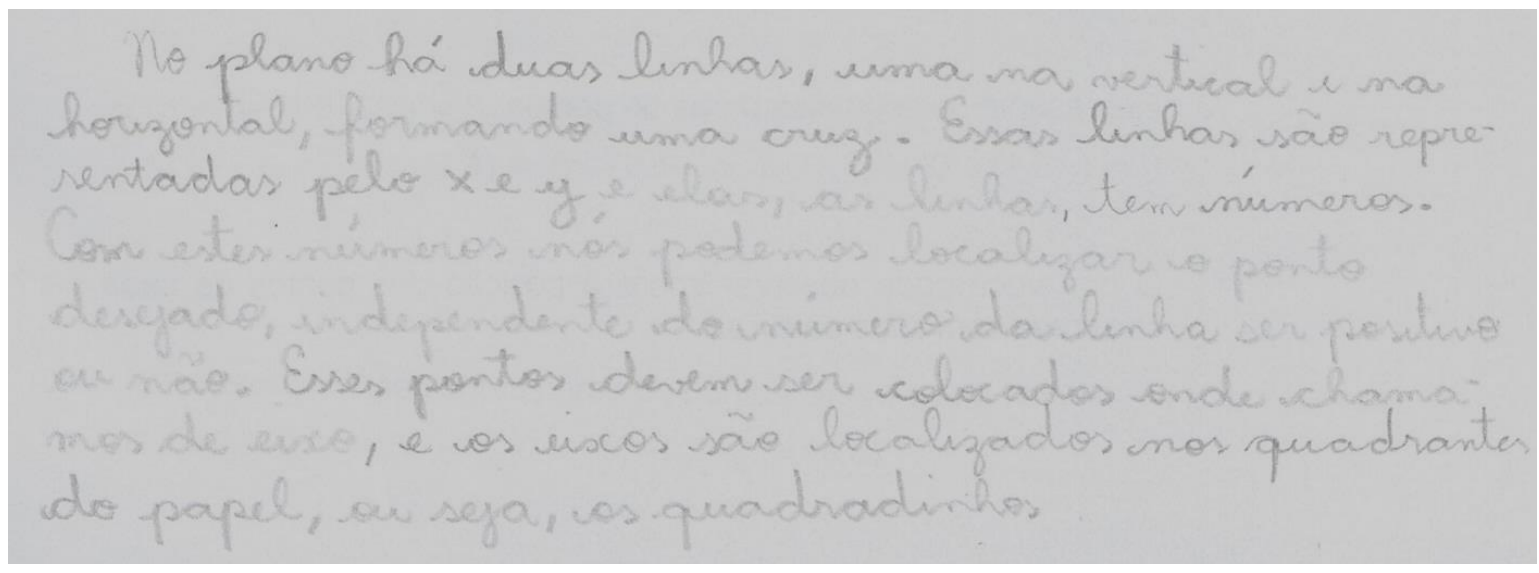

Fonte: Material da experimentação

Neste encontro observamos que alguns alunos, apresentaram dificuldades nas representações gráfica e numérica de pontos e na conversão entre esses registros, além de não estarem familiarizados com a nomenclatura dos elementos do plano cartesiano, apresentando assim algumas imprecisões em seus registros e descrições.

\subsubsection{Encontro 2}

Neste encontro foram terminadas as tarefas do encontro anterior, e nossos objetivos eram trabalhar com alguns casos particulares sobre coordenadas no plano e começar a introdução das coordenadas cartesianas no espaço.

Participaram desse encontro os alunos AD, CA, LA e MA. Com a ausência de LL e TA as duplas foram reorganizadas da seguinte forma: Dupla 1 - CA e MA e Dupla 2 - AD e LA.

Com a Tarefa 2, queríamos levar os alunos a perceberem as características das coordenadas cartesianas de pontos sobre os eixos Ox e Oy. Aqui esperávamos dificuldades na representação numérica dos pontos em relação a sua coordenada nula, a saber, $y=0$ se o ponto pertence ao eixo $O x$ e $x=0$ se o ponto pertence ao eixo $O y$. 
$\mathrm{Na}$ Tarefa 2, a Dupla 1 apresentou seus exemplos de pontos pertencentes aos dois eixos de forma satisfatória, incluindo esboços da representação gráfica de cada ponto. Na segunda parte da questão, a Dupla 1 conseguiu observar a característica que esses pontos apresentam observando que " $x$ sempre valerá 0 " e "y sempre valerá 0 ", porém observamos que trocaram os eixos.

Figura 63: Resposta da Dupla $1^{9}$

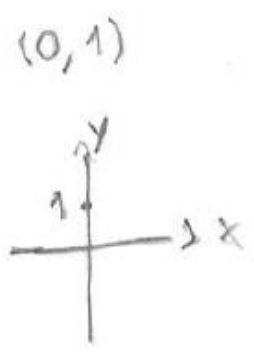

2. Dê 2 exemplos de pontos sobre o eixo OX e 2 exemplos de pontos que

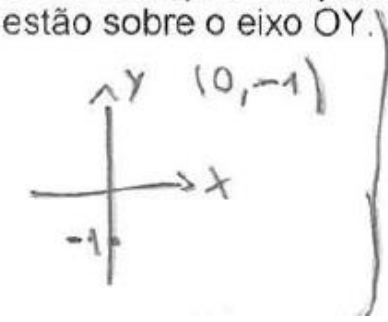
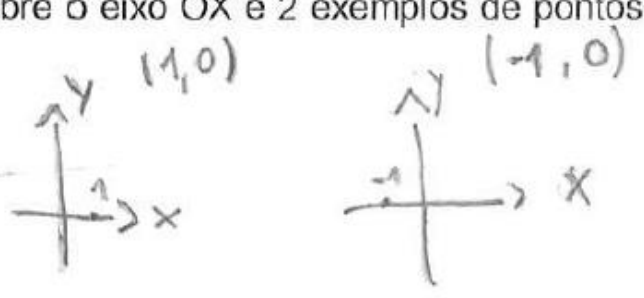

Fonte: Material da experimentação

A Dupla 2 mostrou dificuldades em apresentar seus exemplos. Primeiramente, indicaram o ponto $(3,5)$. Observando esta dificuldade, entregamos à dupla um "modelo" de plano cartesiano usado no jogo da Atividade 1(Figura 56) e reforçamos que o ponto deveria estar sobre os eixos. Os alunos perceberam rapidamente que o ponto $(3,5)$ não pertencia a nenhum dos eixos. Foi ainda solicitado que indicassem onde (em que posição) estaria um ponto do eixo, o que fizeram corretamente. Oralmente, solicitados como poderiam obter um desses pontos, responderam que "não se deve deslocar dos eixos". Feita esta intervenção, eles conseguiram compreender e apresentar exemplos de forma satisfatória.

Figura 64: Resposta corrigida da Dupla 2

2. Dê 2 exemplos de pontos sobre o eixo OX e 2 exemplos de pontos que estão sobre o eixo OY.

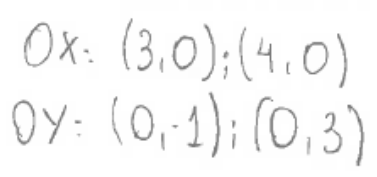

Fonte: Material da experimentação

\footnotetext{
${ }^{9}$ Durante a aplicação da tarefa, foi solicitado oralmente aos alunos que representassem cada ponto no sistema cartesiano e exibissem suas coordenadas.
} 
Já na segunda parte, a Dupla 2 não apresentou uma resposta satisfatória, na qual respondeu sobre a localização dos pontos e não sobre as características das coordenadas dos pontos dos eixos. Praticamente, repetiram o enunciado, afirmando "Pode ser localizado na reta do eixo x" e "Pode ser localizado na reta do eixo y".

Apesar da conversão do registro gráfico para o registro numérico ser congruente, notamos dificuldade na representação da coordenada nula dos pontos sobre os eixos. Acreditamos que essa dificuldade se dá pelo fato de que quando um ponto está sobre um dos eixos, os alunos consideraram que não existe deslocamento na direção da perpendicular ao eixo e esse não-deslocamento não é facilmente percebido pelos alunos como podendo ser representado por uma coordenada nula.

Nos itens 3 e 4, relativos a pares de pontos simétricos em relação aos eixos Ox e Oy respectivamente, a Dupla 2 conseguiu verificar que os pontos eram simétricos, fazendo referência à ideia de espelho e indicaram corretamente qual o eixo de simetria em cada caso.

Figura 65: Resposta da Dupla 2 para a Tarefa 3

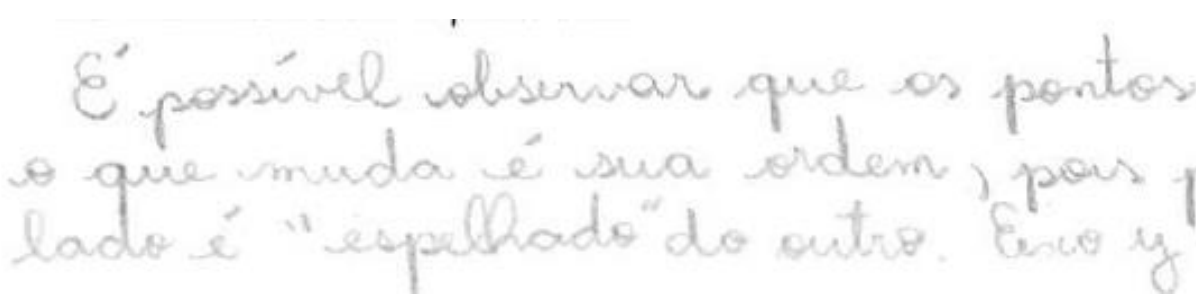

Fonte: Material da experimentação

Ainda assim, há confusão na descrição, pois consideraram que "os pontos são iguais, o que muda é sua ordem", quando na verdade, muda também o sinal da abscissa. Isso se deve, provavelmente, por uma confusão entre distâncias em relação aos eixos e as posições dos pontos no plano cartesiano.

O mesmo ocorreu com a Dupla 1, que fala sobre "ocupar a mesma posição" em relação a um eixo, só que em quadrantes diferentes, porém não menciona a relação de simetria entre os pontos. 
Figura 66: Resposta da Dupla 1 para a Tarefa 4

\section{eles ertāo nos mesmos pariciees a partic do lixe do $x$, mos em quadrantes apastos $(1+4)$ Fonte: Material da experimentação}

Acreditamos que, pelo fato de desconhecerem a nomenclatura relacionada às simetrias, ambas as duplas descrevem de forma imprecisa suas observações.

Para finalizar essa etapa, os alunos relataram suas observações feitas nas tarefas. Para pontos pertencentes aos eixos a Dupla 2 falou que o ponto "vai a partir do zero" aqui se referindo à origem, e que se o ponto está no eixo $O x$, por exemplo, a "segunda coordenada será zero". Já em relação às Tarefas 3 e 4, responderam que o eixo "é um espelho, só mudou o quadrante".

Após as observações realizadas sobre as respostas dadas pelos alunos sentimos a necessidade de adiar as atividades planejadas para os próximos encontros e elaborar mais tarefas visando aprofundar o conceito de simetria em relação a uma reta no plano. Essa mudança é prevista pela metodologia adotada.

Iniciamos a segunda parte do encontro com uma explanação, com objetivo de introduzir o sistema de coordenadas no espaço a partir do plano conforme o previsto, e usando os recursos materiais e o software Geogebra.

De forma dialogada, fomos apresentando os eixos e os planos coordenados a fim de levar os alunos a identificarem os octantes. 


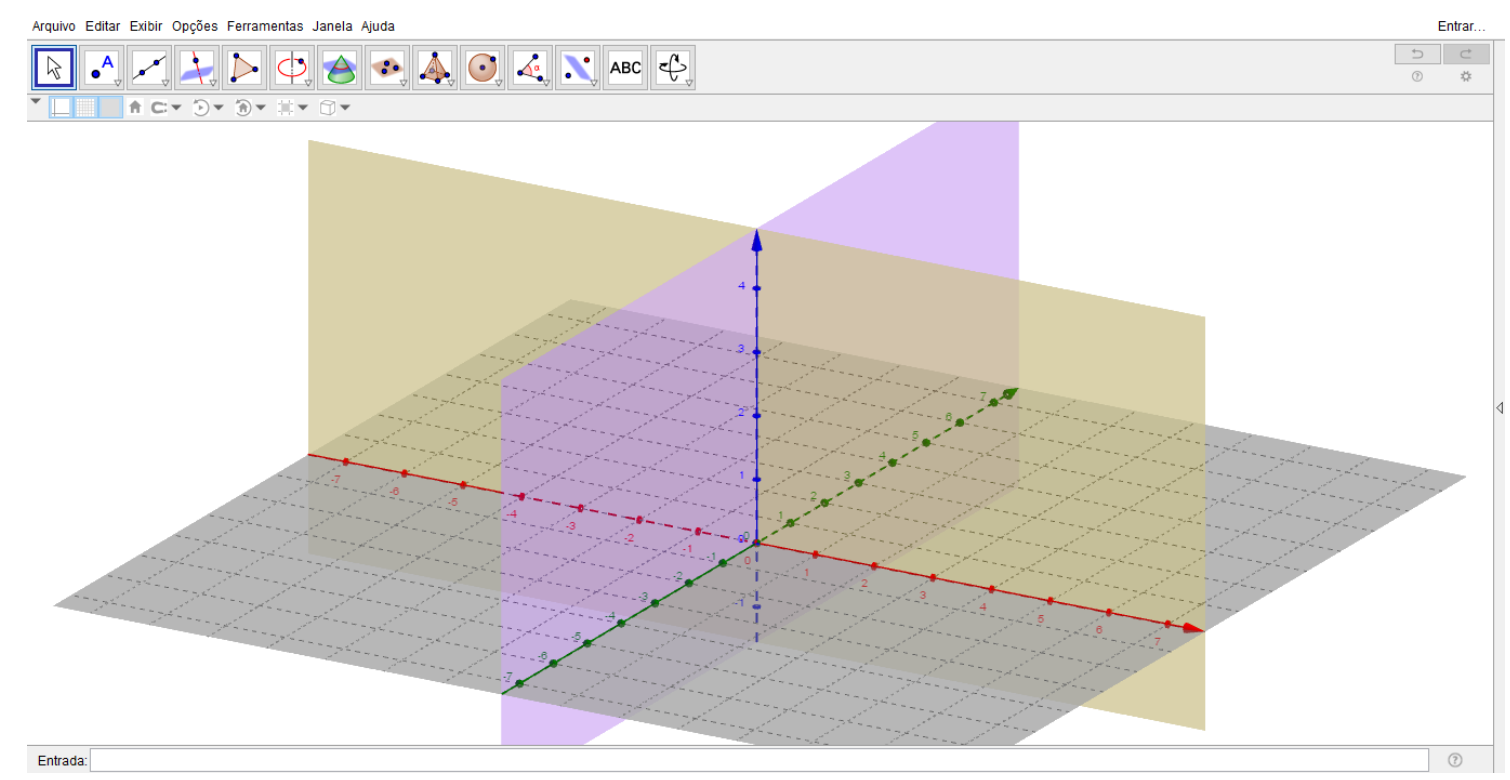

Fonte: Autora

Apresentamos as figuras ilustrativas de cada situação no Geogebra e mudamos os seus pontos de vista por movimentação e rotação do sistema representado. Em seguida, perguntamos aos alunos o que visualizaram e quais elementos identificaram em cada caso.

Escolhemos a Janela 3D do Geogebra, pois a possibilidade de manipular o objeto "pode favorecer o desenvolvimento do pensamento geométrico, inclusive da noção espacial, e dessa forma, auxiliar na resolução do problema" (GARCIA, SEHNEM, JÚNIOR, 2013, p.4).

Observamos que os alunos acompanharam as explicações sobre construção do sistema de coordenadas no espaço, respondendo satisfatoriamente às questões colocadas.

Depois de apresentar a noção de octantes, destacando as 8 regiões em que 0 espaço fica dividido, realizamos um jogo que denominamos de Jogo dos Octantes.

Mantendo-se as mesmas duplas, cada uma deveria indicar o octante onde se localizava o ponto que Ihes era apresentado por meio de suas coordenadas. A figura que segue ilustra os pontos apresentados e o arquivo Geogebra que foi utilizado como referência. 
Figura 68: Jogo dos Octantes

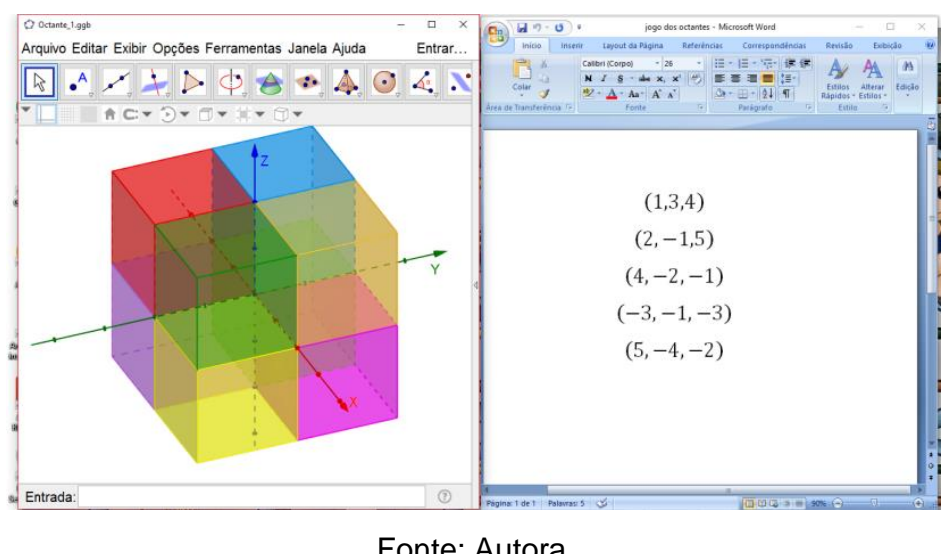

Fonte: Autora

A Dupla 1 não apresentou dificuldades durante o referido jogo. A Dupla 2 apresentou respostas incorretas na indicação de cada octante. No entanto, nossas observações mostraram que esses erros eram devido a não observância da "ordem" usada pra identificar os octantes e os números que the foram associados (cf Figura abaixo). De fato, em diversos casos, os alunos erraram o "número" número do octante, mas acertavam a cor do respectivo octante.

Tabela 5: Respostas no Jogo dos Octantes

\begin{tabular}{|c|c|c|c|}
\hline Ponto & Octante & $\begin{array}{c}\text { Respostas } \\
\text { apresentadas pela } \\
\text { Dupla 1 }\end{array}$ & $\begin{array}{c}\text { Respostas } \\
\text { apresentadas pela } \\
\text { Dupla 2 }\end{array}$ \\
\hline$(1,3,4)$ & $1^{\circ}$ & 1 & 1 \\
\hline$(2,-1,5)$ & $4^{\circ}$ & 4 & 2 \\
\hline$(4,-2,-1)$ & $8^{\circ}$ & 8 & 4 \\
\hline$(-3,-1,-3)$ & $7^{\circ}$ & 7 & 5 \\
\hline$(5,-4,-2)$ & $8^{\circ}$ & 8 & 6 \\
\hline
\end{tabular}

Fonte: Material da experimentação

Nos próximos encontros, trabalhamos com situações no espaço, fazendo o uso do Geogebra por permitir a manipulação de objetos, auxiliando assim os alunos a verificarem e/ou validarem suas conjecturas.

\subsubsection{Encontro 3}


Participaram desse encontro apenas os alunos AD, CA, LL, LA e MA. Com a ausência de TA os alunos foram reorganizadas da seguinte forma: Dupla 1 - CA e MA e o Trio - AD, LL e LA.

O encontro tratou de geometria plana e teve por objetivo trabalhar o conceito simetria em relação a uma reta utilizando os registros numérico, gráfico e língua natural da representação de um ponto, e analisar as conversões entre esses registros.

A escolha por aprofundar o estudo da simetria em relação aos eixos se deu pelo fato de observarmos que os alunos não possuíam uma familiarização com esses conceitos e acreditávamos se tratava de um tema importante, que auxilia na resolução de problemas da Matemática e de outras áreas de conhecimento.

Iniciamos o encontro com duas tarefas onde na primeira esperávamos que os alunos compreendessem que num ponto de coordenadas $(a, b)$, o valor absoluto da primeira coordenada representa a distância ao eixo Oy e o valor absoluto da segunda coordenada representa a distância ao eixo $O x$. Na segunda queríamos verificar se o aluno percebe que os pontos $(a, b)$ e $(b, a)$, são diferentes e que possuem representações diferentes no plano cartesiano.

Nesta questão, Tarefa 1 da $4^{a}$ parte, o aluno $A D$ se confundiu nos pontos $A_{5}=(1,4), A_{6}=(2,4)$ e $A_{7}=(0,8)$. O erro foi notado pelo próprio aluno após discutir com seu trio e assim percebeu que havia invertido as coordenadas e corrigiu. 
Figura 69: : Resposta de AD

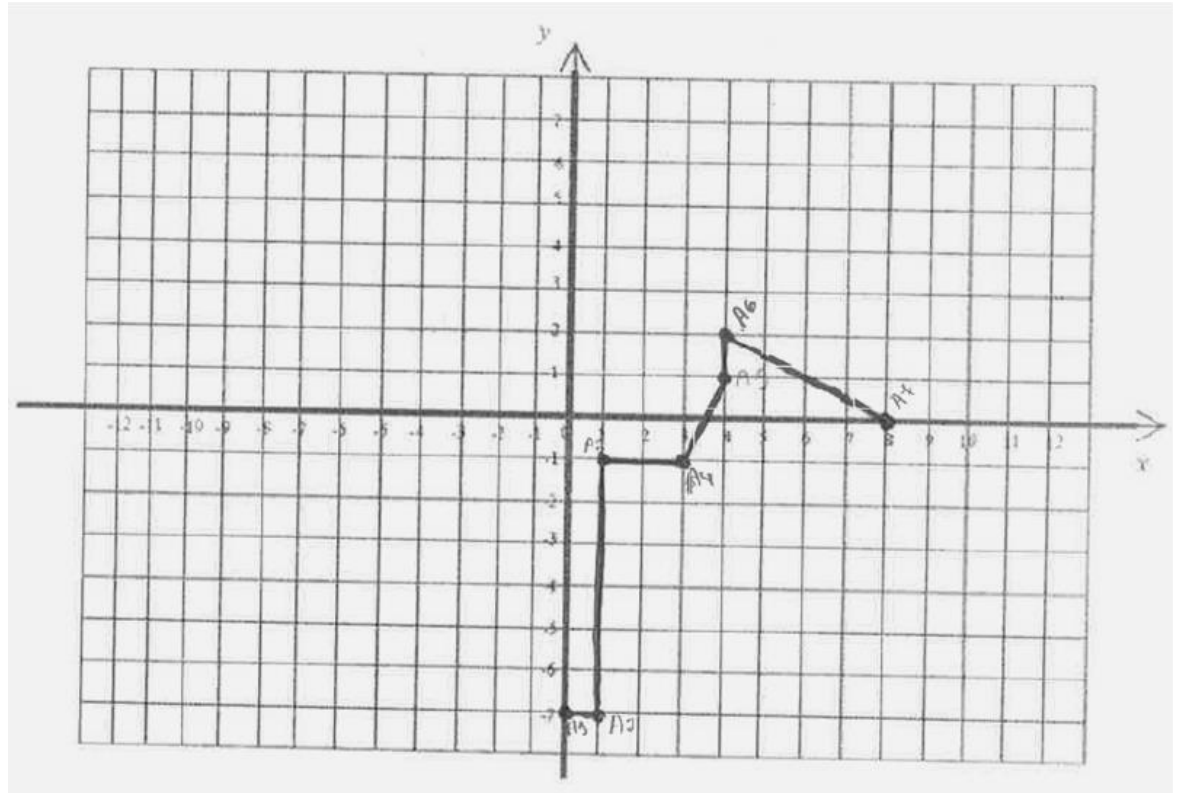

Fonte: Material da experimentação

Figura 70: Resposta de AD após correção do erro

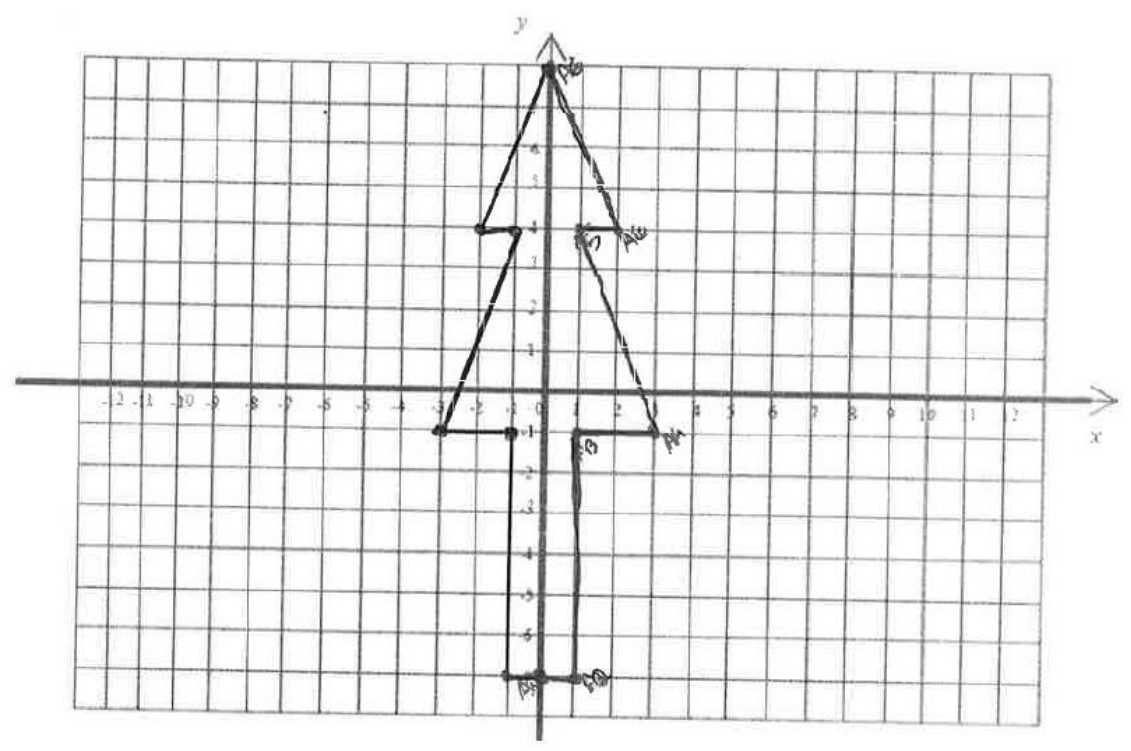

Fonte: Material da experimentação

A Tarefa 3a foi executada como o esperado. Os alunos não apresentaram dificuldades, pois conseguiram perceber que se tratava do desenho de uma "árvore" e a completaram utilizando a simetria entre os pontos. O mesmo ocorreu na Tarefa 4 que, no caso, formava uma "letra E". 
Figura 71: Resposta da Dupla

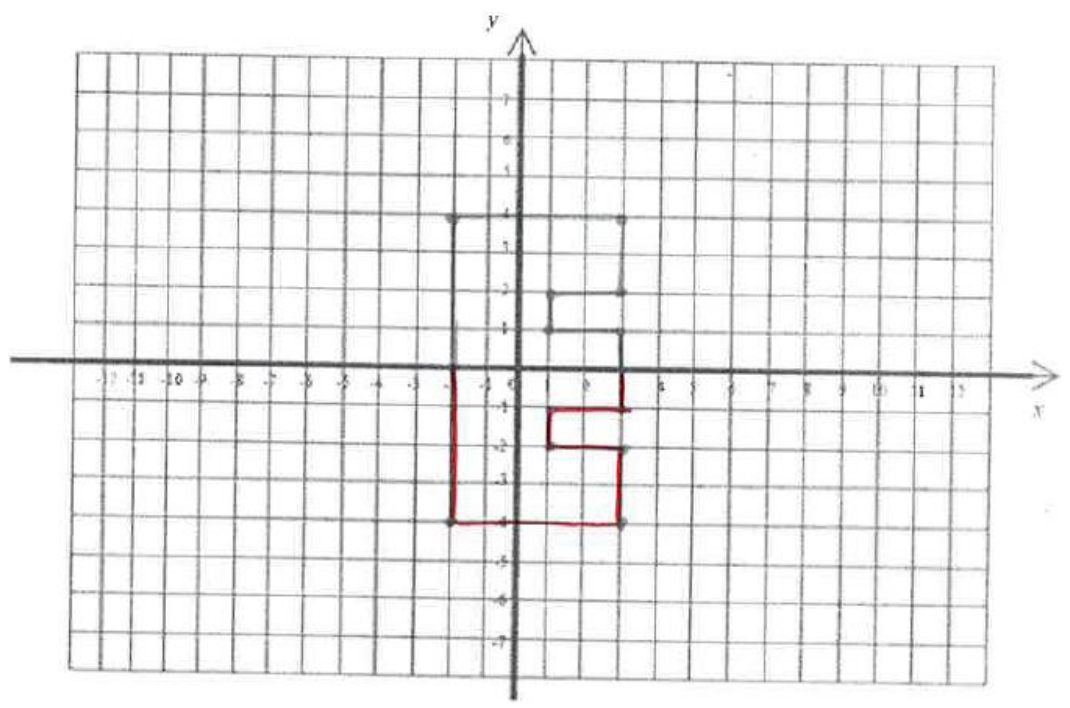

Fonte: Material da experimentação

No momento de descreverem como realizaram as tarefas, a Dupla 1 apresentou em sua resposta "pontos simétricos" e a qual quadrantes eles pertenciam, assim, observamos uma apropriação da nomenclatura já introduzida nos primeiros encontros.

Figura 72: Resposta da Dupla

Eu completaria fagsndo a mesma maracicäo nor pontes simétricos dos $2^{\circ}$ e $3^{\circ}$ - quadrante.

Fonte: Material da experimentação

Já o Trio utilizou expressões como "espelho", "refletissem" e "outro lado".

Figura 73: Resposta do Trio

En inverteria os valores do outro lado. Por exemplo, ma $A_{3}$ os valores são $(1,-1)$ e no outro. lado en colocaria $(-1,-1)$ que nesse caso imverten o lado do $x$. 
Ao analisar as respostas vemos que os alunos apresentaram dificuldades em expressar suas respostas com registro algébrico, ou seja, se utilizam dos pontos no registro numérico e a generalização fica implícita em ambos os casos.

Nas Tarefas $3 b$ e 5 o aluno deveria trabalhar com a conversão entre os registros numérico e gráfico de um ponto no sentido gráfico-numérico e encontrar uma relação entre as coordenadas de um ponto e seu simétrico.

Com essas tarefas esperávamos que os alunos observassem que, na simetria em relação ao eixo Oy a ordenada se mantém e a abscissa troca de sinal. $\mathrm{Na}$ simetria em relação ao eixo $O X$ ocorre o análogo com a abscissa sendo a mesma e ordenada trocando de sinal.

A aluna LL encontrou dificuldades para expressar sua observação na Tarefa $3 b$ e ao repetir a resposta para a Tarefa 5, mostrou uma resposta ainda não satisfatória.

Figura 74: Resposta de LL para a Tarefa 3b

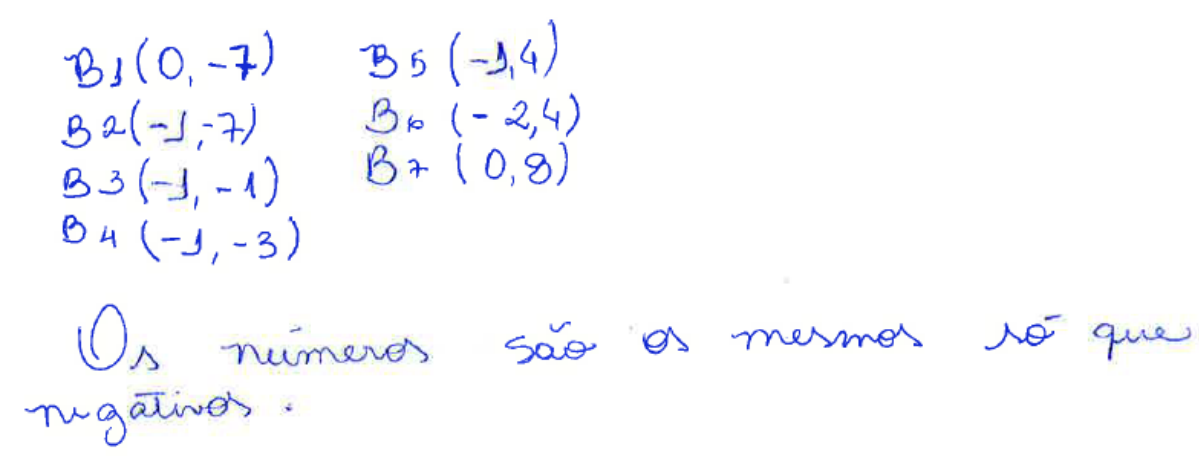

Fonte: Material da experimentação 
Figura 75: Resposta de LL para a Tarefa 5

$$
\begin{aligned}
& A_{s}=(3,1) \\
& A_{2}=(3,2) \\
& A_{3}=(3,4) \\
& A_{4}=(-2,4) \\
& A s=(-2,0) \\
& A_{8}=10,8 \\
& A_{6}=(1,2) \quad\left(B_{1}=(3,-1)\right. \\
& A_{7}=(1,1) \quad\left\{\begin{array}{l}
B_{2}=(3,-1) \\
B_{3}=(3,-2)
\end{array}\right. \\
& \begin{array}{l}
B_{4}=(3,-4) \\
B_{4}=(-2,-4)
\end{array} \\
& B_{S}=(-2,0) \\
& B_{6}=(1,-2) \\
& B==(1,-1) \\
& B 8=(0,3)
\end{aligned}
$$

Fonte: Material da experimentação

Aqui observamos que a aluna encontra dificuldade em fazer conversão do registro numérico para o registro língua natural.

A aluna CA não apresentou uma explicação satisfatória para a tarefa 3b, pois fala apenas em "coordenadas simétricas" não explicitando o que isso significa, porém na tarefa 5 apresenta uma resposta mais detalhada, tornando sua resposta satisfatória.

Figura 76: Resposta de CA para a Tarefa 3b

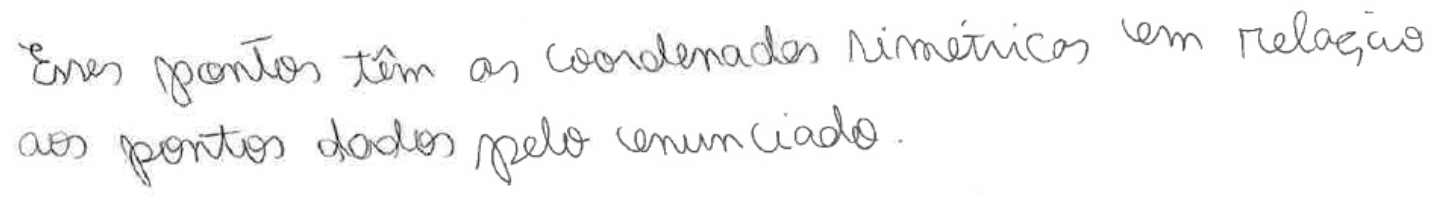

Fonte: Material da experimentação

Figura 77: Resposta de CA para a Tarefa 5
A relaepür untre on coondenados é que a valon de $x$ ne mantém a mermo, e o de $y$ fica negatina

Fonte: Material da experimentação 
O aluno AD fala sobre "reflexão", porém não diz em relação a qual eixo.

Figura 78: Resposta de AD para a Tarefa 3b

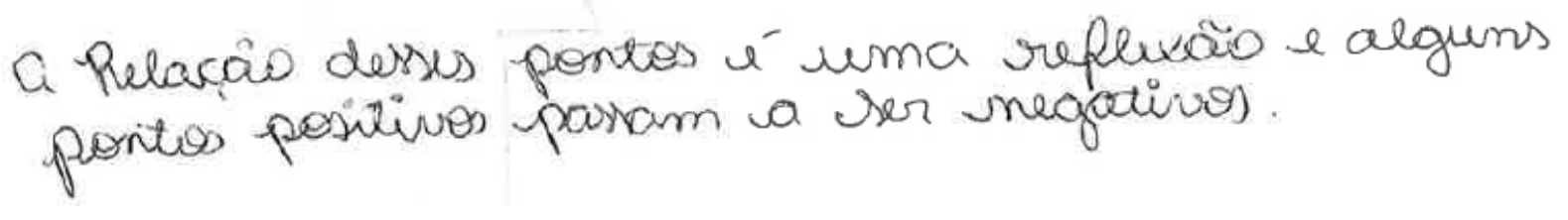

Fonte: Material da experimentação

Observamos nos três casos que os alunos encontram dificuldades em fazer a conversão do registro numérico para o registro língua natural, pois quando relatam que alguns números ficam negativos, levam apenas as coordenadas positivas, ou seja, não observam que o oposto de um número real $a$ qualquer tem como oposto o número real $-a$, e acreditamos que esse fato ocorre por terem a ideia de que o sinal de negativo só é apresentado para representar números negativos. Por esse motivo a conversão entre as unidades significantes de cada registro fica prejudicada.

A resposta mais completa e de acordo como o esperado foi a apresentada por MA.

Figura 79: Resposta de MA para a Tarefa 5

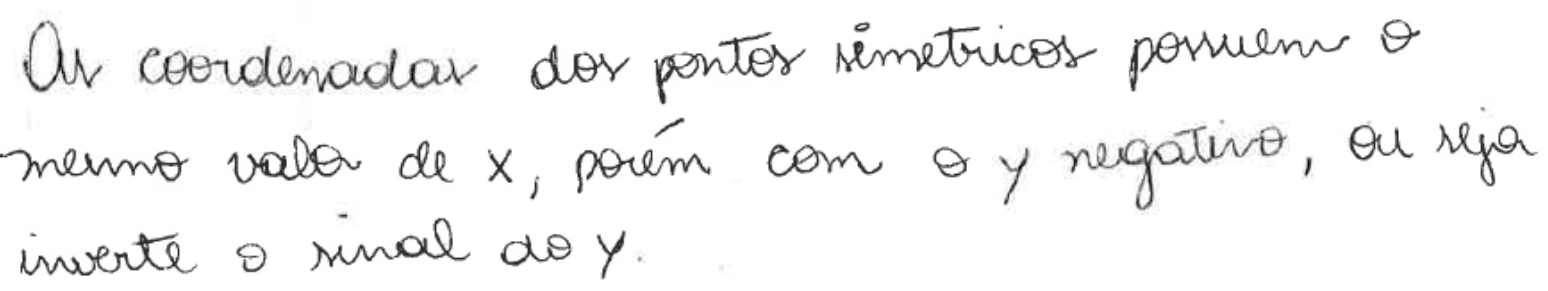
Fonte: Material da experimentação

Com as tarefas presentes observamos que os alunos compreenderam a relação entre as coordenadas de um ponto e seu simétrico em relação aos eixos, porém apresentam dificuldades de expressar os conceitos que observaram.

Analisando as conversões entre os registros observamos que as conversões entre os registros gráfico e numérico são congruentes, como já comentamos nas observações do primeiro encontro. 
Já a conversão entre os registros numérico e língua natural é congruente, pois existe correspondência termo a termo entre as unidades significantes, por exemplo.

Tabela 6: Exemplo de conversão congruente entre registro numérico e registro língua natural para pontos simétricos em relação ao eixo $0 X$.

\begin{tabular}{|c|l|}
\hline Registro numérico & \multicolumn{1}{c|}{ Registro língua natural } \\
\hline$P=(2,-3)$ e $P^{\prime}=(2,3)$ & $\begin{array}{l}P \text { e } P^{\prime} \text { possuem a mesma coordenada em } x \text { e as } \\
\text { coordenadas em y são opostas. }\end{array}$ \\
\hline
\end{tabular}

Fonte: Autora

Para finalizar nossas observações, sentimos a necessidade de trabalhar com os alunos a ideia de generalização e números opostos e como se dá seu registro algébrico de pontos nessas condições.

\subsubsection{Encontro 4}

Neste encontro continuamos nosso trabalho com pontos simétricos em relação aos eixos com o intuito de levar os alunos a generalizar a relação entre suas coordenadas e, por fim, realizar representações no registro algébrico de forma significativa com compreensão das características desse registro.

Participaram desse encontro todos os 6 (seis) alunos, a saber: AD, CA, LL, LA, MA e TA. A organização dos alunos se manteve a mesma do encontro anterior Dupla - CA e MA; Trio - AD, LL e LA. Isso porque, a aluna TA trabalhou individualmente. A escolha de observar a aluna TA individualmente se deu pela necessidade que ela realizasse as tarefas da Atividade em que esteve ausente (para observar as relações entre as coordenadas de um ponto e de seu simétrico em relação aos eixos.)

Outro motivo foi o fato da aluna ter apresentado dificuldade com as representações de pontos na conversão do registro gráfico para o numérico nos primeiros encontros. Já nesse 4ํㅡ, observando suas respostas (ver Figura 80), 
verificamos que a conversão entre esses registros foi realizada de forma satisfatória, o que a colocou em condições de prosseguir na realização das demais atividades.

Figura 80: Resposta de TA

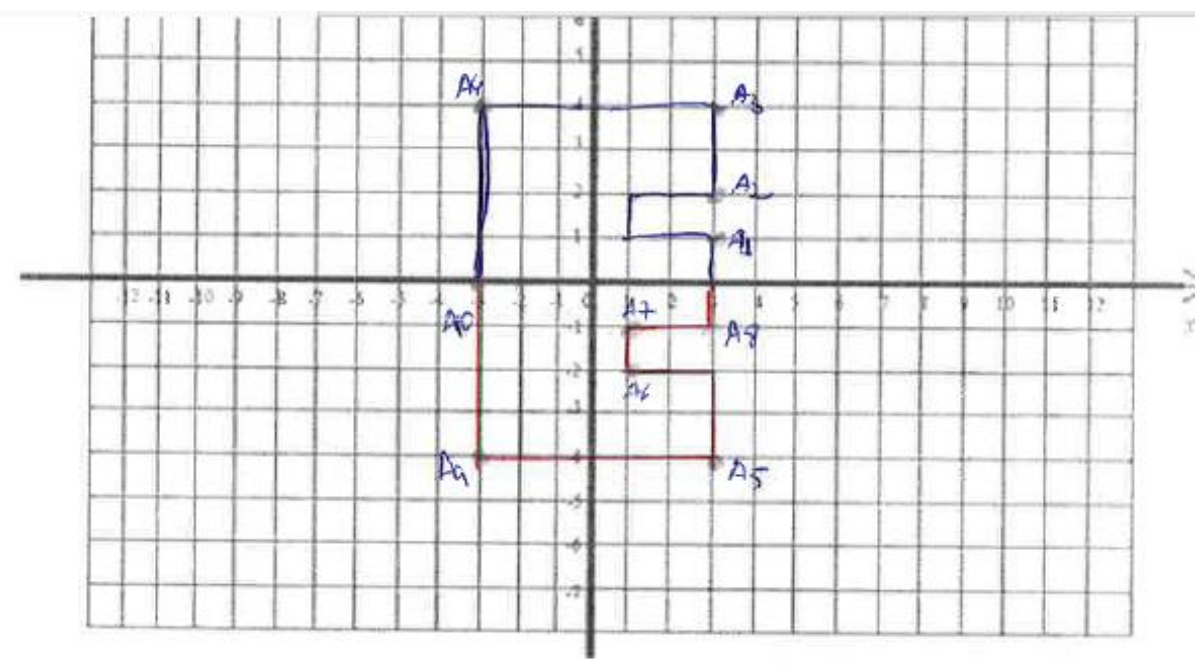

5. Apresente as coordenadas dos pontos que formam a figura. Qual a relação entre as coordenadas dos pontos simétricos?

Coovdenudas

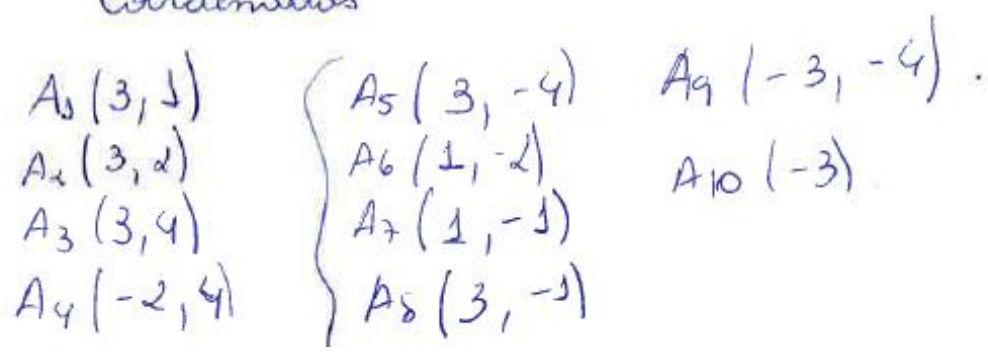

Fonte: Material da experimentação

Observamos apenas dificuldades em apresentar as coordenadas de um ponto sobre o eixo $O x$.

As próximas tarefas foram propostas com o objetivo de levarem os alunos a pensarem em como obter de modo geral as coordenadas do ponto simétrico a outro, em relação a um dos eixos. Para isso foram realizadas duas Tarefas (6 e 7) que trabalhavam com casos particulares e com a observação do referido padrão.

A Dupla não apresentou dificuldades em nenhuma das tarefas. 
Figura 81: Tarefa 6 - Resposta de Dupla

\begin{tabular}{|c|c|c|c|}
\hline Quadrante & Ponto & $\begin{array}{c}\text { Simétrico em relação } \\
\text { ao eixo OX }\end{array}$ & $\begin{array}{c}\text { Simétrico em relação } \\
\text { ao eixo OY }\end{array}$ \\
\hline $1^{\circ}$ & $(6,5)$ & $(6,-5)$ & $(-6,5)$ \\
\hline $2^{\circ}$ & $(-4,2)$ & $(-4,-2)$ & $(4,2)$ \\
\hline $3^{\circ}$ & $(-8,-7)$ & $(-8,7)$ & $(8,-7)$ \\
\hline $4^{\circ}$ & $(1,-4)$ & $(1,4)$ & $(-1,-4)$ \\
\hline
\end{tabular}

Fonte: Material da experimentação

Figura 82: Tarefa 7 - Resposta de Dupla

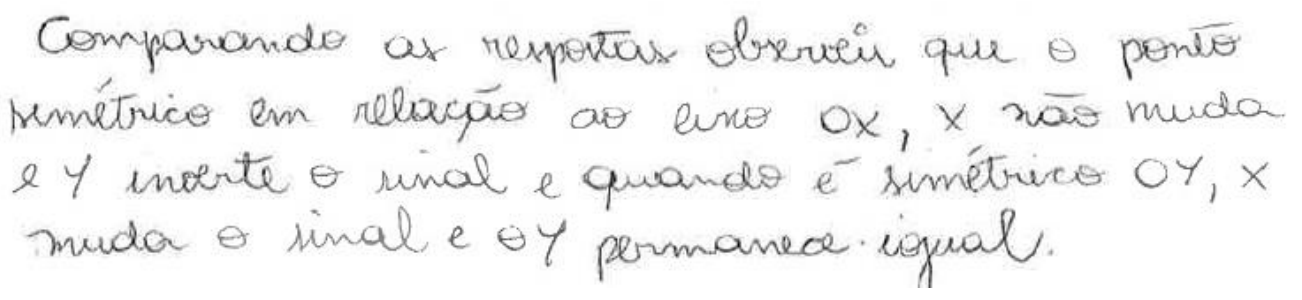

Fonte: Material da experimentação

Analisando as duas tarefas conjuntamente, a dupla conseguiu generalizar e fazer do uso do que Duval (1995) denomina de "língua natural de uso especializado", para expressar suas observações, o que será de grande importância para a próxima tarefa.

A aluna TA, mesmo com uma troca entre as colunas 3 e 4 , ou seja, onde foi indicado o eixo Ox ela considerou eixo Oy e vice-versa, os pontos dos $1^{\circ}$ e $2^{\circ}$ quadrantes, apresentou as coordenadas dos pontos e seus simétrico corretamente, como pode ser visto na Figura 83.

Figura 83: Tarefa 6 - Resposta de TA

\begin{tabular}{|c|c|c|c|}
\hline Quadrante & Ponto & $\begin{array}{c}\text { Simétrico em relação } \\
\text { ao eixo ox }\end{array}$ & $\begin{array}{c}\text { Simétrico em relação } \\
\text { ao eixo OY }\end{array}$ \\
\hline $1^{\circ}$ & $(-5,2)$ & $(-5,-2)$ & $(5,2)$ \\
\hline $2^{0}$ & $(6,2)$ & $(6,-3)$ & $(6,3)$ \\
\hline $3^{0}$ & $(-3,-4)$ & $(-3,4)$ & $(3,4)$ \\
\hline $4^{0}$ & $(10,-2)$ & $(10,2)$ & $(-2,-10)(1-10,-2)$ \\
\hline
\end{tabular}

Fonte: Material da experimentação

Analisando a atividade de conversão entre o registro numérico e o registro da língua natural, não expressou satisfatoriamente o que acontece com as coordenadas 
de dos pontos $P, P^{\prime}$ e $P^{\prime \prime}$. Essa confusão foi a mesma apresentada pelos outros alunos no encontro anterior, então acreditamos que esse tipo de erro é natural nessa fase.

Figura 84: Tarefa 7 - Resposta de TA

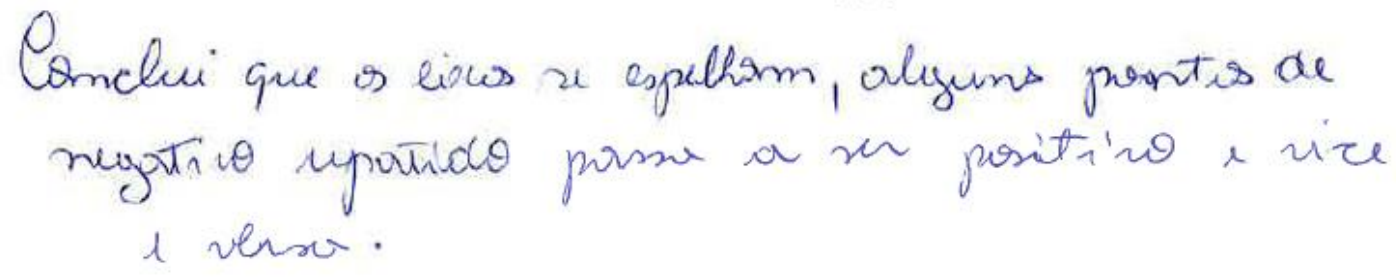

Fonte: Material da experimentação

A mesma troca em relação aos eixos apresentada na resolução da aluna TA ocorreu com o Trio. Mas como nesse caso houve uma discussão entre os integrantes do Trio com essa aluna, no final da atividade, o erro foi observado por eles e, oralmente fizeram a associação correta.

Figura 85: Tarefa 6 - Resposta do Trio

\begin{tabular}{|c|c|c|c|}
\hline Quadrante & Ponto & $\begin{array}{c}\text { Simétrico em relação } \\
\text { ao eixo OX }\end{array}$ & $\begin{array}{c}\text { Simétrico em relação } \\
\text { ao eixo OY }\end{array}$ \\
\hline $1^{\circ}$ & $(4,3)$ & $(-4,3)$ & $(4,-3)$ \\
\hline $2^{\circ}$ & $(-10,6)$ & $(10,6)$ & $(-10,-6)$ \\
\hline $3^{\circ}$ & $(-3,-3)$ & $(3,-3)$ & $(-3,3)$ \\
\hline $4^{\circ}$ & $(7,-5)$ & $(-7,-5)$ & $(7,5)$ \\
\hline
\end{tabular}

Fonte: Material da experimentação

Como consequência, o registro de suas respostas para a Tarefa 7 acabou revelando essa confusão, as respostas da coluna 3 referem-se ao eixo Ou e as da coluna 4 , ao eixo $O x$.

Figura 86: Tarefa 7 - Resposta do Trio

Se o ponto $x$ ustá rosituno ele passa a ver nugativo u se uta unegativo fica porítino tanto no lixo rcomo noy.

Fonte: Material da experimentação 
A resposta do Trio apresenta imprecisão novamente porque referem-se a "ponto", ao invés de "coordenadas" do ponto. Ainda assim, observamos que houve uma evolução significativa no registro língua natural, pois já é apresentada a relação entre as coordenadas e a ideia de números opostos, o que não ocorreu no encontro anterior.

Com base nessas tarefas, objetivamos introduzir o registro algébrico. Com isso, foi pedido aos alunos que representassem, algebricamente, para um ponto genérico $P(x, y)$, as coordenadas do seu ponto simétrico em relação aos eixos, usando as respostas nos itens anteriores.

Verificamos que a Dupla utilizou o registro língua natural para realizar a conversão para o registro simbólico-algébrico.

Figura 87: Tarefa 8 - Resposta da Dupla

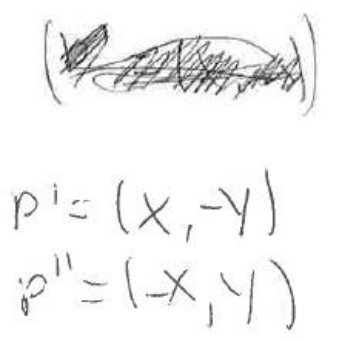

as coordenadon dos pontos D'manteria
a valor de $x$ e mudaria a Mnal do Y no ponto Pi", manteria o valon de $y$ e mudaria o ninal do $X$

10

Fonte: Material da experimentação

Nota-se que a conversão entre os registros da língua natural e algébrico é congruente e foi efetivamente realizado pelos alunos.

No Trio, apenas LA apresentou uma resposta satisfatória, em relação à apresentada na Tarefa 6 , fazendo corretamente uma conversão de representação entre os registros numérico e algébrico.

Figura 88: Tarefa 8 - Resposta de LA

$$
\begin{aligned}
& P=(x, y) \in(-x, y) /(-x, y) \in(x, y) \\
& P^{\prime \prime}=(x, y) \&(x,-y) /(x,-y) \&(x, y)
\end{aligned}
$$


No entanto, destacamos que LA considerou os valores atribuídos às variáveis sempre positivos, já que apresentou dois casos, quando a variável é "positiva" e quando a variável é "negativa". Acreditamos que esse fato ocorreu pelo motivo do aluno considerar que para representar um valor negativo é necessário o uso do sinal " - " e não observou que se pode se atribuir qualquer número real a uma variável.

Os registros dos outros alunos do Trio mostram que eles não compreenderam completamente qual a relação entre as coordenadas dos pontos $P, P^{\prime}$ e $P^{\prime \prime}$, conforme Figura a seguir.

Figura 89: Tarefa 8 - Resposta de LL

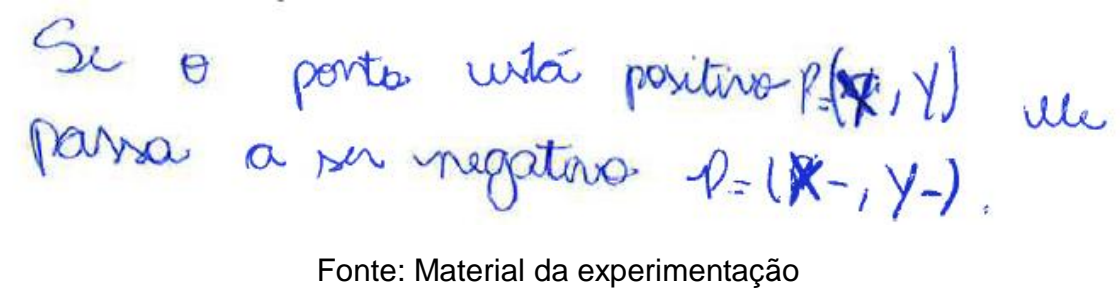

Figura 90: Tarefa 8 - Resposta de AD

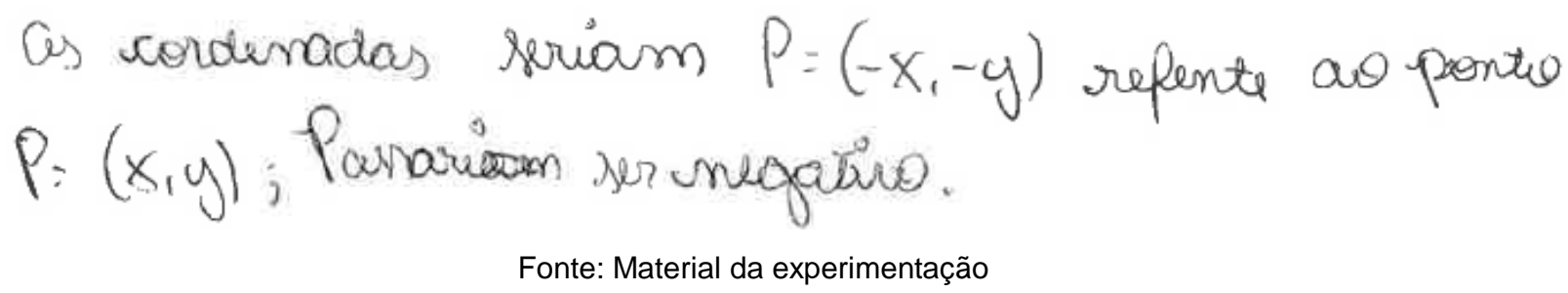

No caso de $A D$ foi verificado, após o encontro, que alguns dos pontos da Tarefa 6 estavam incorretos, o que ocasionou uma dificuldade para encontrar "um padrão" ou relação entre as coordenadas dos pontos $P, P^{\prime}$ e $P^{\prime \prime}$. 
Figura 91: Resposta de AD para Tarefa 6

\begin{tabular}{|c|c|c|c|}
\hline Quadrante & Ponto & $\begin{array}{c}\text { Simétrico em relação } \\
\text { ao eixo OX }\end{array}$ & $\begin{array}{c}\text { Simétrico em relação } \\
\text { ao eixo OY }\end{array}$ \\
\hline $1^{\circ}$ & $(3,2)$ & $(-3,2)$ & $(3,-2)$ \\
\hline $2^{\circ}$ & $(-8,5)$ & $(-8,5)$ & $(-8,-5)$ \\
\hline $3^{0}$ & $(-5,-5)$ & $(-5,-5)$ & $(-5,-5)$ \\
\hline $4^{\circ}$ & $(7,-5)$ & $(4,-5)$ & $(7,5)$ \\
\hline
\end{tabular}

Fonte: Material da experimentação

Após essa observação, retomamos a Tarefa com os alunos AD e LL, com o auxilio do Geogebra para auxiliá-los na verificação das respostas apresentadas por eles.

Através dos casos particulares $A=(3,2)$ e $C=(1,1)$ eles perceberam que os pontos $B$ e $D$ não estavam posicionados onde eles esperavam. No caso ambos apresentaram a generalização das coordenadas do simétrico em relação a origem do sistema de coordenadas.

Figura 92: Verificação da resposta de AD e LL

Arquivo Editar Exibir Opções Ferramentas Janela Ajuda

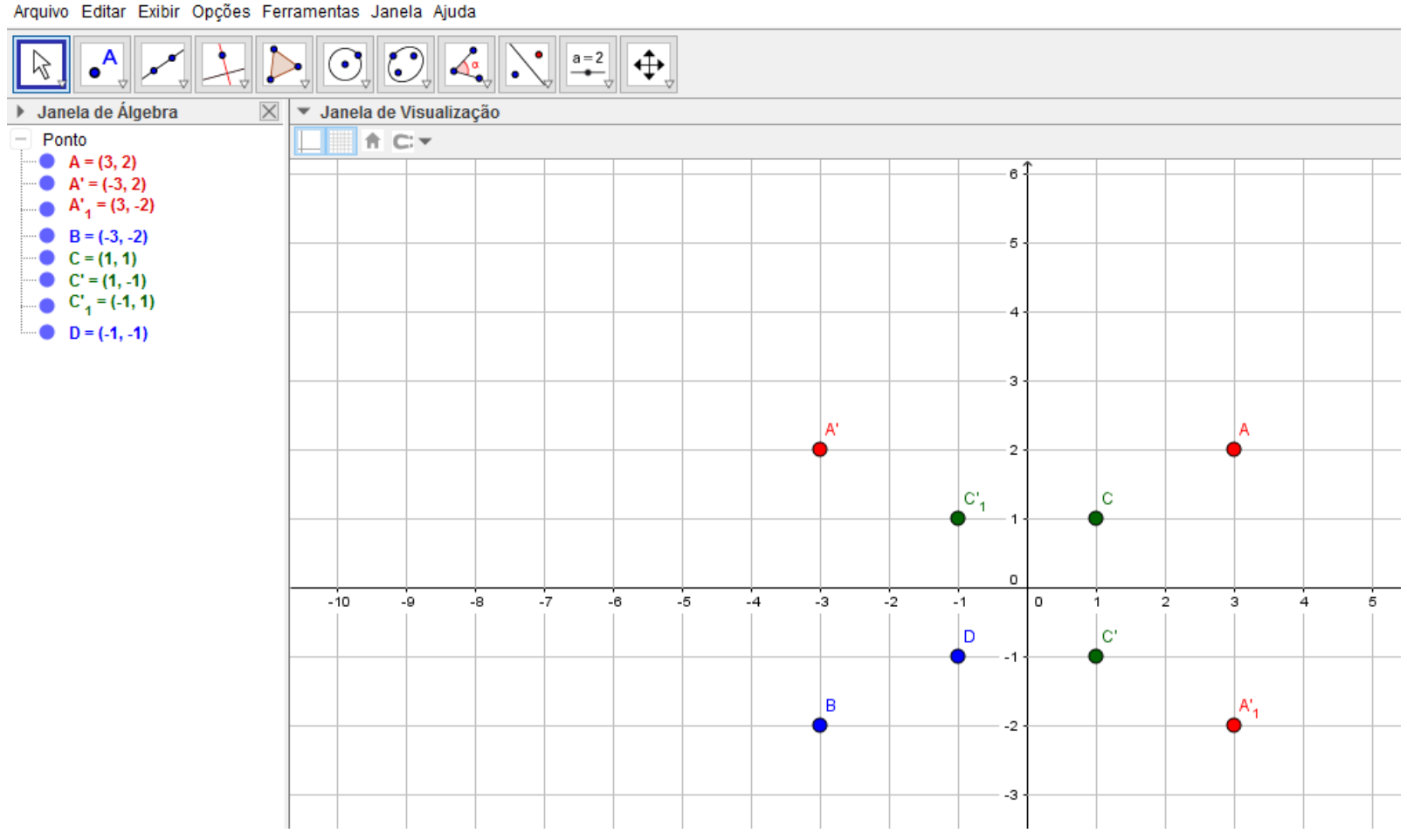

Fonte: Material da experimentação 
Em seguida, apresentamos um ponto qualquer e pedimos para que eles obsevassem 0 que acontecia com as coordenadas dos pontos $P^{\prime}$ e $P^{\prime \prime}$ ao movimentarem o ponto $P$ livremente pela tela.

Figura 93: Casos particulares de simetria nos eixos $O x$ e Oy

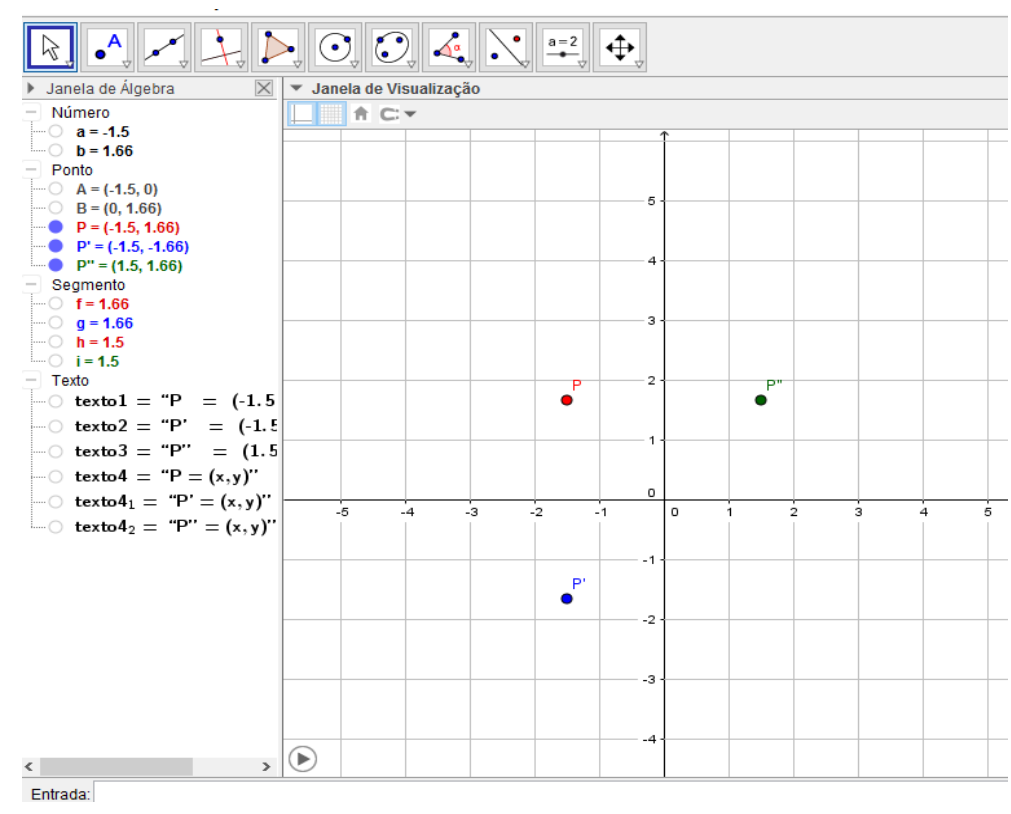

Fonte: Autora

Ao retomar a Tarefa 7, visando apresentarem o ponto $P^{\prime}$ no registro algébrico, tiveram dificuldade. Ao olharem os casos particulares, AD diz "o $x$ fica o mesmo número" em relação ao eixo $O x$, mas demoraram a concluir que portanto, a abscissa vai ser representada pela mesma letra. Após observarem esse fato e como já haviam percebido que a segunda coordenada de $P^{\prime}$ era o oposto, a resposta foi mais rápida e, consequentemente, a resposta para $P^{\prime \prime}$ também.

Figura 94: Tarefa 8 - Resposta corrigida de AD e LL

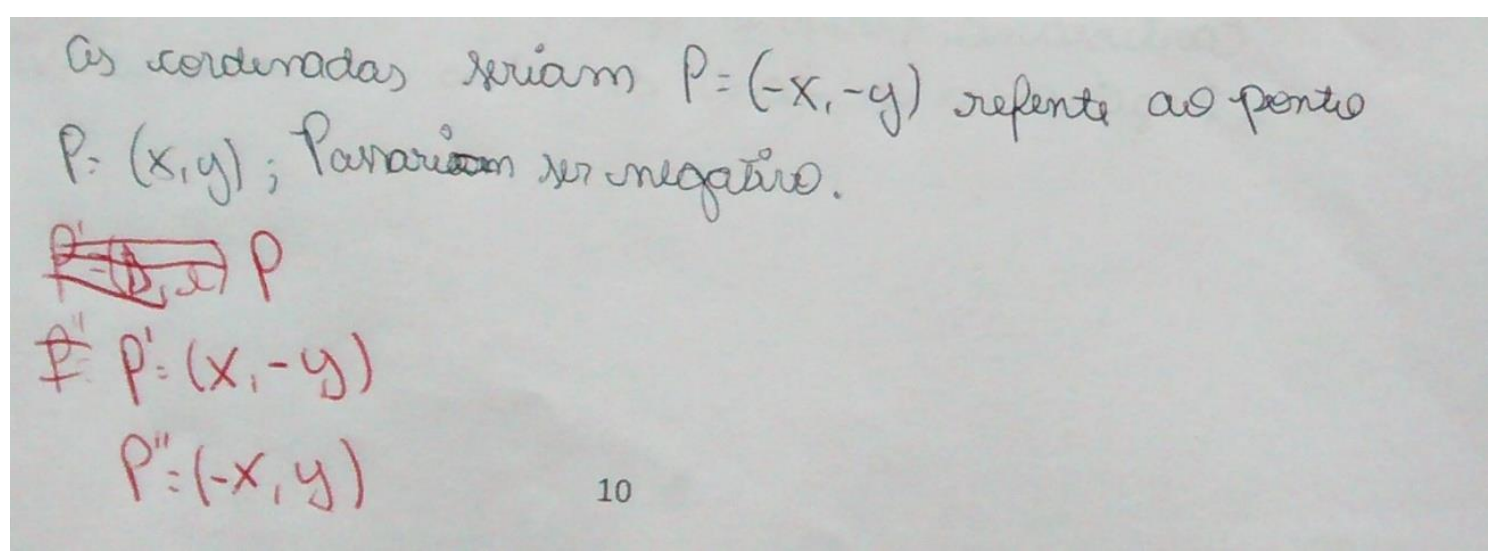


A aluna TA, ao olhar separadamente cada caso de simetria, apresentou uma relação entre as coordenadas $x$ e y e não uma relação entre as coordenadas dos pontos simétricos, como era esperado. Após uma intervenção da professora a aluna observou em seus exemplos da Tarefa 6 o que era esperado e encontrou a resposta para o caso geral $P=(x, y)$.

Figura 95: Tarefa 8 - Resposta de TA

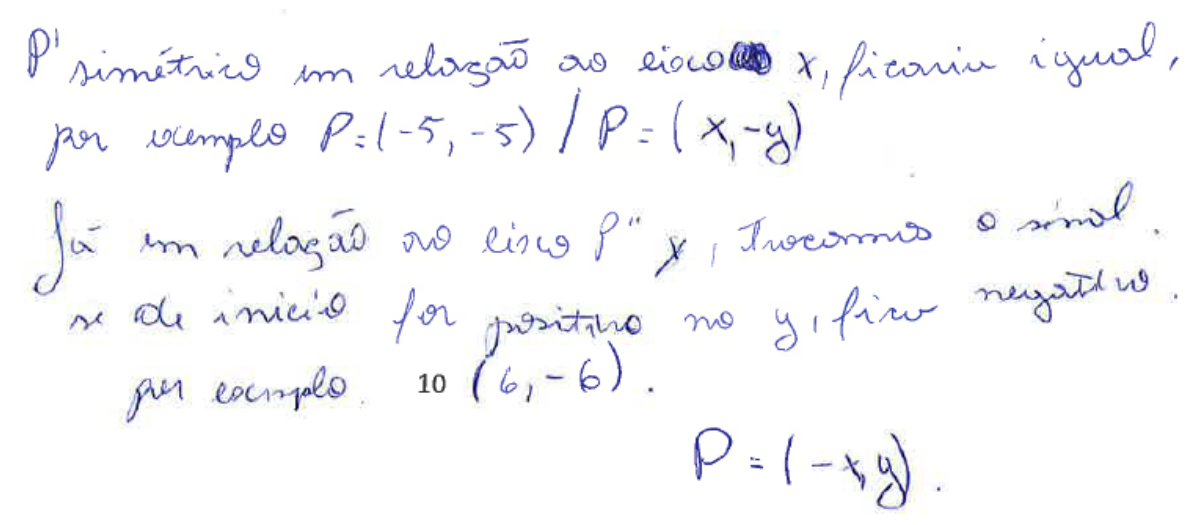

Fonte: Material da experimentação

Nos últimos relatos, as conversões realizadas foram do registro numérico para o registro algébrico e tal conversão pode ser classificada congruente, pelo fato de apresentar uma correspondência semântica dos elementos significantes.

Tabela 7: Análise da congruência na conversão entre os registros numérico e algébrico para pontos

\begin{tabular}{|c|c|c|c|}
\hline & sonto P & $\begin{array}{c}\text { Simétricos em } \\
\text { relação a Ox }\end{array}$ & $\begin{array}{c}\text { Simétrico em } \\
\text { relação a Oy }\end{array}$ \\
\hline $\begin{array}{c}\text { Registro } \\
\text { numérico }\end{array}$ & $(-5,2)$ & $(-5,-2)$ & $(5,2)$ \\
\hline $\begin{array}{c}\text { Registro } \\
\text { algébrico }\end{array}$ & $(x, y)$ & $(x,-y)$ & $(-x, y)$ \\
\hline
\end{tabular}

Fonte: Autora

Neste encontro conseguimos verificar que a conversão entre o registro numérico e o registro algébrico é congruente. Como alguns alunos que realizaram 
essa conversão (alunos do Trio e por TA) apresentaram dificuldades sentimos a necessidade de realizar mais tarefas que trabalhem com a conversão entre esses dois registros.

A conversão entre os registros língua natural e algébrico (realizado pela Dupla) também se mostrou congruente.

\subsubsection{Encontro 5}

O presente encontro teve como objetivo sistematizar o conceito de simetria no plano. Com as tarefas propostas, esperávamos que os alunos observassem as propriedades principais que relacionam dois pontos simétricos (por reflexão em reta) e que se referem ao eixo de simetria ser a mediatriz dos dois pontos, isto é: $P^{\prime}$ é simétrico de $P$ em relação ao eixo $r$ se, e somente, $P^{\prime}$ pertence à reta perpendicular ao eixo $r$ passando por $P$ e $d(P, r)=d\left(P^{\prime}, r\right)$.

Os 6 (seis) alunos estavam presentes e foram organizados da seguinte maneira: Dupla 1 - CA e MA; Dupla 2: AD e LA; e Dupla 3 - LL e TA.

$\mathrm{Na}$ Tarefa 10 os alunos deveriam perceber, por meio de casos particulares que a distância de cada um dos pontos simétricos até o eixo de simetria é sempre a mesma e juntamente com as conclusões da $2^{\text {a }}$ Parte da Atividade 3 , caracterizar a simetria por reflexão em retas.

A tarefa foi realizada sem muitas dificuldades pelas duplas.

Figura 96: Tarefa 10a - Resposta da Dupla 1

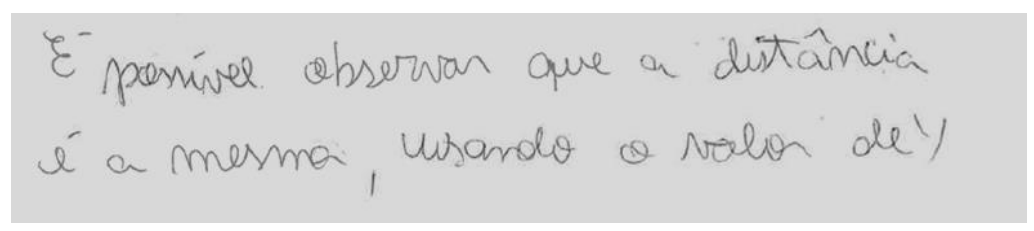

Fonte: Material da experimentação 
Figura 97: Tarefa 10b - Resposta da Dupla 1

As distâncios nāo as mesunes, usando a valon de $x$. Todos as valores nä̀ pastivion pais naì unciste dirtância negetiva

Fonte: Material da experimentação

Figura 98: Tarefa 10a - Resposta da Dupla 2

Que mermo fasendo a reflexĩo dos pontos $(x, y)$ permanucendo o $x$ i mudando o y para unegatiro a distáncio permanece a mesma.

Fonte: Material da experimentação

Figura 99: Tarefa 10b - Resposta da Dupla 2

- unesmo acontec como lito oy porém, of y permanece lo $x$ muda e a dustáncio permaneci a mesma.

Fonte: Material da experimentação

Figura 100: Tarefa 10a - Resposta da Dupla 3

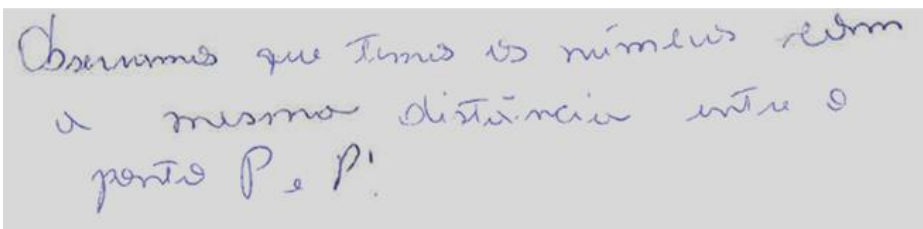

Fonte: Material da experimentação

Figura 101: Tarefa 10b - Resposta da Dupla 3

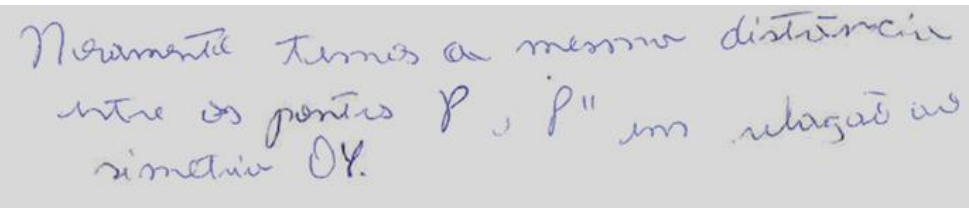

Fonte: Material da experimentação 
Para auxiliar a validação das conjecturas apresentadas pelos alunos, deixamos à disposição um arquivo criado no Geogebra (cf. Figura 102), em que são destacadas as distâncias e os alunos poderiam movimentar o ponto $P$ livremente.

Figura 102: Simetria e distância

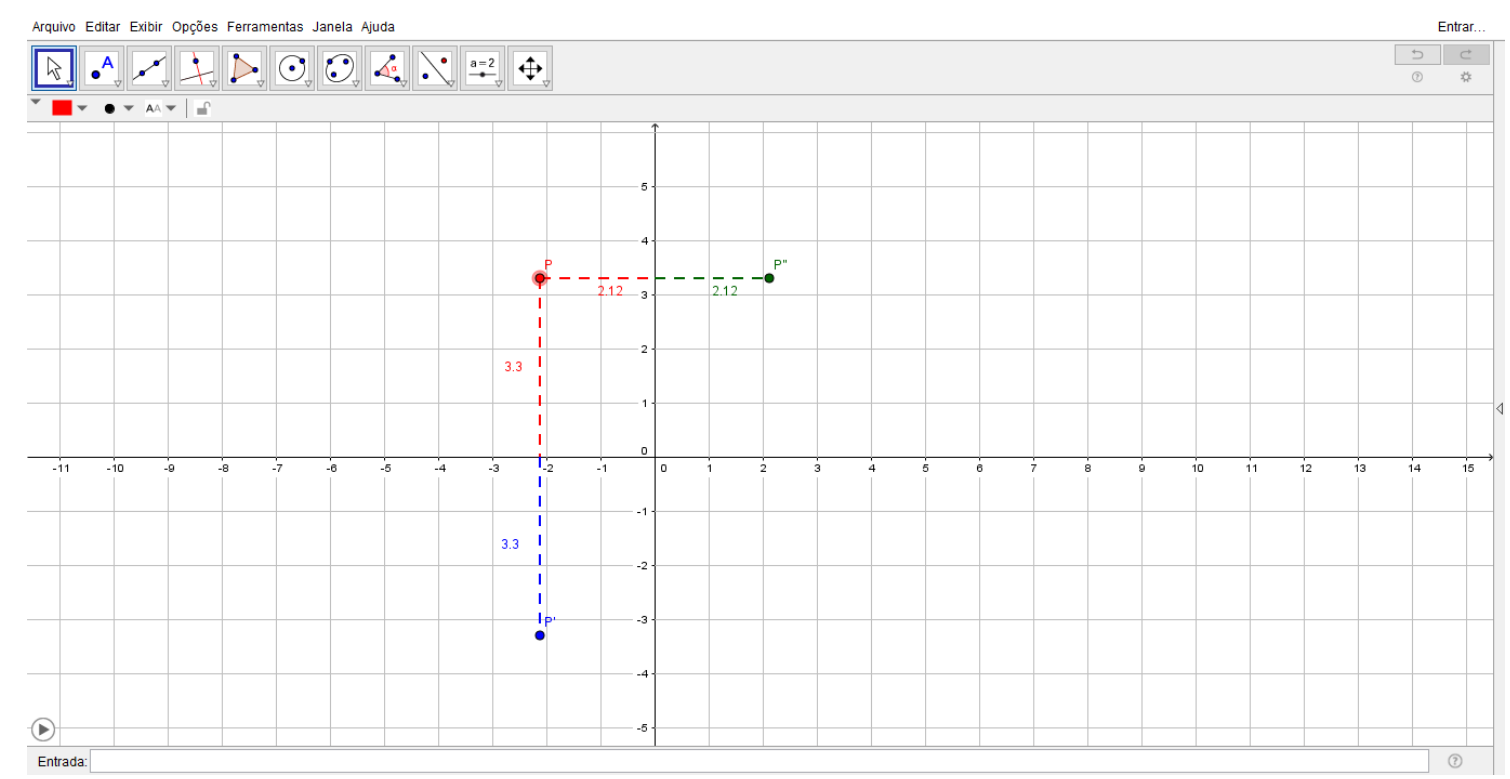

Fonte: A autora

Figura 103: Resposta da Dupla 3

c) Verifique no Geogebra se suas observações valem para mais pontos.

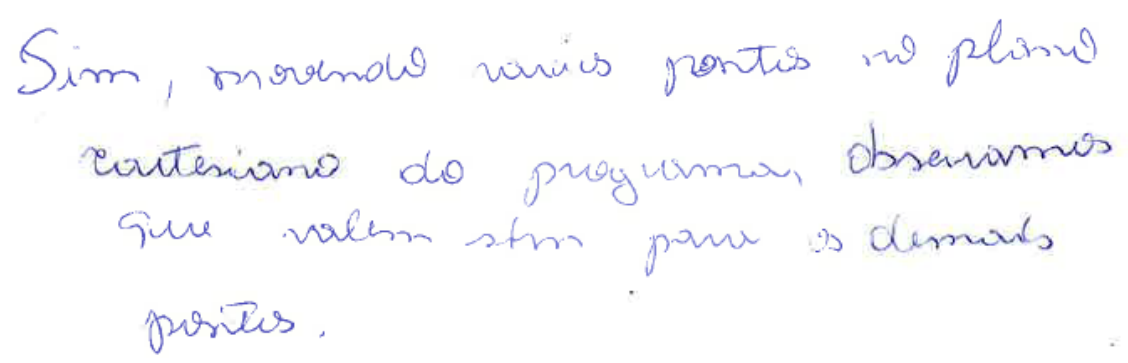

Fonte: Material da experimentação

Como verificamos nos itens anteriores, as duplas observaram e validaram, com a ajuda do Geogebra, que as distâncias em questão eram as mesmas.

Com base no que concluíram na Tarefa 10, propusemos aos alunos que generalizassem o resultado para um ponto $P=(x, y)$ qualquer do plano. Foi desta forma, introduzida a representação algébrica de um ponto genérico $P$. 
Figura 104: Tarefa 11 - Resposta da Dupla 1

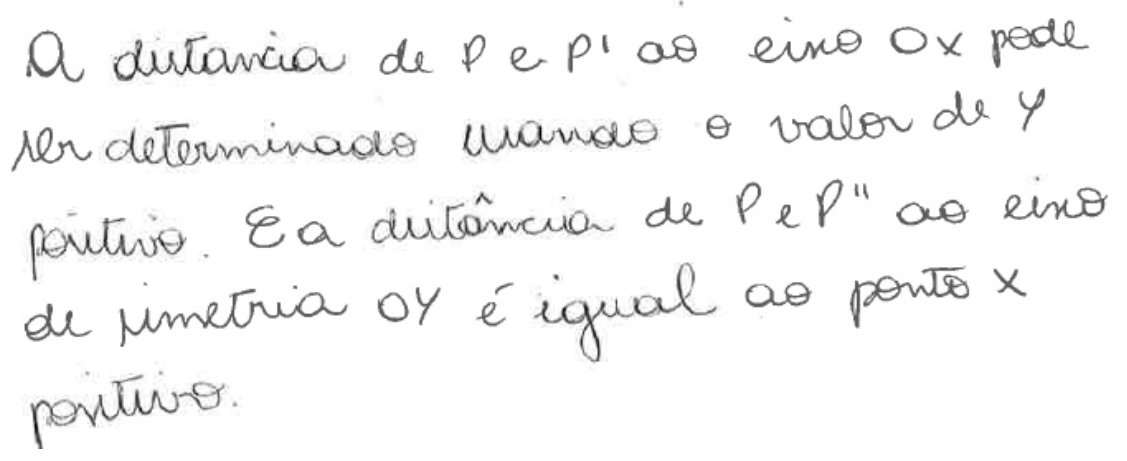

Fonte: Material da experimentação

Figura 105:Tarefa 11 - Resposta da Dupla 2

Com uem ponto $P=(x, y)$ - para pazer a reflexcĩo apenas coloque is y neaptivo e permosnece of Positiro dessa forma determina-se a destâncio.

(1) mesmo acontec ao eixo oy porimo $x$ fico negativo e o y permanece positivo.

Fonte: Material da experimentação

Observa-se que ambas as duplas expressaram suas conclusões em língua natural e a ideia de módulo da coordenada, que é utilizada na distância está presente quando a tomam positiva. A Dupla 3, entretanto, apresentou uma resposta não generalizada, apenas utilizando um exemplo. 


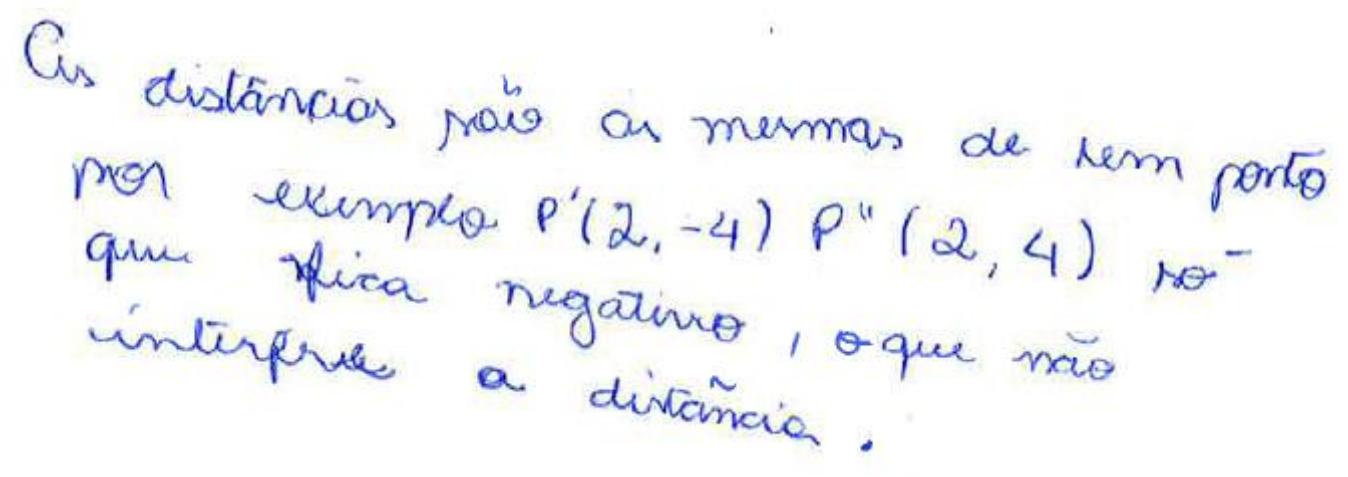

Fonte: Material da experimentação

Para aplicações futuras, pode-se trabalhar a Tarefa em dois itens, um com o registro gráfico, e outro com o registro algébrico.

Nesse encontro observamos que a conversão entre os registros numérico e de língua natural foi congruente. Já a conversão entre o registro língua natural e registro algébrico se mostrou não-congruente, pois para que aconteça é necessário o conhecimento de algumas característica do registro de chegada (no caso representação de módulo no registro algébrico) fazendo com que a conversão não seja espontânea, tanto que nenhuma dupla apresentou a resposta como esperado com representação do ponto simétrico no registro algébrico.

\subsubsection{Encontro 6}

Neste encontro, em função dos resultados descritos anteriormente, retomamos as representações no registro algébrico, visando levar os alunos à generalização dos conceitos e propriedades verificados na Atividade 3 (Parte 1).

Estavam presentes no encontro os alunos $A D, C A$, $L L$ e MA organizados nas seguintes duplas: Dupla 1 - CA e MA e Dupla 2 - AD e LL.

A Tarefa 1 não foi plenamente realizada de acordo com o esperado pelas três duplas, que apresentaram algumas dificuldades nas resoluções de alguns itens que passamos a descrever na sequência. 
A Dupla 1 apresentou dificuldade nos itens (c) e (d) da Tarefa 1, apresentando como resposta um ponto qualquer e, em seguida, relacionando-o a outro ponto de acordo com a "regra" (ou condição) dada, conforme ilustra a figura que segue. Com isso, não houve relação entra as coordenadas de um mesmo ponto, como desejado.

Figura 107: Resposta da Dupla 1

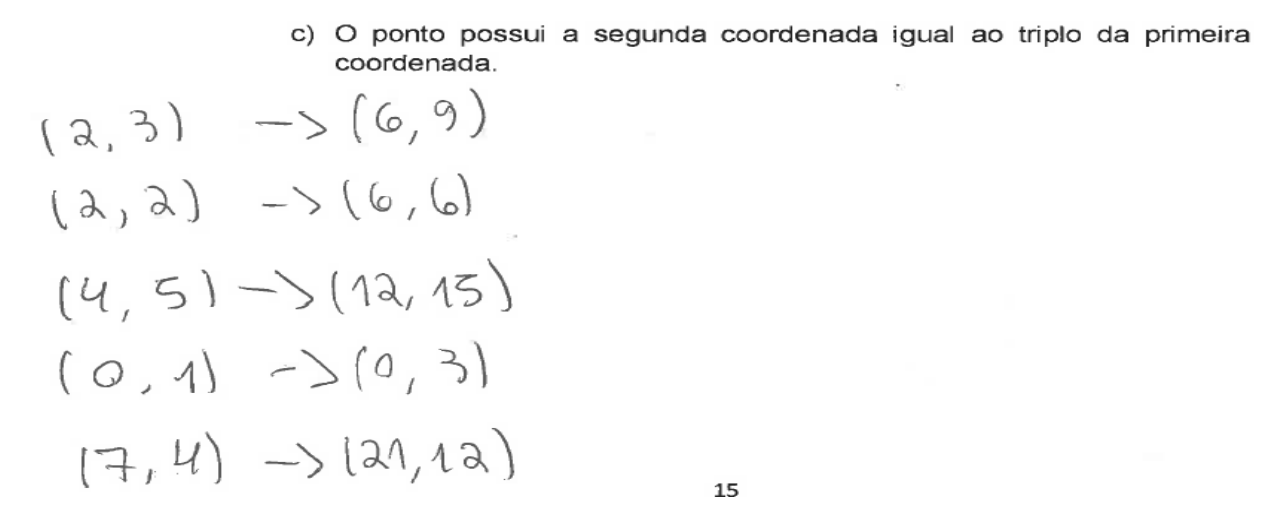

Fonte: Material da experimentação

Figura 108: Resposta da Dupla 1 para o item d

d) O ponto possui em sua primeira coordenada quatro unidades a menos que a segunda coordenada.

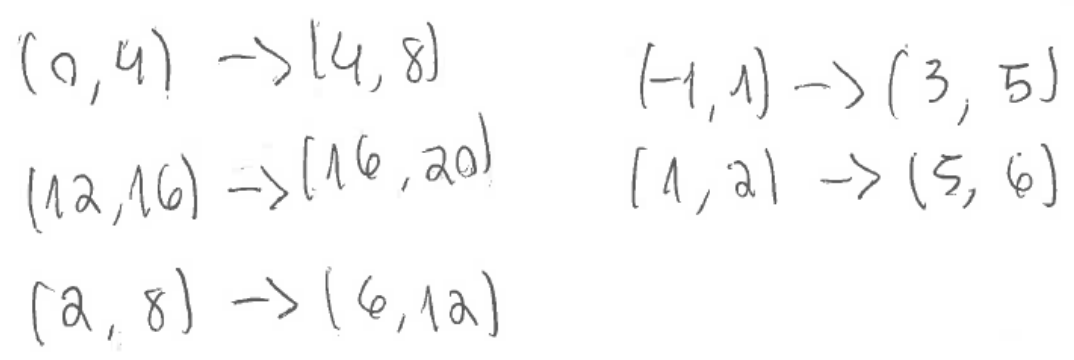

Fonte: Material da experimentação

Em um segundo momento, somente depois de uma intervenção da professora, ressaltando que a resposta esperada era apenas um ponto, a Dupla 1 retomou as questões e refez o exercício de forma correta, mostrando compreensão após a explicação. 
Figura 109: Resposta corrigida da Dupla1

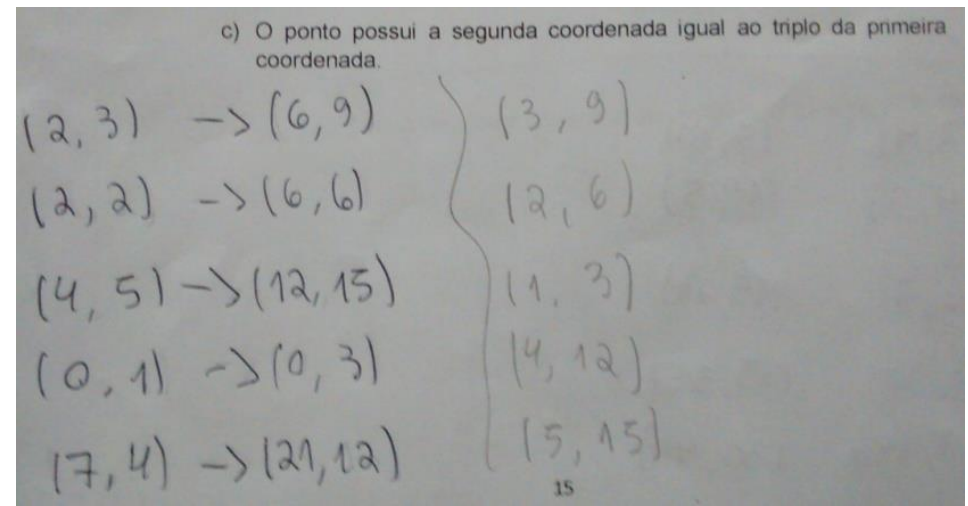

Fonte: Material da experimentação

Figura 110: Resposta corrigida da Dupla 1 para o item d

$$
\begin{aligned}
& (0,4) \rightarrow(4,8) \\
& (-1,1) \rightarrow(3,5) \\
& (12,16) \rightarrow(16,20) \quad[1,2) \rightarrow(5,6) \\
& (2,8) \rightarrow(6,12)
\end{aligned}
$$

Fonte: Material da experimentação

Percebemos aqui que a Dupla 1 teve uma confusão provocada pela má interpretação do enunciado, pois assim que houve a intervenção, as respostas esperadas foram encontradas sem grandes dificuldades. Já os outros itens foram respondidos como o esperado.

Figura 111: Resposta da Dupla 1

a) $O$ ponto pertence ao eixo $O X$

$$
\begin{array}{lll}
(1,0) & (3,0) & (8,0) \\
(-1,0) & (5,0) &
\end{array}
$$

$$
\begin{array}{ll} 
& \text { b) O ponto pertence ao eixo or. } \\
(0,1) & (0,6) \quad(0,2) \\
(0,4) & (0,9)
\end{array}
$$


Já a Dupla 2 apresentou dificuldade iniciais nos itens (a) e (b). No item (a), por exemplo, o primeiro ponto apresentado não pertencia a nenhum dos dois eixos. Novamente a professora fez uma intervenção, solicitando aos alunos que representassem o ponto indicado no plano cartesiano (registro gráfico), e ao fazer isso, a Dupla constatou que o referido ponto não pertencia aos eixos. Invalidaram essa resposta e perceberam que para o ponto estar sobre um dos eixos, uma de suas coordenadas deve ser nula. Com isso, apresentaram todas as respostas corretas á questão.

Figura 112: Resposta da Dupla 2

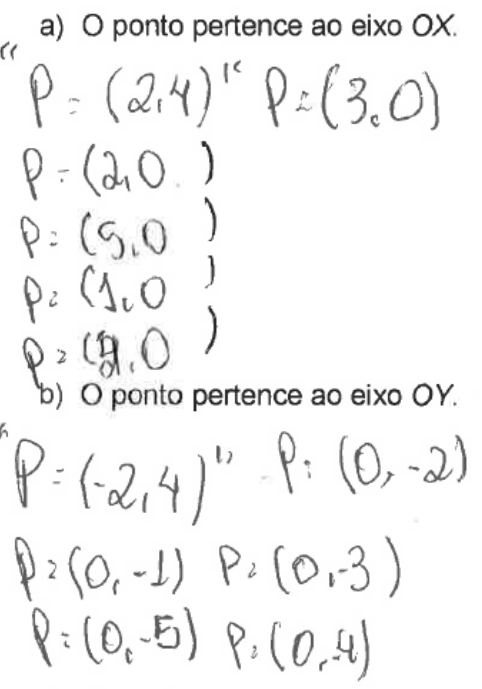

Fonte: Material da experimentação

Aqui temos uma consideração a ser feita sobre a ideia de ponto sobre um eixo, que ainda não estava clara para a Dupla 2. Os mesmos alunos trabalharam juntos no Encontro 2 e apresentaram a mesma dificuldade na Tarefa 2 realizada nesse encontro. Os alunos só conseguem compreender como são as coordenadas de pontos sobre os eixos quando são apresentados no registro gráfico. O registro numérico, para esses alunos, não se mostrou como o mais adequado para expressar essa propriedade dos pontos dos eixos.

Os outros itens foram respondidos sem dificuldades pela Dupla 2. 


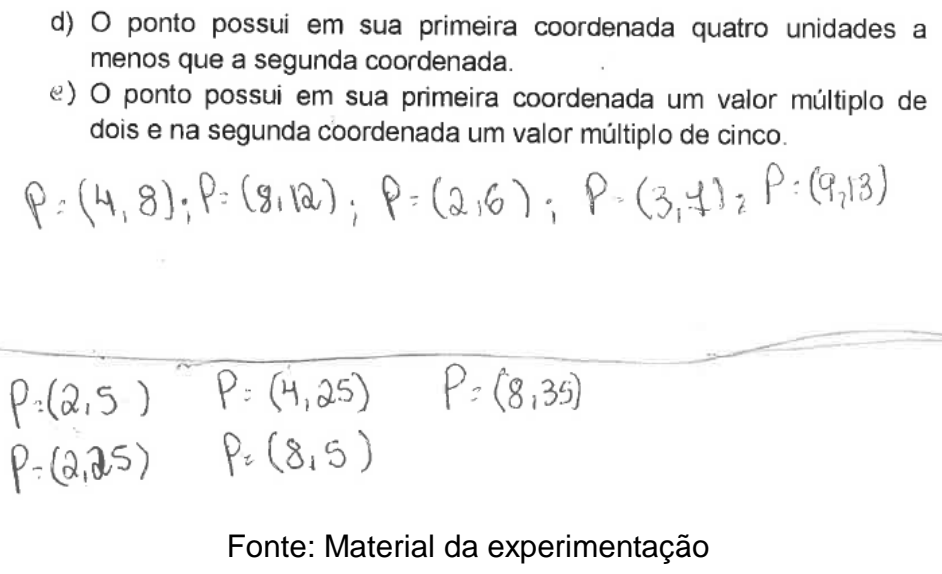

Nas conversões os registros da língua natural e numérico, alguns itens foram por nós considerados como congruentes, e outros não. Nesses casos, confirmou-se a dificuldade dos alunos.

Analisando as respostas dos itens (a) e (b), consideramos que a conversão não foi congruente, pois a Dupla 2, só compreendeu e resolveu esses itens, após realizarem primeiro a conversão para o registro gráfico.

Os itens (c), (d) e (e), consideramos que a conversão foi congruente, pois observamos uma correspondência entre as unidades significantes de ambos os registros.

Na Tarefa 2, os alunos deveriam representar suas conclusões da Tarefa 1 no registro simbólico-algébrico, por meio da generalização do padrão e/ou propriedade observada nos exemplos. Era esperada uma dificuldade por parte dos alunos para os pontos dos itens (c) e (d), devido à indicarem relações entre as coordenadas de um mesmo ponto.

A Dupla 1 apresentou respostas incorretas para os itens (c), (d) e (e), mas devido a confusão apresentada na Tarefa 1. Após as intervenções e retomadas, a Dupla não apresentou problemas em realizar a conversão do registro numérico (exemplos da Tarefa 1) para o registro simbólico-algébrico. 
Figura 114: Resposta da Dupla 1

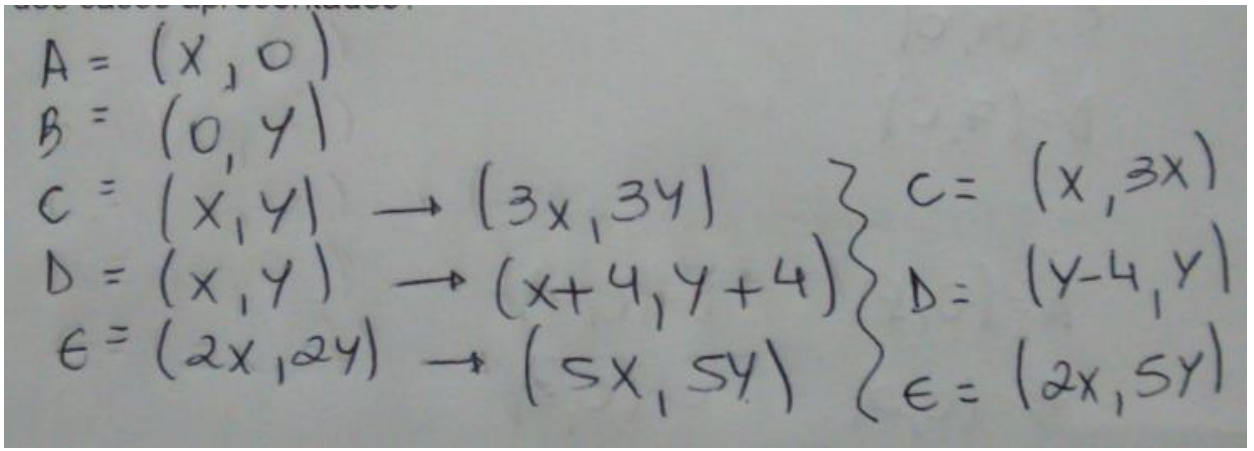

Fonte: Material da experimentação

A Dupla 2 não encontrou dificuldades em compreender a proposta da tarefa, mas apresentou incorreções nos itens (c) e (d).

Figura 115: Resposta da Dupla 2

a) $P(x, 0)=0$ y sempere sera O zerocaso

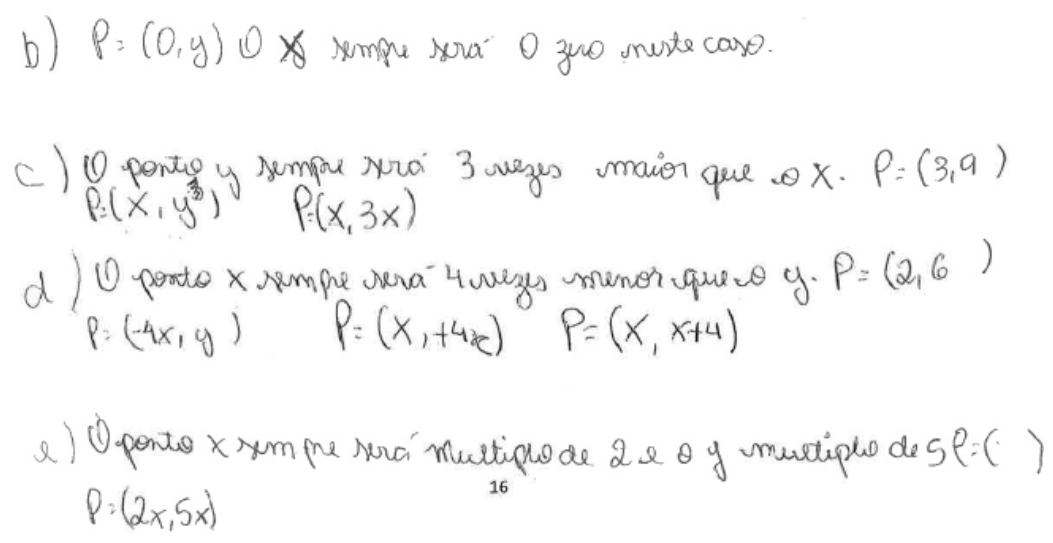

Fonte: Material da experimentação

Como já era esperado, apesar de compreenderem a relação entre as coordenadas nos itens (c) e (d), não conseguiram fazer a conversão da língua natural para o registro simbólico-algébrico de maneira satisfatória. 
Nota-se uma confusão entre as operações, onde trocam "triplo" (multiplicar por 3) por potenciação (elevar ao cubo) e "quatro unidades a menos" (subtrair 4) por "4 vezes menor" (multiplicar por -4). Além disso, não relacionam as coordenadas.

Apenas após a professora explicar as diferenças entre as operações citadas anteriormente, os alunos compreenderam que existia uma relação entre as coordenadas também na forma geral do ponto.

As conversões realizadas nesta atividade são congruentes, tanto do registro língua natural para o simbólico-algébrico, quanto do registro numérico para o registro algébrico. Em ambos os casos, os alunos conseguiram encontrar, sem dificuldade, as correspondências entre as unidades significativas entre os registros.

O encontro atingiu quase todos os seus objetivos. Nos casos onde as coordenadas apresentam uma relação entre si, os alunos mostraram dificuldades (a Dupla 1 em apresentar os exemplos e a Dupla 2 na hora de generalizar).

Aqui vemos que os alunos podem apresentar dificuldades de interpretar equações de objetos geométricos por não compreender a relação entre as coordenadas de pontos pertencentes ao objeto de estudo.

\subsubsection{Encontro 7}

Estavam presentes no encontro os alunos $A D, C A, L L, L A, M A$ e TA organizados em dois trios: Trio 1 - AD, LL e LA e Trio 2 - CA, MA e TA.

O objetivo do encontro era que os alunos "construíssem" um "modelo" do sistema de coordenadas no espaço com materiais concretos para auxiliar na compreensão e visualização dos objetos estudados por nós.

Existem também diferenças da potencialidade entre $M D^{10}$ manipulável e sua representação gráfica, porque, apesar de todas as contribuições da perspectiva, ela não retrata reais dimensões e posições dos lados e faces dos objetos, uma vez que ela camufla o perpendicularismo e o paralelismo laterais. Talvez a melhor das potencialidades do MD seja revelada no momento de construção do

\footnotetext{
${ }^{10}$ Material Didático
} 
MD pelos próprios alunos, pois é durante esta que surgem imprevistos e desafios, os quais conduzem os alunos a fazerem conjecturas e a descobrir caminhos e soluções. (LORENZATO, 2006, p.27-28)

Para a construção uma representação do sistema de coordenadas do espaço os alunos tiveram a sua disposição materiais, tais como palitos, canudos, barbantes e papeis. Para os observarem e trios tirarem suas dúvidas uma representação no Geogebra para que pudessem manipular (cf. Figura 116).

Figura 116: Sistema de coordenadas do espaço no Geogebra

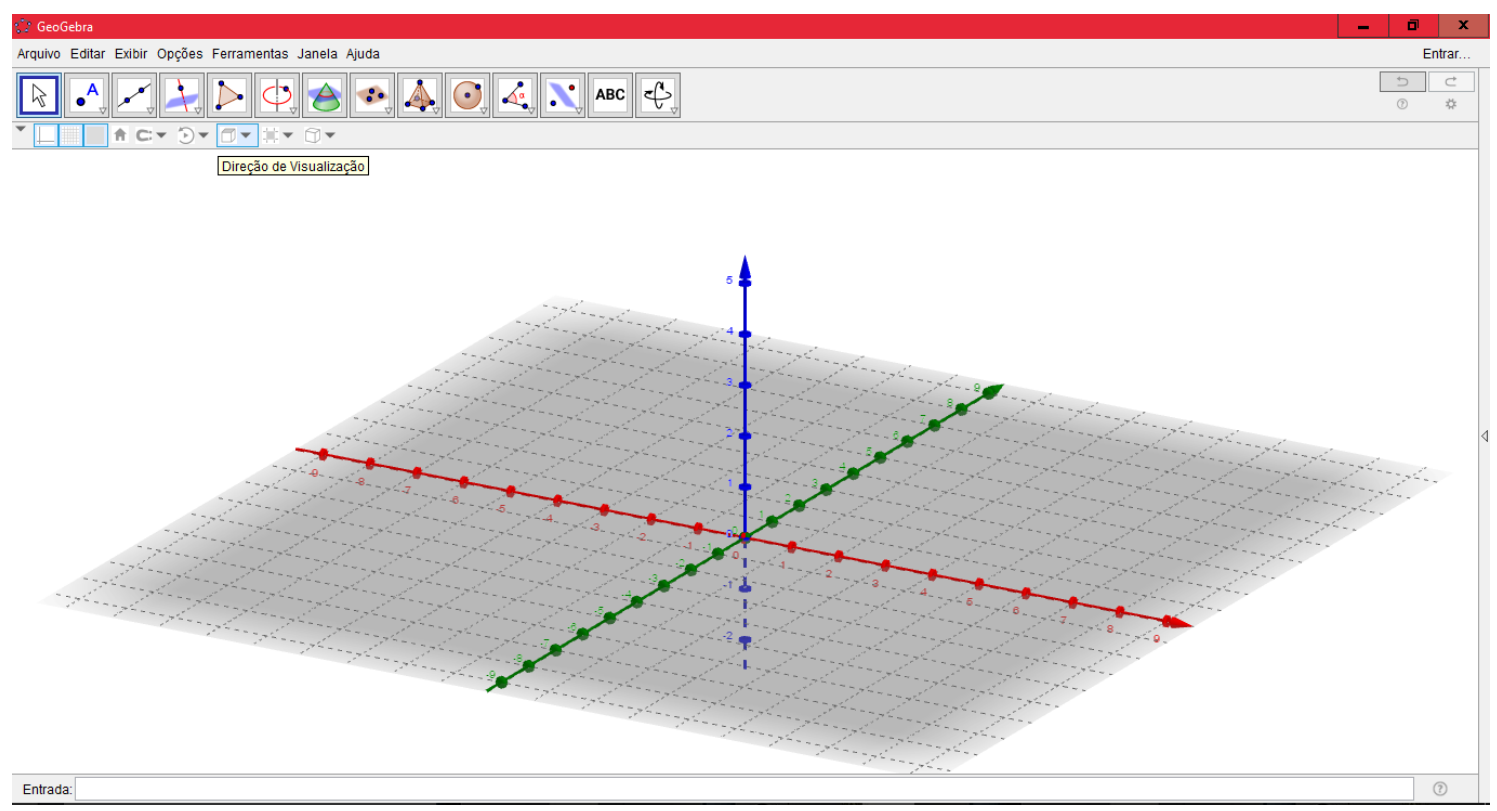

Fonte: A autora

O Trio 1 utilizou papel sulfite, palitos de churrasco e arames. No caso, os alunos reproduziram o plano $O X Y$ no papel quadriculado e um palito de churrasco para representar o eixo OZ, como ilustra a Figura 117. Os palitos nos extremos do papel quadriculado, foram utilizados apenas para a construção ficar mais estável. 
Figura 117: Modelo construído pelo Trio 1

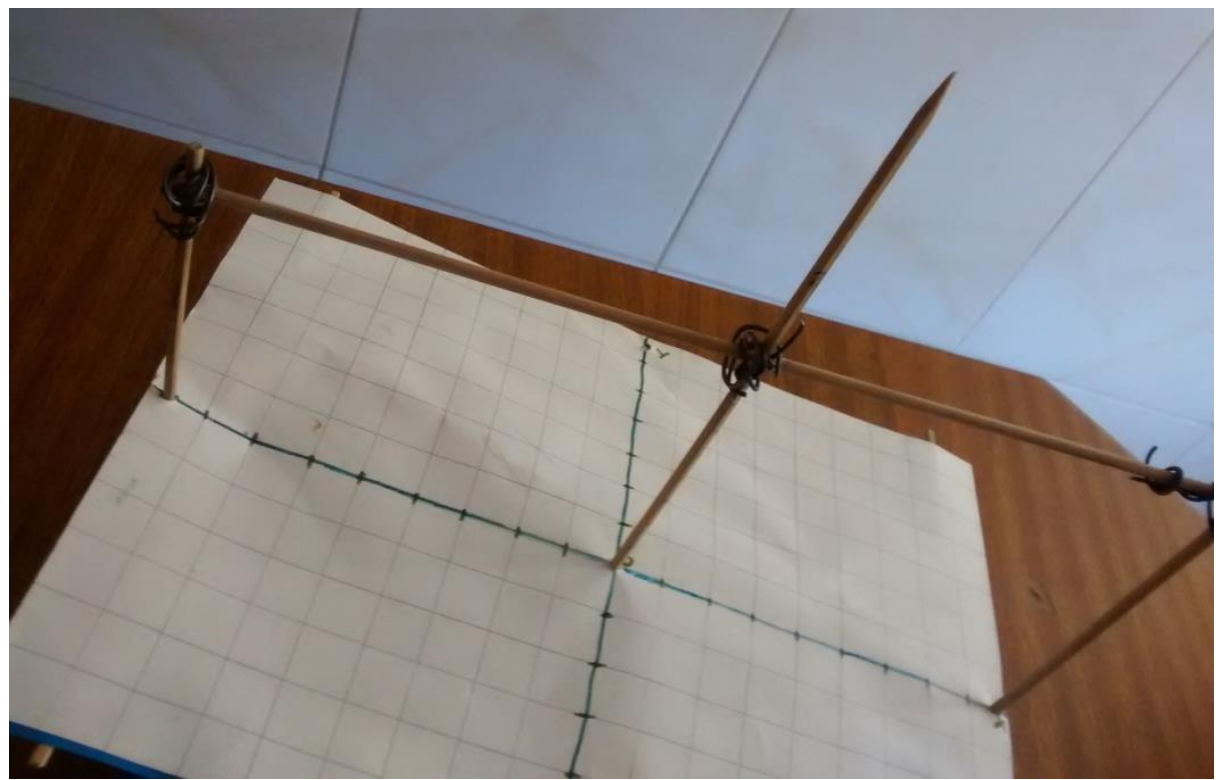

Fonte: Material da experimentação

O Trio 2, para construir seu "modelo" utilizou palitos de churrasco e barbante, indicando escalas nos palitos que representava os eixos (cf. Figura 118).

Com isso, os planos coordenados (em particular o plano Oxy que aparece no Geogebra) não ficam evidentes nessa representação. 
Figura 118: Modelo construído pelo Trio 2

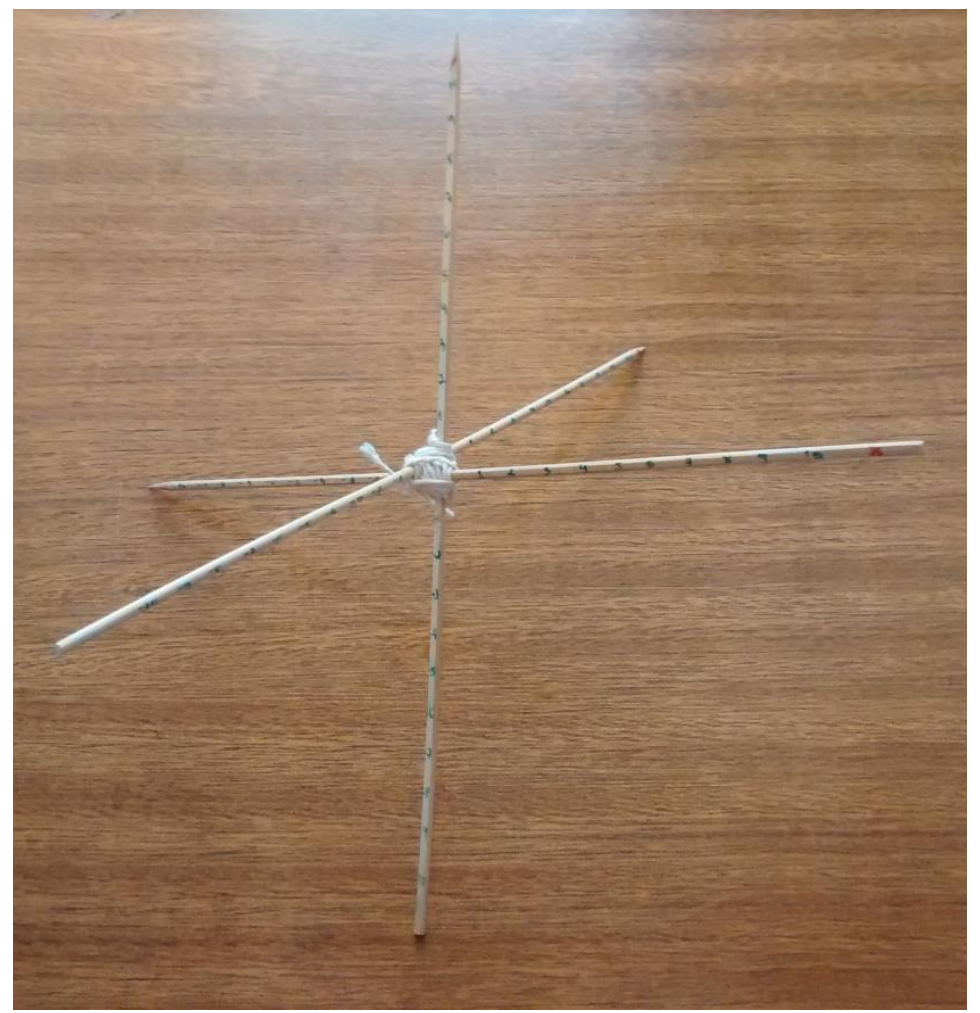

Fonte: Material da experimentação

Ao realizar a construção do modelo o trio orientou o eixo $O z$ no sentido oposto do convencional, que geralmente aparecem nos livros ou aquele apresentado no arquivo do Geogebra.

Figura 119: Sistema de eixos no modelo da Dupla 2 e Sistemas de eixo convencional
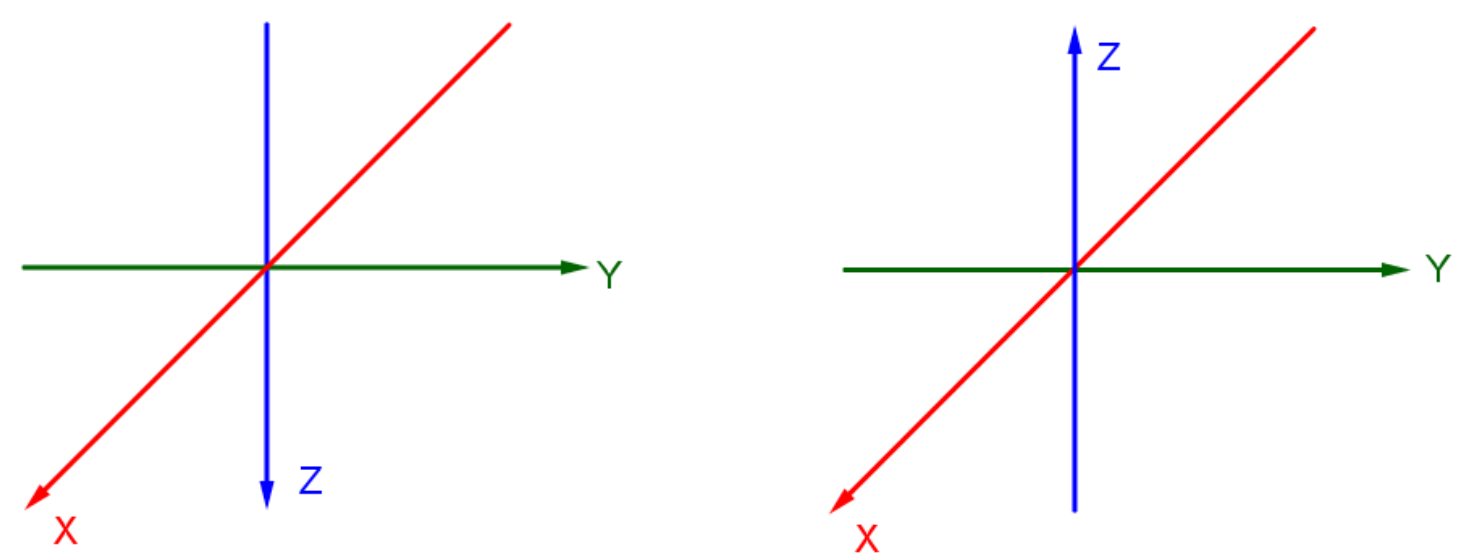
No modelo apresentado pelo Trio 1, destaca-se o plano Oxy e o eixo Oz como sendo perpendicular à esse plano. Acreditamos que essa ideia apresentada pelo grupo seja uma consequência das atividades realizadas nos Encontros 1 e 2, onde falamos de coordenadas cartesianas no plano e coordenadas cartesianas no espaço.

O modelo feito pelo Trio 2 não evidencia nenhum dos três planos, destacando apenas os eixos, as escalas e sua ortogonalidade, intenção explicitada pelo grupo no momento da construção.

Com isso, consideramos que ambos os trios atingiram o objetivo da atividade, pois durante a construção dos modelos foi observado pelo professor, que os alunos revisaram as principais características do sistema de coordenadas cartesianas no espaço.

\subsubsection{Encontros 8 e 9}

Os encontros foram realizados com todos os 6 (seis) alunos participantes do experimento, divididos da seguinte forma: Dupla1 - CA e MA; Dupla 2 - LL e LA e Dupla 3 - AD e TA.

As tarefas propostas apresentavam tiveram como objetivo trabalhar a representação de pontos no espaço dando ênfase na conversão entre os registros numérico e gráfico.

Para a realização das tarefas cada dupla teve a sua disposição um computador com o software Geogebra para devidas verificações e validações de suas respostas.

Com as Tarefa 1 e Tarefa 2 queríamos verificar como os alunos realizavam a conversão entre as representações de um ponto nos registros numérico e no gráfico 
e levando em consideração que a representação gráfica foi apresentada no papel e lápis.

A Dupla 1 teve dificuldade em reproduzir o sistema de coordenadas no espaço, trocando os eixos $\mathrm{Oz}$ e $\mathrm{Oy}$. A confusão foi gerada pelo fato da representação do plano $O x y$ "o eixo $O x$ ser na horizontal e o eixo $O y$ ser representado na vertical" observação feita por CA.

Figura 120: Primeira tentativa apresentada pela Dupla 1

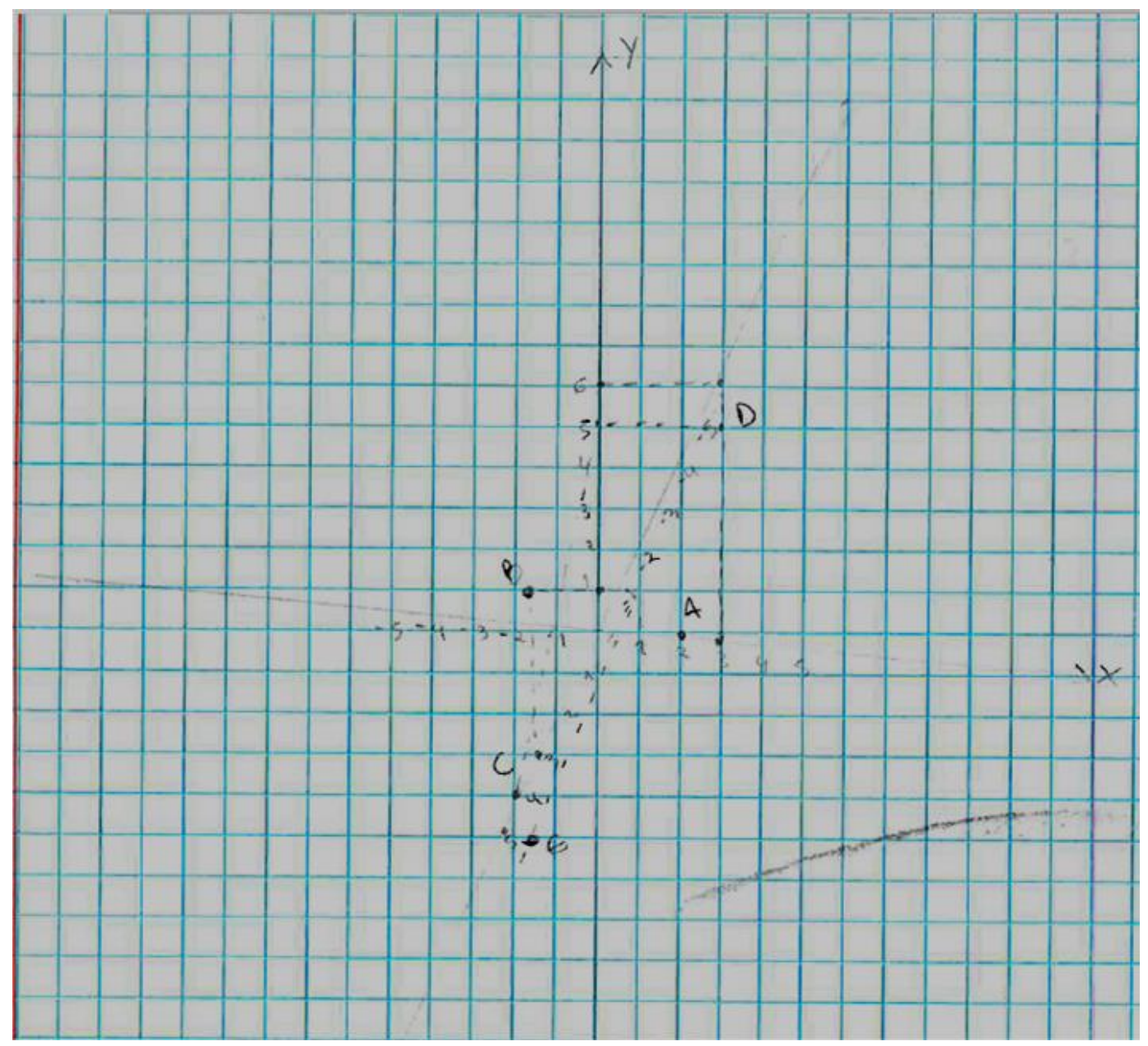

Fonte: Material da experimentação

O erro foi percebido pela professora quando solicitada pela dupla, pois verificaram que suas representações não coincidiam com as apresentadas pelo software. Nesse momento, após discussão, os alunos refizeram com as posições dos eixos convencionais. 
Figura 121: Segunda tentativa apresentada pela Dupla 1

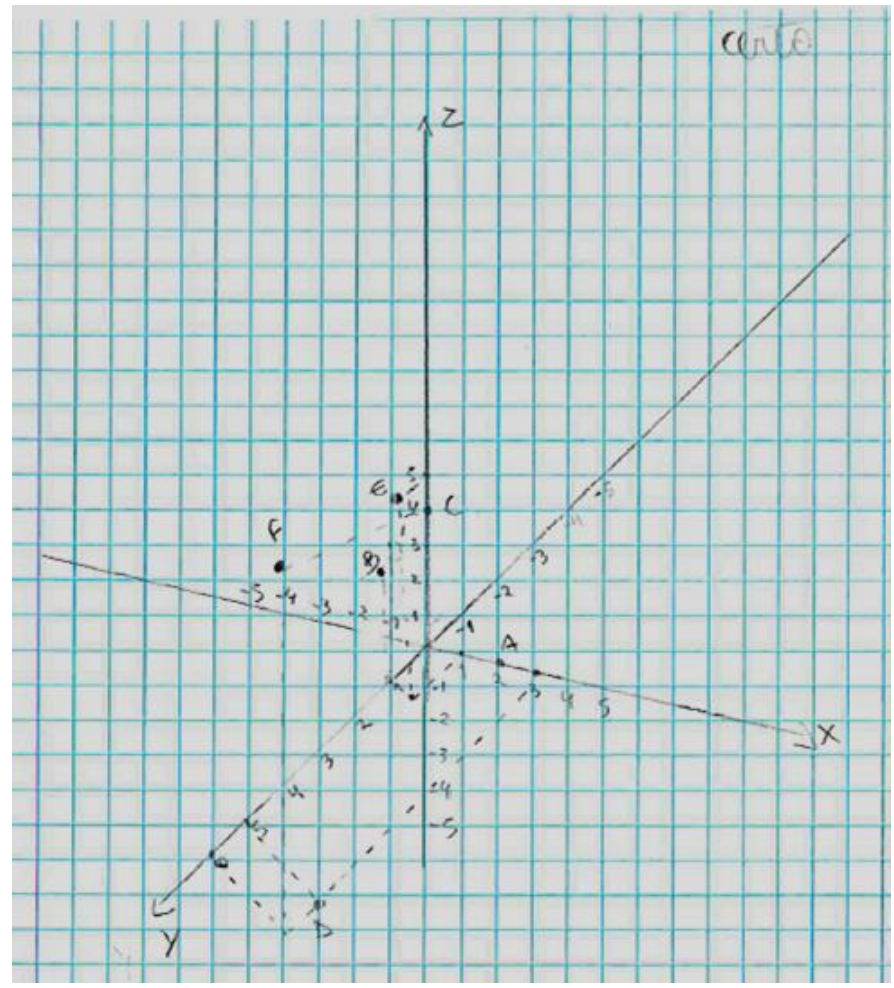

Fonte: Material da experimentação

As duplas 2 e 3 encontraram dificuldades na visualização, a conversão foi realizada de forma satisfatória, porém no momento de representarem, notamos uma dificuldade com as projeções dos pontos. Alem disso, a Dupla 2 só apresentou satisfatoriamente pontos sobre eixos e a Dupla 3 trocou os eixos $O x$ e $O y$. 
Figura 122: Representação apresentada pela Dupla 2

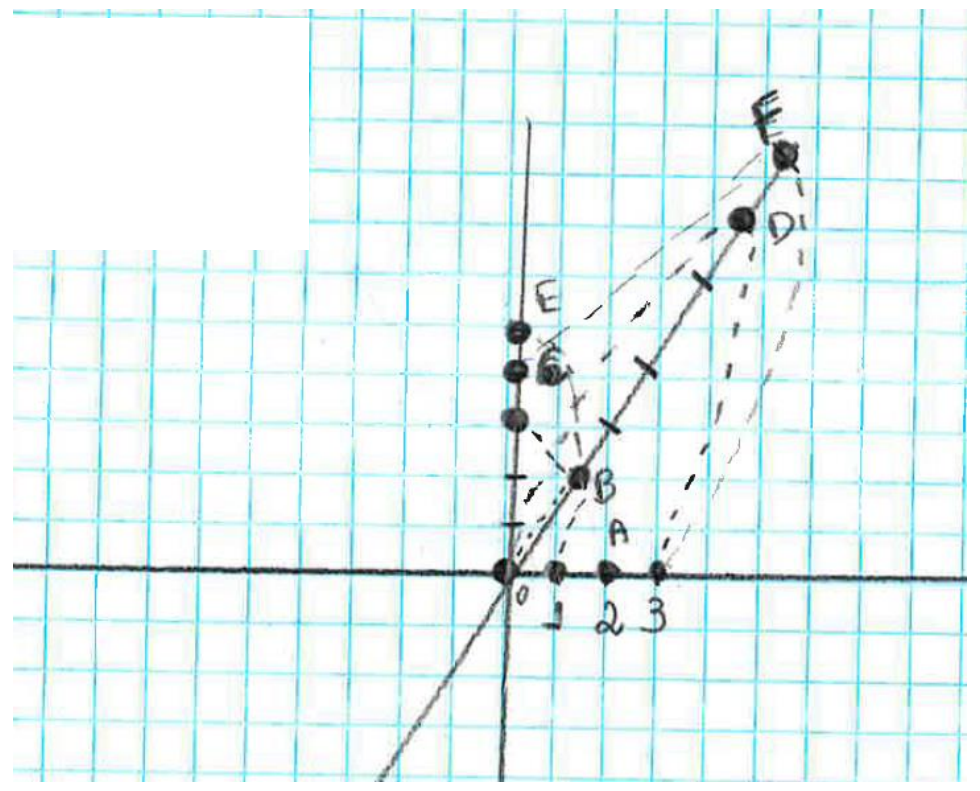

Fonte: Material da experimentação

Figura 123: Representação apresentada pela Dupla 3

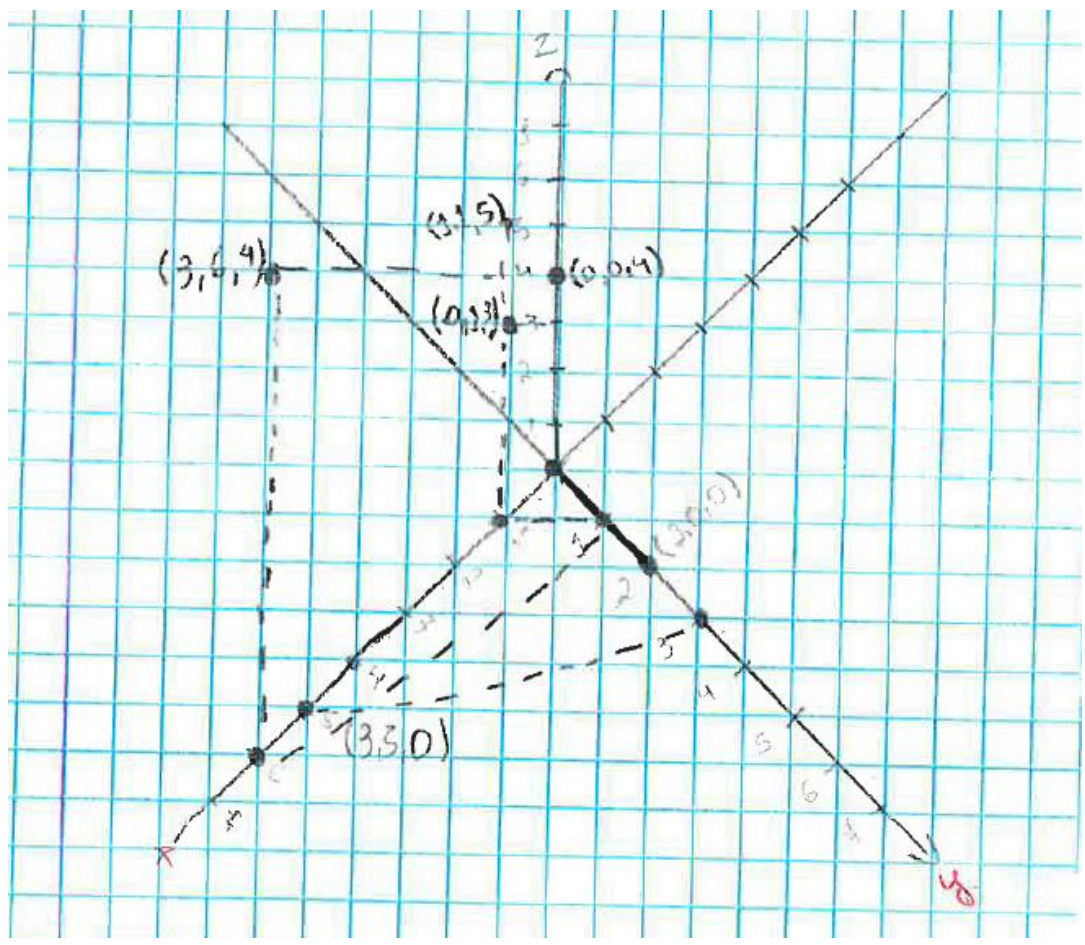

Fonte: Material da experimentação 
Também observamos a representação do sistema de coordenadas no espaço que é tridimensional em um ambiente bidimensional (papel). Como era de se esperar, os alunos apresentaram dificuldades quanto as projeções dos pontos.

Notamos que para os pontos que não pertencem aos eixos ( $B, D, E$ e $F)$ as Dupla 2 e Dupla 3 não apresentaram suas projeções corretamente, ou seja, não usaram as paralelas aos eixos.

Verificada essa dificuldade a professora apresentou um arquivo que mostra as projeções de um ponto qualquer (Figura 124), chamando a atenção para as coordenadas das projeções de cada ponto nos planos coordenados e o que ocorre nas coordenadas ao se movimentar o ponto como elas se movimentam na paralela em relação ao seu eixo.

Figura 124: Representação do sistema de coordenadas do espaço na Janela 2D do Geogebra

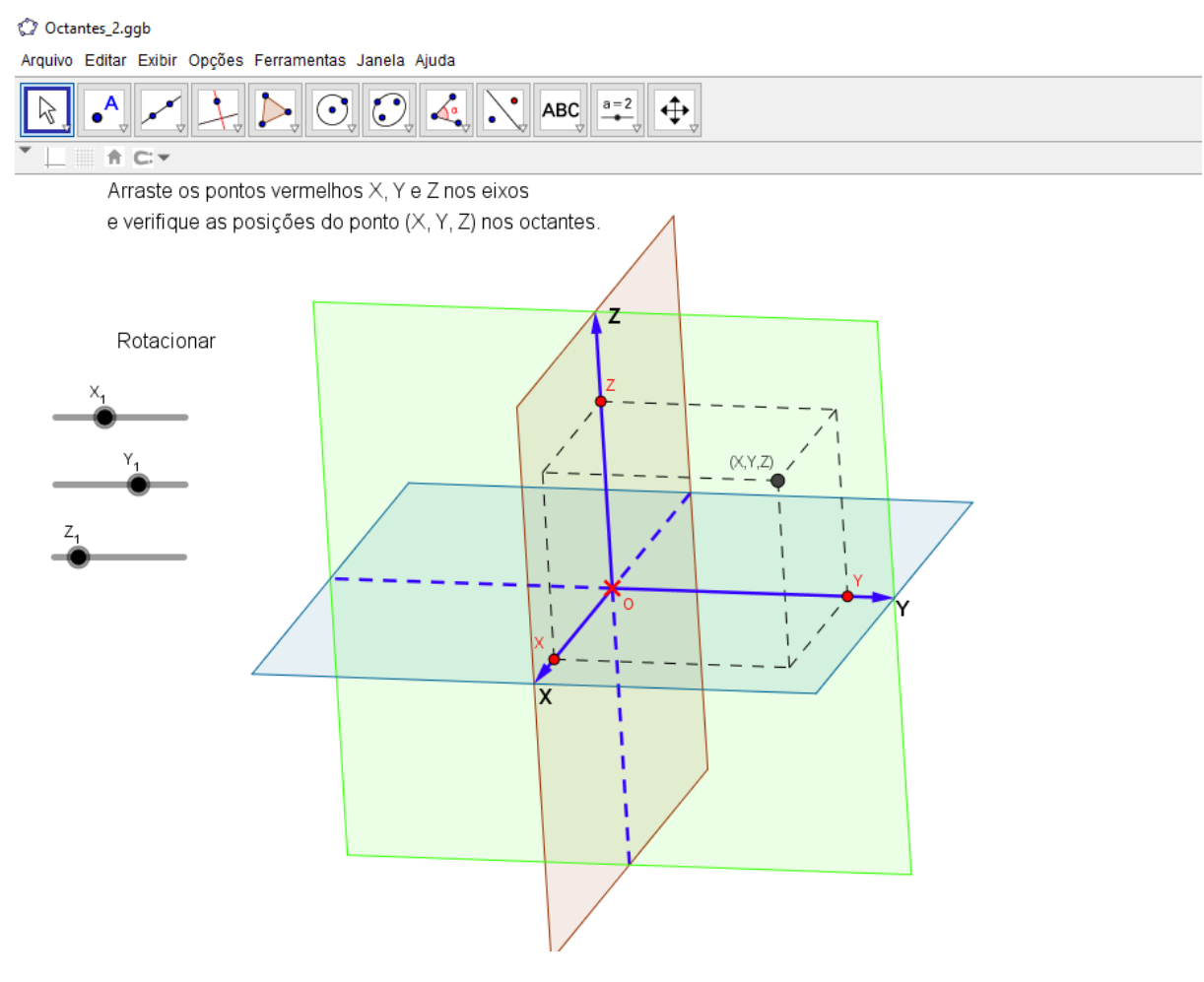

Fonte: A autora

Em seguida, a professora apresentou como exemplo o ponto $(2,4,3)$ com um passo a passo de como encontrá-lo, de forma interativa com os alunos. 
Figura 125: Passo a passo para o ponto $(2,4,3)$

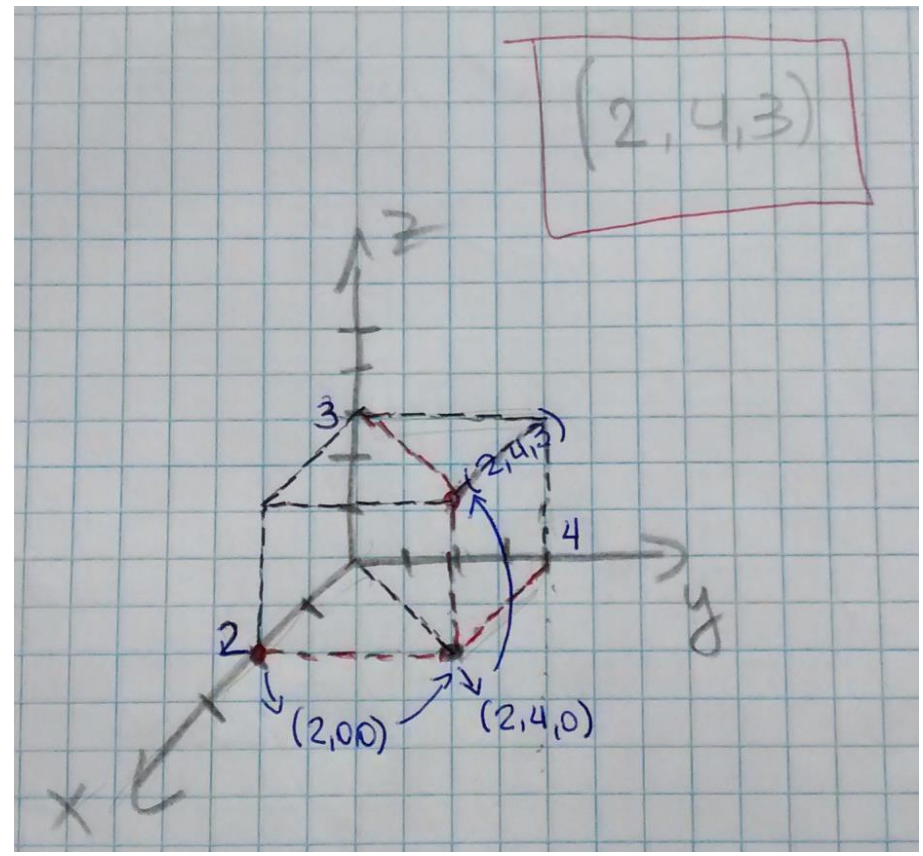

Fonte: A autora

As Tarefas 3 e 4 tinham como objetivos trabalhar com pontos que pertencem aos eixos e como isso é explicitado na sua representação numérica.

As Dupla 1 e Dupla 3 realizaram a Tarefa 3 satisfatoriamente, mostrando compreensão na conversão entre o registro gráfico e o registro numérico.

Figura 126: Resposta apresentada pela Dupla1 para a Tarefa 3

3. O que vocês observam em relação às posições dos pontos $\mathrm{A}$ e C? Explique.

Ambor or pontor ertäo em cima dor eixos,

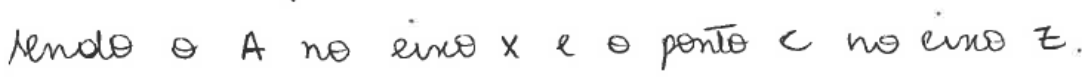

Fonte: Material da experimentação 
Figura 127: Resposta Apresentada pela Dupla 3 para a Tarefa 3

Explique.

Us dois ponies ertär un cima do ailo

\& eles tem uma relacioi invirsa $(2,0,0)$ e $(0,0,4)$.

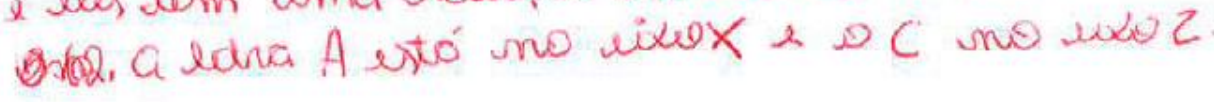

Fonte: Material da experimentação

A Dupla 2 apresentou dificuldades em relação ao que o enunciado da Tarefa 3 propunha, inicialmente olharam apenas para suas coordenadas, como vemos na parte a caneta preta, da resposta. Após a intervenção da professora compreenderam o que era para ser feito e completaram a resposta (parte com caneta azul).

Figura 128: Resposta apresentada pela Dupla 2 para Tarefa 3

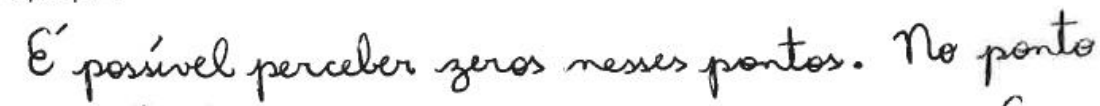
A é possivel wer zeras nos evios yez, no $C$ nos uxas $x$ ey. No exco ty o panto E fica se localizado, já no $x$ é localizado o ponto $A$.

Fonte: Material da experimentação

A Tarefa 4 foi realizada como o esperado pelas três duplas.

Figura 129: Resposta apresentada pela Dupla 1 para a tarefa 4

4. Apresentem as coordenadas de dois pontos que pertencem ao eixo $\mathrm{OY}$

$$
\begin{aligned}
& G=(0,4,0) \\
& H=(0,3,0)
\end{aligned}
$$

Fonte: Material da experimentação 
Figura 130:Resposta apresentada pela Dupla 2 para a Tarefa 4

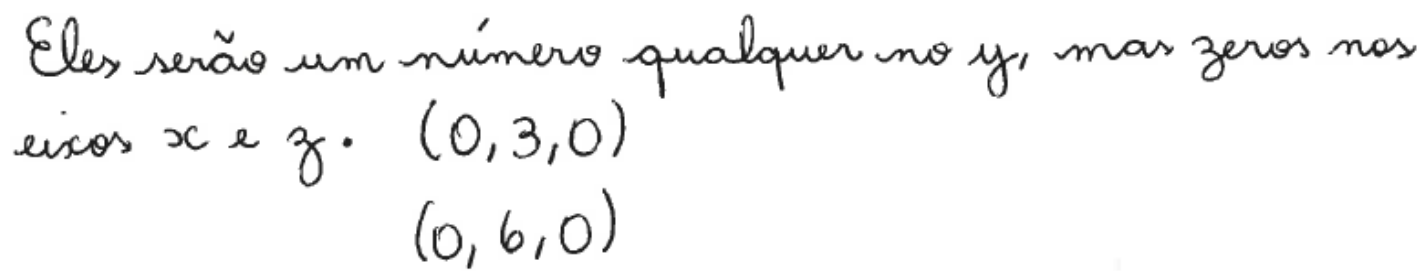

Fonte: material da experimentação

Figura 131: Resposta apresentada pela Dupla 3 para a Tarefa 4

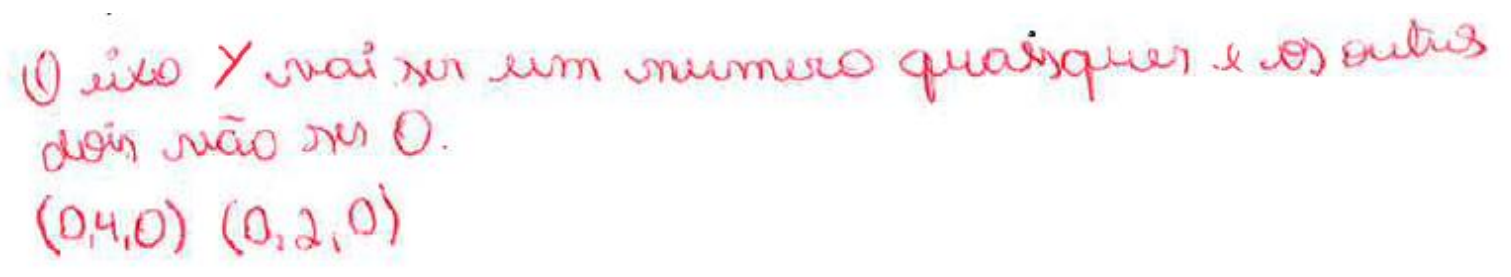

Fonte: material da experimentação

A Dupla 2 e a Dupla 3 apresentaram suas respostas em língua natural e no registro numérico. Observamos aqui que a conversão entre os registros é congruente, pois é feita de maneira natural pelas duplas e não possui características implícitas a um dos registros.

As Tarefas 5, 6 e 7 tiveram os mesmos objetivos que as tarefas anteriores, porém analisar pontos nos planos, ou seja, queríamos verificar como os alunos relacionaram um ponto que pertence a um dos planos Oxy, Oxz ou Oyz com sua representação numérica.

As duplas não apresentaram dificuldades para realizar a Tarefa 5, foi necessária apenas uma intervenção da professora com perguntas para as Dupla 2 e Dupla 3, visando que chegassem a concluir que o plano em questão é o Oxy. 
Figura 132: Resposta apresentada pela Dupla 1 para as Tarefa 5 e Tarefa 6

5. E em relação ao ponto $D$ ? Descrevam com palavras a sua posição no espaço.

- ponto d ertár no plano XY, e entá lacalizado entre dour octanter, e no plano entá localigado no quadmante $t$.

6. Deem mais um exemplo de ponto com a mesma caracteristica do ponto D.

$$
i=(2,8,0)
$$

Fonte: Material da experimentação

Figura 133: Resposta apresentada pela Dupla 2 para as Tarefa 5 e Tarefa 6

Ele tem o algausmo $O$ no exco z. Ele e o ponto $A$ são os úncos pontos que tem o algarusmo nulo no exxo $z$. Sua posizão está no plano xy.

6. Deem mais um exemplo de ponto com a mesma característica do ponto D.

(1) ponto A.

Fonte: Material da experimentação

Figura 134: Resposta apresentada pela Dupla 3 para as Tarefa 5 e Tarefa 6

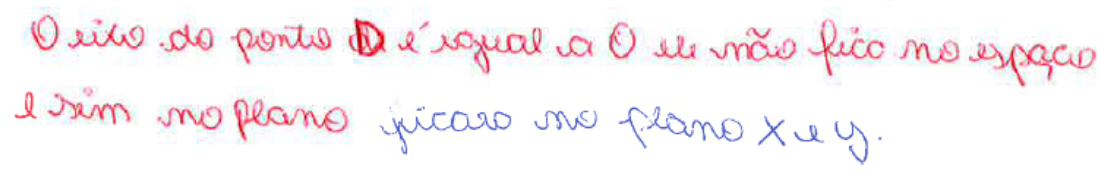

6. Deem mais um exemplo de ponto com a mesma característica do ponto D.

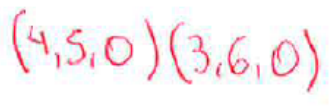


Após a discussão e as intervenções realizadas nas Tarefa 5 e 6 os alunos responderam os itens da Tarefa 7 . Seguem algumas respostas (cf. Figura 135 e Figura 136).

Figura 135: Resposta apresentada pela Dupla 1 para a Tarefa 7

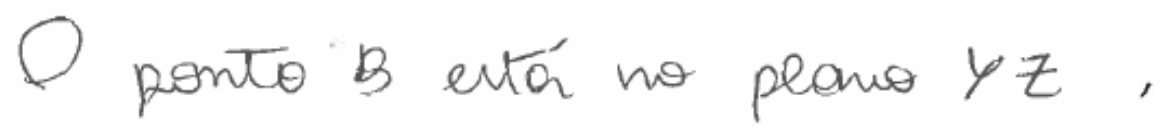

Fonte: Material da experimentação

Figura 136: Resposta apresentada pela Dupla 3 para Tarefa 7

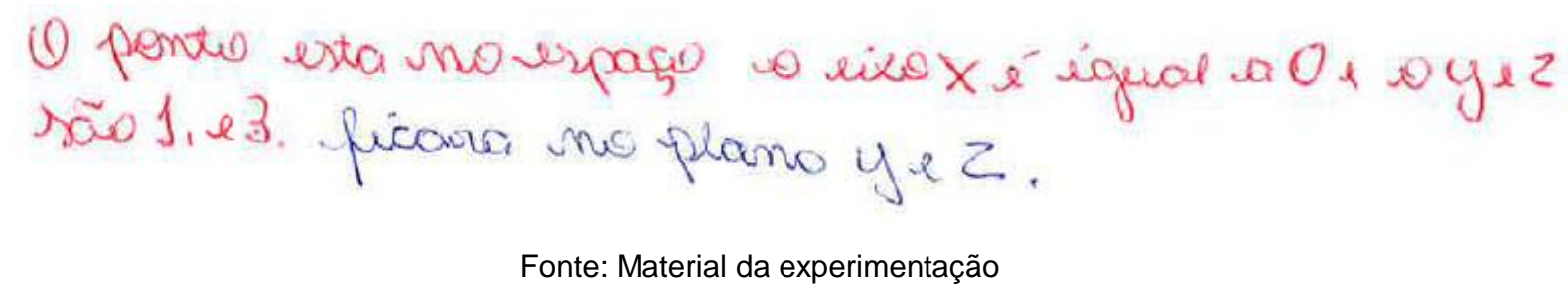

A Dupla 3 colocou em sua resposta que o ponto estava no espaço, pois o sistema de coordenadas no espaço que estava utilizando tinha o plano OYZ na posição vertical, e para que os alunos pudessem "enxergar" o plano, a professora utilizo um arquivo já apresentado para os alunos em encontros anteriores. 
Figura 137: Imagem base para a primeira resposta apresentada pela Dupla 3 para a Tarefa 7

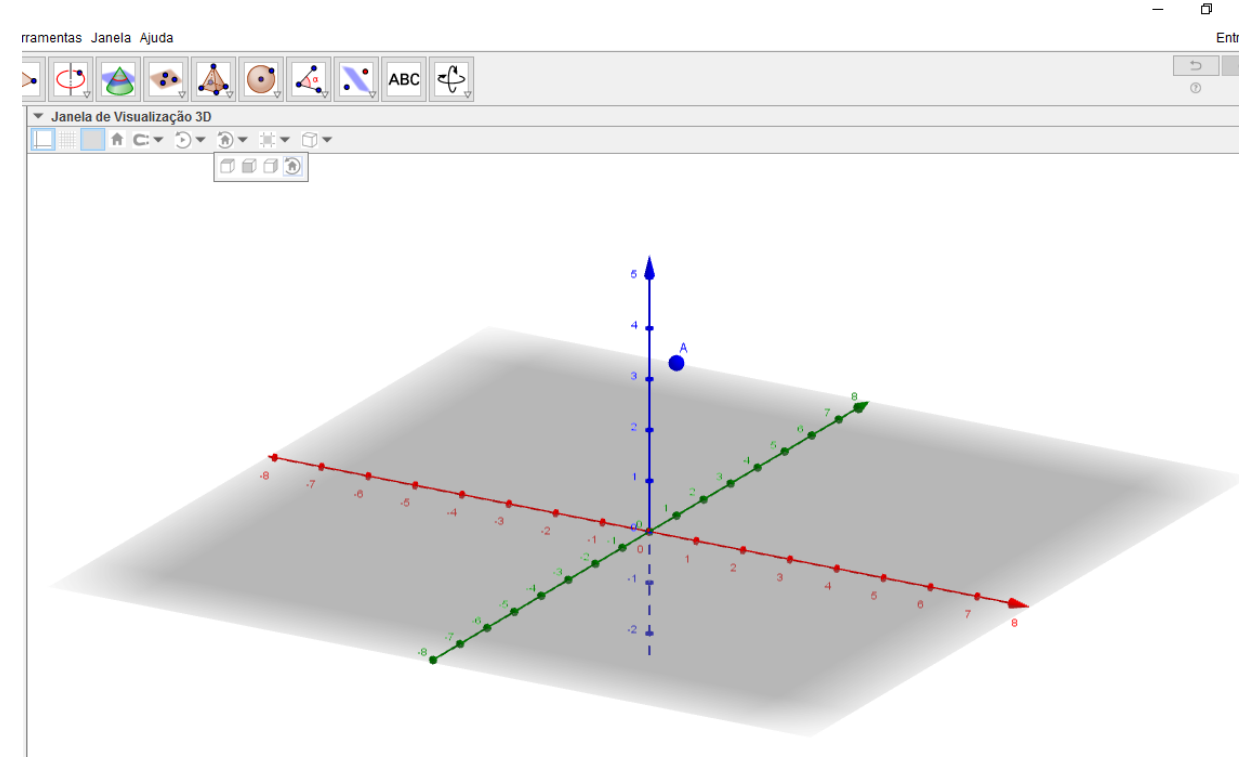

Fonte: Material da experimentação

Figura 138: Imagem base para completar a resposta apresentada pela Dupla 3 para a Tarefa 7

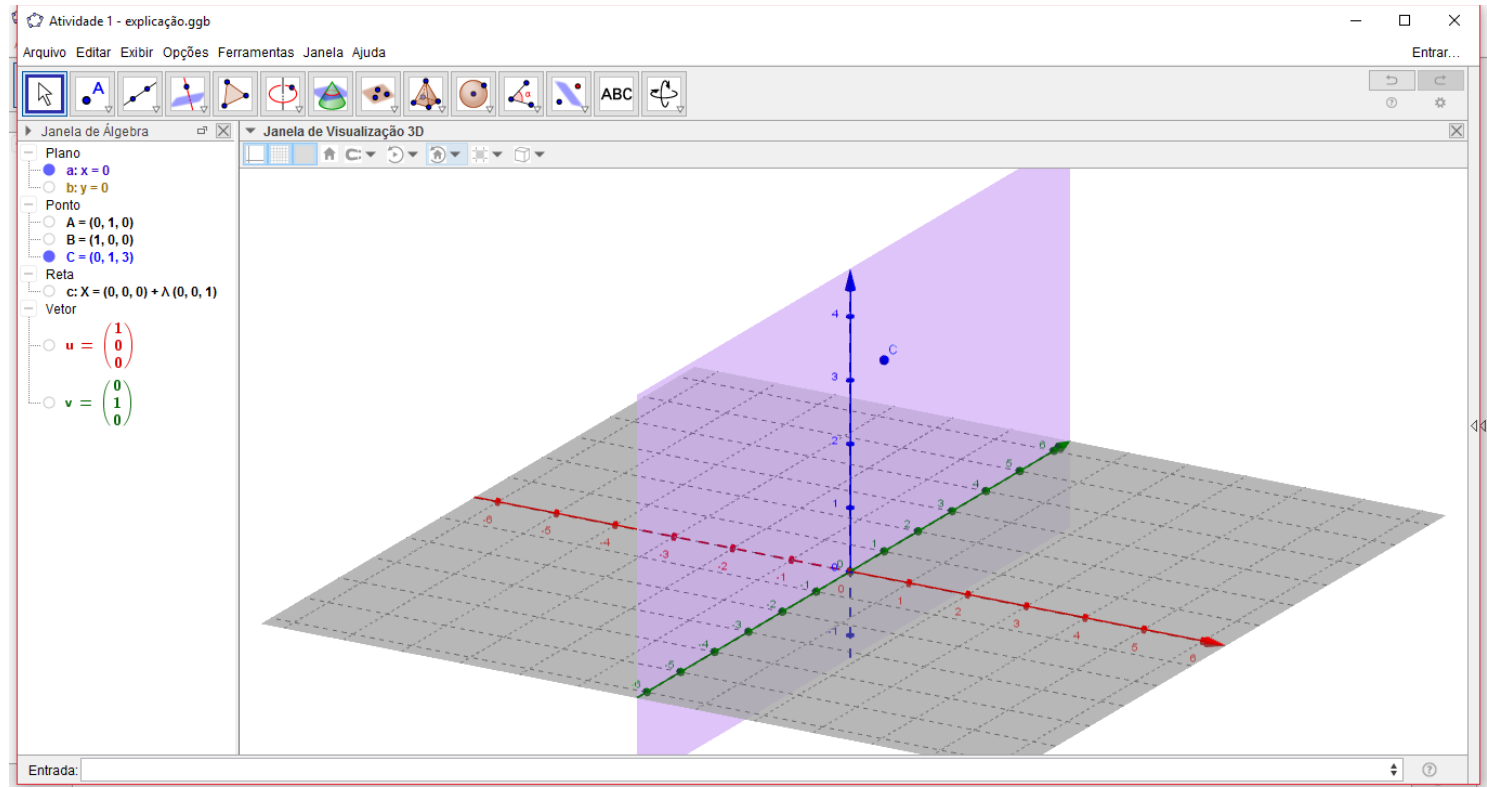

Fonte: Material da experimentação

Apenas a Dupla 2 apresentou dificuldades em registrar sua resposta para a Tarefa 7 , onde não mostrou em qual plano o ponto estava localizado, porém levamos em consideração que a resposta foi realizada antes da intervenção da 
professora. Na tarefa seguinte, veremos que a Dupla compreendeu a posição do ponto.

Figura 139: Resposta apresentada pela Dupla 2 para a Tarefa 7

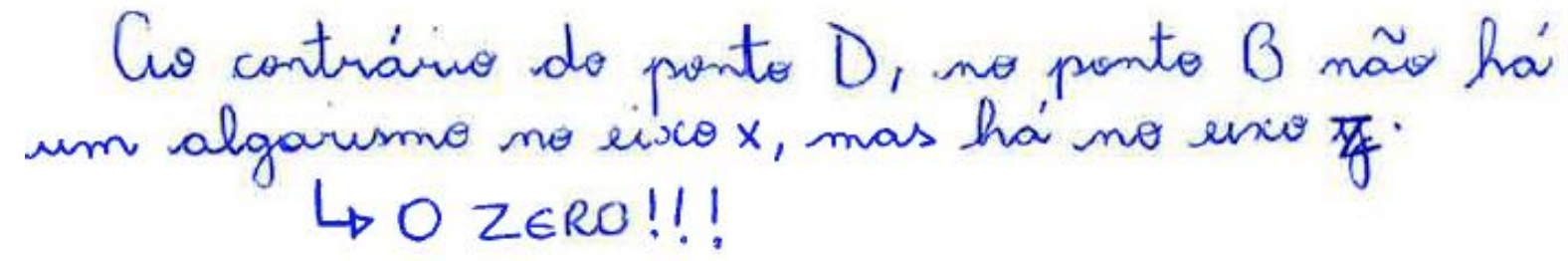

Fonte: material da experimentação

Na última Tarefa do encontro, o objetivo era verificar quais os conceitos compreendidos pelos alunos com as tarefas anteriores sobre projeções de pontos nos planos e nos eixos. A Dupla 1 não encontrou dificuldades para apresentar as respostas aos dois itens ( cf. Figuras que seguem).

Figura 140: Resposta apresentada pela Dupla 1 para a Tarefa 8a

Quando duar cordenadar sao nular, $\theta$ ponto vai pertencer ao eixo com coordenadar diferente de $O$.

Fonte: material da experimentação

Figura 141: Resposta apresentada pela Dupla 1 para a Tarefa 8b

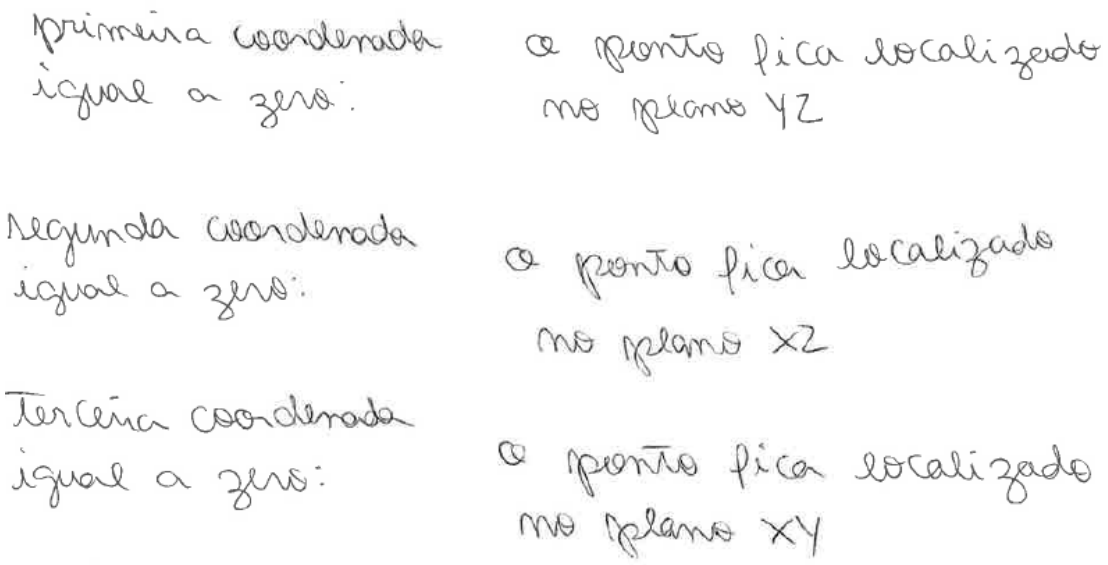

Fonte: Material da experimentação 
Já a Dupla 2 e a Dupla 3 apresentaram casos particulares e apenas com a intervenção da professora, ambas compreenderam o que a tarefa pedia e apresentaram suas respostas.

Figura 142: Resposta apresentada pela Dupla 2 para a Tarefa 8a

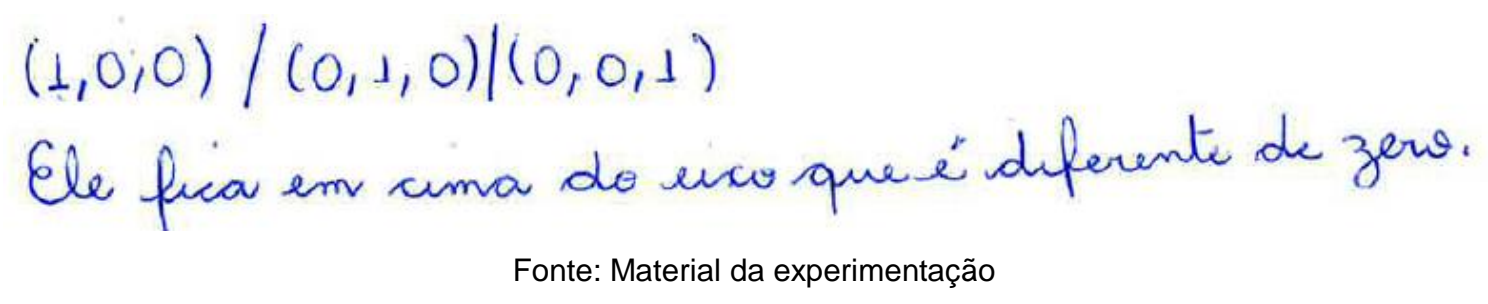
Fonte: Material da experimentação

Figura 143: Resposta apresentada pela Dupla 2 para a Tarefa 8b

$$
\begin{aligned}
& (1,1,0) /(1,0,1) /(0,1,1) \\
& \text { Ele var ficar em un dos trés planos. }
\end{aligned}
$$

Fonte: Material da experimentação 
Figura 144: Resposta apresentada pela Dupla 3 para a Tarefa 8a

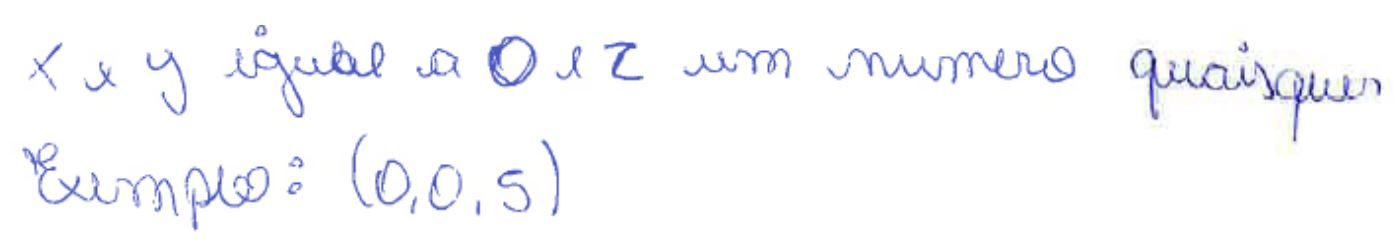

Fonte: Material da experimentação

Figura 145: Resposta apresentada pela Dupla 3 para a Tarefa 8a após a intervenção

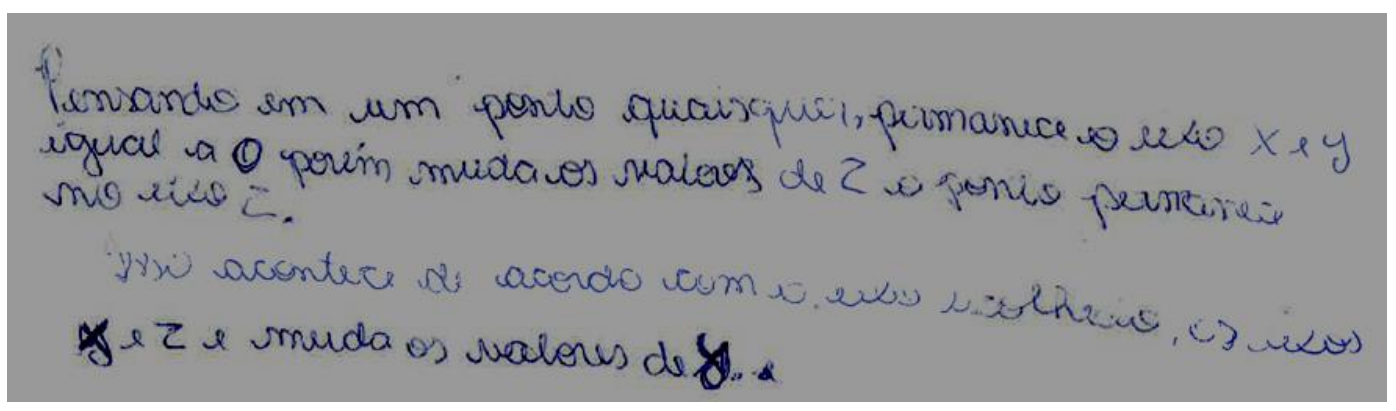

Fonte: material da experimentação

Figura 146: Resposta apresentada pela Dupla 3 para a Tarefa 8b

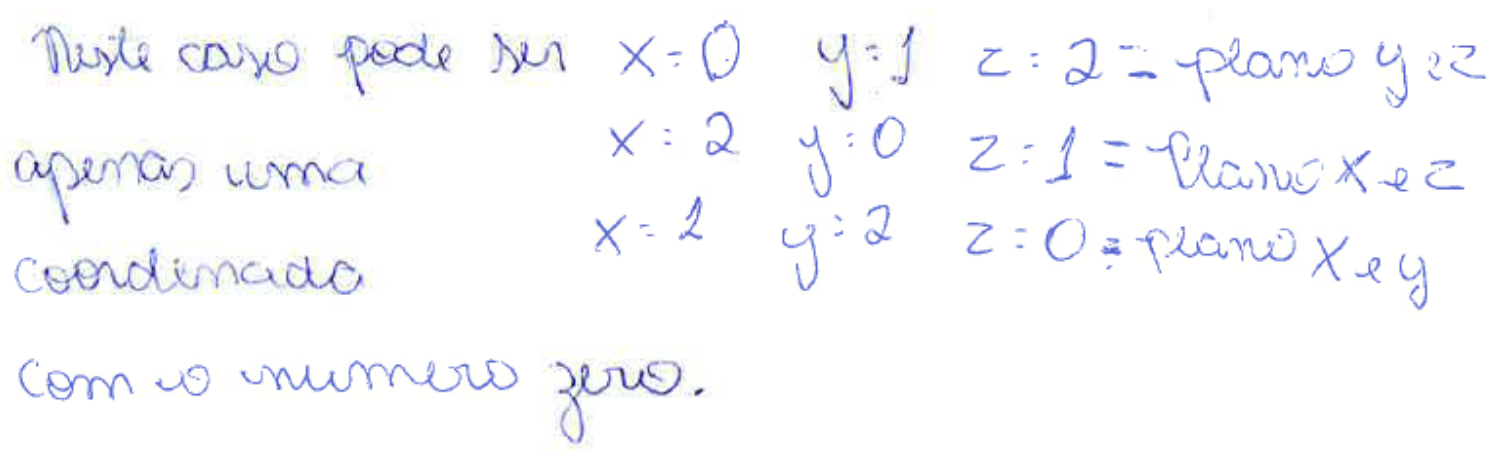

Fonte: Material da experimentação

Consideramos que nesta última Tarefa a conversão do registro língua natural para o registro gráfico é não congruente, pois as Duplas 2 e 3 só conseguiram realizar a tarefa fazendo primeiramente a conversão do registro língua natural para o registro numérico e assim utilizando as observações das tarefas anteriores chegaram a conclusão esperada. 
Com a finalização dos encontros, verificamos que os objetivos das Tarefas foram atingidos, ou seja, os alunos conseguiram compreender os conceitos relacionados às representações de um ponto no espaço.

Observamos que representar graficamente um ponto no espaço em um ambiente bidimensional pode trazer algumas dificuldades devido às distorções geradas pelas projeções contidas na imagem gerada, o que já era esperado.

\subsubsection{Encontro 10}

Participaram do encontro todos os seis alunos da experimentação e foram divididos em duplas para realização das tarefas, a saber: Dupla 1 - AD e TA, Dupla 2 CA e MA e Dupla 3 - LL e LA.

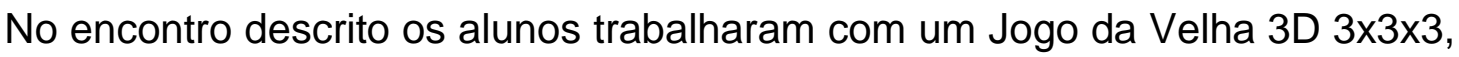
onde utilizamos a estrutura do jogo como uma adaptação do $1^{\circ}$ octante do sistema de coordenadas do espaço.

Figura 147: Exemplar do Jogo da Velha 3D

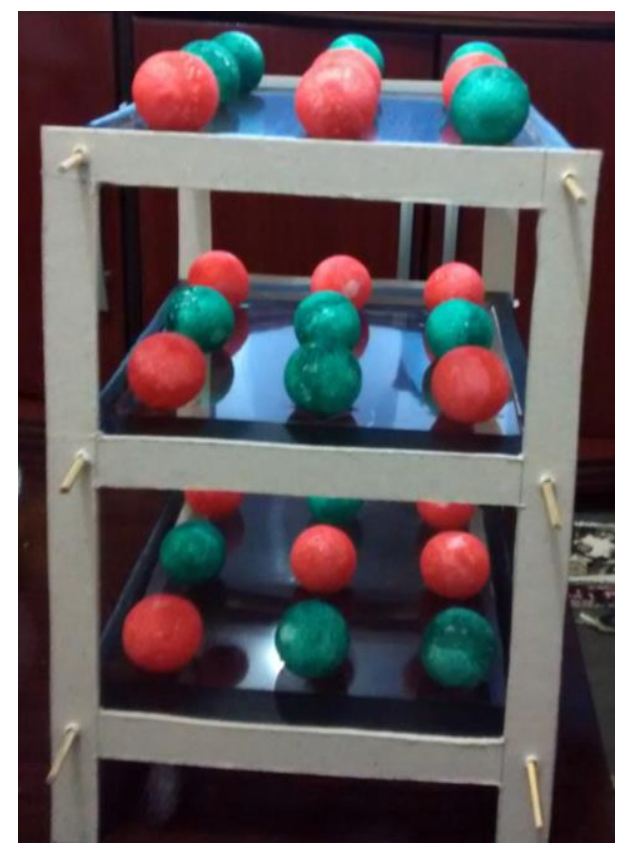

Fonte: A autora 
Escolhemos Jogo da Velha 3D como material pedagógico, por possibilitar o trabalho no espaço. Como afirma Cassiano,

Se o jogo serve de suporte para um conhecimento futuro, tem a finalidade de ser usado como uma ferramenta em que se almeja determinado tipo de resultado, então, o jogo e/ou brinquedo passa a ser classificado como material pedagógico (CASSIANO, 2009, p. 38).

No primeiro momento do encontro, os alunos foram convidados a jogar livremente por aproximadamente 10 minutos e como muitos não conheciam essa versão do jogo, as dúvidas que surgiram estavam relacionadas às jogadas válidas para a solução.

Figura 148: Alunos jogando o Jogo da Velha 3D
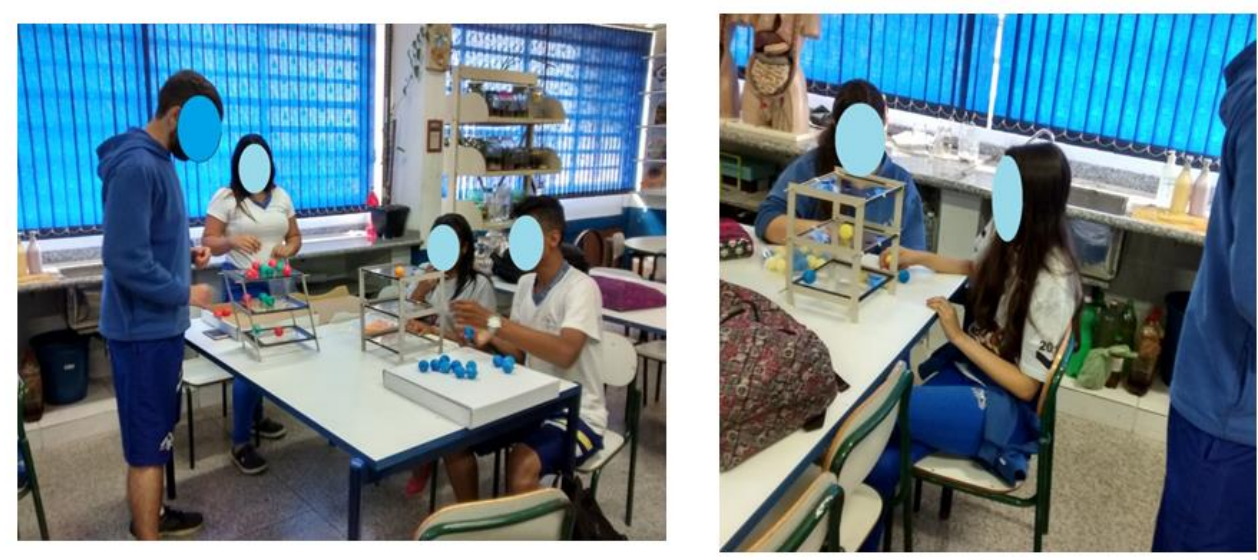

Fonte: Autora

No segundo momento do encontro, os alunos realizaram tarefas que tinham como objetivo analisar como eles lidam com o Material Manipulável ${ }^{11}$ e o quanto esse material ajuda na visualização espacial, dado que possibilita "abstrações cognitivas utilizáveis em resolução de problemas ou em reconhecimento de propriedades geométricas." (FRANCO; MORAN, 2015, p.65).

$\mathrm{Na}$ Tarefa 1 as duplas escolheram como comprimento do cubo 3 unidades de medida, o sistema de coordenadas do espaço com o plano Oxy paralelo as placas do jogo e o eixo $\mathrm{Oz}$ na vertical.

\footnotetext{
${ }^{11}$ Para nossa experiência consideramos Material Manipulável um tipo de registro (não semiótico) figural, baseados nos estudos de Franco e Moran.
} 
A Dupla 1 teve dificuldades para registrar as coordenadas pois estavam confundindo os eixos $O x$ e $O y$, já que a escolha que fizeram na orientação dos eixos foi diferente da trabalhada nas Tarefas anteriores e com isso acabaram gastando um tempo maior nesta tarefa.

Figura 149: Orientação dos eixos escolhida pela Dupla 1 para a Tarefa 1

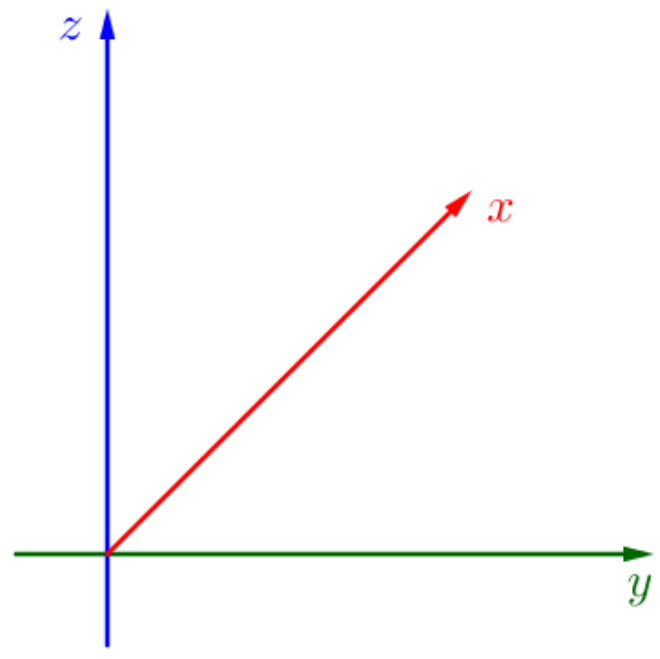

Fonte: A autora
Figura 150: Resposta apresentada pela Dupla 1 para a Tarefa 1

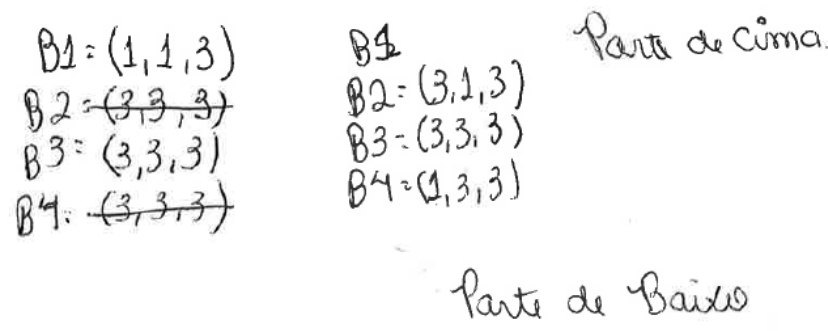

$B 2=(1,1,1)$

$B 2:(1,3,1)$

$B=(3,3,1) B^{3}=(3,3,1)$

$B H=(1,3,1)$

Fonte: Material da experimentação

As Duplas 2 e 3 não apresentaram dificuldades para resolver a tarefa, representando corretamente as coordenadas de todos os pontos ( cf. Figura 151). Nota-se que as representações dos eixos não contemplam as convenções, não explicitando a origem. 
Figura 151: Resposta apresentada pela Dupla 2 para a Tarefa 1

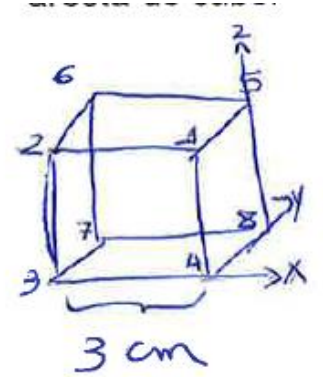

$$
\begin{aligned}
& v_{1}=(3,1,3) \\
& v_{2}=(1,1,3) \\
& v_{3}=(1,1,1) \\
& v_{4}=(3,1,1) \\
& v_{5}=(3,3,3) \\
& v_{6}=(1,3,9) \\
& v_{7}=(1,3,1) \\
& v_{8}=(3,3,1)
\end{aligned}
$$

Fonte: Material da experimentação

Figura 152: Resposta apresentada pela Dupla 3 para a Tarefa 1

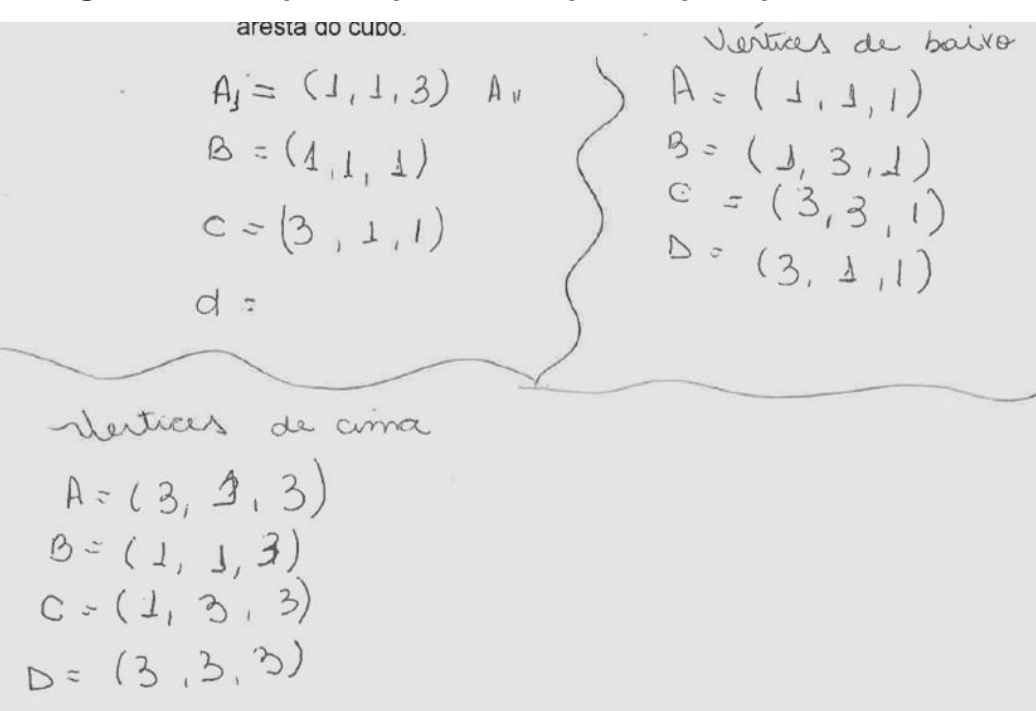

Fonte: Material da experimentação

A Tarefa 1 apresentou uma atividade de conversão congruente do registro figural para o registro numérico.

Apesar das duplas não apresentarem dificuldades, não fizeram a face inferior contida no plano $O x y$, mas isso não interferiu de modo significativo na resolução e objetivos da Tarefa. 
$\mathrm{Na}$ Tarefa 2 os alunos foram levados a pensar nas possíveis soluções ${ }^{12}$ do Jogo da Velha 3D. Na primeira parte da tarefa, as Dupla 1 e Dupla 2 utilizaram o próprio o jogo para contar as possibilidades de soluções, posicionando as bolinhas para facilitar a visualização. Depois de um tempo, porém, perguntaram "se não tem uma forma mais fácil de contar". A professora interviu mostrando que eles poderiam pensar nas possíveis soluções do jogo tradicional (2D) e contar quantos planos eles conseguiam encontrar no Jogo da Velha 3D.

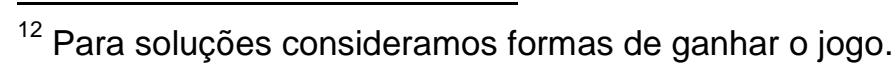



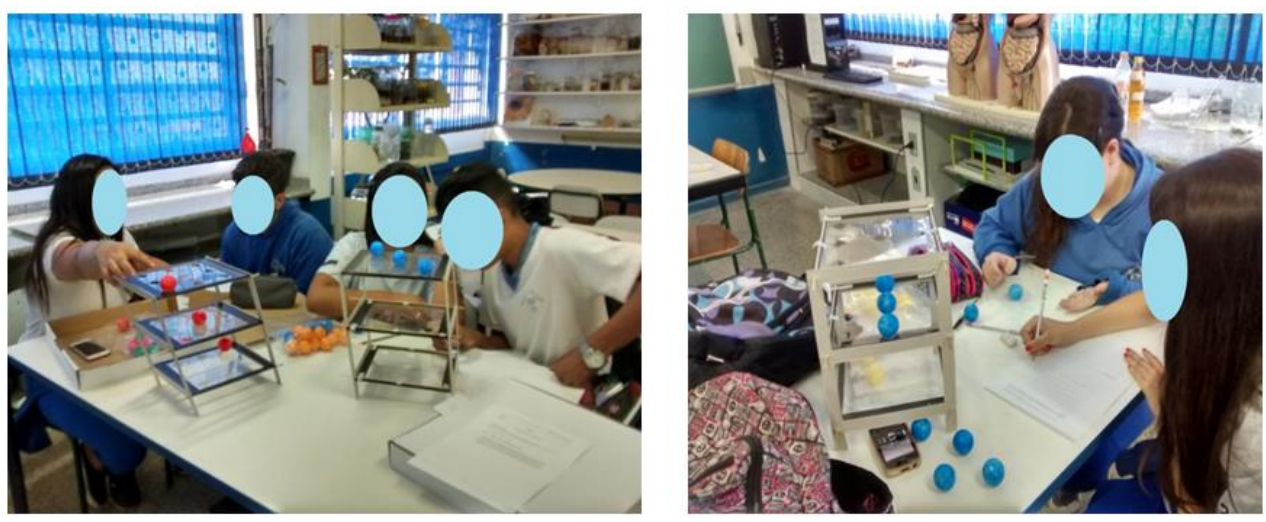

Fonte: A autora

Nesta parte da Tarefa 2, era esperado que as duplas encontrassem 49 soluções como especificado a seguir.

Tabela 8: Soluções do Jogo da Velha 3D

\section{Soluções do Jogo Da Velha 3D}

No Jogo da Velha 3D, temos três planos paralelos a cada um dos planos Oxy, Oxz e Oyz. A seguir temos as possíveis soluções para versão 2D do jogo.

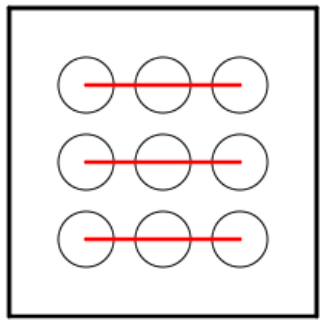

3 soluções

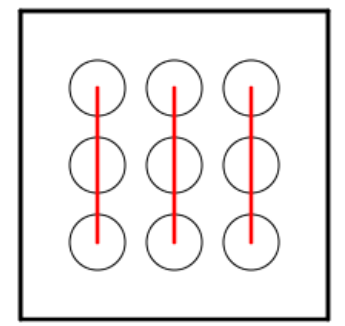

3 soluções

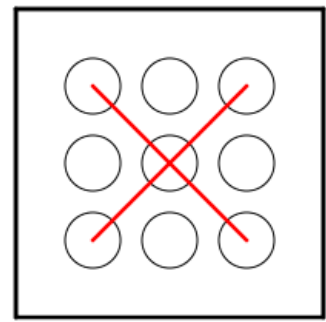

2 soluções

Soluções 2D

Indicamos abaixo o número de soluções considerando, em cada caso, o conjunto de 3 planos paralelos a cada plano coordenado:

$$
\left.\begin{array}{l}
\begin{array}{l}
\text { paralelo à } O x y \rightarrow 3 \times(3+3+2)=24 \\
\text { paralelo à } O x z \\
\text { paralelo à } O y z \rightarrow 3 \times(3+2)=15
\end{array}
\end{array}\right\} 45 \text { soluções }
$$

Além das soluções indicadas, temos que considerar aquelas nas diagonais do cubo (cf. Figura 154), que alinham três pontos. Com isso, tem-se então 49 soluções $(45+4=49)$. 


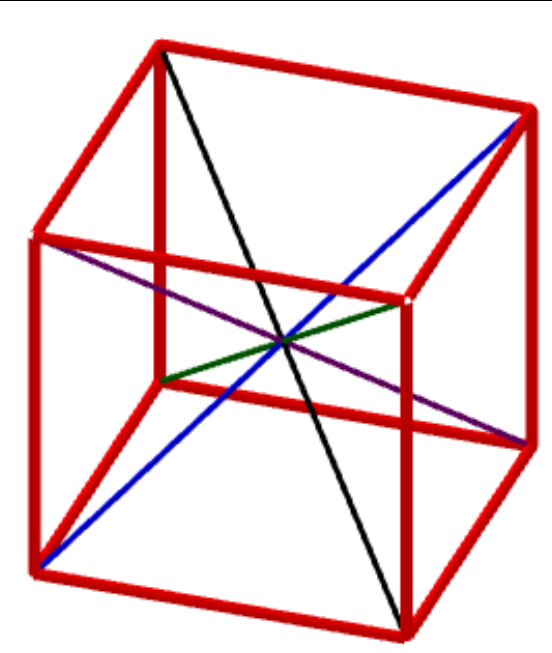

Fonte: A autora

Figura 155: Resposta apresentada pela Dupla 1 para a Tarefa 2

49 porsebilidades.

$(1,3,1)$

Fonte: Material da experimentação

A Dupla 1 demorou um tempo importante para fazer a contagem e pedir auxílio para a professora e, por isso, não teve tempo para realizar a segunda parte da tarefa, somente iniciando com a indicação de coordenadas de dois pontos de uma das soluções observada por eles.

Figura 156: Resposta apresentada pela Dupla 2 para a Tarefa 2

49 passibilidades

Poisubilidade $1 \rightarrow(3,1,1)(3,2,1)(3,3,1)$

Posibilidade $2 \rightarrow(3,1,1)(3,1,2)(3,1,3)$

Porsibilidade $2 \rightarrow(3,1,1)(2,2,2)(1,3,3)$

Possibilidade $4 \rightarrow(2,1,1)(2,2,2)(2,3,3)$

Porsibilidade $s \rightarrow(2,1,1)(2,2,1) \quad(2,3,1)$

Porvibibdade $6 \rightarrow(1,2,2)(2,2,2)(3,2,2)$ 
Vemos aqui que as Duplas 1 e Dupla 2 encontraram as 49 soluções com facilidade após uma intervenção da professora que chamou a atenção para iniciarem com uma organização da contagem em cada plano.

A Dupla 3 não realizou a primeira parte, pois começaram pela segunda e não conseguiram concluir a tarefa em tempo hábil.

$\mathrm{Na}$ segunda parte da Tarefa, foi solicitado às duplas que apresentassem as coordenadas dos pontos de, pelo menos, 6 soluções do jogo (cf. Figura 156).

Da mesma maneira que na primeira parte da tarefa, as Dupla 2 e Dupla 3 utilizaram o jogo para visualizar a posição dos pontos de uma solução desejada e apresentando as coordenadas da bolinha nessa posição.

Ao utilizarem essa estratégia para realizar a tarefa, podemos afirmar que as duplas fizeram uma conversão congruente entre os registros figural, gráfico e numérico, apoiadas no material concreto.

Figura 157: Reposta apresentada pela Dupla 3 para a Tarefa 2

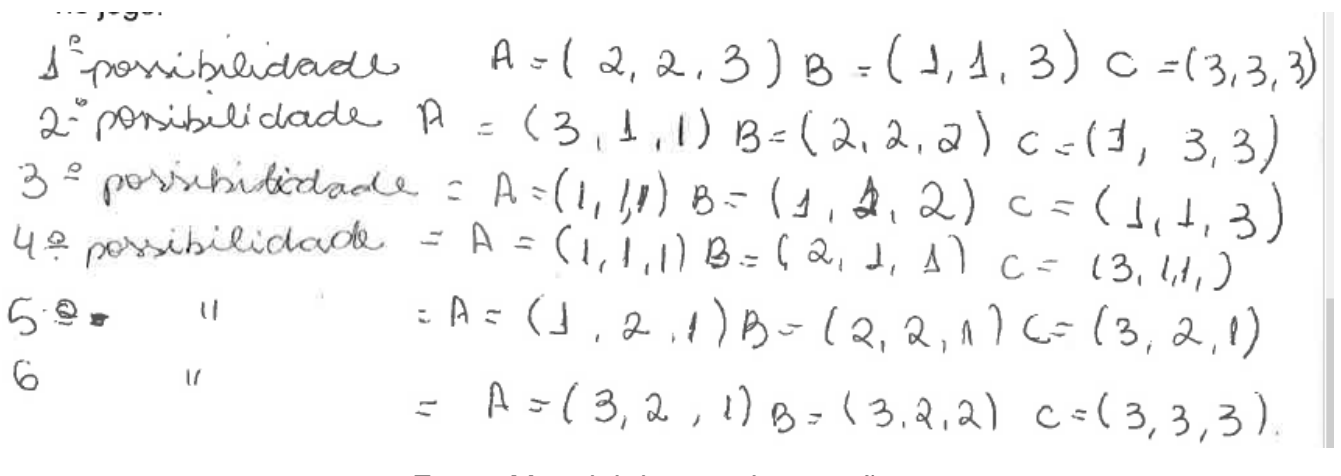

Fonte: Material da experimentação

As duas duplas apresentaram soluções em mais de um plano, espontaneamente. $E$ observa-se que ambas apresentaram uma solução considerando uma diagonal do cubo, mostrando que não se limitaram às soluções mais triviais (cujos três pontos estão em um mesmo plano paralelo ao OXY). O erro da Dupla 3 na última solução parece-nos relativo a uma confusão apenas na ordenada do terceiro ponto, que seria 2 e não 3 como indicado.

Tabela 9: Interpretação gráfica das soluções das Dupla 2 e Dupla 3 para a Tarefa 2 


\begin{tabular}{|c|l|l|}
\hline & \multicolumn{1}{|c|}{ Dupla 2 } & \multicolumn{1}{c|}{ Dupla 3 } \\
\hline 1 & Paralela ao eixo $O y$ & $\begin{array}{l}\text { Diagonal do plano paralelo ao } \\
\text { plano Oxy }\end{array}$ \\
\hline 2 & Paralela ao eixo $O z$ & Diagonal do cubo \\
\hline 3 & Diagonal do cubo & Paralela ao eixo $O z$ \\
\hline 4 & $\begin{array}{l}\text { Diagonal do plano paralelo ao } \\
\text { plano Oyz }\end{array}$ & Paralela ao eixo $O x$ \\
\hline 5 & Paralela ao eixo $O y$ & Paralela ao eixo $O x$ \\
\hline 6 & Paralela ao eixo $O x$ & Não é solução \\
\hline
\end{tabular}

Fonte: A autora

Observamos que a atividade exigiu mais tempo do que o planejado para a mesma, inicialmente de 50 minutos. Acreditamos que são necessárias duas horas-aula para a realização das Tarefas 1 e 2, com tempo para os alunos jogarem, se familiarizarem com a proposta e apresentarem as soluções em coordenadas.

As tarefas atingiram globalmente seus objetivos e o uso de materiais manipuláveis, aliados ao jogo, contribuiu para que os alunos compreendessem o funcionamento do sistema de coordenadas no espaço, no sentido de identificarem coordenadas de pontos tanto nos eixos e planos paralelos aos planos coordenados, quanto para posições mais especificas, como por exemplo, as diagonais.

\subsection{Propostas de atividades para continuidade de exploração de coordenadas no espaço}

A seguir, apresentaremos uma sequência de atividades envolvendo coordenadas no espaço, de forma a dar continuidade à exploração do sistema cartesiano 3D e introduzir o cálculo de distâncias no plano e no espaço.

A opção continua sendo de utilização do software Geogebra, tanto como instrumento de visualização quanto para validação experimental de possíveis conjecturas elaboradas pelos alunos. 
A concepção das atividades mantém-se apoiada na Teoria de Duval (2009), buscando articulação entre os registros numérico, algébrico e gráfico, pois confirmamos a pertinência das atividades de conversão na experimentação anterior. Em particular, a ideia central é enfatizar observações no registro gráfico em um primeiro momento e, a partir dele, levar os alunos a apresentem conjecturas, verificando casos particulares no próprio Geogebra e, por fim, atingindo um nível de generalização de suas conclusões em termos do registro algébrico-simbólico, o que se distingue da abordagem usual no ensino.

Para o caso da distância entre dois pontos no espaço, utilizaremos projeções ortogonais de forma a reduzi-lo ao caso de distâncias no plano e o Teorema de Pitágoras, que pode ser retomado nesta ocasião. O objetivo é levar o aluno a visualizar e formular uma estratégia para calcular tais distâncias, sem apresentar, de início, as fórmulas usuais que aparecem nos livros didáticos. Acreditamos, assim, tornar o aprendizado desses conceitos um processo mais significativo para os alunos, focado em experimentações, visualização e análise de casos particulares para apoiar a generalização dos resultados.

Cabe observar que, por questões de cunho prático e alterações nas condições iniciais da experimentação, em particular, diminuição do número de encontros presenciais com os alunos participantes, as referidas atividades, que fazem parte do Design desde a proposta inicial, não puderam ser experimentadas e, consequentemente, não puderam ser analisadas em detalhes didaticamente. No entanto, pelo descrito no tópico anterior, entendemos serem tais atividades plenamente pertinentes e viáveis de serem aplicadas com alunos do Ensino Médio, na continuidade do primeiro conjunto analisado.

\subsubsection{Atividade 1: Coordenadas no Espaço}

Objetivos: A atividade procura trabalhar com pontos pertencentes a subconjuntos do espaço OXYZ, no caso, os eixos (OX, OY e OZ) e planos (OXY, OXZ e OYZ) coordenados e, com isso, dar ao aluno uma base para trabalhar com projeções ortogonais (Atividade 2). Para tal, exploraremos o fato do Geogebra possibilitar o uso simultâneo dos ambientes tridimensional e bidimensional, onde alterações realizadas em um dos ambientes acarretam as mesmas alterações no segundo. 
Figura 158: Interação entre o espaço $O X Y Z$ e o plano $O X Z$ no Geogebra

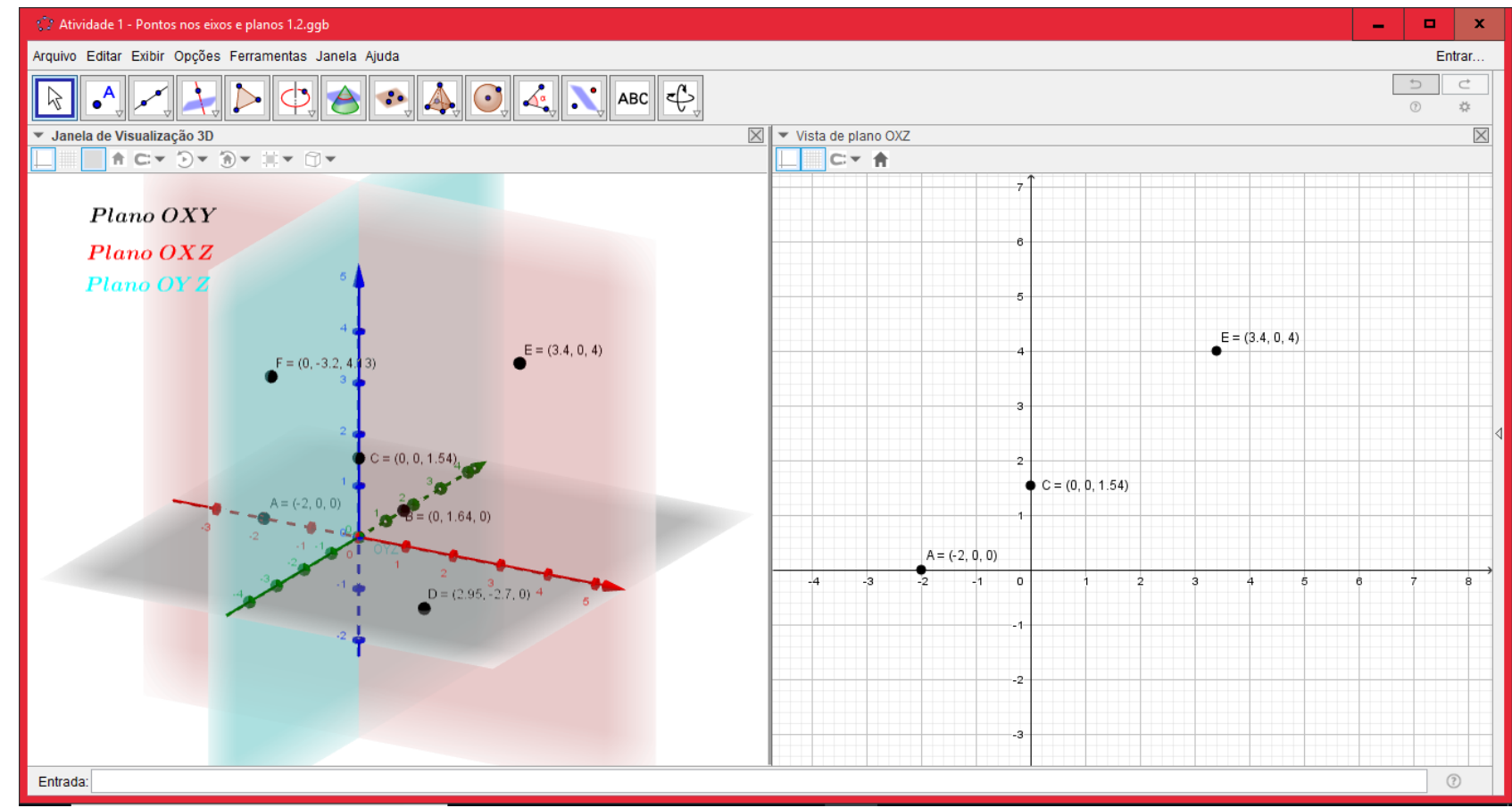

Fonte: A autora

Outra característica que queremos que os alunos observem é que as componentes da direção que o ponto se movimenta estão relacionadas com as coordenadas que variam e essa variação depende da sua localização.

\section{Atividade 1: Coordenadas no Espaço}

Abra o arquivo Atividade1_Coordenadas_no_espaço.ggb.

Na figura apresentada no Geogebra, encontram-se os pontos $A, B, C, D, E$ e $F$ com suas respectivas coordenadas.

\section{Tarefa 1}

Movimente cada um dos pontos e complete a tabela, apresentando as novas coordenas dos pontos conforme sua posição. 


\begin{tabular}{|c|l|l|l|}
\hline Ponto & Posição 1 & Posição 2 & Posição 3 \\
\hline$A$ & & & \\
\hline$B$ & & & \\
\hline$C$ & & & \\
\hline$D$ & & & \\
\hline$E$ & & & \\
\hline$F$ & & & \\
\hline
\end{tabular}

Como são as coordenadas dos pontos em cada caso?

\begin{tabular}{|c|c|c|c|}
\hline Ponto & $\begin{array}{c}1^{\text {a }} \text { coordenada } \\
\text { (abscissa) }\end{array}$ & $\begin{array}{c}2^{\text {a }} \text { coordenada } \\
\text { (ordenada) }\end{array}$ & $\begin{array}{c}3^{\text {a }} \text { coordenada } \\
\text { (cota) }\end{array}$ \\
\hline$A$ & & & \\
\hline$B$ & & & \\
\hline$C$ & & & \\
\hline$D$ & & & \\
\hline$E$ & & & \\
\hline$F$ & & & \\
\hline
\end{tabular}

Apresente a principal característica de cada ponto, ou seja, o que você observou ao preencher a tabela anterior.

\section{Tarefa 2}


Abra a janela de visualização $2 D$. O plano apresentado é o $O X Y$.

O que os pontos neste plano têm em comum em relação às suas coordenadas?

Como podemos expressar as coordenadas de um ponto $P$ qualquer no plano $O X Y$ ?

Crie a vista $2 \mathrm{D}$ do plano $O X Z$.

O que os pontos neste plano têm em comum em relação às suas coordenadas?

Como podemos expressar as coordenadas de um ponto $P$ qualquer no plano $O X Z$ ?

Crie a vista 2D do plano OYZ.

O que os pontos neste plano têm em comum em relação às suas coordenadas?

Como podemos expressar as coordenadas de um ponto $\mathrm{P}$ qualquer no plano OYZ?

\section{Tarefa 3}

Complete a tabela com os pontos que aparecem em cada plano.

\begin{tabular}{|c|c|c|c|}
\hline & Plano OXY & Plano OXZ & Plano OYZ \\
\hline Pontos & & & \\
\hline
\end{tabular}

Quais pontos aparecem em um único plano? O que você observa das suas coordenadas?

Quais os pontos que aparecem em mais de um plano?

\begin{tabular}{|l|l|l|}
\hline Ponto & Planos & Eixo comum \\
\hline & & \\
\hline & & \\
\hline & & \\
\hline & & \\
\hline Como podemos expressar as coordenadas de um ponto qualquer sobre cada eixo \\
\hline
\end{tabular}




\begin{tabular}{|c|c|}
\hline \multicolumn{1}{|l|}{ coordenado? } \\
\hline Eixos & Coordenadas \\
\hline$O X$ & \\
\hline$O Y$ & \\
\hline$O Z$ & \\
\hline
\end{tabular}

\section{Tarefa 4}

No Geogebra, movimente os pontos para completar a tabela.

\begin{tabular}{|c|c|c|}
\hline Localização do ponto & $\begin{array}{l}\text { Quantidade de coordenadas } \\
\text { que variam }\end{array}$ & $\begin{array}{c}\text { Quantidade de direções que } \\
\text { se move* }\end{array}$ \\
\hline \multicolumn{3}{|l|}{ Eixos } \\
\hline \multicolumn{3}{|l|}{ Planos } \\
\hline Espaço & & \\
\hline $\mathrm{n}$ relação aos eixos (istc & em relação às direções de O〉 & $X, O Y$ e $O Z)$ \\
\hline
\end{tabular}

Expectativas: Para esta atividade, esperamos que os alunos observem ao fim das Tarefas 1, 2 e 3 que:

Ponto $A$ tem a $1^{\text {a }}$ coordenada (abscissa) variando e as outras duas nulas, pois é um ponto criado sobre o eixo $O X$;

Ponto $B$ tem a $2^{\mathrm{a}}$ coordenada (ordenada) variando e as outras duas nulas, pois é um ponto criado sobre o eixo OY;

Ponto $C$ tem a $3^{\text {a }}$ coordenada (cota) variando e as outras duas nulas, pois é um 
ponto criado sobre o eixo $O Z$;

Ponto $D$ tem as $1^{\underline{a}}$ e $2^{\underline{a}}$ coordenadas variando e $3^{\underline{a}}$ nula, pois é um ponto criado no plano $O X Y$;

Ponto $E$ tem as $1^{\text {a }}$ e $3^{\underline{a}}$ coordenadas variando e $2^{\underline{a}}$ nula, pois é um ponto criado no plano $O X Z$;

Ponto $F$ tem as $2^{\underline{a}}$ e $3^{\underline{a}}$ coordenadas variando e $1^{\underline{a}}$ nula, pois é um ponto criado no plano OYZ.

Para a Tarefa 4, esperamos que os alunos observem que em um ponto, o número de coordenadas que variam é o mesmo que o número de direções (em relação às direções de $O X, O Y$ e $O Z$ ) que esse ponto pode se movimentar e isso determina sua localização, considerando eixos e planos coordenados e o espaço como um todo.

Orientação para o professor: Para essa atividade 0 professor pode criar os planos $O X Y, O X Z$ e $O Y Z$ com os alunos ou já levá-los prontos para aula.

As tarefas onde se pedem uma resposta generalizada sobre as coordenadas dos pontos, podem apresentar respostas em língua natural, e esse formato de resposta também é válido, pois o objetivo das atividades é fazer com que os alunos compreendam os conceitos nelas contidos de forma significativa.

\subsubsection{Atividade 2: Projeções de pontos nos planos coordenados e nos eixos coordenados.}

Objetivos: A atividade está voltada para o estudo das projeções ortogonais de pontos no espaço sobre os planos $O X Y, O X Z$ e $O Y Z$ e sobre os eixos $O X, O Y$ e $O Z$. Utilizaremos as projeções ortogonais para trabalhar, nas próximas atividades, a distância entre dois pontos no espaço.

Através das construções das projeções ortogonais queremos levar o aluno a identificar as principais características das coordenadas dos pontos que representam tais projeções. 


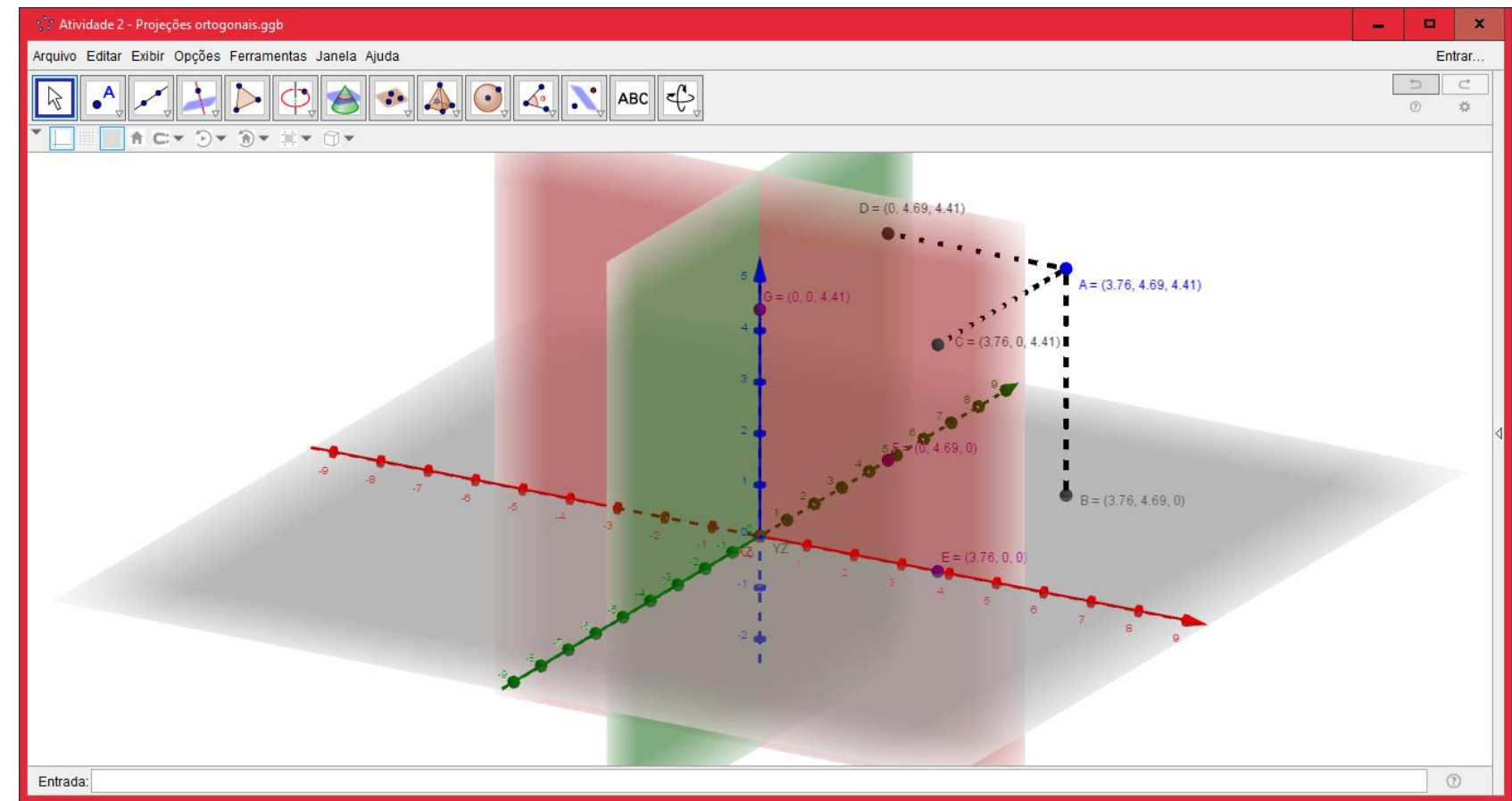

Fonte: $\mathrm{A}$ autora

Atividade 2: Projeções de pontos nos planos coordenados e nos eixos coordenados.

\section{Tarefa 1}

Atividade de construção: Siga os passos a seguir para construir os pontos $A, B, C$ e $D$.

Passo 1: Na barra de entrada digite $A=(3,2,1)$ e clique "Enter". Movimente o ponto $A$ livremente e observe suas coordenadas.

Passo 2: Na barra de ferramentas, selecione a opção "Reta Perpendicular" ( seguida selecione o ponto $A$ e o plano $O X Y$.

Passo 3: Na barra de ferramentas selecione a "Interseção de Dois Objetos", como na figura a seguir, e depois selecione a reta criada no Passo 2 e o plano $O X Y$. Será criado um ponto $B$. 


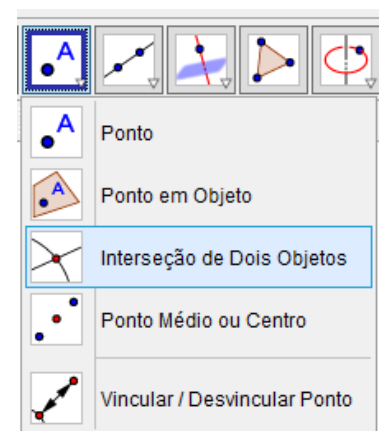

Passo 4: Repita os Passos 2 e 3 utilizando o plano OXZ. Será criado o ponto $C$.

Passo 5: Repita os Passos 2 e 3 utilizando o plano OYZ. Será criado o ponto $D$.

Passo 6: Esconda as retas criadas.

Passo 7: Na barra de ferramentas, selecione "Segmento", como na figura a seguir, e crie os segmentos $\overline{A B}, \overline{A C}$ e $\overline{A D}$.

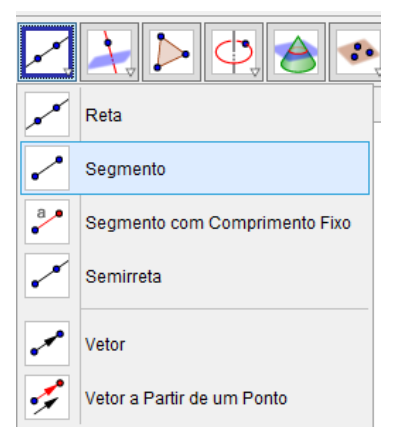

Os pontos $B, C$ e $D$ são as projeções ortogonais do ponto $A$ nos planos $O X Y, O X Z$ e $O Y Z$, respectivamente.

\section{Tarefa 2}

Agora, movimente o ponto $A$ e descreva como serão as coordenadas das projeções ortogonais nos planos coordenados? 


\begin{tabular}{|c|c|}
\hline Plano & Coordenadas da projeção \\
\hline$O X Y$ & \\
\hline$O X Z$ & \\
\hline$O Y Z$ & \\
\hline
\end{tabular}

\section{Tarefa 3}

1) Movimente o ponto $A$ de modo a coincidir com o ponto $B$.

O que podemos dizer da localização do ponto $A$ ? O que aconteceu com os pontos $C$ e $D$ ?

2) Movimente o ponto $A$ de modo a coincidir com o ponto $C$.

O que podemos dizer da localização do ponto $A$ ? O que aconteceu com os pontos $B$ e $D$ ?

3) Movimente o ponto $A$ de modo a coincidir com o ponto $D$.

O que podemos dizer da localização do ponto $A$ ? O que aconteceu com os pontos $B$ e $C$ ?

\section{Tarefa 4}

1) Considere os pontos a seguir e as observações nas Tarefas 2, 3 e 4 e complete a tabela. 


\begin{tabular}{|c|c|c|c|c|}
\hline \multicolumn{2}{|c|}{} & \multicolumn{2}{|c|}{$\begin{array}{c}\text { Projeção } \\
\text { Ponto }\end{array}$} & \multicolumn{2}{|c|}{$\begin{array}{c}\text { Projeção } \\
\text { ortogonal em OX }\end{array}$} & $\begin{array}{r}\text { Projeção } \\
\text { ortogonal em OY ortogonal em OZ }\end{array}$ \\
\hline$(3,1,0)$ & & & & \\
\hline$(4,0,-2)$ & & & & \\
\hline$(0,-6,2)$ & & & & \\
\hline
\end{tabular}

2) Descreva como são as coordenas das projeções ortogonais dos pontos $(7,-5,4)$ e $(4,2,-4)$ em cada caso.

a) Nos planos $O X Y, O X Z$ e $O Y Z$.

b) Nos eixos $O X, O Y$ e $O Z$.

\section{Tarefa 5}

Atividade de construção: Siga os passos a seguir para construir as projeções ortogonais de $A$ sobre os eixos coordenados.

Passo 1: Na barra de ferramentas, selecione a opção "Reta Perpendicular" (" seguida selecione o ponto $A$ e eixo $O X$.

Passo 2: Na barra de ferramentas, selecione a opção "Interseção de Dois Objetos" ( e depois selecione a reta criada no Passo 1 e o eixo $O X$. Será criado um ponto $E$, projeção ortogonal de $A$ sobre o eixo $O X$.

Passo 3: Repita os Passos 1 e 2 utilizando o eixo $O Y$. Será criado um ponto $F$, projeção ortogonal de $A$ sobre o eixo $O Y$.

Passo 4: Repita os Passos 1 e 2 utilizando o eixo OZ. Será criado um ponto G, projeção 
ortogonal de $A$ sobre o eixo $O Z$.

1) Com a construção feita, verifique suas respostas da Tarefa 4.

2) Observando as coordenadas de $E, F$ e $G$ apresentam as características esperadas da Tarefa 4?

3) Para um ponto qualquer $P=(a, b, c)$ como serão as coordenadas das suas projeções ortogonais sobre os eixos $O X, O Y$ e $O Z$ ?

Obs.: Ao terminar a atividade salve seu arquivo, pois será utilizado nas atividades seguintes.

Expectativas: Esperamos que o aluno compreenda que as coordenadas dos pontos que representam as projeções ortogonais de um ponto no espaço, se relacionam com as coordenadas do próprio ponto, ou seja, as projeções ortogonais do ponto $(a, b, c)$ nos planos OXY, OXZ e OYZ, são $(a, b, 0),(a, 0, c)$ e $(0, b, c)$, respectivamente e sobre os eixos OX, OY e OZ, são os pontos $(a, 0,0),(0, b, 0)$ e $(0,0, c)$, respectivamente.

Esperamos que através das construções o aluno observem as características citadas anteriormente e às valide no Geogebra.

\subsubsection{Atividade 3: Distância de um ponto aos eixos e planos coordenados}

Objetivos: Partindo da figura gerada na Atividade 2, a proposta desta atividade é o cálculo das distâncias entre o ponto $A$ e os planos $O X Y, O X Z$ e $O Y Z$, assim como, as distâncias entre o ponto $A$ e os eixos coordenados $O X, O Y$ e $O Z$.

Para isso, levaremos o aluno realizar construções de planos paralelos aos planos $O X Y, O X Z$ e $O Y Z$ passando por A e através de observações nas imagens feitas no Geogebra buscar estratégias para encontrar tais distâncias. 
Figura 160: Construção de plano paralelo ao plano $O X Y$ passando pelo ponto $A$ e sua Vista $2 D$

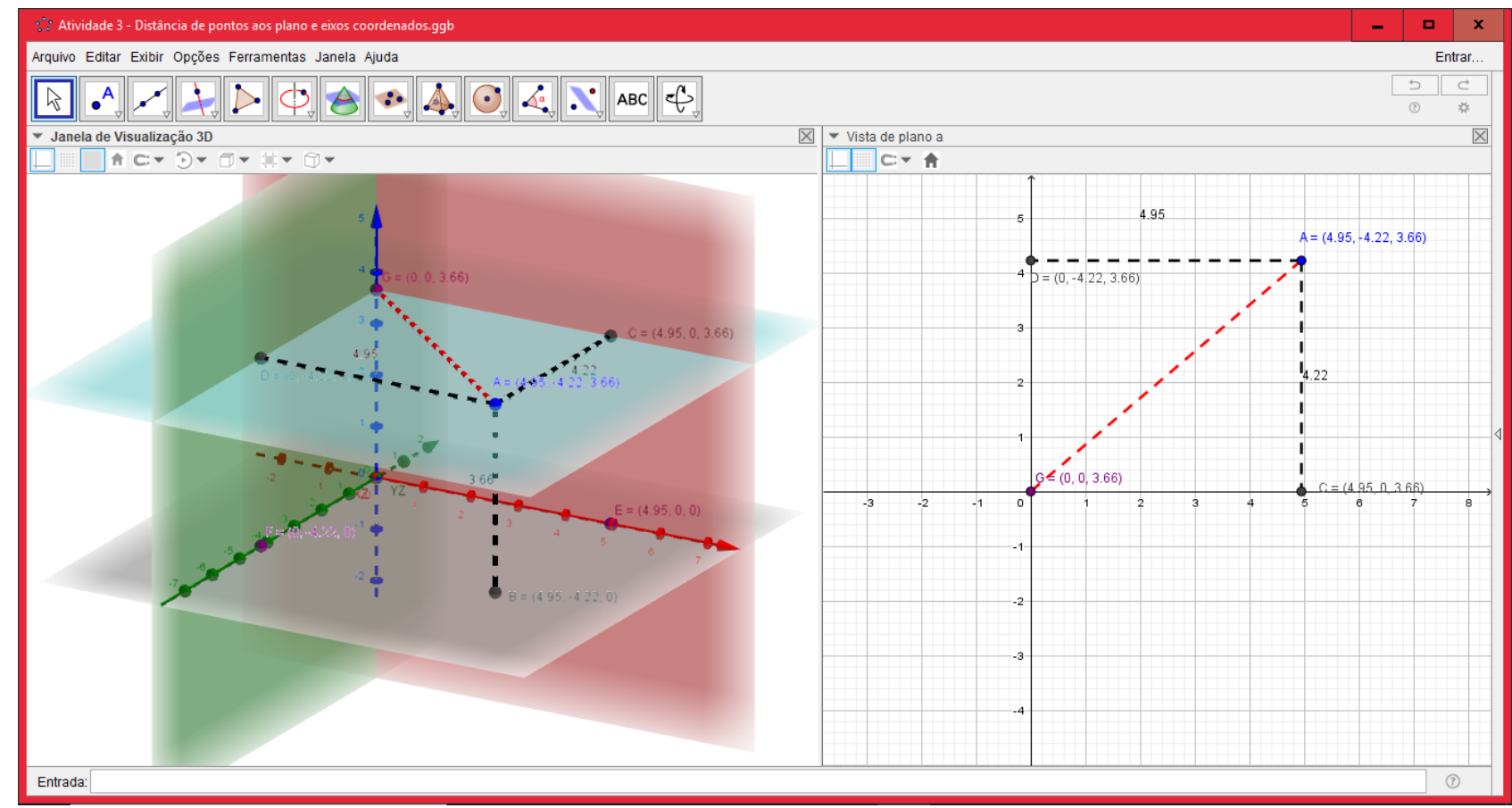

Fonte: A autora

\section{Atividade 3: Distância de um ponto aos eixos e planos coordenados}

Para iniciar a atividade, no Geogebra, abra o arquivo criado na Atividade 2.

$\mathrm{Na}$ barra de ferramentas, selecione a opção "Distância, Comprimento ou Perímetro", como na figura a seguir, e clique nos segmentos $\overline{A B}, \overline{A C}$ e $\overline{A D}$. Os valores gerados serão as medidas de comprimento desses segmentos.

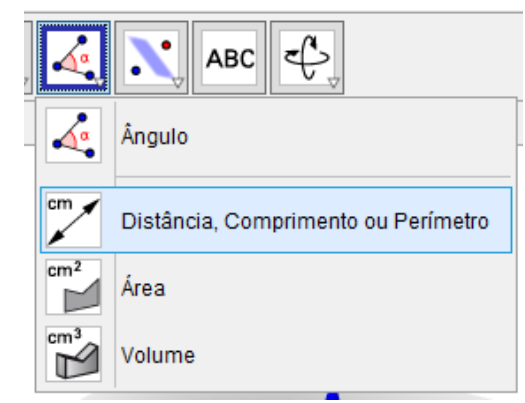

\section{Tarefa 1}


1) Escolha três posições para $A$, em octantes diferentes, e marque a medida do comprimento de cada segmento $\overline{A B}, \overline{A C}$ e $\overline{A D}$.

\begin{tabular}{|c|c|c|c|}
\hline & Posição 1 & Posição 2 & Posição 3 \\
\hline Ponto $A$ & & & \\
\hline$A B$ & & & \\
\hline$A C$ & & & \\
\hline$A D$ & & & \\
\hline
\end{tabular}

Descreva o que observou entre os comprimentos anotados e o ponto $A$.

2) Com base nas observações anteriores, considere os pontos $A=(3,-4,4)$ e $B, C$ e $D$, suas projeções ortogonais nos planos $O X Y, O X Z$ e $O Y Z$, respectivamente.

3) Qual o valor dos comprimentos dos segmentos $\overline{A B}, \overline{A C}$ e $\overline{A D}$ ?

4) Agora no Geogebra, posicione o ponto A nas coordenadas (3,- 4, 4) e verifique sua resposta.

5) Sabendo que os pontos $B, C$ e $D$ pertencem aos planos $O X Y, O X Z$ e $O Y Z$, respectivamente, o que podemos dizer da distância de $A$ aos planos coordenados?

\section{Tarefa 2}

Atividade de construção: Determinação da distância de A aos eixos coordenados.

Passo 1: Na barra de ferramentas, selecione a opção "Plano por três pontos" $(\stackrel{\square}{\square})$ e em seguida selecione os pontos $A, G$ e $D$. Será criado o plano a.

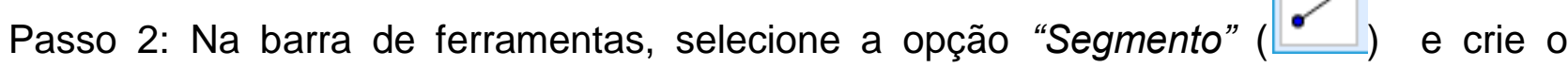
segmento $\overline{A G}$.

Passo 3: Crie a Vista 2D do plano a. 
1) A distância de $A$ ao eixo $O Z$ é a mesma que o comprimento do segmento $\overline{A G}$. Descreva uma estratégia para determinar essa distância.

Utilizando essa estratégia determine a distância do ponto $A=(-1,2,-3)$ ao eixo $O Z$. Verifique no Geogebra o seu resultado.

2) Repita o Passo 1 para os pontos $A, F$ e $B$. Será criado o plano $b$.

Repita o Passo 2 para $\overline{A F}$.

Repita o Passo 3 para o plano $b$.

Qual o significado do comprimento do segmento $\overline{A F}$ ?

Calcule a distância do ponto $A=(-2,3,4)$ ao eixo $O Y$ ?

Verifique no Geogebra o seu resultado.

3) Repita o Passo 1 para os pontos $A, E$ e $C$. Será criado o plano $c$.

Repita o Passo 2 para $\overline{A E}$.

Repita o Passo 3 para o plano $c$.

Qual o significado do comprimento do segmento $\overline{A E}$ ?

Calcule a distância do ponto $A=(3,-3,-4)$ ao eixo $O X$ ?

Verifique no Geogebra o seu resultado.

\section{Tarefa 3}

Para finalizar a atividade, conte para os outros alunos as estratégias que utilizou para determinar as distâncias do ponto $A$ aos planos $O X Y, O X Z$ e $O Y Z$ e as distâncias entre 0 ponto $A$ e os eixos $O X, O Y$ e $O Z$.

Obs.: Ao terminar a atividade salve seu arquivo, pois será utilizado nas atividades seguintes.

Expectativas: Esperamos que o aluno ao realizar a atividade compreenda que a 
distância de um ponto a um plano ordenado é a mesma que a distância desse mesmo ponto a sua projeção ortogonal nesse plano. Ao fim da atividade, o aluno deverá ter concluído que as distâncias aos planos $O X Y, O X Z$ e $O Y Z$ coincide com o valor absoluto da terceira coordenada (cota), segunda coordenada (ordenada) e a primeira coordenada (abscissa) de $A$, respectivamente.

Para a distância entre o ponto $\mathrm{A}$ e os eixos ordenados, esperamos que $\mathrm{o}$ aluno observe a existência de triângulos retângulos, onde a distância desejada é a medida do comprimento da hipotenusa deste retângulo.

$\mathrm{Na}$ tarefa que finaliza a atividade, o aluno pode escolher contar sua estratégia através de um exemplo ou de maneira generalizada.

\subsubsection{Atividade 4: Distância entre dois pontos no plano e no espaço}

Objetivos: A atividade tem como objetivos levar os alunos a elaborarem estratégias para o calculo da distância entre dois pontos no espaço.

A primeira tarefa está focada apenas na distância até a origem do sistema de coordenadas do espaço, enquanto a segunda tarefa tem seu foco em pontos quaisquer do espaço. 
Figura 161: Imagem para a determinação da distância entre dois pontos no espaço

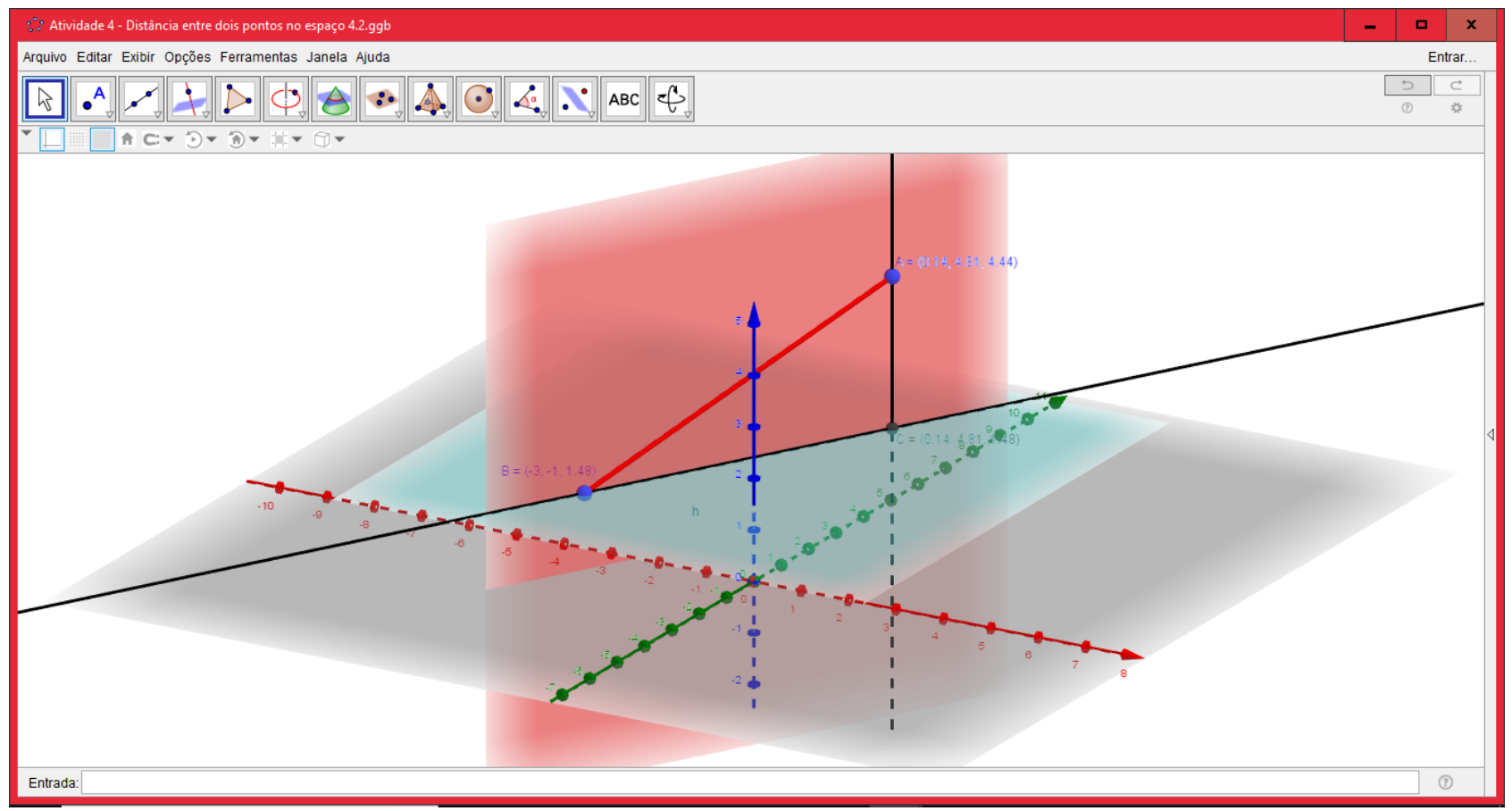

Fonte: A autora

\section{Atividade 4: Distância entre dois pontos no plano e no espaço}

Para iniciar a atividade abra o arquivo no Geogebra criado na Atividade 3, crie um ponto $O=(0,0,0)$ na barra de Entrada e clique "Enter".

Crie um plano passando pelo ponto $A$ e o eixo $O Z$, será criado o plano d.Exiba a vista $2 \mathrm{D}$ do plano $d$.

\section{Tarefa 1}

1) Com a construção e as informações da Atividade 3 descreva uma estratégia para o cálculo da distância entre os pontos $A$ e $O$.

2) Com a estratégia elaborada, calcule a distância entre os pontos $A=(-1,-$ 4,3) e $O=(0,0,0)$.

Verifique seu resultado no Geogebra.

3) Movimente o ponto $A$ para duas posições distintas e calcule a distância entre $A$ e $O$. 


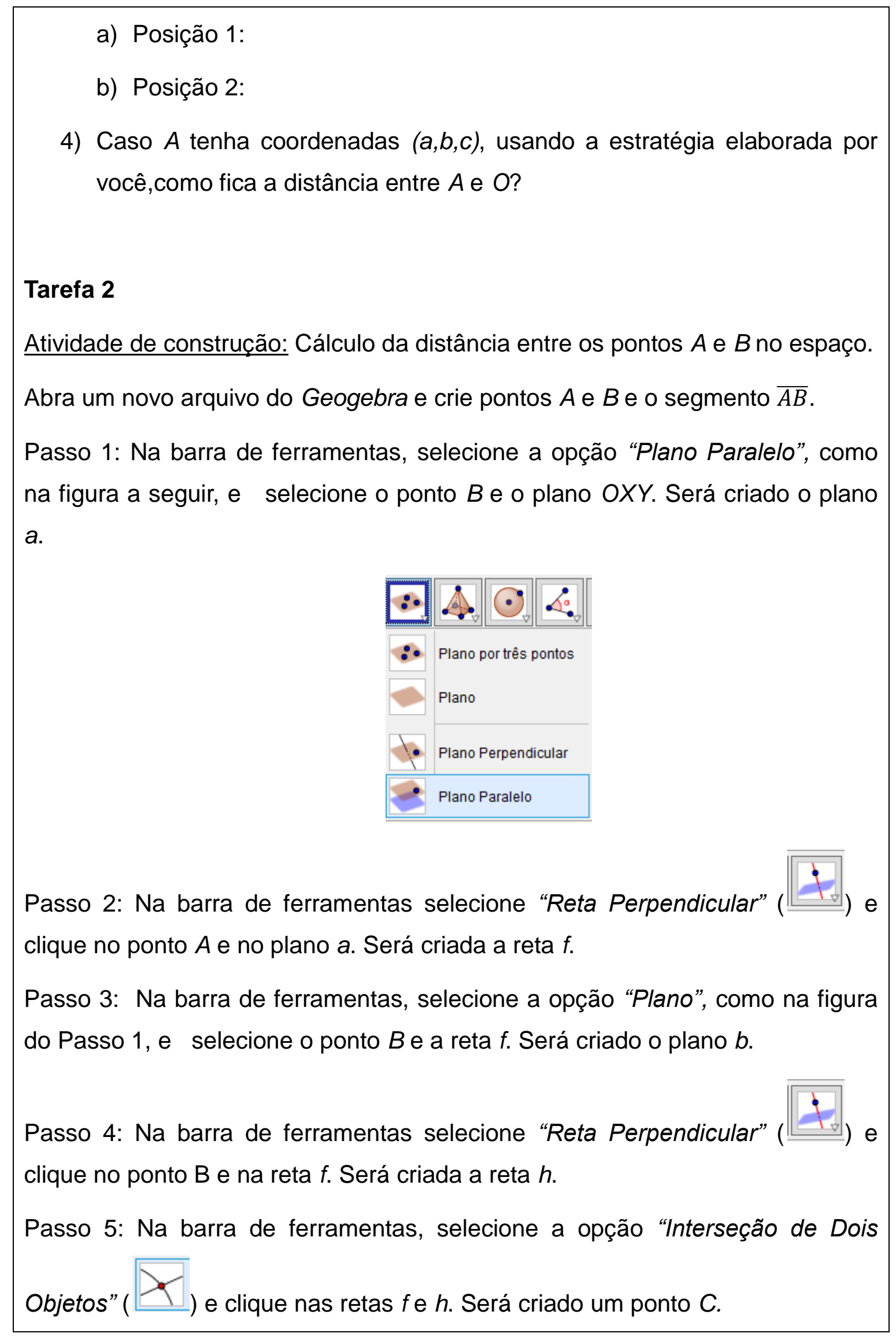


1) Observando a imagem, elabore uma estratégia para o cálculo da distância entre os pontos $A$ e $B$.

2) Movimente os pontos $A$ e $B$ e com a estratégia elaborada calcule a distância entre eles.

\begin{tabular}{|c|l|l|l|}
\hline Posição & Ponto $A$ & Ponto $B$ & Distância entre $A$ e $B$ \\
\hline 1 & & & \\
\hline 2 & & & \\
\hline
\end{tabular}

Verifique seu resultado no Geogebra.

3) Descreva com suas palavras como você explicaria para um colega a estratégia que elaborou para encontrar a distância entre dois pontos quaisquer no espaço.

Expectativas: Esperamos que o aluno observe que para determinar essas distâncias, basta utilizar as mesmas estratégias da Atividade 3, porém aplicando duas vezes, já que o problema consiste em encontrar a medida da hipotenusa de triângulo retângulo cujo um de seus catetos é a hipotenusa de um segundo triângulo retângulo.

\subsubsection{Atividade 5: Distância entre ponto e reta no plano - Composição de áreas}

Objetivos: A atividade tem como objetivo levar os alunos a calcular distâncias entre um ponto $P$ e uma reta passando pelos pontos $A$ e $B$ no plano através da composição de áreas de polígonos. 
Figura 162: Construção do trapézio para a composição das áreas

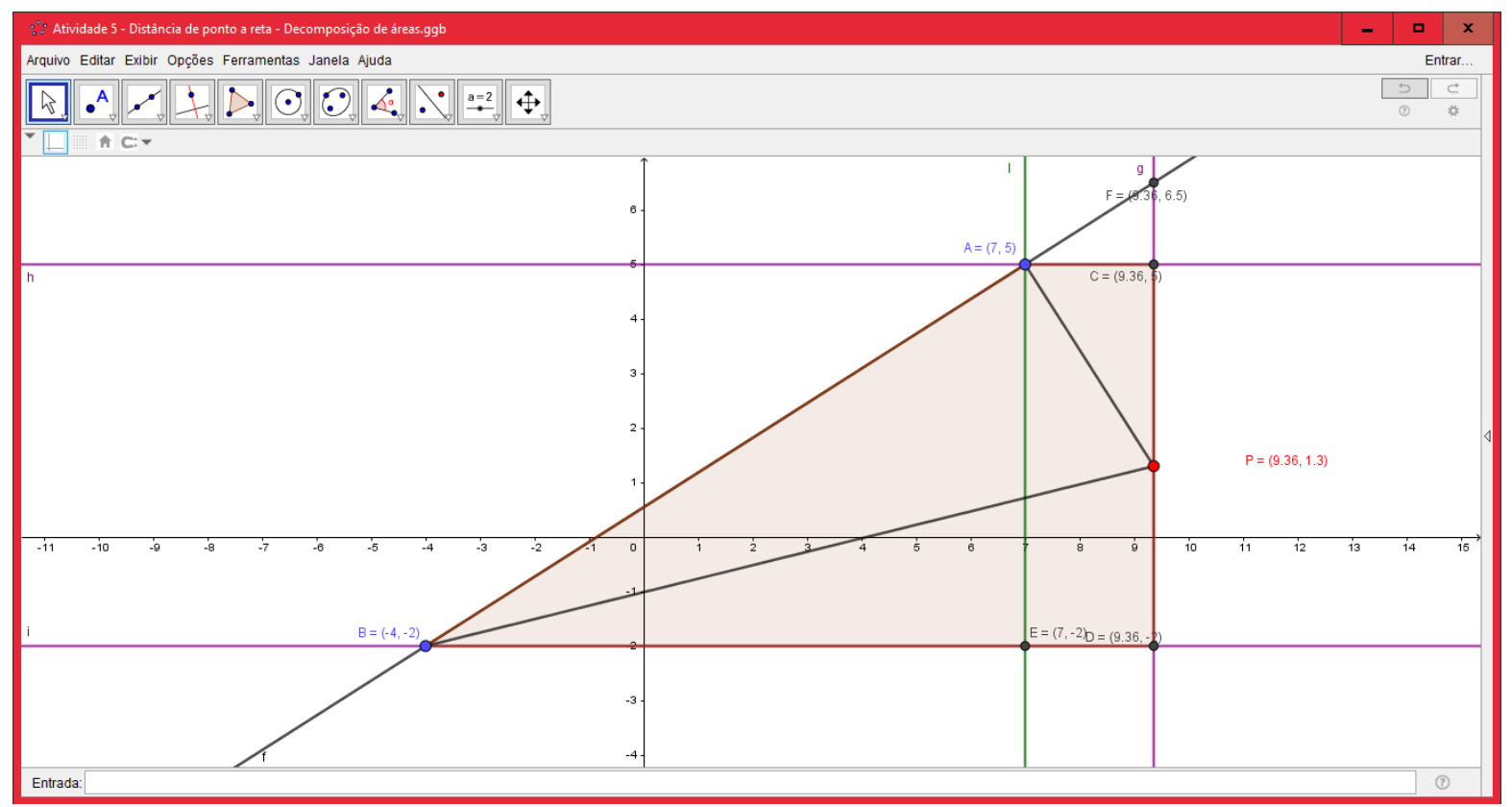

Fonte: A autora

Atividade 5: Distância entre ponto e reta no plano - Composição de áreas

\section{Tarefa 1}

Atividade de Construção:

Passo 1: Na barra de ferramentas, selecione a opção "Reta" ( $\stackrel{\circ}{=}$ e crie uma reta passando pelos pontos $A$ e $B$. Será criada a reta $f$.

Passo 2: Na barra de ferramentas, selecione a opção "Ponto" $\stackrel{\bullet^{A}}{\bullet_{\nabla}}$ ) e crie o ponto $P$.

Passo 3: Na barra de ferramentas selecione "Reta Perpendicular" ( ponto $P$ e no eixo OX. Será criada a reta $g$.

Passo 4: Repita os Passo 3 para o ponto $A$ e o eixo $O Y$ e em seguida para o ponto $B$ e o eixo $O Y$. Serão criadas as retas $h$ e $i$, respectivamente. 
Passo 5: Na barra de ferramentas selecione "Interseção de Dois Objetos" clique nas retas $g$ e $h$ e em seguida nas retas $g$ e $i$. Serão criados os pontos $C$ e D, respectivamente.

Passo 6: Na barra de ferramentas, selecione a opção "Segmento"

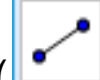
) e crie os segmentos $\overline{A P}$ e $\overline{B P}$.

\section{Tarefa 2}

1) Os pontos $A, B, D$ e $C$ formam quadrilátero que por sua vez está dividido em três triângulos. Qual a relação entre as áreas desses polígonos?

2) Explique como podemos calcular a área de cada um desses polígonos?

3) Movimente o ponto $P$ para uma posição qualquer e calcule as áreas dos polígonos.

\begin{tabular}{|l|l|l|l|}
\hline Ponto $P$ & Área $A B D C$ & \\
\hline Ponto $A$ & & Área $A C P$ & \\
\hline Ponto $B$ & & Área BCP & \\
\hline & & Área $A B P$ & \\
\hline
\end{tabular}

4) A medida altura do triângulo $A B P$ coincide com a distância do ponto $P$ á reta que assa pelos pontos $A$ e $B$. Para o exemplo do item anterior qual será essa distância?

Confira seu resultado no Geogebra.

5) Utilizando sua estratégia determine a distância do ponto $P=(8,2)$ à reta que passa pelos pontos $A=(3,4)$ e $B=(-3,1)$.

Confira seu resultado no Geogebra.

\section{Tarefa 3}


Determine a distância do ponto $P=(-1,3)$ à reta que passa pelos pontos $A=(7,5) \mathrm{e}$ $B=(-4,-2)$.

Confira seu resultado no Geogebra.

\section{Tarefa 4}

1) Descreva como você realizou a Tarefa 3 para um colega.

2) A solução que ele encontrou foi a mesma que a sua? Descreva as diferenças as soluções.

Expectativas: Esperamos que o aluno observe que a distância entre o ponto $P$ e a reta $\overleftrightarrow{A B}$ coincide com a medida da altura do triângulo $A B P$ e de posse desta informação busque estratégias para encontrar o valor da área do triângulo $A B P$ através das composições de áreas.

$\mathrm{Na}$ Tarefa 2, apresentamos um exemplo onde o quadrilátero $A B C D$ é um trapézio compostos pelo triângulo $A B P$ e mais dois triângulos retângulos $A C P$ e $B D P$. Já na Tarefa 3 apresentamos um exemplo onde o quadrilátero $A B C D$ não é convexo, esperamos que os alunos diante de duas situações diferentes possam encontrar estratégias diferentes para resolver os problemas propostos.

Orientações para o professor: $\mathrm{Na}$ Tarefa 2, caso algum aluno em sua construção não entrar um trapézio, deve ser orientado a movimentar o ponto $\mathrm{P}$ até uma posição de modo a fazer os pontos $A, B, C$ e $D$ formarem um trapézio. Casos diferentes serão explorados na Tarefa 3.

Nesta atividade apresentamos dois casos que podem ocorrer de acordo com a posição relativa entre o ponto $P$ e a reta $\overleftrightarrow{A B}$, o(a) professor(a) pode questionar os alunos sobre as posições possíveis e sugerir que calculem a distância para esses outros casos. 


\section{Capítulo 4 - Conclusão}

Esta pesquisa foi motivada por nossa experiência com alunos do Ensino Básico que apresentavam dificuldades em compreender de maneira significativa objetos geométricos como circunferência e retas através de suas representações gráfica e algébrica.

Para iniciá-lo realizamos um questionário com alunos ingressantes nos cursos de Licenciatura em Matemática e Física, com o objetivo de verificar como esses alunos interpretavam esses objetos geométricos apenas com seus conhecimentos do Ensino Básico. Ao analisarmos as respostas apresentadas concluímos que muitos não conseguem estabelecer uma conexão entre as possíveis representações dos objetos (pontos e retas) e suas diferentes interpretações na reta real, plano cartesiano e espaço cartesiano.

Também verificamos como os livros didáticos abordam os conteúdos sobre geometria analítica e para isso analisamos como os objetos geométricos do nosso interesse são apresentados de acordo com a teoria de Duval sobre registros de representação semiótica. Verificamos que a maioria das coleções analisadas faz na maior parte do tempo o uso de fórmulas e representações algébrica e gráfica e com poucas conversões entre registros. Outra observação é em relação ao estudo dos objetos no espaço, todas as coleções trabalham apenas com os objetos no plano. Esse fato corrobora com os resultados apresentados no questionário, onde a maioria dos alunos não conseguiu responder questões sobre o espaço por nunca ter estudado $o$ assunto.

Com esses dados propusemos atividades sobre o cálculo de distâncias, sem o uso de fórmulas, entre objetos do plano e do espaço. Porém para trabalhar com essas distâncias sentimos a necessidade de fazer antes um trabalho com coordenadas no plano e no espaço.

Em nossa experimentação, apresentamos atividades onde os sistemas de coordenadas cartesianas tanto no plano quanto no espaço foram trabalhados com o auxílio do software Geogebra e com materiais manipuláveis. 
Devido a alguns imprevistos não foi possível aplicar na experimentação as atividades sobre distâncias, porém as deixamos como propostas de atividades.

Apesar do estudo da Geometria Analítica no espaço não estar presente explicitamente nos currículos do Ensino Médio, por meio de nosso experimento concluímos que ela pode ser trabalhada sem grandes dificuldades para os alunos, sendo que ao longo dos dez encontros da nossa experimentação os alunos criaram uma familiaridade com o uso de coordenadas do plano e do espaço e suas representações, realizando atividades de conversão das representações. 


\section{Referências Bibliográficas}

BORSOI, C. Geometria Analítica e GrafEq: Compreensão de conceitos a partir do diálogo entre representações. In: XII Encontro Gaúcho de Educação Matemática, 2015,Porto Alegre. Anais eletrônicos, Porto Alegre, 2015. Disponível em: http://ebooks.pucrs.br/edipucrs/anais/anais-do-egem/assets/2015/1670704017B.pdf. Acesso em: 28 jan 2016.

BRASIL. Ministério da Educação e Cultura (MEC). Guia de Livros Didáticos PNLD Ensino Médio - Matemática. Brasília: SEF/MEC, 2015.

BRASIL, Ministério da Educação e Cultura (MEC). Parâmetros Curriculares Nacionais para o Ensino Médio, Brasília: SEF/MEC, 2000.

BRAVIANO, G. LUNARDELLI, G. C. M. O desenvolvimento da Habilidade de Visualização Espacial por meio de atividades lúdico-pedagógicas. In: VI Congresso Internacional de Ensino da Matemática, 2013, Canoas. Anais eletrônicos, Canoas, 2013. Disponível em:

http://www.conferencias.ulbra.br/index.php/ciem/vi/paper/viewFile/875/321. Acesso em: 12 dez 2017.

CALIXTO, R. A., CARDOSO, A., SOUZA JR, J. C. Geogebra 3D: Uma ferramenta para estudo de volumes no Ensino Médio. Revista da Universidade de Vale do Rio Verde, Três Corações, v.12, n.1, p. 755-764, 2014. Disponível em: http://periodicos.unincor.br/index.php/revistaunincor/article/view/1433/pdf_160. Acesso em: 16 jan 2016.

CASSIANO, M. O jogo do NIM: uma alternativa para reforçar o algoritmo da divisão no sexto ano do ensino fundamental. 2009. 154 f. Dissertação (Mestrado em Educação) - Pontifícia Universidade Católica de São Paulo, São Paulo, 2009. 
D'AMORE, B. Epistemologia e didática da Matemática. Tradução de: Maria Cristina Bonomi Barufi. 1ª ed. São Paulo: Escrituras Editora, 2005.

DANTE, L. R. Matemática: Contexto e Aplicações. 2. ed. São Paulo: Editora Ática, 2014.

DUVAL, Raymond. Semiósis e Pensamento Humano: Registros semióticos e aprendizagens intelectuais (Fascículo I), Tradução de: Lênio Fernandes Levy e Marisa Rosâni Abreu da Silveira, $1^{a}$ ed. São Paulo: Livraria da Física, 2009.

DUVAL, Raymond. Abordagem cognitiva de geometria em termos de congruência. Tradução do artigo original em francês de: Méricle Tadeu Moretti. REVEMAT: Revista Eletrônica de Educação Matemática, Florianópolis/SC, v. 7, n. 1, p. 118138, jul. 2012. ISSN 1981 - 1322.

Disponível em: https://periodicos.ufsc.br/index.php/revemat/article/view/19811322.2012v7n1p118/22382. Acesso em: 15 mai. 2015.

FIOREZE, L. A., HALBERSTADT,F. F. O ensino e aprendizagem de Geometria Analítica: A questão do pensamento generalizador com o software GrafEq In: XII Encontro Gaúcho de Educação Matemática, 2015,Porto Alegre. Anais eletrônicos, Porto Alegre, 2015. Disponível em:

http://ebooks.pucrs.br/edipucrs/anais/anais-do-egem/assets/2015/1417944021.pdf. Acesso em: 28 jan 2016.

FRANCO, V. S, MORAN, M. Tratamentos figurais e mobilização de Registros para a resolução de problemas de geometria. REVEMAT: Revista Eletrônica de Educação Matemática. Florianópolis/SC, v.10, n.2, p. 61-75, 2015.

GARCIA, J.F., SEHNEM, R., SIMÕES JÚNIOR, R. Geogebra 3D: Uma nova possibilidade no ensino-aprendizagem da geometria. In: III Salão de Iniciação Científica e Inovação Tecnológica, 2013, Bento Gonçalves. Anais eletrônicos: IFRS, 2013. Disponível em: 
http://www.bento.ifrs.edu.br/site/midias/arquivos/201502981923515scit-_rafaela.pdf. Acesso em: 16 jan 2016.

GIMENEZ, J., LINS, R. C. Perspectivas em Aritmética e Álgebra para o século XXI, Campinas/SP: Papirus Editora, 1997.

JOLY, M. C. R. A.; MUNER, L. C.; PRIETO, G.; SILVA, D. V.; Visualização Espacial e desempenho em Matemática no Ensino Médio e Profissional. Avaliação Psicológica. Itatiba, v. 10, n. 2, p. 181-191, ago 2011. Disponível em http://pepsic.bvsalud.org/scielo.php?pid=S16774712011000200009\&script=sci_abstr act\&tIng=pt. Acesso em: 23. nov. 2017

KARRER, Mônica. Articulação entre Álgebra Linear e Geometria: um estudo sobre as Transformações Lineares na perspectiva dos Registros de Representações Semiótica. 2006, 435 f. Tese de Doutorado (Educação Matemática- Pontifícia Universidade Católica de São Paulo, São Paulo, 2009.

LEONARDO, F. M. de. Conexões com a Matemática. 2. ed. São Paulo: Editora Moderna, 2013.

LOPES, M. R. M., VERONA, V. A. Aplicação da Geometria Espacial em Ambientes Diversos. Paraná. Disponível em:

http://www.diaadiaeducacao.pr.gov.br/portals/pde/arquivos/2455-8.pdf. Acesso em: 23. nov. 2017

LORENZATO, Sergio. Laboratório de ensino de matemática e materiais didáticos manipuláveis. In: LORENZATO, S. (Org.) O Laboratório de Ensino de Matemática na formação de professores. São Paulo: Autores Associados, 2006, p. 3-37.

PAIVA, M. Matemática Paiva. 2. ed. São Paulo: Editora Moderna, 2013. 
RESENDE, A. C., FERREIRA, F. N. Uma Proposta para o Ensino de Geometria Espacial de Posição na EJA. 2013. 38 f. Trabalho de Conclusão de Curso do Mestrado Profissional em Matemática - PROFMAT, Universidade Federal de São João del-Rei - UFSJ, Sociedade Brasileira de Matemática - SBM, 2013.

SOUZA, J. Novo Olhar - Matemática. 2. ed. São Paulo: Editora FTD, 2013.

TURRIONI, A. M. S. PEREZ, G. Implementando um laboratório de educação matemática para apoio na formação de professores. In: LORENZATO, S. (Org.) Laboratório de Ensino de Matemática na formação de professores. São Paulo: Autores Associados, 2006, p. 57-76. 


\section{Anexos}

\section{Anexo I - Análise do questionário para estudantes ingressantes do IME e IF USP 2016}

O questionário a seguir foi aplicado em duas turmas de alunos ingressantes nos cursos de Licenciatura em Matemática e Licenciatura em Física da Universidade de São Paulo ${ }^{13}$, na disciplina de Geometria Analítica.

\section{Questão 1}

Explique o que significam as expressões abaixo:
a) $x=1$
b) $x<0$
c) $x=y$
d) $x^{2}=9$
e) $y^{2}+x^{2}-4=0$

\section{$\underline{\text { Respostas }}$}

Era esperado que os alunos conseguissem fazer a interpretação dessas expressões no contexto da Geometria Analítica espacial levando em consideração os sistemas de coordenadas na reta, no plano e no espaço.
a) $x=1$

\section{Resposta esperada}

$\mathrm{Na}$ reta real, esta equação representa um ponto de coordenada $x=1$; no plano o conjunto dos pontos $(1, y)$ que formam uma reta paralela ao eixo $O y$

\footnotetext{
${ }^{13} 44$ alunos da Matemática e 31 alunos da Física.
} 
passando no eixo $O x$ no ponto $(1,0)$; e no espaço o conjunto de pontos $(1, y, z)$ que formam um plano vertical (paralelo ao plano $O y z$ ) passando pelo ponto $(1,0,0)$.

\section{$\underline{\text { Respostas obtidas }}$}

Tabela 10: Respostas apresentadas pelos estudantes na Questão 1 Item a

\begin{tabular}{|l|c|c|}
\hline \multicolumn{1}{|c|}{ Respostas } & IME & FISICA \\
\hline Resposta esperada & 2 & ---- \\
\hline $\begin{array}{l}\text { Ponto na reta de coordenada } x=1 \text { e reta paralela ao } \\
\text { eixo Oy passando no eixo Ox no ponto (1,0) }\end{array}$ & ---- & 1 \\
\hline Ponto na reta de coordenada $x=1$ & 4 & 7 \\
\hline $\begin{array}{l}\text { Reta paralela ao eixo Oy passando no eixo Ox no ponto } \\
\text { (1,0) }\end{array}$ & 6 & 2 \\
\hline Equação do 1o grau & 4 & 2 \\
\hline Valor numérico da incógnita/variável é 1 & 27 & 17 \\
\hline Ponto no plano cartesiano & 1 & ---- \\
\hline Ponto (sem especificar onde) & ---- & 1 \\
\hline Reta crescente passando por (1,0) & ---- & ---- \\
\hline Branco & & 1 \\
\hline
\end{tabular}

Fonte: A autora

b) $x<0$

\section{$\underline{\text { Resposta esperada }}$}

$\mathrm{Na}$ reta são os pontos com coordenadas estritamente negativas e que se localizam a esquerda da origem; no plano são todos os pontos $(x, y)$ que pertencem 
aos segundo e terceiro quadrantes ${ }^{14}$, excluindo os eixos $O x$ e $O u$; e no espaço são os pontos $(x, y, z)$ que possuem a abscissa estritamente negativa.

\section{$\underline{\text { Respostas obtidas }}$}

Tabela 11: Respostas apresentadas pelos estudantes na Questão 1 Item b

\begin{tabular}{|l|c|c|}
\hline \multicolumn{1}{|c|}{ Respostas } & IME & FISICA \\
\hline Resposta esperada & 1 & ---- \\
\hline $\begin{array}{l}\text { Pontos na reta com coordenadas negativas e pontos do } \\
\text { plano com abscissa negativa }\end{array}$ & ---- & ---- \\
\hline Pontos na reta com coordenadas negativas & 4 & 7 \\
\hline Pontos do plano com abscissa negativa & 2 & 3 \\
\hline Inequação do 1o grau & 3 & 5 \\
\hline Valor numérico da incógnita/variável é menor que zero & 32 & 16 \\
\hline Semi plano limitado por uma reta inclinada & 1 & ---- \\
\hline Função definida para $x<0$ & ---- & ---- \\
\hline Branco & & 1 \\
\hline
\end{tabular}

Fonte: A autora

c) $x=y$

\section{$\underline{\text { Resposta esperada }}$}

No plano são os pontos $(x, x)$ que formam a reta bissetriz dos quadrantes ímpares e no espaço são os pontos $(x, x, z)$ formando um plano vertical que contem a reta bissetriz dos quadrantes ímpares do plano $O x y$.

\section{$\underline{\text { Respostas obtidas }}$}

${ }^{14}$ Os eixos Ox e Oy dividem o plano em quatro regiões denominadas quadrantes. Os nomes dos quadrantes são indicados no sentido anti-horário, sendo o primeiro o que contém os pontos com as coordenadas positivas. 
Tabela 12: Respostas apresentadas pelos estudantes na Questão 1 Item c

\begin{tabular}{|l|c|c|}
\hline \multicolumn{1}{|c|}{ Respostas } & IME & FISICA \\
\hline Resposta esperada & 1 & ---- \\
\hline $\begin{array}{l}\text { Pontos }(x, x) \text { que formam a reta bissetriz dos } \\
\text { quadrantes ímpares }\end{array}$ & 12 & 5 \\
\hline $\begin{array}{l}\text { Pontos }(x, x, z) \text { formando um plano vertical que contem } \\
\text { a reta bissetriz dos quadrantes ímpares do plano Oxy }\end{array}$ & ---- & ---- \\
\hline Incógnitas/variáveis com o mesmo valor numérico & 22 & 14 \\
\hline Equação & ---- & ---- \\
\hline Os planos das abscissas e coordenadas iguais & 1 & ---- \\
\hline Números que apresentam propriedades iguais & 1 & ---- \\
\hline Incógnitas iguais & 2 & 5 \\
\hline Função & ---- & 2 \\
\hline$x$ e $y$ mesmo valor na reta real & ---- & 1 \\
\hline Reta & --- & 1 \\
\hline Pontos no plano com mesmas coordenadas & 1 & 1 \\
\hline Identidade & -- \\
\hline Dois pontos no plano cartesiano com mesmo valor & & 1 \\
\hline Branco & - & \\
\hline
\end{tabular}

Fonte: A autora

d) $x^{2}=9$

\section{Resposta esperada}

Na reta são os pontos de coordenadas $x=-3$ e $x=3$, no plano são os pontos $(-3, y)$ e $(3, y)$ que formam as retas paralelas ao eixo $O u$ passando no eixo Ox nos pontos $(-3,0)$ e $(3,0)$ e no espaço são os pontos $(-3, y, z)$ e $(-3, y, z)$ que 
formam os planos verticais passando pelas retas formadas pelos pontos $(-3, y, 0)$ e $(3, y, 0)$.

\section{$\underline{\text { Respostas obtidas }}$}

Tabela 13: Respostas apresentadas pelos estudantes na Questão 1 Item d

\begin{tabular}{|c|c|c|}
\hline Respostas & IME & FISICA \\
\hline Resposta esperada & ---- & --- \\
\hline $\begin{array}{l}\text { Pontos da reta de coordenadas } x=-3 \text { e } x=3 \text { ou retas } \\
\text { paralelas ao eixo Ou passando no eixo Ox nos pontos } \\
(-3,0) \text { e }(3,0)\end{array}$ & ---- & ---- \\
\hline Pontos da reta de coordenadas $x=-3$ e $x=3$ & 5 & ---- \\
\hline Ponto na reta de coordenada $x=3$ & $\begin{array}{l}--- \\
---\end{array}$ & 1 \\
\hline $\begin{array}{l}\text { Retas paralelas ao eixo } O u \text { passando no eixo } O x \text { nos } \\
\text { pontos }(-3,0) \text { e }(3,0)\end{array}$ & 1 & 1 \\
\hline $\begin{array}{l}\text { Reta paralela ao eixo Ou passando no eixo } O x \text { no ponto } \\
(3,0)\end{array}$ & ---- & 1 \\
\hline Equação do $2^{\circ}$ grau & 10 & 3 \\
\hline Valor numérico da incógnita/variável 3 e - 3 & 25 & 19 \\
\hline Parábola & ---- & 3 \\
\hline Ponto 3 & $\begin{array}{c}--- \\
-1\end{array}$ & 1 \\
\hline Dois pontos & 2 & 1 \\
\hline Igualdade de uma igualdade & $-\overline{---}$ & 1 \\
\hline Branco & 1 & ---- \\
\hline
\end{tabular}

Fonte: Autora

e) $y^{2}+x^{2}-4=0$

\section{$\underline{\text { Resposta esperada }}$}


No plano é a circunferência centrada na origem e de raio 2 e no espaço é o cilindro centrado na origem e de raio 2.

\section{$\underline{\text { Respostas obtidas }}$}

Tabela 14: Respostas apresentadas pelos estudantes na Questão 1 Item e

\begin{tabular}{|l|c|c|}
\hline \multicolumn{1}{|c|}{ Respostas } & IME & FISICA \\
\hline Resposta esperada & 1 & ---- \\
\hline Circunferência centrada na origem e de raio 2 & 10 & 9 \\
\hline Cilindro centrado na origem e de raio 2 & --- & ---- \\
\hline Circunferência centrada no ponto (2,2) e de raio 2 & 1 & ---- \\
\hline Função & 1 & ---- \\
\hline Função do 2o grau & 2 & ---- \\
\hline Equação do 2o grau com duas incógnitas & 1 & ---- \\
\hline Valor numérico com duas incógnitas/variáveis & 10 & 5 \\
\hline Cônica: parábola & 1 & 1 \\
\hline Equação de um objeto circular & 1 & ---- \\
\hline Equação/expressão & 6 & 7 \\
\hline Equação de um sistema & 1 & ---- \\
\hline Figura e seus pontos & ---- & 1 \\
\hline Teorema de Pitágoras & ---- \\
\hline$x+y=2$ & 1 & 1 \\
\hline Triângulo & & 6 \\
\hline Branco & & \\
\hline
\end{tabular}

Fonte: A autora

As próximas questões foram aplicadas apenas para os alunos da Física. 


\section{Questão 2}

Represente no plano cartesiano as seguintes desigualdades:
a) $x<y$
b) $y<x$
c) $x^{2}>1$
d) $y^{2}>x^{2}$

\section{$\underline{\text { Respostas }}$}

Aqui é esperado que o aluno interprete as desigualdades como condições que os pontos do plano devem satisfazer para formar determinados conjuntos.
a) $x<y$

Figura 163: Resposta esperada Questão 2 item a

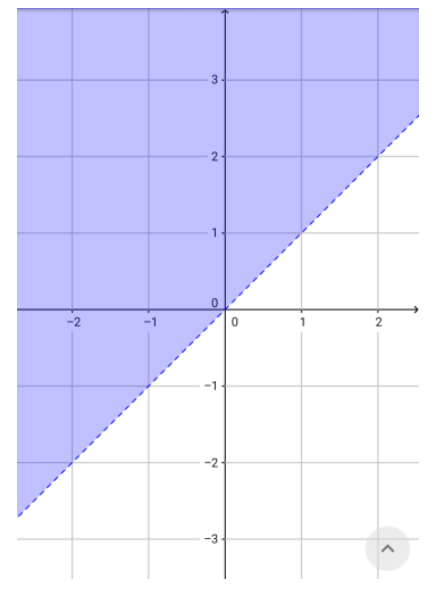

Fonte: A autora

$\underline{\text { Respostas obtidas }}$ 
Gráfico 10: Respostas apresentadas pelos estudantes para a Questão 2 item a

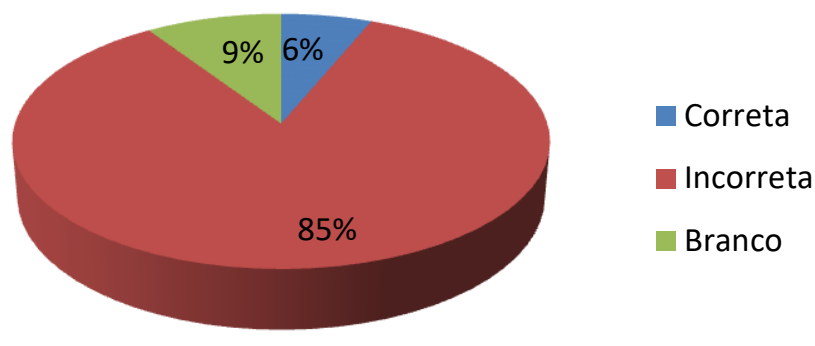

Fonte: A autora

A resposta mais próxima da correta continha a região $x>y$ (Figura 164). Outras respostam apresentavam uma reta (Figura 165) ou um caso particular com a abscissa menor que a ordenada (Figura 166).

Figura 164: Resposta obtida para Questão 2

Item a

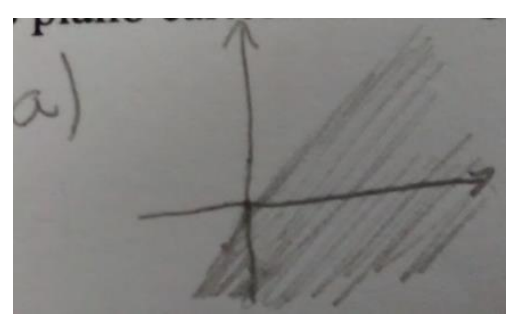

Fonte: Questionário

Figura 165: Resposta obtida para Questão 2 Item a

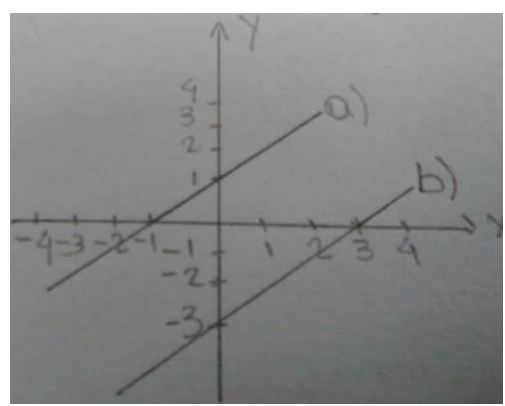

Fonte: Questionário
Figura 166: Resposta obtida para Questão 2 Item a

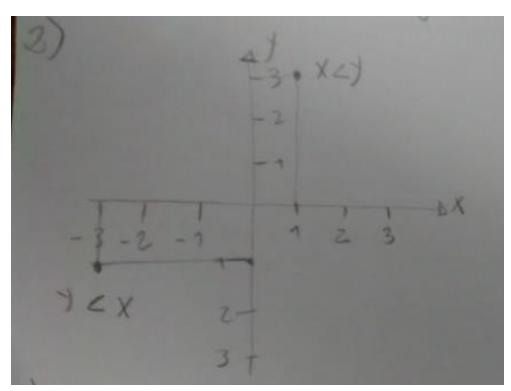

Fonte: Questionário 
b) $y<x$

Figura 167: Resposta esperada Questão 2 item b

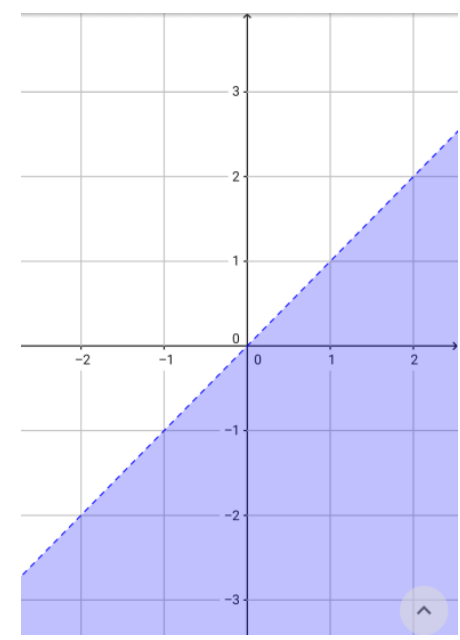

Fonte: A autora

\section{$\underline{\text { Respostas obtidas }}$}

Gráfico 11: Respostas apresentadas pelos estudantes para a Questão 2 item b

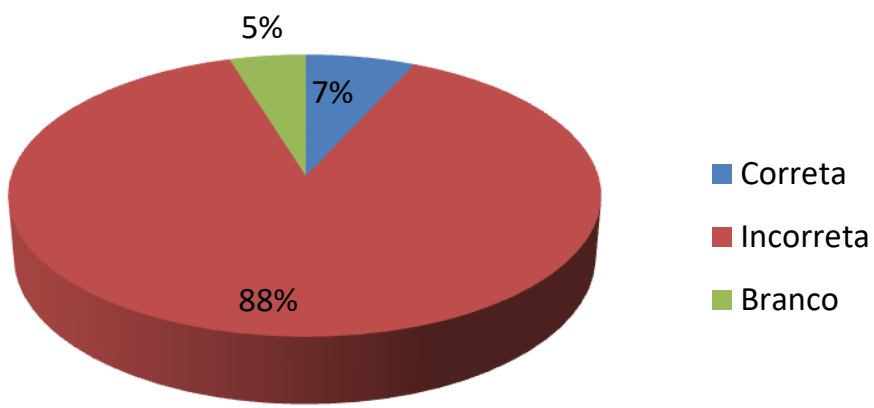

Fonte: A autora

A resposta mais próxima da correta continha a região $y>x$ (Figura 168). Outras respostam apresentavam uma reta (Figura 165) ou um caso particular com a ordenada menor que a abscissa (Figura 166). 
Figura 168: Resposta obtida para Questão 2 Item b

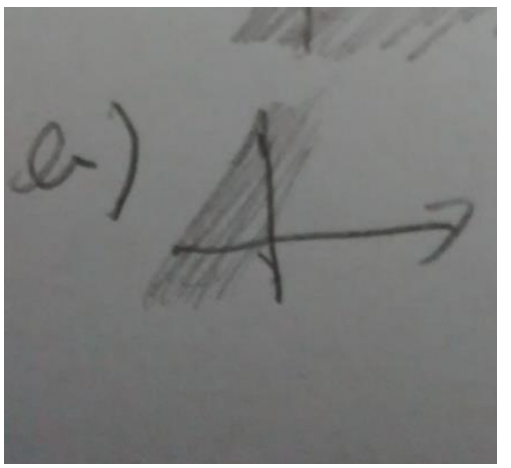

Fonte: Questionário

c) $x^{2}>1$

Figura 169: Resposta esperada Questão 2 item c

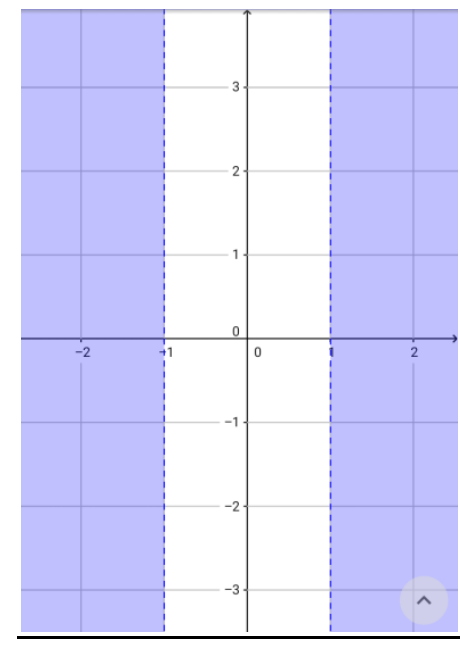

Fonte: A autora

\section{Respostas obtidas}

Gráfico 12: Respostas apresentadas pelos estudantes para a Questão 2 item c

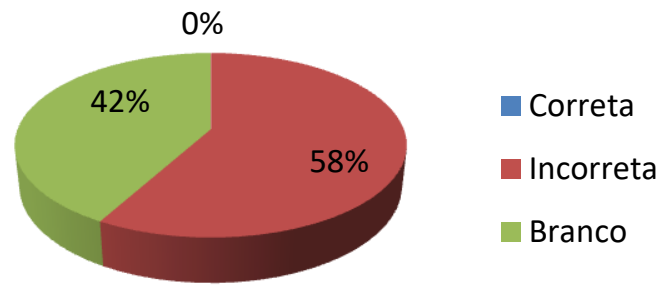

Fonte: A autora 
Algumas respostas apresentavam a resposta apenas no caso da reta (

Figura 170) e no plano uma das respostas considerou apenas os pontos de abscissa positiva (Figura 171). Outras apresentaram uma parábola (Figura 172).

Figura 170: Resposta obtida para Questão 2

Item c

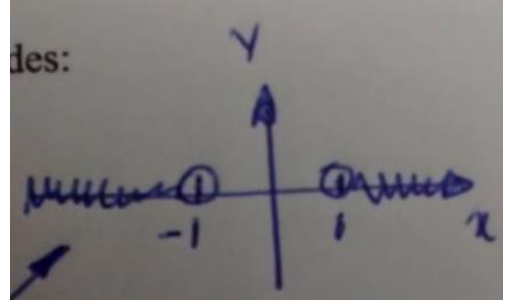

Fonte: Questionário
Figura 172: Resposta obtida para Questão 2

Item c

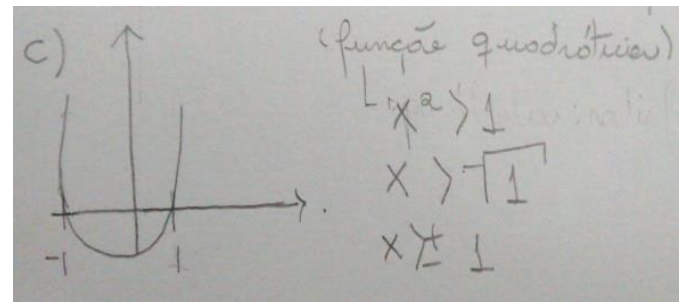

Fonte: Questionário

Figura 171: Resposta obtida para Questão 2 Item c

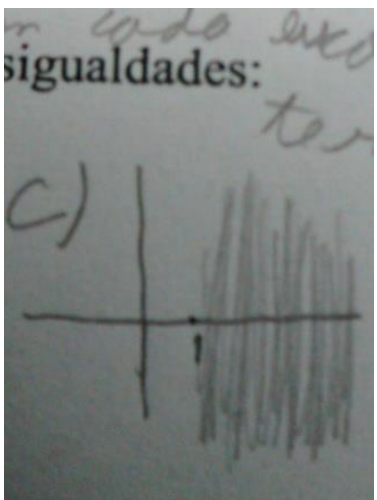

Fonte: Questionário

d) $y^{2}>x^{2}$ 
Figura 173: Resposta esperada Questão 2 item d

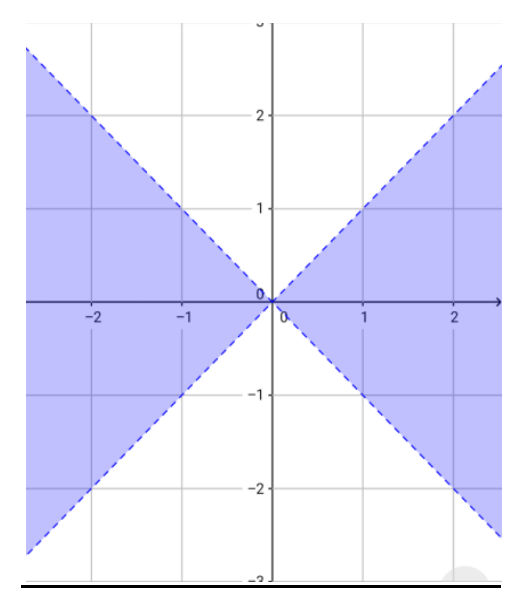

Fonte: A autora

\section{$\underline{\text { Respostas obtidas }}$}

Gráfico 13: Respostas apresentadas pelos estudantes para a Questão 2 item d

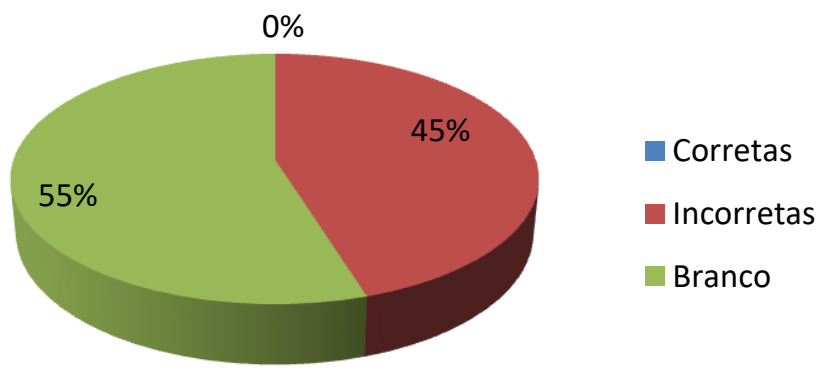

Fonte: A autora

Uma das respostas incorretas apresentou uma parábola (Figura 174).

Figura 174: Resposta obtida para Questão 2 Item d

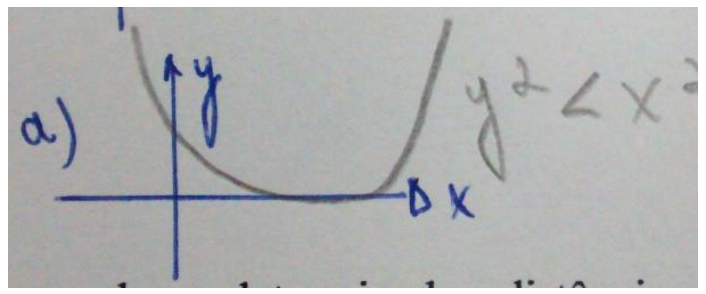

Fonte: Questionário 


\section{Questão 3}

Explique como pode ser determinada a distância entre dois pontos de uma a reta. E entre dois pontos de um plano? E no caso do espaço?

\section{$\underline{\text { Resposta esperada }}$}

Na reta dados dois pontos de coordenadas $x$ e $y$ temos $d=|x-y|$.

Figura 175: Resposta esperada Questão3 na reta

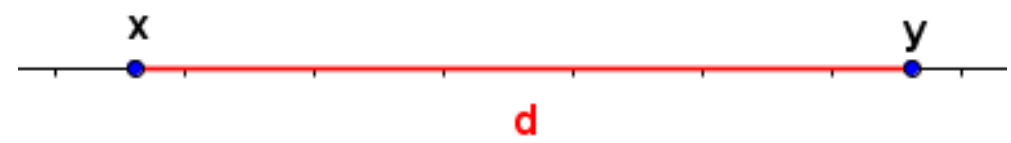

Fonte: A autora

No plano dados dois pontos $A=\left(x_{A}, y_{A}\right)$ e $B=\left(x_{B}, y_{B}\right)$.

Figura 176: Resposta esperada Questão 3 no plano

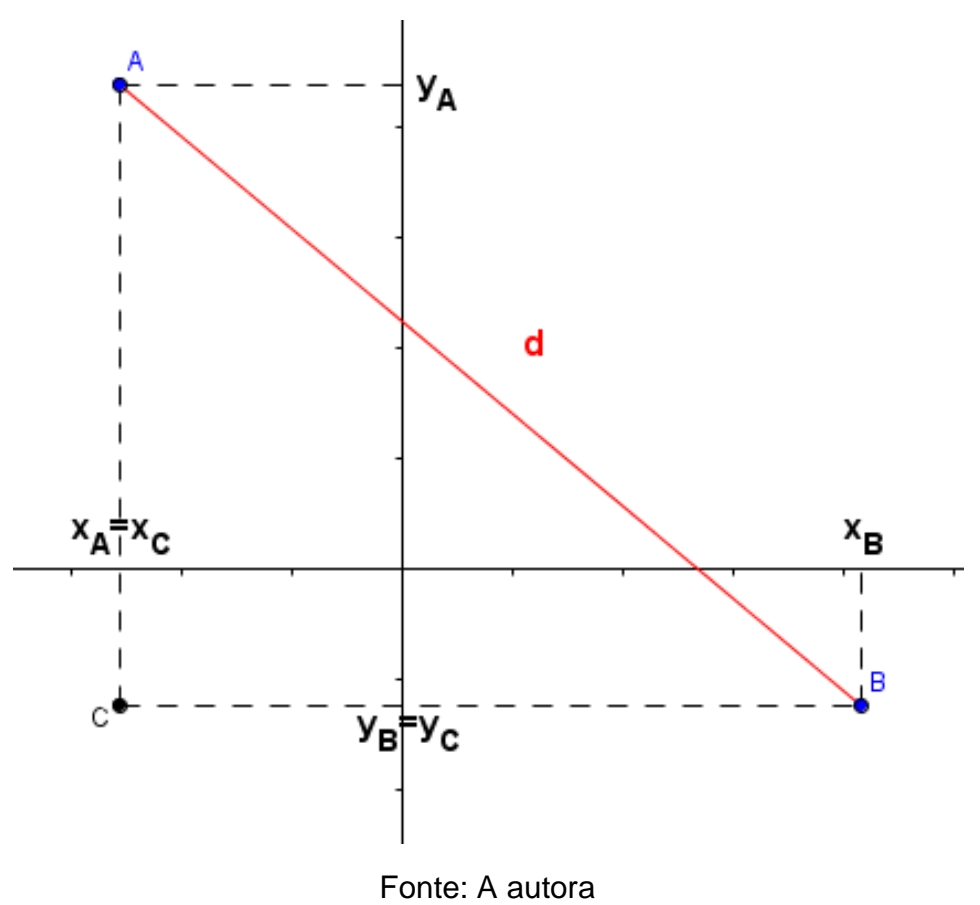


Observando o triângulo retângulo $\mathrm{ABC}$ e aplicando o Teorema de Pitágoras tem-se:

$$
d=\sqrt{\left(x_{C}-x_{B}\right)^{2}+\left(y_{A}-y_{C}\right)^{2}} \Leftrightarrow d=\sqrt{\left(x_{A}-x_{B}\right)^{2}+\left(y_{A}-y_{B}\right)^{2}} .
$$

No espaço, dados dois pontos $A=\left(x_{A}, y_{A}, z_{A}\right)$ e $B=\left(x_{B}, y_{B}, z_{B}\right)$.

Figura 177: Resposta esperada Questão 3 no espaço

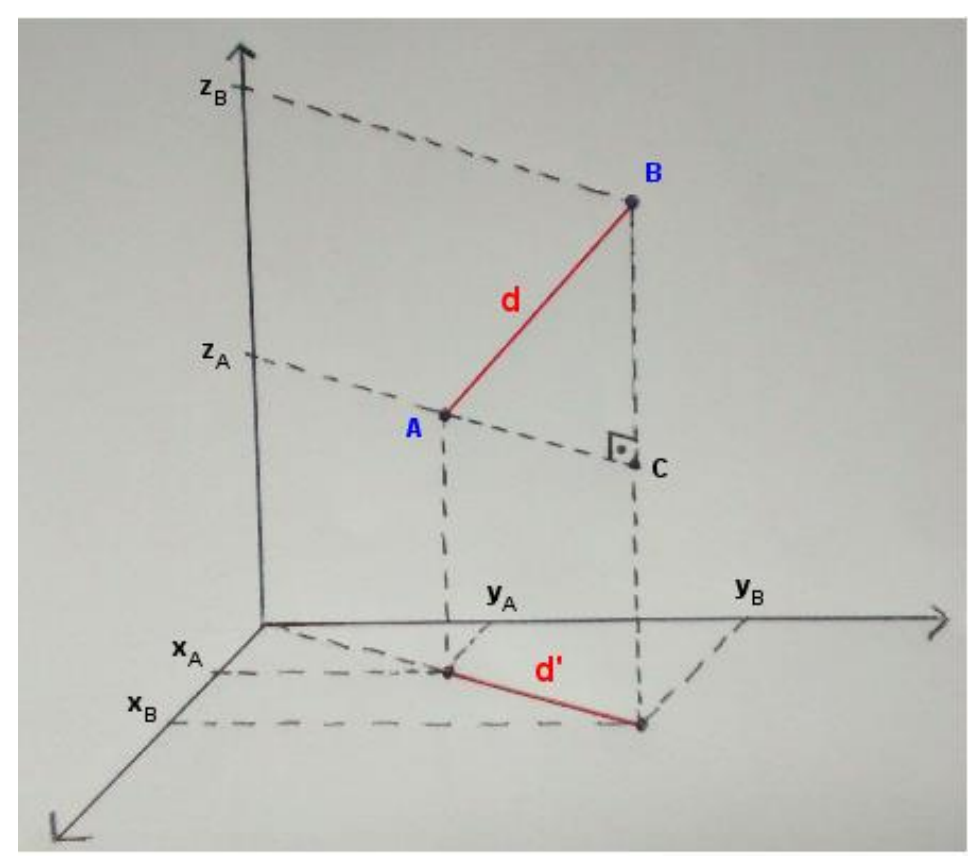

Fonte: $A$ autora

Observando o triângulo retângulo $\mathrm{ABC}$ e aplicando o Teorema de Pitágoras tem-se:

$$
d=\sqrt{d^{\prime 2}+\left(z_{A}-z_{B}\right)^{2}} \Leftrightarrow d=\sqrt{\left(x_{A}-x_{B}\right)^{2}+\left(y_{A}-y_{B}\right)^{2}+\left(z_{A}-z_{B}\right)^{2}}
$$

onde $d^{\prime}$ é a distância das projeções dos pontos A e B no plano Oxy.

\section{$\underline{\text { Respostas obtidas }}$}


Gráfico 14: Respostas apresentadas pelos estudantes para Questão 3

\section{Distância entre dois pontos}

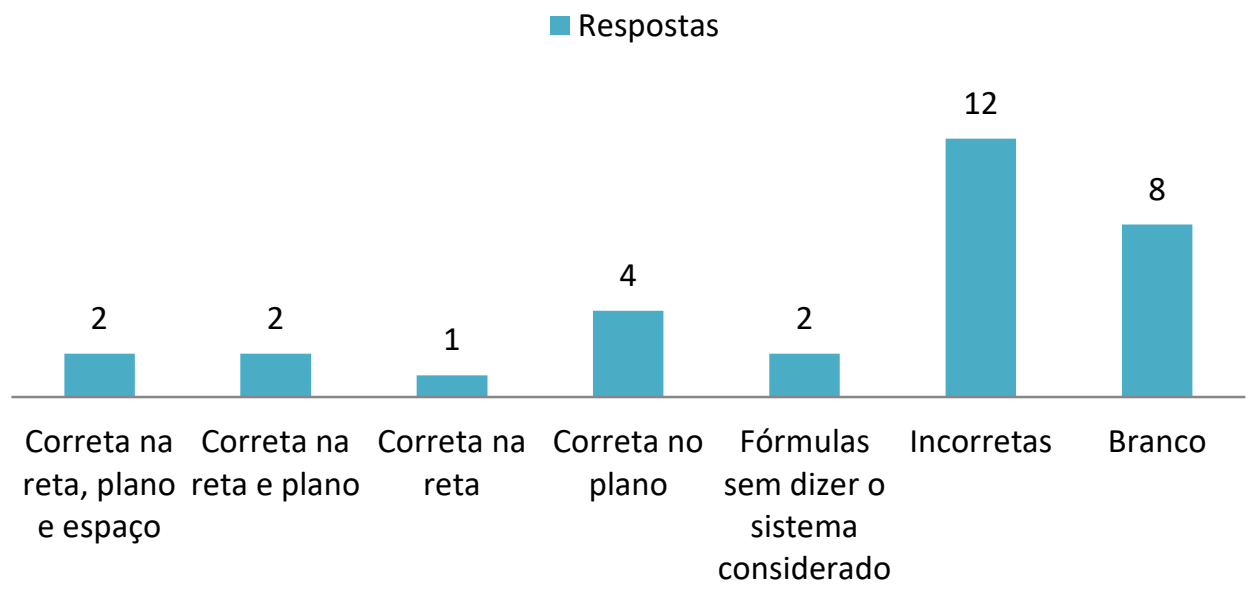

Fonte: A autora

Algumas respostas apresentaram uma confusão com fórmulas, trocando o caso do plano com a reta (Figura 178) e até mesmo apresentando a fórmula da distância de ponto à reta (Figura 179).

Figura 178: Resposta obtida para Questão 3

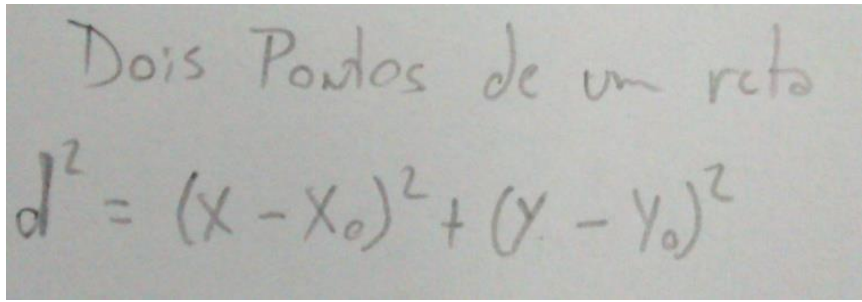

Fonte: Questionário

Figura 179: Resposta obtida para Questão 3

* distäncia entre dois powtos: $d=\sqrt{\left(x_{A}-x_{b}\right)^{2}+\left(y_{A}-y_{D}\right)^{2}}$

- distánaca entre dois pontos: $d=\frac{\left|a x_{0}+b y o+c\right|}{\sqrt{a^{2}+b^{2}}}$

* espaco: nunca estudei

Fonte: Questionário 


\section{Anexo II - Análise dos Livros PNLD 2015}

A seguir são apresentadas algumas características observadas na análise das quatro coleções do PNLD 2015, no que diz respeito à abordagem da Geometria Analítica e, em particular, ao cálculo de distâncias.

Coleção 1: Conexões com a Matemática (LEONARDO, 2013)

\section{Panorama da obra}

De acordo com a resenha da coleção no Guia do PNLD (BRASIL, 2014), no estudo dos tópicos que nos interessam, podemos destacar:

$\checkmark$ O conteúdo é abordado exclusivamente no Volume 3.

$\checkmark$ Predominância do uso de fórmulas e procedimentos algébricos.

$\checkmark$ São propostos muitos exercícios.

$\checkmark$ Equações da reta apresentadas de forma fragmentada.

$\checkmark$ Deduções bem articuladas com outros campos da Matemática escolar.

$\checkmark$ Dedução das equações das cônicas de forma satisfatória.

\section{Abordagem do conteúdo sobre distâncias}

As distâncias entre dois pontos e de ponto à reta são trabalhadas apenas no plano.

Para a Distância entre dois pontos, o livro apresenta a dedução da fórmula $d=\sqrt{\left(x_{A}-x_{B}\right)^{2}+\left(y_{A}-y_{B}\right)^{2}}$ utilizando o registro gráfico e o Teorema de Pitágoras. Primeiramente, é feito um caso particular (com pontos específicos dados por meio de suas coordenadas) e depois, o caso geral.

Após apresentar alguns exercícios resolvidos, são propostos 12 exercícios que contemplam esse tópico. Em relação a tais exercícios, pode-se observar os seguintes tipos:

Aplicação direta da fórmula. 
$>$ Determinação de coordenadas de um ponto dada sua distância a um segundo ponto.

$>$ Determinação de pontos equidistantes.

> Problemas envolvendo triângulos (classificação, obter altura).

$>$ Aplicações envolvendo área, perímetro ou diagonal de polígonos.

Os exercícios não apresentam representações gráficas em seus enunciados, que são propostos frequentemente a língua natural. Em alguns casos, o uso desse registro fica implícito e a conversão é a cargo do aluno.

No caso da Distância entre ponto e reta, o livro apresenta um exemplo que é solucionado levando em consideração conceitos apresentados anteriormente. Logo em seguida, a fórmula $d=\frac{\left|a x_{P}+b y_{P}+c\right|}{\sqrt{a^{2}+b^{2}}}$ é apresentada, sem sua dedução.

São propostos aos alunos 8 exercícios que contemplam:

> Aplicação direta da fórmula apresentada.

$>$ Distância entre retas paralelas.

> Determinação de coordenadas de um ponto dada sua distância a uma reta.

$>$ Pontos equidistantes a duas retas.

$>$ Altura de triângulo.

$>$ Área, perímetro e diagonal de polígonos.

No Guia do Professor, verifica-se que o objetivo é a realização dos exercícios enfatizando o registro simbólico-algébrico, onde apenas 4 dos 20 exercícios, trazem a representação gráfica em suas soluções, dadas nesse Guia.

Coleção 2: Matemática: Contexto e Aplicações (DANTE, 2014)

\section{Panorama da obra}

De acordo com a resenha da colação no Guia (BRASIL, 2014), no estudo dos tópicos que nos interessam, podemos destacar: 
$\checkmark$ O conteúdo é abordado nos Volumes 1 e 3.

$\checkmark$ Apresenta contexto histórico.

$\checkmark$ Mostra a Geometria Analítica como uma importante conexão entre a Geometria e a Álgebra.

$\checkmark$ Concentra-se nos estudos da reta, circunferência e das cônicas.

$\checkmark$ Dedução das equações das cônicas é feita de forma muito extensa.

\section{Abordagem do conteúdo sobre distâncias.}

As distâncias entre dois pontos e ponto e reta são trabalhadas apenas no plano.

A fórmula de Distância entre dois pontos no plano já é apresentada no Volume 1 no capítulo sobre Funções e são propostos ao aluno 2 exercícios para aplicá-la diretamente.

No terceiro volume esse conteúdo é retomado de forma mais aprofundada. São apresentados exemplos gráficos de segmentos verticais, horizontais e inclinados com os cálculos de seus comprimentos e logo em seguida a fórmula $d=\sqrt{\left(x_{2}-x_{1}\right)^{2}+\left(y_{2}-y_{1}\right)^{2}}$ é deduzida utilizando o Teorema de Pitágoras.

Em um dos exercícios resolvidos o que chama atenção é o fato de trazer uma representação gráfica com uma observação de que seria dispensável. Logo em seguida são propostos 9 que contemplam

Aplicação direta da fórmula.

> Determinação de coordenadas de um ponto dada sua distância a um segundo ponto.

$>$ Pontos equidistantes.

$>$ Problemas com triângulos.

Para a Distância de ponto e reta é apresentado um exemplo utilizando assuntos já abordados no livro e em seguida é apresentada a fórmula $d=\frac{\left|a x_{P}+b y_{P}+c\right|}{\sqrt{a^{2}+b^{2}}}$ é apresentada sem sua dedução.

São apresentados alguns exercícios resolvidos seguidos de 5 exercícios para 
que o aluno realize

Aplicação direta da fórmula.

Distância entre retas paralelas.

Determinação de coordenadas de um ponto dada sua distância a uma reta.

$>$ Problemas com triângulo.

Nenhum dos exercícios apresenta em seus enunciados representações gráficas e o Manual do Professor apresenta apenas um exercício com representação gráfica.

Coleção 3: Matemática - Paiva (PAIVA, 2013)

\section{Panorama da obra}

De acordo com a resenha da colação no Guia (BRASIL, 2014), no estudo dos tópicos que nos interessam, podemos destacar:

$\checkmark$ O conteúdo é abordado exclusivamente no Volume 3.

$\checkmark$ Estabelece uma relação básica da Geometria Analítica entre as figuras geométricas e suas equações (ou inequações).

$\checkmark$ Equações da reta apresentadas de forma fragmentada.

$\checkmark$ Apresenta aplicações para circunferências.

$\checkmark$ As cônicas são apresentadas através de suas origens e aplicações.

\section{Abordagem do conteúdo sobre distâncias.}

A Distância entre dois pontos é feita na reta de uma forma sutil, mas como ferramenta para o cálculo no plano. Para o plano, a fórmula $d=\sqrt{\left(x_{A}-x_{B}\right)^{2}+\left(y_{A}-y_{B}\right)^{2}}$ é apresentada sem sua dedução, apenas um caso particular, onde dois pontos são dados através de suas coordenadas, e resolvido com Teorema de Pitágoras. 
Um dos exercícios resolvidos sugere dois tipos de solução, uma com a representação gráfica e aplicando o Teorema de Pitágoras e outra com a aplicação da fórmula.

São propostos 6 exercícios que contemplam os seguintes itens

Aplicação direta da fórmula.

> Determinação de coordenadas de um ponto dada sua distância a um segundo ponto.

> Problemas com triângulos (perímetro, mediatriz)

Alguns exercícios apresentam em seus enunciados problemas fora do contexto matemático.

A Distância de ponto à reta é apresentada em um capítulo complementar sobre retas e inicialmente é apresentado um caso particular onde são utilizados conhecimentos já trabalhos anteriormente no livro e logo e seguida é apresentada a fórmula $d=\frac{\left|a x_{0}+b y_{0}+c\right|}{\sqrt{a^{2}+b^{2}}}$ sem a sua demonstração.

Os 6 exercícios propostos apresentam

> Aplicação direta da fórmula.

> Distância entre retas paralelas.

> Determinação de coordenadas de um ponto dada sua distância a uma reta.

> Pontos equidistantes a duas retas.

$>$ Altura de triângulo.

No Suplemento com Orientações para o Professor, apenas um dos exercícios apresenta representação gráfica, mesmo no início dando importância para as diferentes representações de um objeto.

Coleção 4: Novo Olhar: Matemática (SOUZA, 2013)

\section{Panorama da obra}


De acordo com a resenha da colação no Guia (BRASIL, 2014), no estudo dos tópicos que nos interessam, podemos destacar:

$\checkmark$ O conteúdo é abordado exclusivamente no Volume 3.

$\checkmark$ Articulação com o estudo da reta referente à função afim e conexões com soluções de um sistema linear nos volumes 1 e 2 .

$\checkmark$ Não explora a inter-relação entre parábola e função quadrática.

$\checkmark$ Apresenta boas referências históricas que auxiliam no desenvolvimento dos conteúdos.

$\checkmark$ Utilização de barbante e instrumentos geométricos para construção de cônicas.

$\checkmark$ Apresenta aplicações para as cônicas.

\section{Abordagem do conteúdo sobre distâncias.}

O cálculo de Distância entre dois pontos é introduzido pelo caso onde o segmento formado pelos pontos é vertical ou horizontal através de casos particulares. Em seguida é dado um caso particular onde esse segmento é inclinado e depois a fórmula $d=\sqrt{\left(x_{B}-x_{A}\right)^{2}+\left(y_{B}-y_{A}\right)^{2}}$ é deduzida usando as ideias do caso particular.

As atividades resolvidas já apresentam problemas mais elaborados, um sobre classificação de triângulos e outro sobre circuncentro.

São propostas 10 atividades que contemplam:

> Aplicação direta da fórmula.

> Determinação de coordenadas de um ponto dada sua distância a um segundo ponto.

$>$ Pontos equidistantes.

> Problemas com triângulos (classificação, verificação de quando três segmentos podem formar um triângulo).

$>$ Construção de retângulo através de um desafio.

Alguns exercícios apresentam em seus enunciados problemas fora do contexto 
matemático.

O cálculo da Distância entre ponto e reta é introduzido através de um caso particular onde sua determinação é feita com o uso de conhecimentos prévios e logo em seguida a fórmula $d=\frac{\left|a x_{P}+b y_{P}+c\right|}{\sqrt{a^{2}+b^{2}}}$ é apresentada e sem a sua dedução.

As atividades resolvidas apresentam problemas com distância entre retas paralelas e altura de triângulo.

São propostas 4 atividades que contemplam

Aplicação direta da fórmula.

$>$ Distância entre retas paralelas.

$>$ Determinação de coordenadas de um ponto dada sua distância a uma reta.

$>$ Problemas com polígonos.

As Orientações para o Professor apresentam as soluções das atividades de forma algébrica e apena 3 das 14 atividades possuem representação gráfica. 


\section{Anexo III - Atividades aplicadas na experimentação ${ }^{15}$}

\section{Atividade 1: Sistema de Coordenadas no plano}

1로 Parte - Jogo Batalha Naval

Batalha Naval é um jogo de tabuleiro disputado por dois jogadores com o objetivo de encontrar a posição que cada embarcação do oponente ocupa e afundálas.

Aqui vamos jogar uma versão adaptada desse jogo.

\section{Como jogar}

1. No tabuleiro que recebeu organize suas embarcações.

\begin{tabular}{|c|c|c|}
\hline Embarcação & Espaço ocupado & Quantidade \\
\hline Porta Avião & 5 quadrados & 1 \\
\hline Encouraçado & 4 quadrados & 2 \\
\hline Cruzador & 3 quadrados & 3 \\
\hline Submarino & 2 quadrados & \\
\hline
\end{tabular}

$\checkmark$ As embarcações devem ocupar os quadrados na extensão de uma linha ou de uma coluna de modo que duas embarcações não se toquem ou se sobreponham.

$\checkmark$ Deve ser distribuída pelo menos uma embarcação em cada quadrante.

\footnotetext{
${ }^{15}$ Alguns enunciados foram modificados de acordo com as considerações e sugestões da banca de defesa da dissertação.
} 
$\checkmark$ Cada jogador não deve revelar ao seu oponente a localização de suas embarcações.

2. Seu objetivo é acertar uma das coordenadas que fazem parte das embarcações do seu do oponente.

$\checkmark$ Indique ao seu oponente um ponto (tiro) no plano cartesiano dando as coordenadas $x$ e $y$ desse ponto. Lembrando que as coordenadas $x, y$ são pares ordenados $(x, y)$ em que o primeiro número corresponde ao deslocamento na horizontal e o segundo ao deslocamento vertical.

$\checkmark$ A cada jogada, registre em seu tabuleiro de jogadas a representação gráfica do ponto que indicou.

$\checkmark$ Seu oponente deve marcar o ponto correspondente no seu tabuleiro e avisá-lo se você acertou uma embarcação, ou se acertou a água. Caso tenha acertado uma embarcação, seu oponente deverá informá-lo qual delas foi atingida. Caso ela tenha sido afundada, também deverá ser informá-lo. Uma embarcação é afundada quando todos os quadrados que formam essa embarcação forem atingidos.

$\checkmark$ Se você acertar o alvo, terá direito a nova jogada e assim sucessivamente até acertar a água ou até que tenha afundado todas as embarcações. Se você acertar a água, passa a vez para o seu oponente.

$\checkmark$ Para acertar uma embarcação, basta acertar um dos vértices de um dos quadrados em que a embarcação está ancorada.

$\checkmark$ Para afundar uma embarcação, é preciso acertar pelo menos um dos vértices de cada um dos quadrados em que a embarcação está ancorada. 
3. Ganha o jogo quem afundar todas as embarcações ou maior número de embarcações durante o tempo estipulado para o jogo.

\section{2ㅁate - Plano Cartesiano}

1. Você acabou de ser apresentado a um plano cartesiano. Agora descreva todos os seus elementos (origem, eixos, quadrantes) e como devem proceder para representar pontos nesse sistema e/ou indicar as coordenadas de pontos já marcados.

2. Dê 2 exemplos de coordenadas de pontos que estão sobre o eixo $O X$ e 2 exemplos de coordenadas de pontos que estão sobre o eixo OY.

Como são as coordenadas de um ponto:
i. sobre o eixo OX?
ii. sobre o eixo OY?

3. Represente os seguintes pares de pontos: $P=(1,2)$ e $P^{\prime}=(-1,2)$; $Q=(-3,4)$ e $Q^{\prime}=(3,4) ; R=(-5,5)$ e $R^{\prime}=(5,5)$.

O que você pode observar sobre a posição dos pontos de cada par? Descreva com suas palavras.

4. Represente os seguintes pares de pontos: $M=(4,1)$ e $M^{\prime}=(4,-1)$; $N=(2,3)$ e $N^{\prime}=(2,-3) ; O=(6,-6)$ e $O^{\prime}=(6,6)$. 
O que você pode observar sobre a posição dos pontos de cada par? Descreva com suas palavras.

Conclusões:

\section{Atividade 2: Sistema de Coordenadas no espaço}

\section{Jogo dos octantes}

1. Se organizem em duas equipes.

2. Você e sua equipe têm o objetivo de acertar o octante no qual cada ponto apresentado pertence.

$\checkmark$ A equipe terá 1 minuto para discutir qual o octante.

$\checkmark$ Quando solicitado, um membro da equipe deve levar a placa correspondente ao octante escolhido.

\begin{tabular}{|l|l|}
\hline Ponto & Octante \\
\hline & \\
\hline & \\
\hline & \\
\hline & \\
\hline & \\
\hline
\end{tabular}

3. Ganha a equipe que acertar o maior número de octantes.

\section{Conclusões:}




\section{Atividade 3: Sistema de Coordenadas no plano e espaço}

1롤 Parte: Simetrias no plano

1. Represente no plano cartesiano a seguir os pontos:
$A_{1}=(0,-7)$
$A_{4}=(3,-1)$
$A_{7}=(0,8)$
$A_{2}=(1,-7)$
$A_{5}=(1,4)$
$A_{3}=(1,-1)$
$A_{6}=(2,4)$

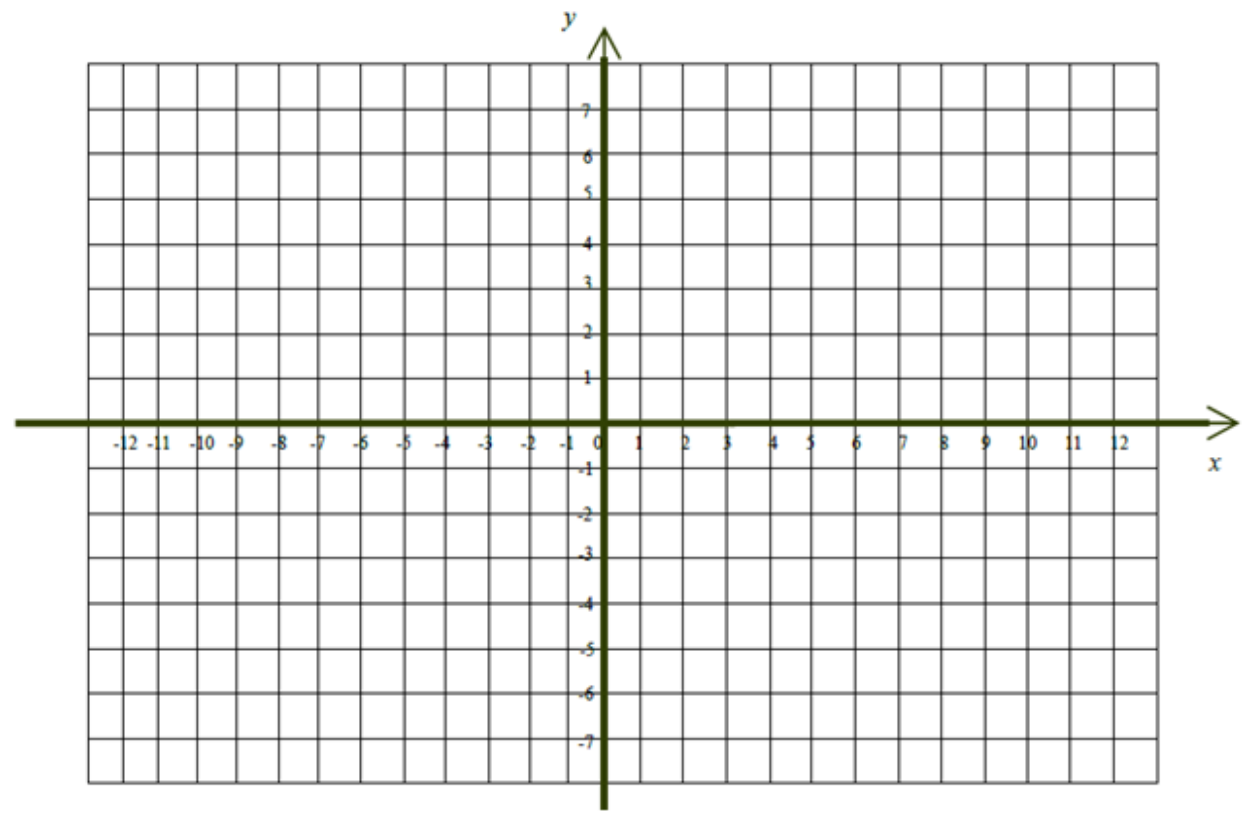

2. Marque os segmentos $\overline{A_{1} A_{2}}, \overline{A_{2} A_{3}}, \overline{A_{3} A_{4}}, \overline{A_{4} A_{5}}, \overline{A_{5} A_{6}}$ e $\overline{A_{6} A_{7}}$.

3. Observe a figura formada e responda: 
a) Sabendo que esta imagem é simétrica em relação ao eixo $O x$, como você a completaria?

b) Apresente as coordenadas dos pontos que você utilizou para completar a imagem? Qual a relação desses pontos com os dados pelo enunciado?

4. Sabendo que a figura a seguir é simétrica em relação ao eixo Ox, complete-a.

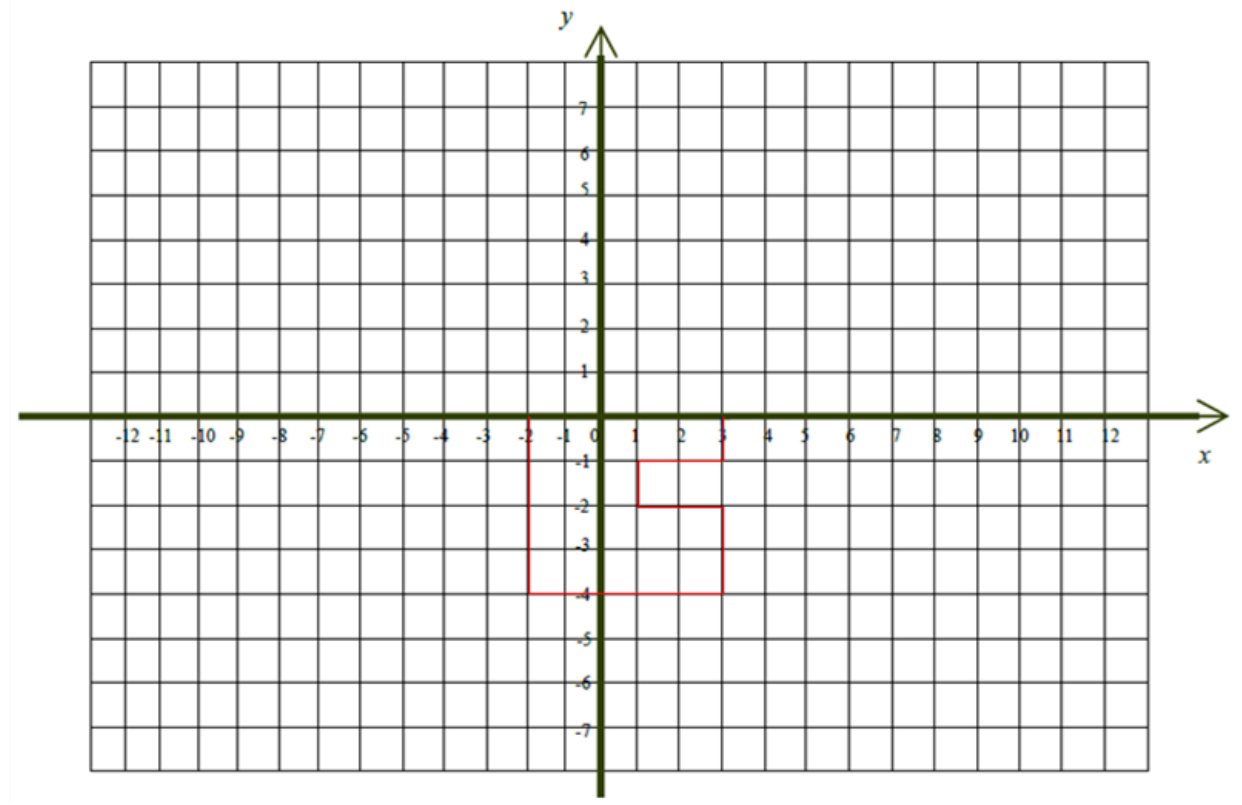

5. Apresente as coordenadas dos pontos que formam a figura. Qual a relação entre as coordenadas dos pontos simétricos?

6. Escolha um ponto do plano em cada quadrante e complete a tabela. 


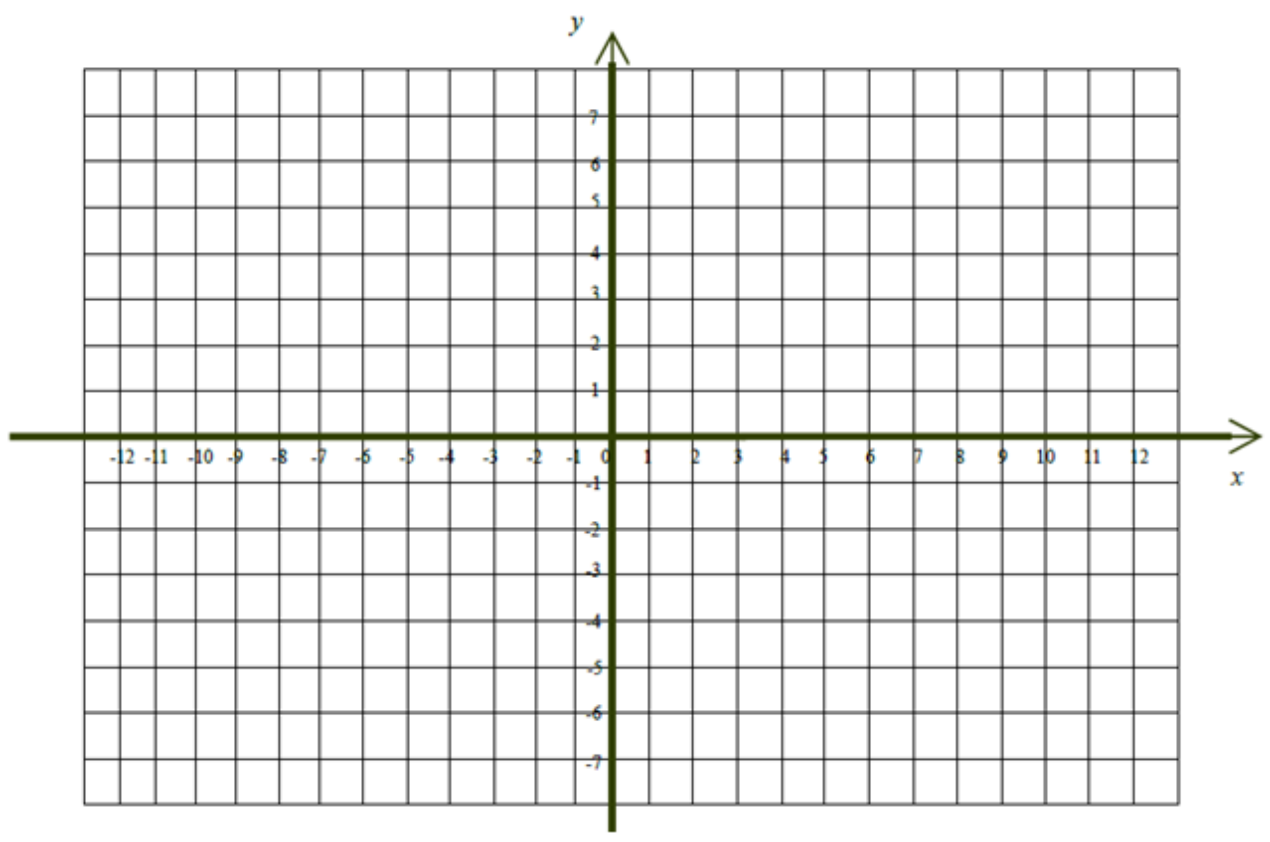

\begin{tabular}{|c|l|c|c|}
\hline Quadrante & Ponto & $\begin{array}{c}\text { Simétrico em relação } \\
\text { ao eixo Ox }\end{array}$ & $\begin{array}{c}\text { Simétrico em relação } \\
\text { ao eixo Oy }\end{array}$ \\
\hline $1^{\circ}$ & & & \\
\hline $2^{\circ}$ & & & \\
\hline $3^{\circ}$ & & & \\
\hline $4^{\circ}$ & & & \\
\hline
\end{tabular}

7. Comparando as respostas obtidas na questão anterior, o que você repara sobre as coordenadas dos pontos que são simétricos em relação aos eixos $O x$ ? E os simétricos em relação ao eixo $O y$ ?

8. Dado um ponto qualquer no plano $P=(x, y)$, como você representaria as coordenadas dos pontos $P^{\prime}$ simétrico em relação ao eixo $O X$ e $P^{\prime \prime}$ simétrico em relação ao eixo OY?

\section{Conclusões:}


9. TAREFA ${ }^{16}$ : Crie uma imagem que apresente simetria em relação ao eixo $O X$ e outra que apresente simetria em relação ao eixo $O Y$.

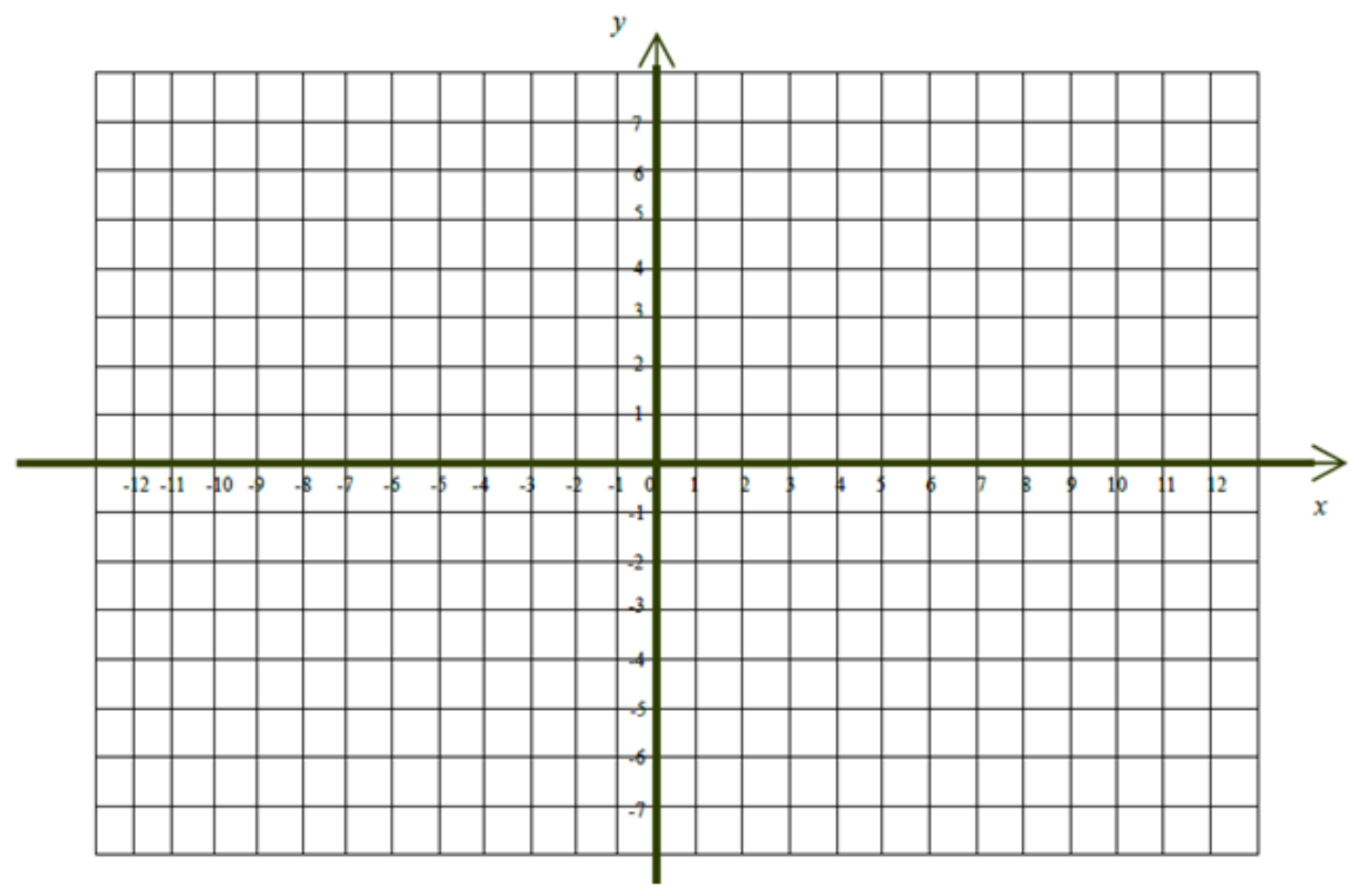

${ }^{16}$ Tarefa opcional 


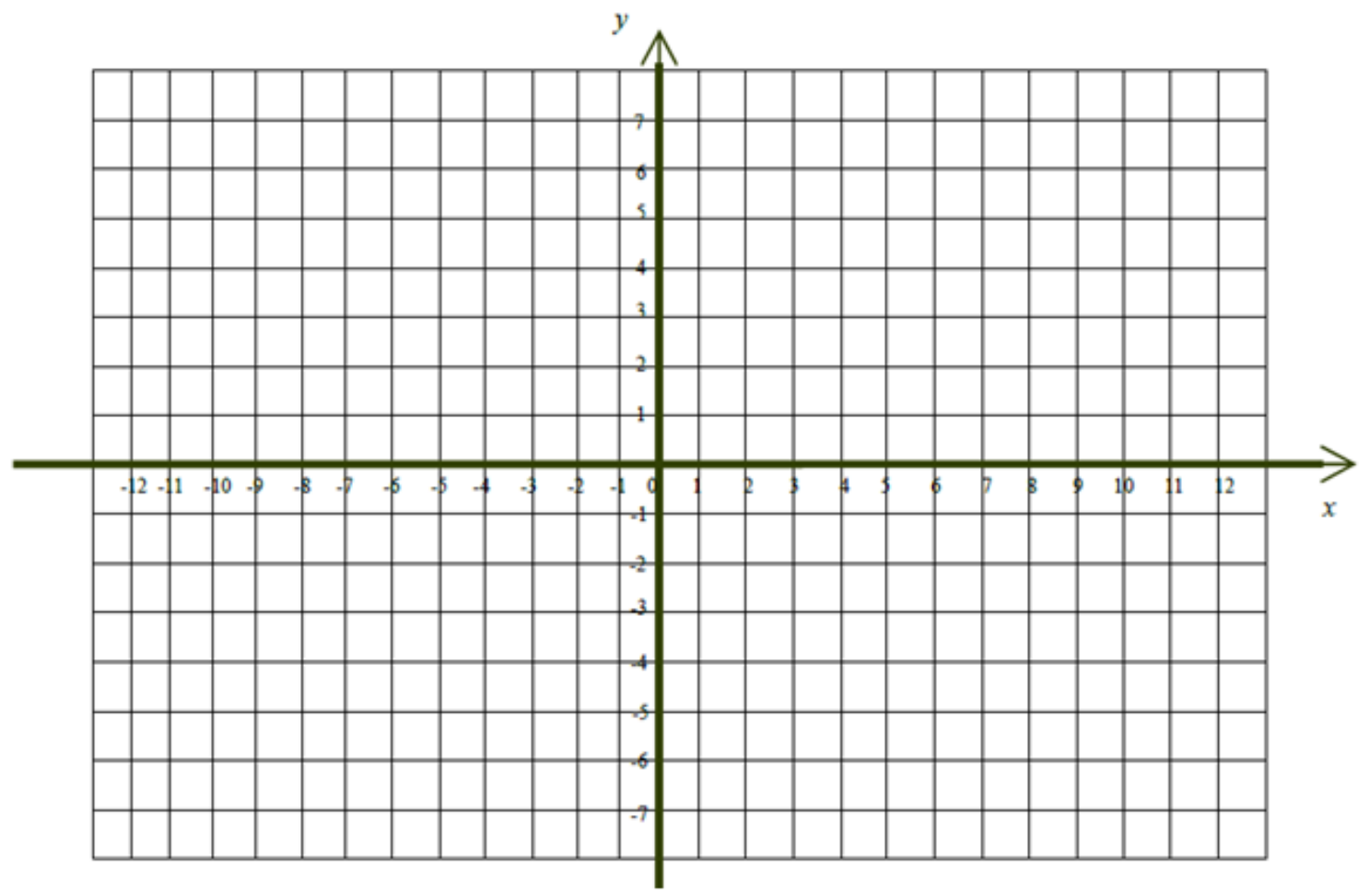

10. Escolha 6 posições para o ponto $P$ e preencha a tabela.

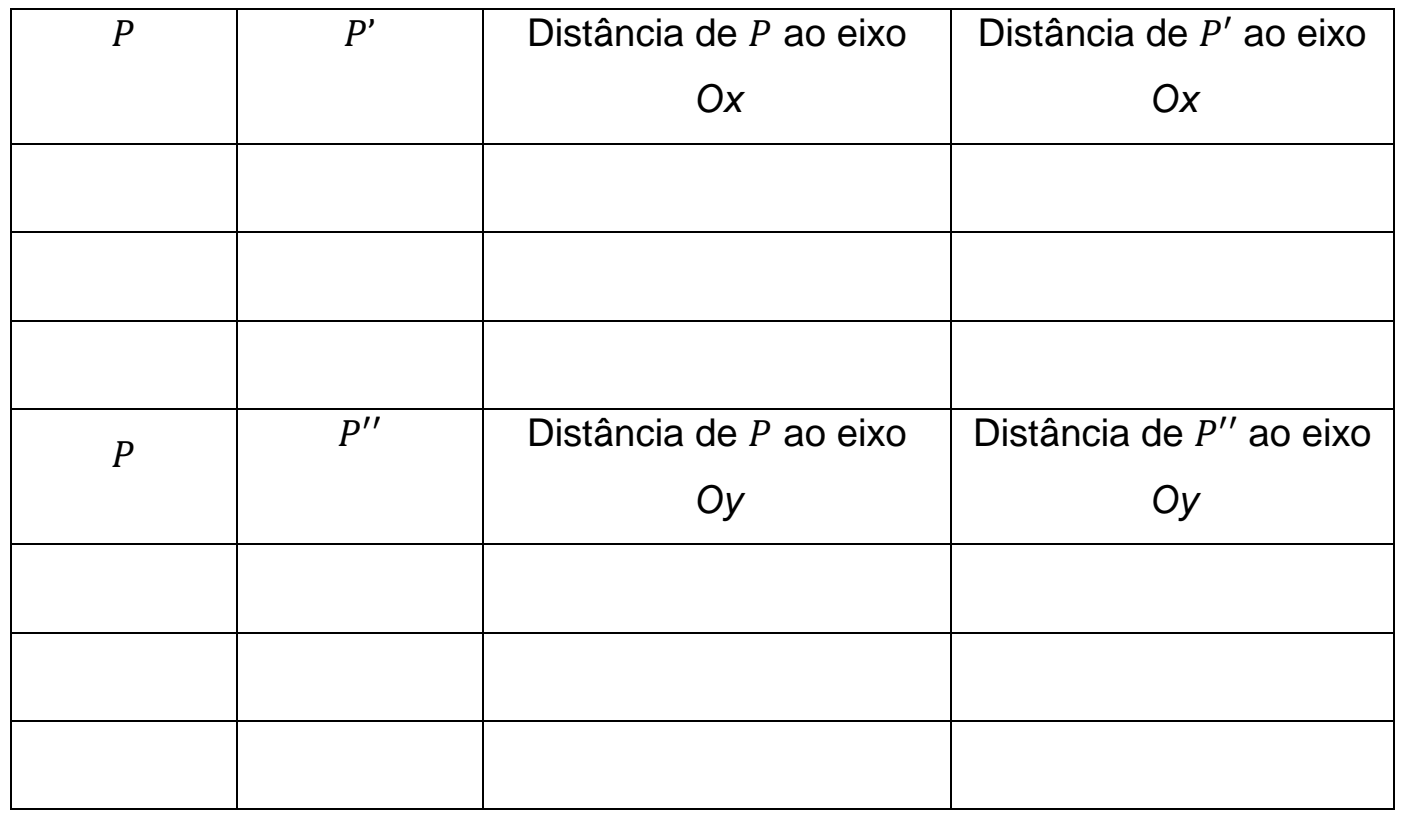

a) O que você pode observar sobre as distâncias de $P$ e de $P^{\prime}$ ao eixo de simetria $O x$ ? 
b) E para as distâncias de $P$ e de $P^{\prime \prime}$ ao eixo de simetria $O y$ ?

c) Verifique no Geogebra se suas observações valem para mais pontos.

11. Considerando as observações do exercício anterior, como se faz para determinar as distâncias de $P=(x, y)$ e $P^{\prime}=(x,-y)$ ao eixo de simetria $O x$ ? E no caso das distâncias de $P=(x, y)$ e $P^{\prime \prime}=(-x, y)$ ao eixo de simetria $O y$ ?

\section{Atividade 3: Sistema de Coordenadas no plano e espaço}

\section{2ª Parte:Generalizações}

1. Em cada item apresente 5 pontos que sigam as regras estabelecidas.

a) O ponto pertence ao eixo $O x$.

b) O ponto pertence ao eixo $O y$.

c) O ponto possui a segunda coordenada igual ao triplo da primeira coordenada.

d) A primeira coordenada do ponto tem quatro unidades a menos que a segunda coordenada.

e) O ponto possui coordenadas inteiras, em que sua primeira coordenada múltipla de dois e na segunda coordenada múltipla de cinco.

2. Agora como você faria para representar um caso geral para cada item do exercício anterior, ou seja, como é a forma dos pontos de cada um dos casos apresentados?

Atividade 3: Sistema de Coordenadas no plano e espaço

3ª Parte - Construção de um modelo 
1. Se organizem em dois grupos.

2. Utilizando os materiais disponíveis, construam um "modelo" de um sistema de coordenadas no espaço.

Materiais para a tarefa

$\checkmark$ Papel cartão (branco e colorido)

$\checkmark$ Papel quadriculado

$\checkmark$ Palito de churrasco

$\checkmark$ Arame

$\checkmark$ Barbante

$\checkmark$ Canudos

$\checkmark$ Tesoura

$\checkmark$ Régua

$\checkmark$ Cola

$\checkmark$ Fita adesiva

$\checkmark$ Canetas hidrográficas

$\checkmark$ Lápis de cor

Como vocês representariam um ponto no sistema de coordenadas que construíram?

3. Apresentem seu modelo, brevemente, para os outros participantes.

Anotações:

Atividade 3: Sistema de Coordenadas no plano e espaço

4ª Parte - Tarefas de fixação 
1. Em um papel quadriculado esbocem 0 1ํㅡㄹ octante de um sistema $O X Y Z$ e representem os pontos a seguir.

$$
\begin{array}{ll}
A=(2,0,0) & D=(3,5,0) \\
B=(0,1,3) & E=(1,1,5) \\
C=(0,0,4) & F=(3,6,4)
\end{array}
$$

2. Agora, representem cada ponto na Janela $3 D$ do Geogebra, e comparem com sua representação.

3. Onde está situado o ponto A? E o ponto C?

4. Dê exemplos de dois pontos pertencentes ao eixo Oy. Quais são suas coordenadas?

5. Descreva a posição do ponto $D$ no espaço.

6. Dê mais um exemplo de ponto com a mesma característica do ponto D.

7. Onde está situado o ponto B?

8. Explique com palavras como podem ser descritas as posições de pontos que têm:

a) duas de suas coordenadas nulas.

b) apenas uma de suas coordenadas nula. 
Conclusões:

Atividade 4: Jogo da Velha 3D

1ㄹ Parte - O Jogo

O Jogo da Velha 3D é uma versão espacial do tradicional Jogo da Velha e pode ser encontrado com estruturas de $3 \times 3 \times 3$ ou $4 \times 4 \times 4$.

1. Jogue o jogo por 10 minutos.

\section{$2^{a}$ Parte - Relação com coordenadas no espaço}

1. Considerando que a estrutura do Jogo da Velha 3D tem formato de um cubo, coloque-o no primeiro octante (de forma que as arestas fiquem paralelas aos eixos coordenados e a face inferior contida no plano OXY).

2. Apresente as coordenadas das posições que se localizam nos vértices desse cubo. Para realizar essa tarefa, escolha um comprimento para a aresta do cubo.

3. Quantas são as possibilidades de vitória no Jogo da Velha 3D? Apresente as coordenadas de, pelo menos, 6 possibilidades de vitória no jogo 


\section{Anexo IV - Construção do Jogo da Velha 3D}

Para montar um Jogo da Velha 3D utilizamos os seguintes materiais:

- 1 folha de acetato

- 28 bolinhas de isopor de $35 \mathrm{~mm}$

- 6 palitos para churrasco

- Papel Contact colorido

- 1 folha de papel roler

- Tinta colorida

\section{$\underline{\text { Peças para jogar }}$}

Para as peças para jogar, as que seriam equivalentes aos " $X$ " e "O" no jogo tradicional, utilizamos bolinhas de isopor coloridas (14 de cada cor)

Figura 180: Peças Jogo da Velha 3D

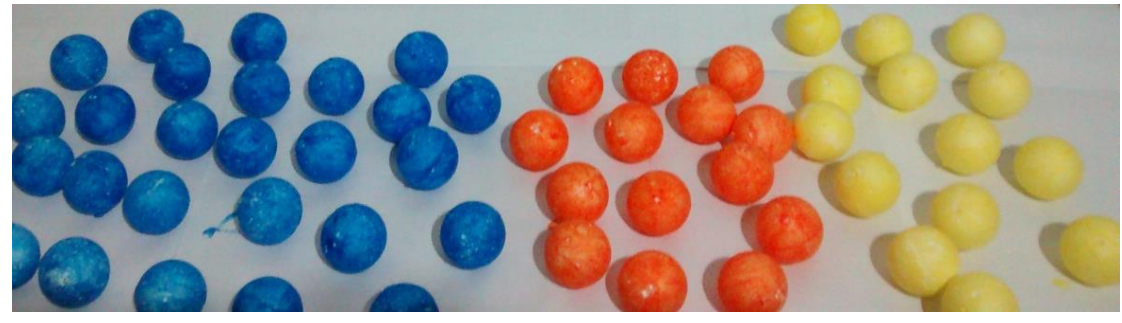

Fonte: A autora

\section{Estrutura}

Para a confecção da estrutura lateral do jogo utilizamos papel roler. 
Figura 181: Estrutura lateral do Jogo da Velha 3D

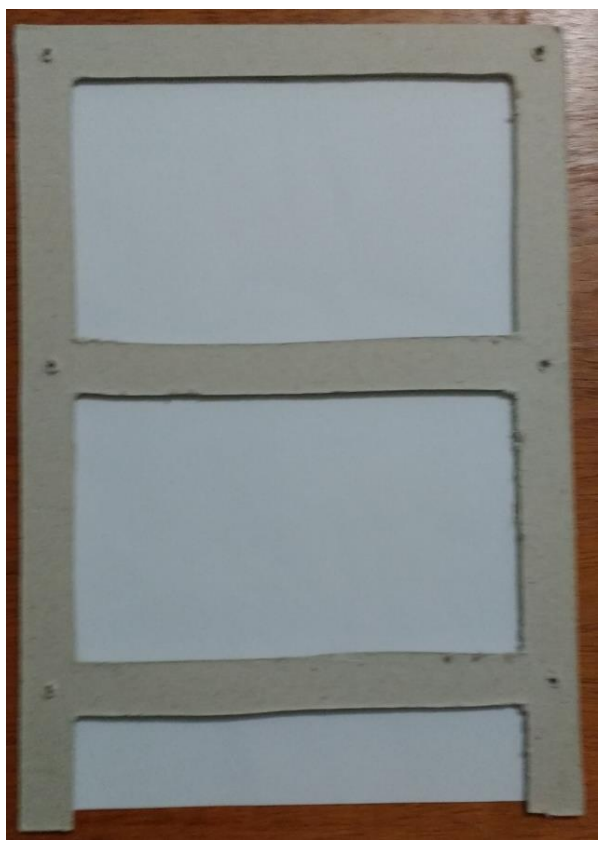

Fonte: A autora
Figura 182: Esboço da estrutura lateral do Jogo da Velha 3D

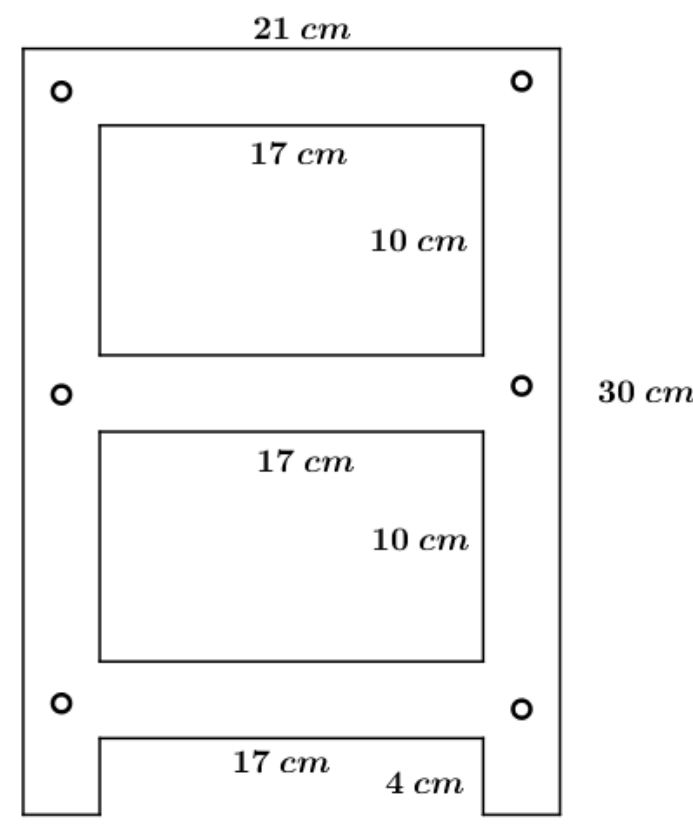

Fonte: A autora

\section{$\underline{\text { Tabuleiros }}$}

Para a confecção dos tabuleiros utilizamos três placas de acetato com nove cavidades cada como nas figuras a seguir. 
Figura 183: Passo 1 do tabuleiro do Jogo da Velha 3D

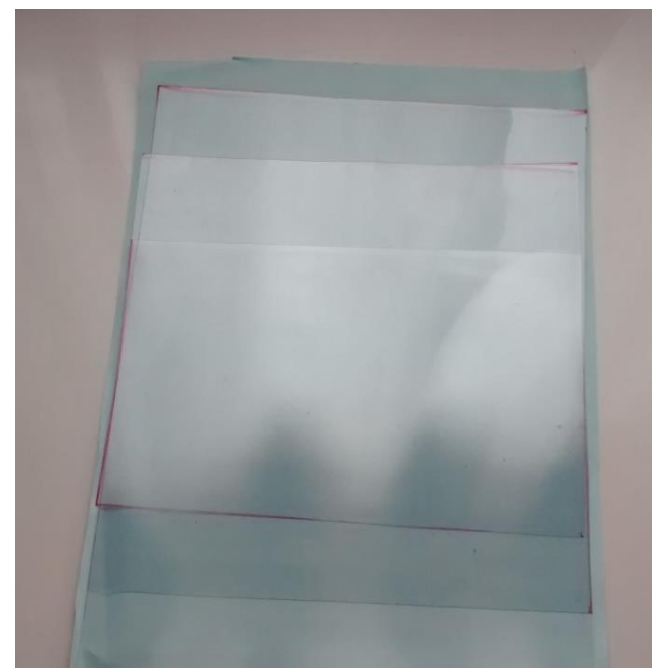

Fonte: A autora

Figura 184: Passo 2 do tabuleiro do Jogo da Velha 3D

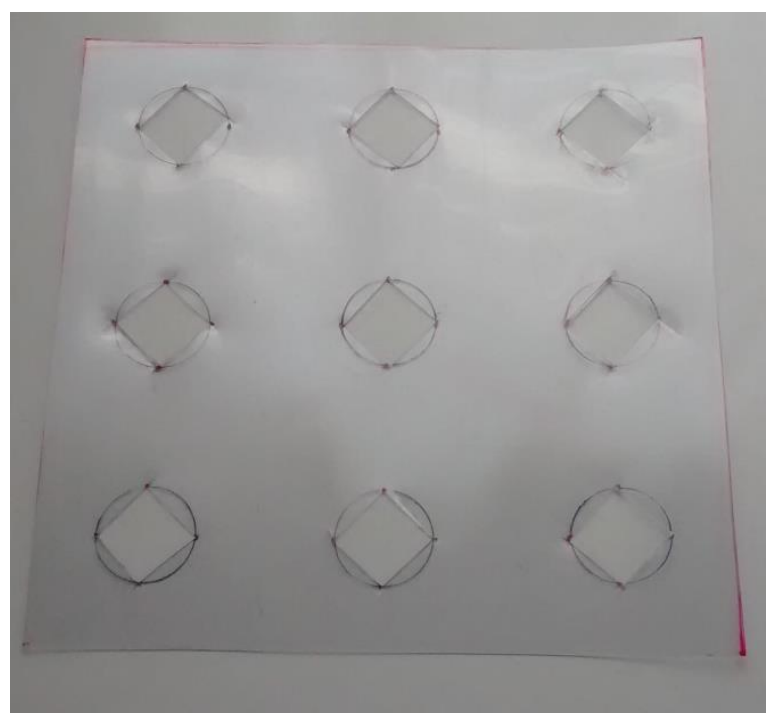

Fonte: A autora
Figura 185: Esboço do Passo 2 do tabuleiro do Jogo da Velha 3D

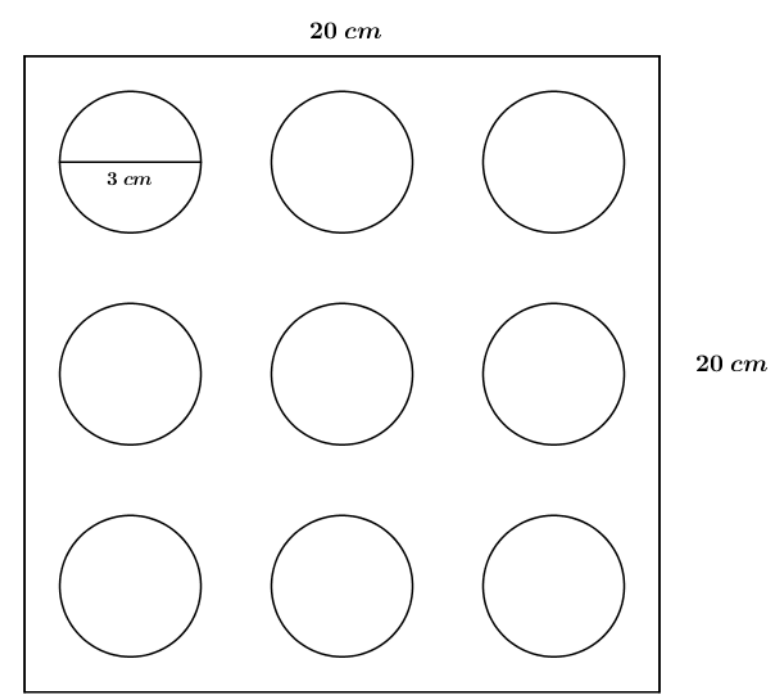

Fonte: A autora

Para que as laterais ficassem firmes utilizamos 8 tiras de papel roler ( 4 de 2 $\mathrm{cm} \times 20 \mathrm{~cm}$ e 4 de $1 \mathrm{~cm} \times 18 \mathrm{~cm}$ ) e para o acabamento papel contact colorido. 
Figura 186: Passo 3.1 do tabuleiro do Jogo da Velha 3D

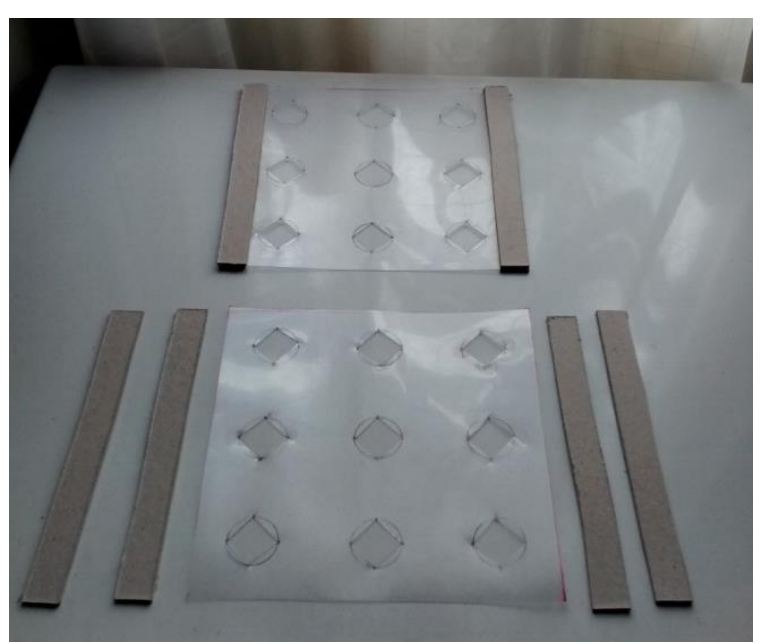

Fonte: A autora
Figura 187: Passo 3.2 do tabuleiro do Jogo da Velha 3D

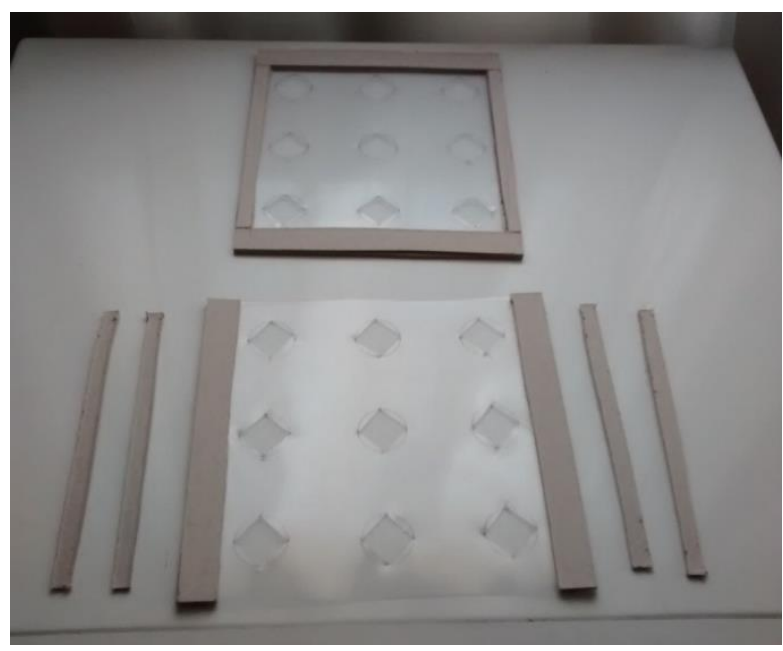

Fonte: A autora

Figura 188: Passo 4 do tabuleiro do Jogo da Velha 3D

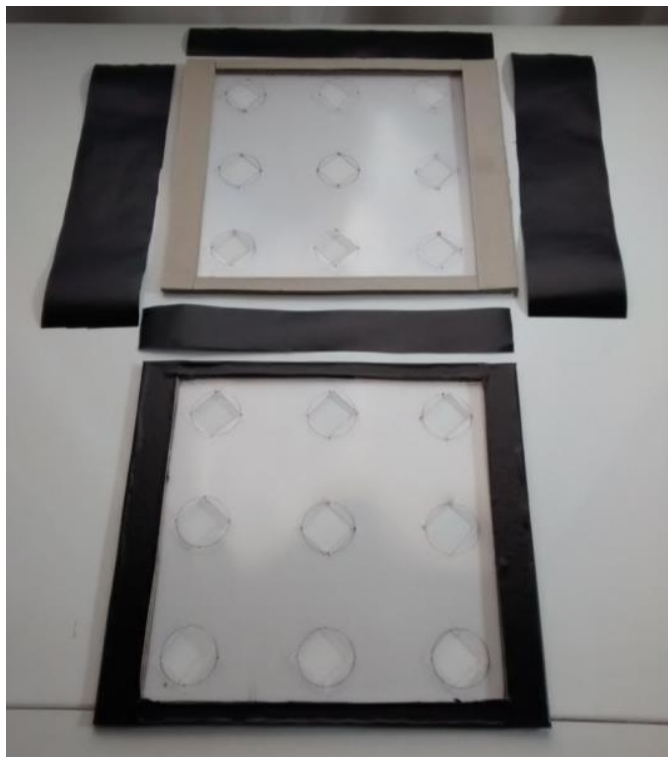

Fonte: A autora

Para o encaixe na estrutura utilizamos seis palitos para churrasco de com 30 cm cada. 
Figura 189: Passo 5 do tabuleiro do Jogo da Velha 3D

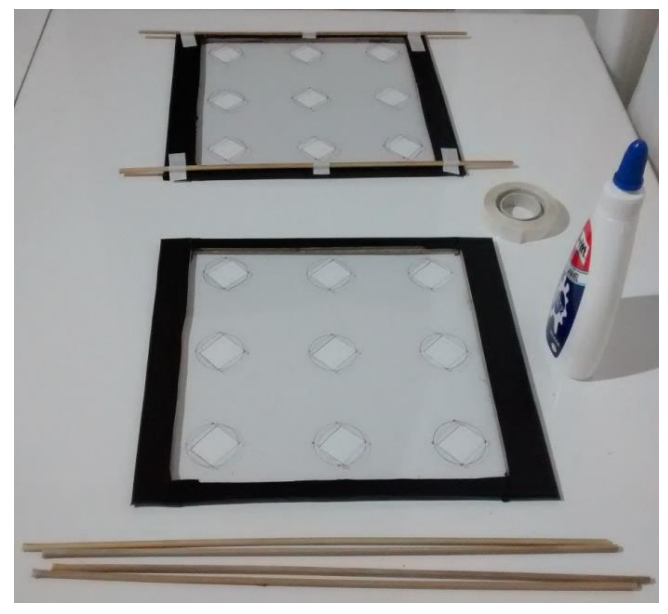

Fonte: A autora

Terminada a confecção das peças o tabuleiro fica como nas figuras a seguir.

Figura 190: Jogo da Velha 3D pronto

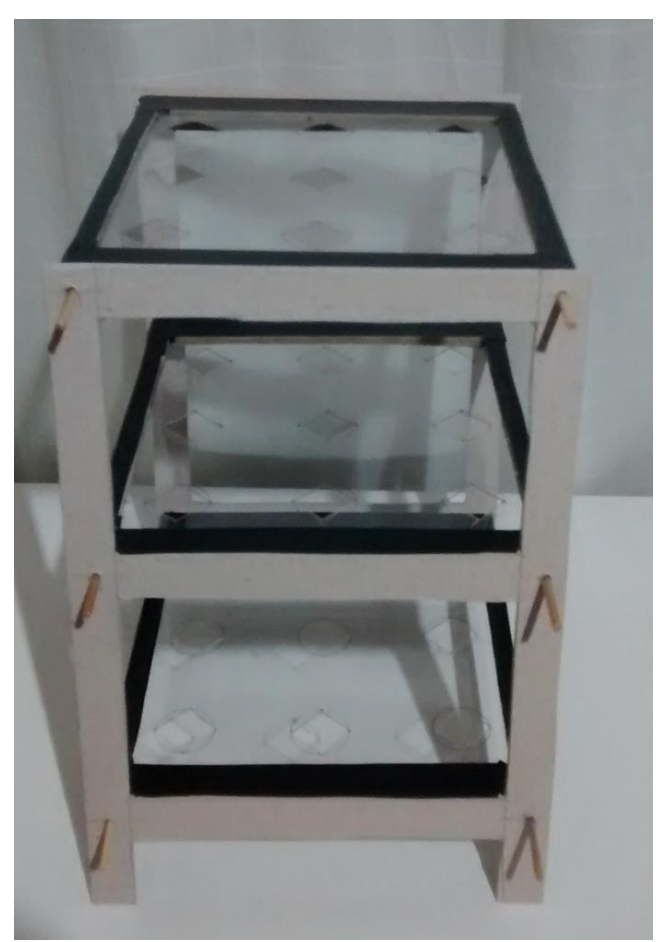

Fonte: A autora 
Figura 191: Jogo da Velha 3D pronto

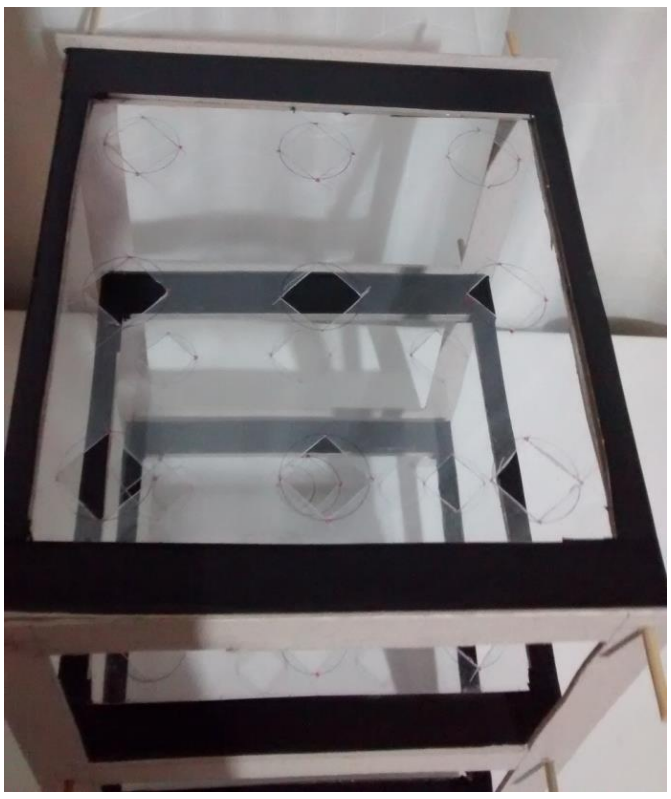

Fonte: A autora

Figura 192: Jogo da Velha 3D pronto

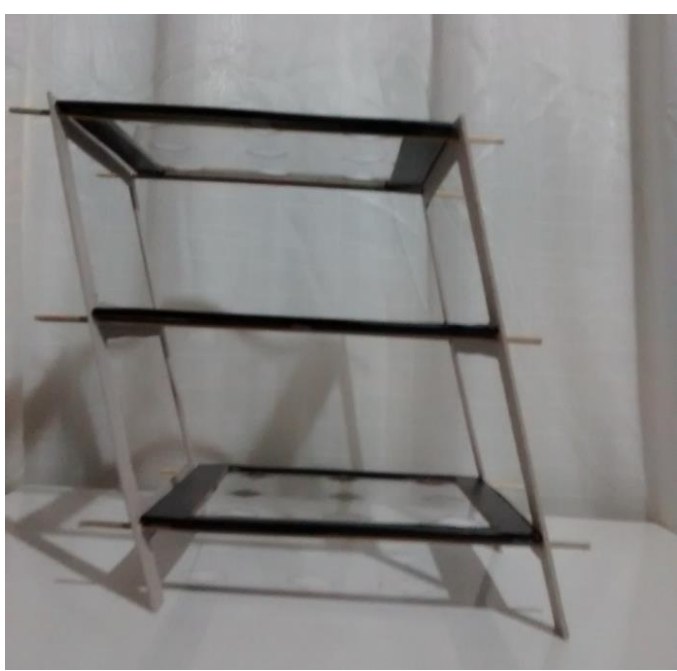

Fonte: A autora 